Aus dem Institut für Herz- und Kreislaufphysiologie

(Prof. Dr. med. D. M. Katschinski)

im Zentrum Physiologie und Pathophysiologie

der Medizinischen Fakultät der Universität Göttingen

\title{
Membranprotein-Komposition von Kardiofibroblasten \\ in Normoxie und Hypoxie
}

\author{
INAUGURAL-DISSERTATION \\ zur Erlangung des Doktorgrades \\ der Medizinischen Fakultät der \\ Georg-August-Universität zu Göttingen
}

\author{
vorgelegt von \\ Johannes Böttger \\ aus
}

Flensburg

Göttingen 2019 
Dekan:

Referentin

Ko-Referent:

Promotor-Vertretung:
Prof. Dr. H. K. Kroemer

Prof. Dr. D. M. Katschinski

Prof. Dr. Peter Schu

Prof. Dr. Thomas Meyer

Datum der mündlichen Prüfung: 24.10.2019 
Hiermit erkläre ich, die Dissertation mit dem Titel "Membranprotein-Komposition von Kardiofibroblasten in Normoxie und Hypoxie" eigenständig angefertigt und keine anderen als die von mir angegebenen Quellen und Hilfsmittel verwendet zu haben.

Göttingen, den 


\section{Publikation}

Ergebnisse der vorliegenden Dissertation wurden im folgenden Artikel veröffentlicht:

Wottawa M, Naas S, Böttger I, Belle GJ van, Möbius W, Revelo NH, Heidenreich D, Ahlen M von, Zieseniss A, Kröhnert K, et al. (2017): Hypoxia-stimulated membrane trafficking requires T-plastin. Acta Physiol 221, 59-73 


\section{Inhaltsverzeichnis}

Abbildungsverzeichnis ......................................................................................... III

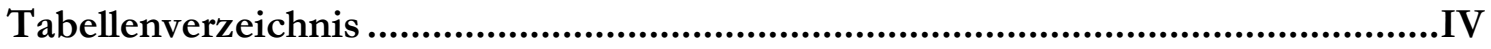

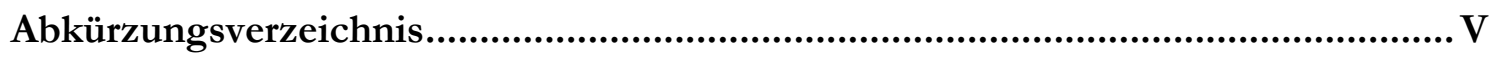

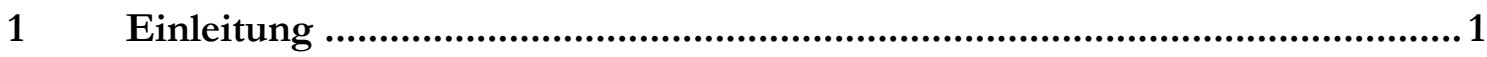

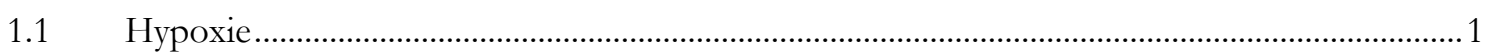

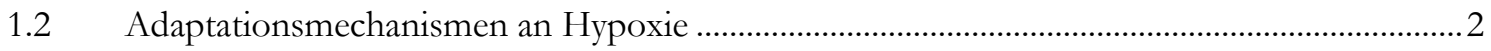

1.2.1 Nicht-Transkriptions-abhängige Adaptationsmechanismen an Hypoxie ...................................2

1.2.2 Transkriptions-abhängige Adaptation an Hypoxie durch Hypoxie-induzierbare

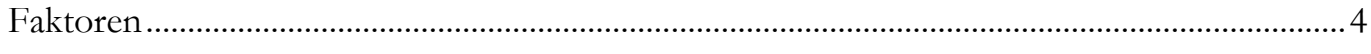

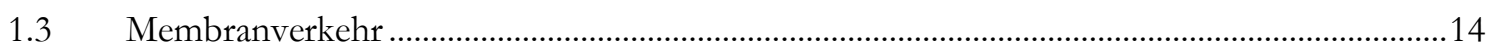

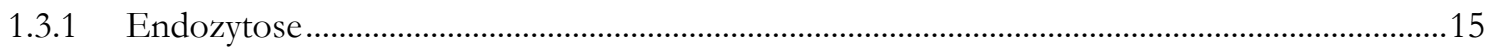

1.3.2 Einfluss von Hypoxie auf den Membranverkehr.................................................................19

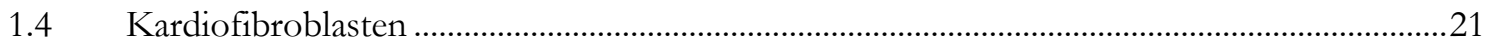

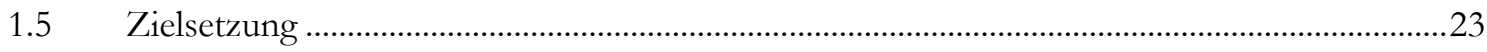

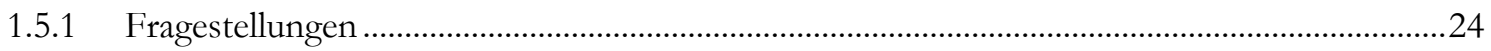

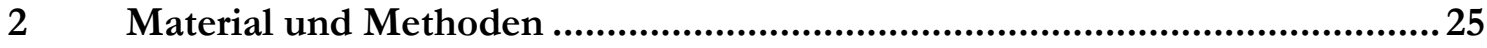

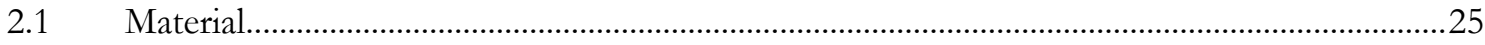

2.1.1 Reagenzien und Bestandteile von Zellkulturmedien .............................................................25

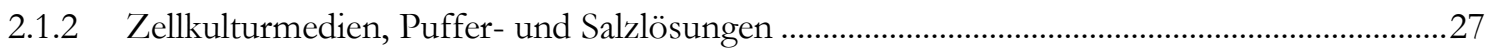

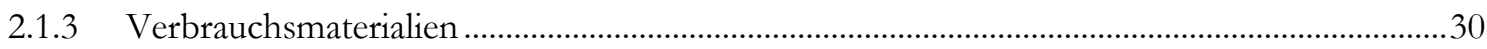

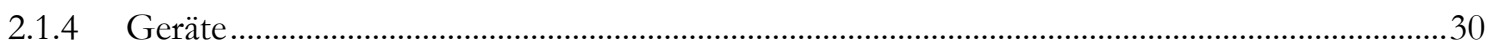

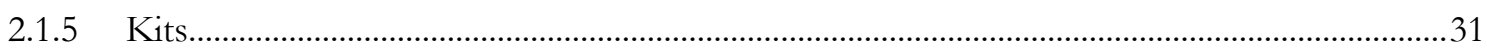

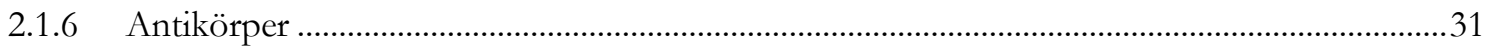

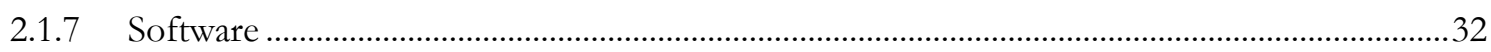

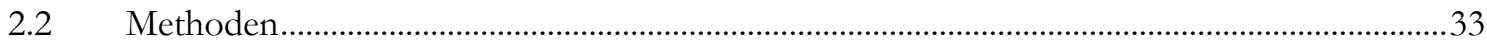

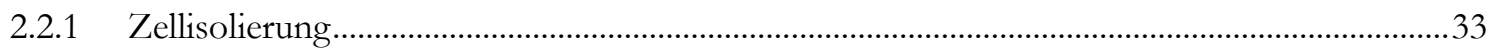

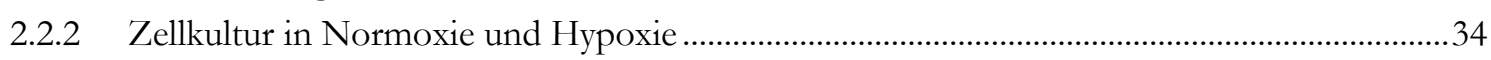

2.2.3 FM 1-43-Färbung und konfokale Mikroskopie .........................................................................

2.2.4 Proteinextraktion, Auftrennung und Western-Blot-Analyse...................................................39

2.2.5 SILAC-Markierung, Zellmembranisolierung und Proteomanalyse ............................................. 43

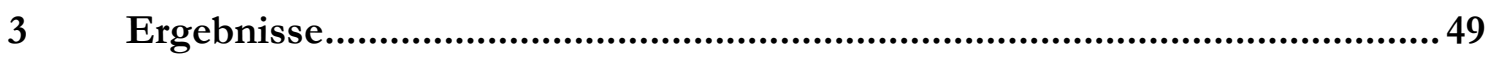

3.1 Analyse des Gesamtmembranverkehrs von Fibroblasten unter Hypoxie.................................49

3.1.1 Inkubation von Kardiofibroblasten bei Hypoxie für sechs Stunden führt zur Stabilisierung von HIF-1 $\alpha$...........................................................................................................4

3.1.2 Kardiofibroblasten zeigen unter Hypoxie in der Analyse der Endozytose eine verstärkte FM 1-43-Fluoreszenz und eine veränderte Morphologie intrazellulärer Vesikel 
3.1.3 Inkubation von Schwanzfibroblasten bei Hypoxie für sechs Stunden führt zur Stabilisierung von HIF-1 $\alpha$.

3.1.4 Schwanzfibroblasten zeigen unter Hypoxie in der Analyse der Endozytose eine erhöhte FM 1-43-Fluoreszenz und eine veränderte Morphologie intrazellulärer Vesikel .....53

3.1.5 Die Stabilisierung von HIF- $1 \alpha$ ist in Kardiofibroblasten durch Reoxygenierung reversibel.

3.1.6 Veränderungen der unter Hypoxie beobachteten FM 1-43-Fluoreszenz und Vesikelgröße sind in Kardiofibroblasten nach Reoxygenierung vollständig reversibel

3.2 Analyse des Plasmamembranproteoms von Kardiofibroblasten unter Normoxie und Hypoxie.

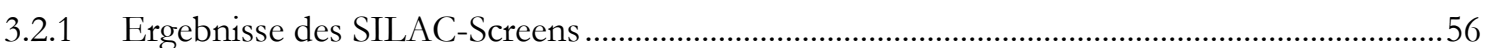

3.2.2 Klassifikation im SILAC-Screen Hypoxie-abhängig differenziell identifizierter Proteine ....60

4 Diskussion.

4.1 Hypoxie induziert in Kardiofibroblasten eine Zunahme der endozytotischen Membraninternalisierung

4.2 Die Hypoxie-induzierte Zunahme der endozytotischen Membraninternalisierung ist nicht spezifisch für Kardiofibroblasten.....

4.3 Die Hypoxie-induzierte Zunahme der endozytotischen Membraninternalisierung ist durch Reoxygenierung vollständig reversibel

4.4 Hypoxie beeinflusst die Plasmamembrankomposition von Kardiofibroblasten .....

4.4.1 Klassifikation der in der Plasmamembran Hypoxie-abhängig differenziell exprimierten

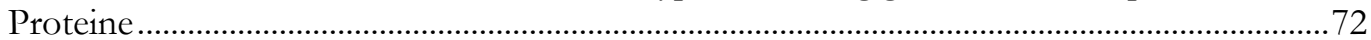

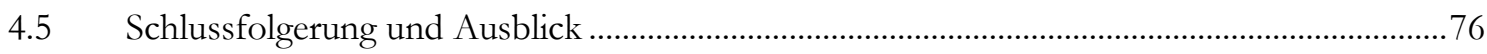

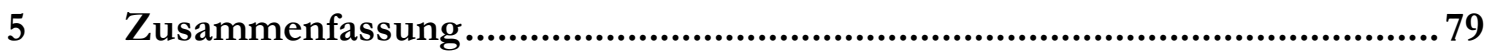

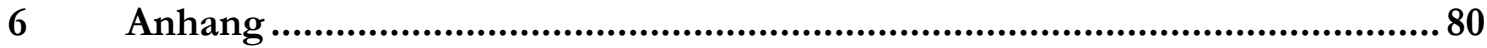

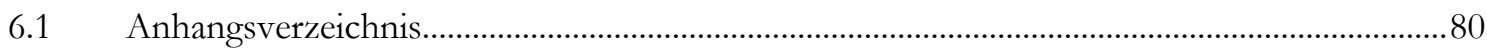

6.2 Im SILAC-Screen als Hypoxie-abhängig differenziell reguliert identifizierte Proteine .........80

6.3 FM 1-43-Färbung von über drei Passagierungen kultivierten Kardiofibroblasten unter

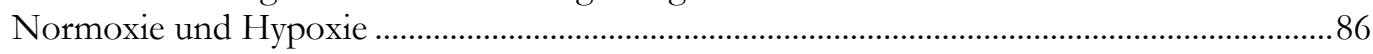




\section{Abbildungsverzeichnis}

Abbildung 1: Sauerstoff-abhängige Regulation der HIF-Transkriptionsfaktoren.............................. 9

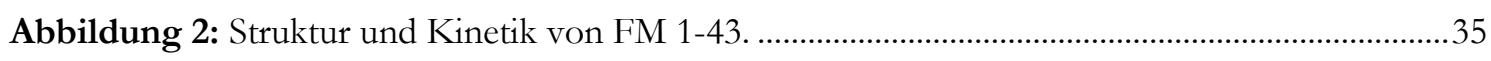

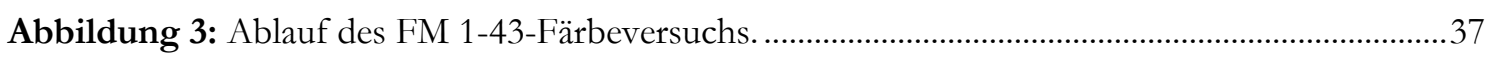

Abbildung 4: Versuchsaufbau der quantitativen Proteom-Analyse mittels SILAC-Markierung......44

Abbildung 5: Coomassie-Brillant-Blau-Färbung der aufgetrennten Membranproteine und Membran-assoziierten Proteine nach SILAC-Markierung........

Abbildung 6: Nachweis von HIF-1 $\alpha$ in Kardiofibroblasten durch Western-Blot-Analyse nach sechsstündiger Inkubation unter Hypoxie.

Abbildung 7: FM 1-43-Färbung von Kardiofibroblasten unter Normoxie und Hypoxie.

Abbildung 8: Nachweis von HIF-1 $\alpha$ in Schwanzfibroblasten durch Western-Blot-Analyse nach sechsstündiger Inkubation unter Hypoxie.

Abbildung 9: FM 1-43-Färbung von Schwanzfibroblasten in Normoxie und Hypoxie.

Abbildung 10: Nachweis von HIF-1 $\alpha$ in Kardiofibroblasten durch Western-Blot-Analyse nach sechsstündiger Inkubation unter Hypoxie und nach anschließender Reoxygenierung.

Abbildung 11: FM 1-43-Färbung von Kardiofibroblasten in Normoxie, Hypoxie und nach Reoxygenierung.

Abbildung 12: Ergebnisse des SILAC-Screens.

Abbildung 13: Histogramm der normierten Signalintensitäten im SILAC-Screen identifizierter Proteine.

Abbildung 14: Im SILAC-Screen Hypoxie-abhängig differenziell identifizierte Proteine. 59

Abbildung 15: PANTHER-Datenbank-Klassifikation der im SILAC-Screen unter Hypoxie vermehrt identifizierten Proteine.

Abbildung 16: PANTHER-Datenbank-Klassifikation der im SILAC-Screen unter Hypoxie vermindert identifizierten Proteine. 


\section{Tabellenverzeichnis}

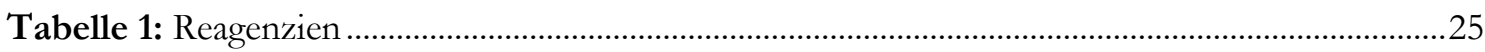

Tabelle 2: Bestandteile von Zellkulturmedien...........................................................................2

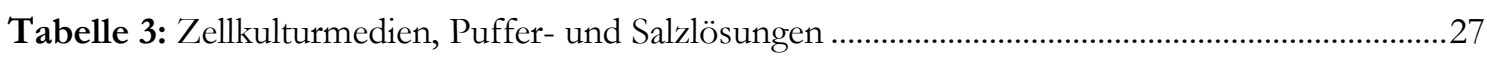

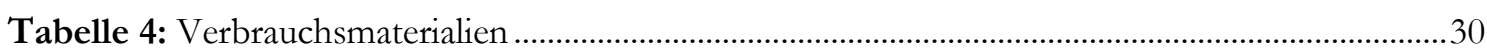

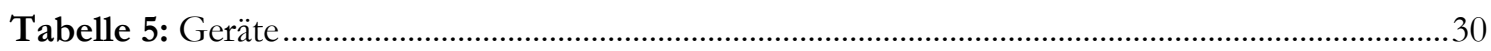

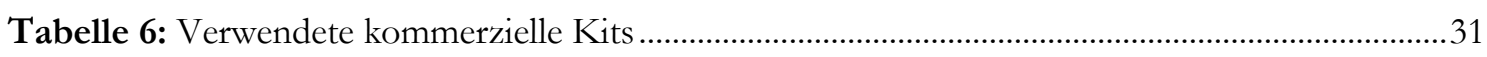

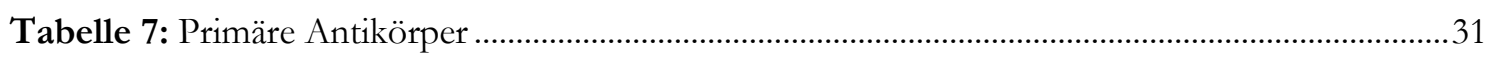

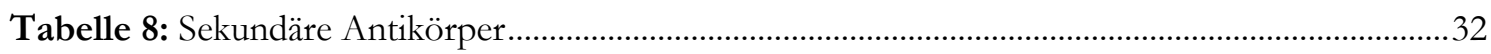

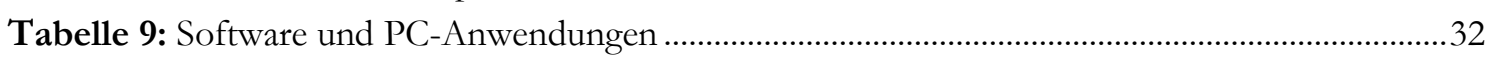

Tabelle 10: Benötigte Mengen der Reagenzien zur Bestimmung der Proteinkonzentration ...............40

Tabelle 11: Bestandteile eines Polyacrylamid-Gels .............................................................................41

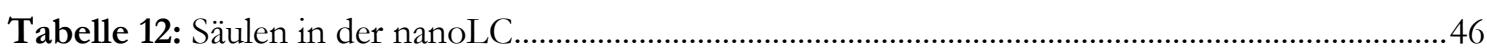

Tabelle 13: Schlagworte, die in der manuellen Auswertung des SILAC-Screens zur Einordnung der Proteine verwendet wurden.............................................................................4

Tabelle 14: G-Proteine und mit G-Proteinen interagierende Proteine, die im SILAC-Screen unter Hypoxie vermehrt in bzw. assoziiert mit der Plasmamembran nachgewiesen wurden

Tabelle 15: G-Proteine und mit G-Proteinen interagierende Proteine, die im SILAC-Screen unter Normoxie vermehrt in bzw. assoziiert mit der Plasmamembran nachgewiesen wurden...... 


\section{Abkürzungsverzeichnis}

ABTS

2,2'-Azino-bis-(3-ethylbenzothiazolin-6-sulfonsäure) Diammoniumsalz

ADP

Adenosindiphosphat

AMP

AMPA

Adenosinmonophosphat

a-amino-3-hydroxy-5-methyl-4-isoxazoleproprionic acid ( $\alpha$-amino-3-hydroxy-5methyl-4-isoxazol-proprionsäure)

AMPK

Andenosinmonophosphat-aktivierte Kinase

AP

APS

AOTF

aqua dest

Arf

Arf-GAP

ARNT

ATP

BSA

$\mathrm{CBFHH}$

CME

DDA

DMEM

DNA

DTT

DRK

ECL

EDTA

EGF

EZM

FIH

FKBP

FKS

GAP

GDP

GEF

GO

GPI

GTP

GTPase

G-Protein

$\mathrm{HCl}$

HEPES

HIF
Adapterprotein

Ammoniumpersulfat

acousto-optical tunable filter (Akusto-optischer durchstimmbarer Filter)

Destilliertes Wasser

Adenosindiphosphat-Ribosylierungsfaktor

Adenosyl-Ribosylierungsfaktor-GTPase aktivierendes Protein

aryl bydrocarbon receptor nuclear translocator (Arylhydrokarbonrezeptor Nukleustranslokator)

Adenosintriphosphat

bovines Serumalbumin

kalzium- und bikarbonatfreie Hanks-Lösung mit HEPES

clathrin-mediated endocytosis (Clathrin-vermittelte Endozytose)

data-dependent acquisition (Daten-abhängige Aquise)

Dulbecco's Modified Eagle Medium

deoxyribonucleic acid (Desoxyribonukleinsäure)

Dithiothreitol

Deutsches Rotes Kreuz

enhanced chemiluminescence (verstärkte Chemilumineszenz)

Ethylendiamintetraazetat

epidermal growth factor (Epidermaler Wachstumsfaktor)

extrazelluläre Matrix

factor inbibiting HIF (HIF-inhibierender Faktor)

FK506-bindendes Protein

fetales Kälberserum

GTPase-aktivierendes Protein

Guanosindiphosphat

guanine nucleotide exchange factor (Guaninnukleotid-Austauschfaktor)

Genontologie

Glykosylphosphatidylinositol

Guanosintriphosphat

Guanosintriphosphatase

Guanosintriphosphat-bindendes Protein

Hydrochlorid (Salzsäure)

2-(4-(2-Hydroxyethyl)-1-piperazinyl)-ethansulfonsäure

Hypoxie-induzierbarer Faktor 
HRE bypoxia response element (Hypoxie-responsives Element)

HSP Hitzeschockprotein

iNOS Induzierbare Stickstoffmonoxidsynthase

$\mathrm{K}_{\mathrm{m}} \quad$ Michaelis-Menten-Konstante

MAP Mitogen-aktiviertes Protein

mCLING membrane-binding-fluorophore-cysteine-lysine-plamitoyl group (Mebran-bindendeFluorophor-Zystein-Lysin-Palmitoylgruppe)

MEM NEAA minimum essential medium non-essential amino acids

$\mathrm{MgSO}_{4} \quad$ Magnesiumsulfat

$\mathrm{miR}$

mRNA messenger ribonucleic acid (Boten-Ribonukleinsäure)

mTOR mechanistic target of rapamycin (mechanistisches Ziel von Rapamyzin)

MW molecular weight (Molekulargewicht)

NADPH Nikotinamidadenindinukleotidphosphat

$\mathrm{NADH} \quad$ Nikotinamidadenindinukleotid

NCE

NEAA

non-clathrin endocytosis (nicht-Clathrin-vermittelte Endozytose)

non-essential amino acids (nicht-essentielle Aminosäuren)

NKM Nicht-Kardiomyozyten

NO

Stickstoffmonoxid

NOS Stickstoffmonoxidsynthase

ODDD oxygen-dependent degradation domain (sauerstoffabhängige

Degradationsdomäne)

P Passage

PANTHER protein analysis through evolutionary relationships (Proteinanalyse durch evolutionäre Verbindungen)

PBS

phosphate-buffered saline (phosphatgepufferte Salzlösung)

$\mathrm{pH}$

potentia bydrogenii (negativer dekadischer Logarithmus der

Wassserstoffionenkonzentration)

PHD Prolylhydroxylase-Domäne-enthaltendes Enzym

PI3K Phosphoinositid-3-Kinase

PK PANTHER-Klassifikationsnummer

PMT photomultiplier tube (Photoelektronenverfielfacher)

$\mathrm{pO}_{2} \quad$ Sauerstoffpartialdruck

Ppm parts per million (Millionstel)

pVHL Von-Hippel-Lindau Tumorsuppressor E3 Ubiquitin Ligase

Rac Ras-related C3 botulinum toxin substrate (Ras-ähnliches C3 BotulinumtoxinSubstrat)

RACK receptor for activated C kinase (Rezeptor der aktivierten Proteinkinase C)

Ras

Ras-related in brain (Ras-ähnlich im Gehirn)

Redox- Reduktions-Oxidations-

Rheb Ras bomolog enriched in brain (Ras Homolog angereichert im Gehirn)

RNA ribonucleic acid (Ribonukleinsäure)

ROI regions of interest (Bereiche von Interesse)

ROS reactive oxygen species (reaktive Sauerstoffspezies) 
Rpm revolutions per minute (Umdrehungen pro Minute)

SDS sodium dodecyl sulfate (Natriumdodecylsulfat)

SDS PAGE sodium dodecyl sulfate polyacrylamide gel electrophoresis (Natriumdodecylsulfat Polyacrylamid-Gelelektrophorese)

Sirt Sirtuin

SILAC stable isotope labeling with amino acids in cell culture (Stabile Isotopenmarkierung mit Aminosäuren in Zellkultur)

SSAT Spermidin/Spermin-N1-Azetyltransferase

Stip stressinduziertes Phosphoprotein

SUMO

small ubiquitin-like modifier (kleines Ubiquitin-verwandtes Modifikatorprotein)

TEMED Tetraethylmethyldiamin

TGF transforming growth factor (Transformierender Wachstumsfaktor)

TMR Transmembranrezeptor

Trappc trafficking protein particle complex (Transport-Proteinpartikelkomplex)

TRIS Tris(hydroxymethyl)-aminomethan

WGA wheat germ agglutinin (Weizenkeim-Agglutinin) 


\section{$1 \quad$ Einleitung}

\subsection{Hypoxie}

Molekularer Sauerstoff $\left(\mathrm{O}_{2}\right)$ ist von essentieller Bedeutung für das Überleben von Zellen (Carreau et al. 2011). Aerob lebende Organismen beziehen Energie durch die Extraktion von Elektronen aus Nahrungssubstraten. Die elektrische potentielle Energie wird in Adenosintriphosphat (ATP) als nutzbarer chemischer Form gespeichert. Durch Elektronenabgabe von reduzierten Substraten wie reduziertem Nikotinamidadenindinukleotid (NADH) und Succinat an Komplexe der mitochondrialen Atmungskette wird der Transport von Protonen über die innere Mitochondrienmembran ermöglicht und ein elektrochemischer Gradient aufgebaut. Die Elektronen werden über Reduktions-Oxidations (Redox)-Cofaktoren entlang eines Energiegradienten in der Atmungskette weitertransportiert und in den meisten biologischen Systemen schließlich an $\mathrm{O}_{2}$ abgegeben, der hierdurch zu Wasser reduziert wird. Der durch den Protonentransport aufgebaute elektrochemische Gradient wird durch das mitochendrienmembranständige Enzym ATPSynthase zur Produktion von ATP genutzt (Hosler et al. 2006).

Im menschlichen Körper wird $\mathrm{O}_{2}$ durch Diffusion in den Lungen aufgenommen und gelangt mit dem Blutstrom, überwiegend an Hämoglobin gebunden, in die kapillären Endstromgebiete. Von hier erreicht er entlang eines Partialdruckgradienten durch Diffusion die Mitochondrien (Bateman et al. 2003). Der physiologische $\mathrm{O}_{2}$-Partialdruck $\left(\mathrm{pO}_{2}\right)$ in den Endorganen wird als Gewebenormoxie bezeichnet (Carreau et al. 2011) und variiert zwischen $72 \pm 20 \mathrm{mmHg}\left(9,48 \pm 2,59 \% \mathrm{O}_{2}\right)$ im renalen Kortex (Muller et al. 1998) und 10 mm Hg (1,32\% $\left.\mathrm{O}_{2}\right)$ im Nierenmark (Baumgärtl et al. 1972). Der Begriff Normoxie entspricht dem atmosphärischen $\mathrm{pO}_{2}$ von etwa $150 \mathrm{mmHg}\left(19,95 \% \mathrm{O}_{2}\right)$, wohingegen Hypoxie einem geringeren $\mathrm{pO}_{2}$ als bei Gewebenormoxie und einem $\mathrm{O}_{2}$-Mangel im Gewebe entspricht (Carreau et al. 2011). Die vollständige Abwesenheit von $\mathrm{O}_{2}$ im Gewebe $\left(0 \% \mathrm{O}_{2}\right)$ wird als Anoxie bezeichnet (Höckel und Vaupel 2001).

Ein Missverhältnis von $\mathrm{O}_{2}$-Bedarf und $\mathrm{O}_{2}$-Angebot im Gewebe ist Merkmal der Pathophysiologie unterschiedlicher Erkrankungen wie Myokardinfarkt (Handley et al. 2011), Apoplex (Lipton 1999; Hossmann 2012) und Entzündungen (Wakefield et al. 1989; Hartmann et al. 2000; Nizet und Johnson 2009; Bandarra et al. 2014). Viele solide Tumoren weisen hypoxische Areale auf (Vaupel et al. 2007), wobei Tumorhypoxie mit einer schlechteren Prognose assoziiert ist (Höckel et al. 1993; Brizel et al. 1996).

Die Oxygenierung des Blutes und der Gewebe können sich in vivo schnell verändern (Richardson et al. 1995; Dempsey et al. 2010). Der Organismus muss somit in der Lage sein, kurzfristig auf einen $\mathrm{O}_{2}$-Mangel zu reagieren. Hypoxie führt zu Veränderungen im zellulären 
Kohlenhydratstoffwechsel mit Induktion der Glykolyse und Entkopplung des Zitratzyklus (Payen et al. 2015), einer verstärkten Angio- und Erythropoese (Giaccia et al. 2004; Ratcliffe 2013), einer Steigerung des Atemminutenvolumens (Sato et al. 1992) sowie perinatal einer vermehrten Katecholaminausschüttung aus dem Nebennierenmark (Brown et al. 2010). Es bestehen im Organismus jedoch auch unter physiologischen Bedingungen hypoxische Nischen, die Überleben, Proliferation und Differenzierung der Zellen regulieren (Depping et al. 2004; Ramírez-Bergeron et al. 2004; Krishnan et al. 2008; Simon und Keith 2008).

\subsection{Adaptationsmechanismen an Hypoxie}

Es wurde eine Vielzahl von zellulären Mechanismen beschrieben, die eine Reaktion des Organismus auf Hypoxie ermöglichen (Ward 2008; Taabazuing et al. 2014; Prabhakar und Semenza 2015). Auf molekularer Ebene führt akute Hypoxie zu schnellen, jedoch kurzlebigen Reaktionen, die meist auf der posttranslationalen Modifikation bereits exprimierter Proteine beruhen (Prabhakar und Semenza 2012). Chronische Hypoxie induziert hingegen durch Veränderung der Boten-Ribonukleinsäure (mRNA, messenger ribonucleic acid)- und Proteinexpression eine langsamere und länger anhaltende Reaktion (ebd.)

\subsubsection{Nicht-Transkriptions-abhängige Adaptationsmechanismen an Hypoxie}

Eine frühzeitige Hypoxieerkennung ist notwendig, um durch Anpassung von Parametern wie dem pulmonalen Gefäßtonus, Sympathikusaktivität und Atemfrequenz den Erhalt der systemischen kardiovaskulären und respiratorischen Homöostase zu gewährleisten (Swenson 2013; Fernández-Agüera et al. 2015; Prabhakar und Semenza 2015). Eine zentrale Rolle spielen hierbei Typ-1-Zellen des Karotisglomus (Weir et al. 2005). Die Latenzzeit bis zur Rezeptorantwort des Karotisglomus beträgt 0,2-0,3 Sekunden und die maximale Chemorezeptoraktivität wird nach ein bis fünf Sekunden erreicht (Black et al. 1971; Ponte und Purves 1974). Dieser schnellen Reaktion liegt die Inhibition von Kaliumkanälen zugrunde, wodurch eine Depolarisation der Typ-1-Zellen, Spannungs-abhängiger Kalziumeinstrom und Neurosekretion ermöglicht werden (Nurse 2010).

\subsubsection{Veränderte Gasotransmitterproduktion durch Häm-haltige Enzyme}

Ein möglicher Mechanismus für eine rasche zelluläre Reaktion auf Hypoxie ist eine verminderte Kohlenstoffmonoxid (CO)-Produktion durch Hämoxygenase 2 (Yuan et al. 2015), die $\mathrm{zu}$ einer Disinhibition der Schwefelwasserstoff $\left(\mathrm{H}_{2} \mathrm{~S}\right)$-Synthese durch Cystathionin- $\gamma$-Lyase führt (Peng et al. 2010). $\mathrm{H}_{2} \mathrm{~S}$ hemmt Kalzium-abhängige MaxiKaliumkanäle direkt (Telezhkin et al. 2010), wobei die Bedeutung dieses Mechanismus in vivo nicht abschließend geklärt ist (Prabhakar 2013).

Analog zur verminderten CO-Produktion sinkt unter Hypoxie auch die Bereitstellung von Stickstoffmonoxid (NO) durch das Enzym neuronale NO-Synthase (NOS) in den efferenten Nervenfasern des Karotisglomus (Prabhakar et al. 1993). Hierdurch entfällt die Stimulation 
Kalzium-abhängiger Kaliumströme in den Typ-1-Zellen (Li et al. 2004; Li et al. 2010) und die Inhibition der Cystathionin- $\gamma$-Lyase durch NO (Yuan et al. 2015). Wasserstoffperoxid wird durch die bei Hypoxie verminderte Oxidation zu Thiosulfat und anschließend zu Sulfat auch als direkter $\mathrm{O}_{2}$-Sensor diskutiert (Olson 2013). Eine Kausalität wird aufgrund der möglichen Oxidation von Wasserstoffperoxid durch reaktive Sauerstoffspezies (ROS, reactive oxygen species) jedoch infrage gestellt (Taabazuing et al. 2014).

\subsubsection{Veränderung des mitochondrialen Energiestoffwechsels}

Einen weiteren potentiellen $\mathrm{O}_{2}$-abhängigen Mechanismus stellen die Mitochondrien als größter intrazellulärer $\mathrm{O}_{2}$-Konsument dar (Waypa et al. 2016). Eine reduzierte ATPProduktion durch verminderte oxidative Phosphorylierung kann direkt zelluläre Reaktionen beeinflussen (Varas et al. 2007). Auch eine Aktivierung der Adenosinmonophosphat (AMP)aktivierten Kinase (AMPK) durch eine Verringerung des ATP/AMP-Quotienten kann über die Phosphorylierung von Zielproteinen wie Ionenkanälen eine schnelle zelluläre Anpassung an Hypoxie vermitteln (Wyatt et al. 2007; Evans et al. 2009). Dieser Mechanismus wird jedoch aufgrund der hohen $\mathrm{O}_{2}$-Affinität der Zytochrom-c-Oxidase (Chandel et al. 1997) in Zweifel gezogen (Waypa et al. 2016). Eine zelltypspezifische geringere $\mathrm{O}_{2}$-Affinität der Zytochrom-c-Oxidase in bestimmten Geweben wurde postuliert (Buckler und Turner 2013). Eine hypoxiebedingt reduzierte Zytochrom-c-Oxidase-Aktivität kann durch blockierten mitochondrialen Elektronentransport zur Akkumulation von Pyruvat und einer vermehrten Laktatproduktion führen. Durch die Expression des laktatsensitiven Geruchsrezeptors Olfr78 auf Typ-1-Zellen des Karotisglomus ist eine Hypoxie-Erkennung möglich (Chang et al. 2015).

\subsubsection{Veränderung des Redox-Gleichgewichtes und der Produktion von reaktiven} Sauerstoffspezies

ROS sind als sauerstoffhaltige reaktive Spezies definiert und umfassen unter anderem Superoxid $\left(\mathrm{O}_{2}{ }^{-}\right)$, Wasserstoffperoxid $\left(\mathrm{H}_{2} \mathrm{O}_{2}\right)$ und das Hydroxylradikal $\left(\mathrm{OH}^{-}\right)$( $\mathrm{Li}$ et al. 2016). $\mathrm{O}_{2}{ }^{-}$ist instabil und dismutiert spontan oder katalysiert durch Superoxiddismutase (SOD) zu Wasserstoffperoxid (Cash et al. 2007). Es kann jedoch auch mit NO zu Peroxynitrit $\left(\mathrm{ONOO}^{-}\right)$reagieren, Eisen-Schwefel-Cluster oder Häm-Eisen oxidieren (Brandes et al. 2014). Das Zitratzyklus-Enzym Aconitase wird durch $\mathrm{O}_{2}^{-}$inaktiviert (Gardner 1997). $\mathrm{H}_{2} \mathrm{O}_{2}$ ist verhältnismäßig stabil, kann biologische Membranen durchqueren und eignet sich somit als Botenstoff über längere Distanzen (Rhee 2006).

Ein Modell für die Funktion der Mitochondrien als initialer $\mathrm{O}_{2}$-abhängiger Signalweg ist die hypoxische Modifikation des zytosolischen Redoxpotentials und der ROS-Produktion durch Komplexe der Atmungskette. Bei fehlendem $\mathrm{O}_{2}$ als Elektronenakzeptor liegen die Komplexe der Atmungskette im reduzierten Zustand vor. Dies führt zu einem Überwiegen von Reduktionsäquivalenten wie NADH und Glutathion (GSH) innerhalb der vorgeschalteten zytosolischen Redoxpaare (White et al. 1988; Leach et al. 2001; Ward 2008). Auch eine durch 
Verminderung von $\mathrm{O}_{2}$-Angebot und mitochondrialen Elektronentransport verringerte ROSProduktion würde ein Überwiegen von Reduktionsäquivalenten begünstigen (Sham 2002). Es existieren jedoch widersprüchliche Daten hinsichtlich des Effektes von Hypoxie auf die ROS-Produktion. Während einige Autoren in glatten Gefäßmuskelzellen der Pulmonalarterien und des Ductus Arteriosus verminderte ROS-Spiegel bei $\mathrm{O}_{2}$-Mangel beschreiben (Bonnet et al. 2006; Weir und Archer 2010), zeigen andere Daten einen Anstieg von Sauerstoffradikalen unter Hypoxie in pulmonalarteriellen glatten Muskelzellen und verschiedenen anderen Zelltypen (Vanden Hoek et al. 1998; Mansfield et al. 2005; Zhao et al. 2007). Diese Diskrepanz ist möglicherweise durch unterschiedliche Methodik hinsichtlich Hypoxiedauer, Kohlenstoffdioxid ( $\left.\mathrm{CO}_{2}\right)$-Partialdrücken, pH-Einstellung und ROSMesstechniken zu erklären (Dunham-Snary et al. 2017). Eine auf subzelluläre Kompartimente begrenzte ROS-Akkumulation ist nicht durch jede verwendete Technik nachweisbar (Waypa et al. 2010; Sommer et al. 2016).

Die Generierung von Sauerstoffradikalen ist an den Komplexen I, II und III der Atmungskette möglich (Waypa et al. 2016). Begünstigend wirkt ein mitochondriales Membranpotential von $-180 \mathrm{mV}$, das bei einer Membrandicke von $7 \mathrm{~nm}$ eine elektrische Feldstärke von $257.000 \mathrm{~V} / \mathrm{cm}$ verursacht. Hierdurch werden Anionen, sofern sie sich innerhalb der inneren Mitochondrienmembran befinden, in den intermembranösen Raum gedrängt (Sabharwal und Schumacker 2014). Daten von unterschiedlichen Zelltypen deuten auf eine $\mathrm{O}_{2}$-Sensorfunktion mit Hypoxie-induzierter ROS-Bildung an Komplex III hin (Guzy et al. 2005; Waypa et al. 2013). In Typ-1-Zellen des Karotisglomus führt eine hohe anaplerotische Stoffwechselaktivität und Succinat-abhängige Mitochondrienfunktion möglicherweise über eine Akkumulation von reduziertem Chinon zur ROS-Produktion an Komplex I der Atmungskette (Fernández-Agüera et al. 2015). Auch zum Teil zellmembranständige Nikotinamidadenindinukleotidphosphat (NADPH)-Oxidasen sind eine Quelle für ROS und möglicher $\mathrm{O}_{2}$-Sensor (Fu et al. 2000; Nisimoto et al. 2014). Dieser Mechanismus ist jedoch nicht abschließend geklärt (Archer et al. 1999; Kahles und Brandes 2013). ROS können eine Vielzahl von zellulären Reaktionen beeinflussen (Zhang et al. 2016b; Aldosari et al. 2018). Im Kontext von Hypoxie wurden unter anderem die Induktion des Proteinkinase C Signalweges (Rathore et al. 2008), Interaktion mit Ionenkanälen (Veit et al. 2015) und Aktivierung von AMPK (Mungai et al. 2011) beschrieben.

\subsubsection{Transkriptions-abhängige Adaptation an Hypoxie durch Hypoxie- induzierbare Faktoren}

Hypoxie-induzierbare Faktoren (HIF) sind Hauptregulatoren der $\mathrm{O}_{2}$-Homöostase, üben aber auch darüber hinausgehend weitere biologische Funktionen aus (Prabhakar und Semenza 2012; Bishop und Ratcliffe 2014). Der HIF-Hydroxylase-Pfad kontrolliert einen komplexen Transkriptionsmechanismus, der in praktisch jeder tierischen Zelle nachweisbar ist (Bishop und Ratcliffe 2014). Die HIF-Transkriptionsfaktoren sind bei Säugetieren von zentraler Bedeutung für die Morphogenese von Embryo und Plazenta in der hypoxischen 
Umgebung des Uterus (Jauniaux et al. 2000; Krishnan et al. 2008; Dunwoodie 2009; Pringle et al. 2010). Sie regulieren die basale (Brown et al. 2009) und Hypoxie-induzierte Katecholaminproduktion (Carabelli et al. 2007; Wong et al. 2010) sowie die Funktion des Karotisglomus (Kline et al. 2002; Roux et al. 2005; Peng et al. 2011). HIFTranskriptionsfaktoren regulieren die Angiogenese (Forsythe et al. 1996; Manalo et al. 2005) und Erythropoese (Semenza und Wang 1992; Yoon et al. 2006).

\subsubsection{Struktur und Funktion von HIF}

HIF ist ein heterodimerer basischer Helix-Loop-Helix-Transkriptionsfaktor mit einer Per/Arnt/Sim (PAS)-Domäne. Er besteht aus einer von drei HIF- $\alpha$ Untereinheiten im Komplex mit der 91-94 kDa großen HIF- $\beta$ Untereinheit (Wang et al. 1995; Ema et al. 1997; Tian et al. 1997; Gu et al. 1998). Die $\beta$-Untereinheit oder Arylhydrokarbonrezeptor Nukleustranslokator (ARNT, aryl bydrocarbon receptor nuclear translocator) (Hoffman et al. 1991) wird konstitutiv exprimiert und ist im Gegensatz zur $\alpha$-Untereinheit in weitere, nicht Hypoxie-spezifische Transkriptionsregulationsmechanismen involviert (Ratcliffe 2013). Die ebenfalls konstitutiv synthetisierte $\alpha$-Untereinheit (Hirsilä et al. 2003) wird $\mathrm{O}_{2}$-abhängig degradiert (Salceda und Caro 1997).

Die am besten beschriebene $\alpha$-Isoform ist HIF-1 $\alpha$ (Berra et al. 2003; Löfstedt et al. 2007). HIF-1 $\alpha$ hat unter Normoxie eine Halbwertszeit von weniger als fünf Minuten (Huang et al. 1996). Unter Hypoxie transloziert HIF- $\alpha$ in den Nukleus (Kallio et al. 1998), dimerisiert mit HIF- $\beta$ (Jiang et al. 1996a) und induziert die Transkription von Genen, die ein Hypoxieresponsives Element (HRE) enthalten (Semenza et al. 1996; Fandrey et al. 2006). Als Transkriptionsregulator begünstigt das Protein p300 die HIF-1 $\alpha$-abhängige Genexpression (Arany et al. 1996; Ebert und Bunn 1998). Genomweit wurden mehr als 500 HIFBindungsstellen identifiziert (Schödel et al. 2011). Während viele Bindungsstellen sowohl mit HIF- $1 \alpha$ als auch mit HIF- $2 \alpha$ interagieren, sind einige spezifisch für HIF-1 $\alpha$, jedoch nur wenige für HIF-2 $\alpha$ (Mole et al. 2009). Die Spezifität für unterschiedliche Zielgene ist abhängig vom Zelltyp und wird durch Transaktivatorproteine beeinflusst (Hu et al. 2007).

Von der $120 \mathrm{kDa}$ Isoform HIF-1 $\alpha$ (Wang et al. 1995) existieren mehrere Spleißvarianten (Gothié et al. 2000; Chun et al. 2001; Lee et al. 2004). Einige üben durch verminderte Transkriptionsaktivität oder Antagonisierung der HIF-1-induzierten Transkription gewebespezifisch eine dominant-negative Regulatorfunktion aus (Chun et al. 2002; Depping et al. 2004). HIF-1 $\alpha$ ist notwendig für die Ausbildung von Kapillaren während der Embryogenese (Ryan et al. 1998). Der Knockout von HIF-1 $\alpha$ führt zum Tod des Embryos durch kardiovaskuläre Fehlbildungen und vermindertes Überleben kephaler Mesenchymzellen (Iyer et al. 1998; Krishnan et al. 2008). HIF-1 $\alpha$ ist in vivo bereits unter Normoxie nachweisbar (Stroka et al. 2001). Die Mehrzahl der Zielgene von HIF-1 $\alpha$ wird kontextabhängig exprimiert, sodass in unterschiedlichen Zelltypen verschiedene Proteine induziert werden (Semenza 2014). Zielgene von HIF-1 $\alpha$ sind pro-glykolytische Enzyme (Seagroves et al. 2001; Hu et al. 2003) wie der insulinunabhängige Glukosetransporter Glut-1 
(Ebert et al. 1995), Pyruvatkinase (Semenza et al. 1994) und Laktatdehydrogenase A (LDHA) (Firth et al. 1995; Semenza et al. 1996) sowie Transkriptionsfaktoren (Manalo et al. 2005).

Die Deletion von HIF-1 $\alpha$ führt unter Hypoxie zu einem paradoxen Anstieg des intrazellulären ATP-Spiegels. Jedoch führt die mitochondriale ROS-Produktion zu einem vermehrten Absterben der Zellen (Zhang et al. 2008; Semenza 2012). Die HIF-1 $\alpha$-vermittelte Expression mehrerer Isoformen der Pyruvatdehydrogenase-Kinase (PDK) vermindert den Substratfluss entlang der Atmungskette und reduziert die mitochondriale ROS-Produktion (Denko et al. 2003; Kim et al. 2006; Papandreou et al. 2006). Auch über die $\mathrm{O}_{2}$-abhängige Expression unterschiedlicher Subtypen der Zytochrom-c-Oxidase ermöglicht HIF-1 eine Anpassung der Zellatmung an Hypoxie mit optimierter ATP-Produktion und reduzierter Bildung von ROS (Fukuda et al. 2007).

Über die Induktion glykolytischer Enzyme reguliert HIF-1 $\alpha$ die Funktion von Makrophagen und neutrophilen Granulozyten (Cramer et al. 2003). Zudem spielt HIF-1 $\alpha$ eine zentrale Rolle in der Differenzierung von regulatorischen T-Zellen und $\mathrm{T}_{\mathrm{H}} 17$-Effektorzellen (Sitkovsky 2009; Dang et al. 2011; Clambey et al. 2012). HIF-1 $\alpha$ reguliert zudem verschiedene Mikro-RNAs (miR) (Kulshreshtha et al. 2007; Camps et al. 2014; Sun und Peng 2015) und moduliert durch Interaktion mit anderen Transkriptionsfaktoren die HRE-unabhängige Transkription (Gustafsson et al. 2005; Koshiji et al. 2005). Durch die Bindung an gegensinnige HREs (rHREs, reverse bypoxia response elements) der DNA reprimiert HIF-1 die Transkription negativ regulierter Zielgene (Mazure et al. 2002; Jeong et al. 2007; Lee et al. 2010). Über die HIF-abhängige Expression von Histon-Demethylasen wird die epigenetische Homöostase unter Hypoxie reguliert (Xia et al. 2009).

Auch die Expression von HIF-2 $\alpha$ ist in Normoxie nachweisbar (Wiesener et al. 1998). Während HIF-1 $\alpha$ ubiquitär exprimiert wird (Wenger et al. 1996; Wiener et al. 1996), gibt es Unterschiede in der gewebe- und zelltypspezifischen Expression von HIF-2 $\alpha$ (Ema et al. 1997; Wiesener et al. 2002). Im Gegensatz zu HIF-1 $\alpha$ wird HIF-2 $\alpha$ weniger bei akuter und schwerer Hypoxie als bei leichter und längerfristiger Hypoxie induziert (Wiesener et al. 1998; Holmquist-Mengelbier et al. 2006). HIF-2 $\alpha$ spielt eine zentrale Rolle in der evolutionären Adaptation der Bewohner des Tibet-Plateaus an die hypobare Hypoxie der Höhenlage (Beall et al. 2010; Yi et al. 2010). HIF-2 $\alpha$ reguliert die Expression von Erythropoetin (Warnecke et al. 2004; Rankin et al. 2007; Kapitsinou et al. 2010) und die intestinale Eisenabsorption (Mastrogiannaki et al. 2009). Über die Induktion des Transkriptionsfaktors Oct-4 spielt HIF-2 $\alpha$ eine wichtige Rolle in der Regulation von Stammzellen (Covello et al. 2006; Forristal et al. 2010). Durch die Induktion des Transformierenden Wachstumsfaktors- $\alpha$ (TGF- $\alpha$, transforming growth factor-a) (Gunaratnam et al. 2003) und Zyklin D1 (Baba et al. 2003) beeinflusst HIF-2 $\alpha$ die Zellproliferation. HIF-2 $\alpha$ wird während der Embryogenese von einer Vielzahl von Geweben exprimiert (Flamme et al. 1997) und ist notwendig für die embryonale Katecholaminproduktion (Tian et al. 1998), vaskuläres Remodeling (Peng et al. 2000) und Lungenreifung (Compernolle et al. 2002). HIF-2 $\alpha^{-/}$Mäuse zeigen vielfältige 
Organpathologien, mitochondriale Dysfunktion mit gestörter ROS-Homöostase und metabolische Veränderungen (Scortegagna et al. 2003).

Die Effekte von HIF-1- und HIF-2-abhängiger Genexpression sind zum Teil gegenläufig. Durch die Zytokin-induzierte differenzielle Makrophagenpolarisation überwiegt in einer M1Immunantwort die HIF-1 $\alpha$-vermittelte Expression der induzierbaren NOS (iNOS). Bei einer M2-Immunantwort wird hingegen über HIF-2 $\alpha$ das Enzym Arginase 1 induziert. Arginase 1 begrenzt die Verfügbarkeit von L-Arginin für die iNOS. Dies ermöglicht eine differenzielle Regulierung der NO-Produktion (Takeda et al. 2010). HIF-1 und HIF-2 haben divergente Effekte auf die Zellproliferation (Raval et al. 2005). Während HIF-1 $\alpha$ proapoptotisch wirken kann (Carmeliet et al. 1998) und unter anderem durch Inhibition von myc (Koshiji et al. 2004) die Zellproliferation hemmt (Goda et al. 2003), verstärkt HIF-2 $\alpha$ über erhöhte mycTranskriptionsaktivität die Zellproliferation (Gordan et al. 2007). Für die globale Hypoxieabhängige Genexpression spielt HIF-1 $\alpha$ gegenüber HIF-2 $\alpha$ eine übergeordnete Rolle (Elvidge et al. 2006).

Von HIF-3 $\alpha$ werden verschiedene Spleißvarianten exprimiert (Maynard et al. 2003). HIF-3 $\alpha$ bildet hierdurch inaktive Komplexe mit anderen HIF- $\alpha$-Isoformen und inhibiert die HIFabhängige Transkription (Makino et al. 2001). In menschlichen embryonalen Stammzellen reguliert HIF-3 $\alpha$ über die Induktion von HIF-2 $\alpha$-abhängiger Transkription die Differenzierung und Proliferation (Forristal et al. 2010).

\subsubsection{Regulation von HIF}

Die Aktivität und der Abbau von HIF werden durch posttranslationale Hydroxylierung reguliert. Diese Reaktion wird durch Eisen-abhängige Dioxygenasen (ProlylhydroxylaseDomäne enthaltende Enzyme, PHDs) katalysiert (Epstein et al. 2001; Loenarz und Schofield 2008). Die Hydroxylierung von HIF- $\alpha$ erfolgt an den Prolinresten Pro402 und Pro564 (Ivan et al. 2001; Jaakkola et al. 2001; Masson et al. 2001; Yu et al. 2001) der $\mathrm{O}_{2}$-abhängigen Degradationsdomäne (ODDD, oxygen-dependent degradation domain) (Huang et al. 1998). Der Abbau der $\alpha$-Untereinheit erfolgt über die von-Hippel-Lindau-Tumorsuppressor E3Ubiquitinligase (pVHL) (Maxwell et al. 1999; Cockman et al. 2000; Masson et al. 2001). Die hydroxylierten Prolinreste der $\alpha$-Untereinheit dienen der Bindung von pVHL und ermöglichen die Polyubiquitinylierung und die anschließende proteasomale Degradation (Kallio et al. 1999). Unter Normoxie liegen die drei $\alpha$-Untereinheiten jeweils gebunden an Hitzeschockprotein 90 (HSP90) vor. Dies verhindert die unspezifische, nicht durch pVHL vermittelte Degradierung von HIF- $\alpha$ (Katschinski et al. 2004; Kong et al. 2006). Der Rezeptor der aktivierten Proteinkinase C 1 (RACK1, receptor for activated C kinase 1) kompetiert mit HSP90 um die Bindung von HIF- $1 \alpha$ und möglicherweise auch HIF- $2 \alpha$. Dies führt zur Ubiquitinylierung und dem Abbau der HIF- $\alpha$ Untereinheit (Liu et al. 2007).

Eine Hydroxylierung des Asparaginrestes Asn803 in der C-terminalen Transkripitionsaktivator-Domäne von HIF-1 $\alpha$ durch die Asparaginylhydroxylase HIF-inhibierender Faktor 
(FIH, factor inbibiting HIF) reduziert die Interaktion mit dem TranskriptionskoaktivatorProtein p300 (Mahon et al. 2001; Lando et al. 2002). Die $\mathrm{O}_{2}$-Affinität von FIH ist höher als die der PHDs (Koivunen et al. 2004), sodass die Hydroxylierung von Asn803 bei moderater Hypoxie einen Mechanismus zur Verhinderung einer Hypoxie-Antwort darstellen kann (Masson et al. 2012). Die $\mathrm{O}_{2}$-abhängige Regulation des HIF-Transkriptionsweges ist in Abbildung 1 dargestellt. Das Protein CITED2 bindet p300 an derselben Stelle wie HIF-1 $\alpha$ (Freedman et al. 2003). Die hypoxische Induktion von CITED2 ermöglicht ein negatives Feedback auf die HIF-1-abhängige Gentranskription (Bhattacharya et al. 1999). HIF-1 $\alpha$ zeigt eine stärkere FIH-abhängige Hydroxylierung als HIF-2 $\alpha$. Hierdurch wird eine differenzielle Regulation mit einem Überwiegen der HIF- $2 \alpha$-abhängigen Transkription bei geringer ausgeprägter Hypoxie ermöglicht (Bracken et al. 2006; Yan et al. 2007).

Die Stabilisierung von HIF-1 $\alpha$ erfolgt graduell nach Ausmaß der Hypoxie (Jiang et al. 1996b). $\mathrm{HIF}-1 \alpha$ ist in vitro bereits zwei Minuten nach anoxischem oder hypoxischem $\left(0,5 \% \mathrm{O}_{2}\right)$ Stimulus nachweisbar und akkumuliert weiter bis 60 Minuten nach Expositionsbeginn. Die maximale DNA-Bindung wird ebenfalls nach 60 Minuten beobachtet. Nach Exposition mit 60-minütiger Anoxie oder Hypoxie ist HIF-1 $\alpha 32$ Minuten nach Reoxygenierung nicht mehr nachweisbar (Jewell et al. 2001). 


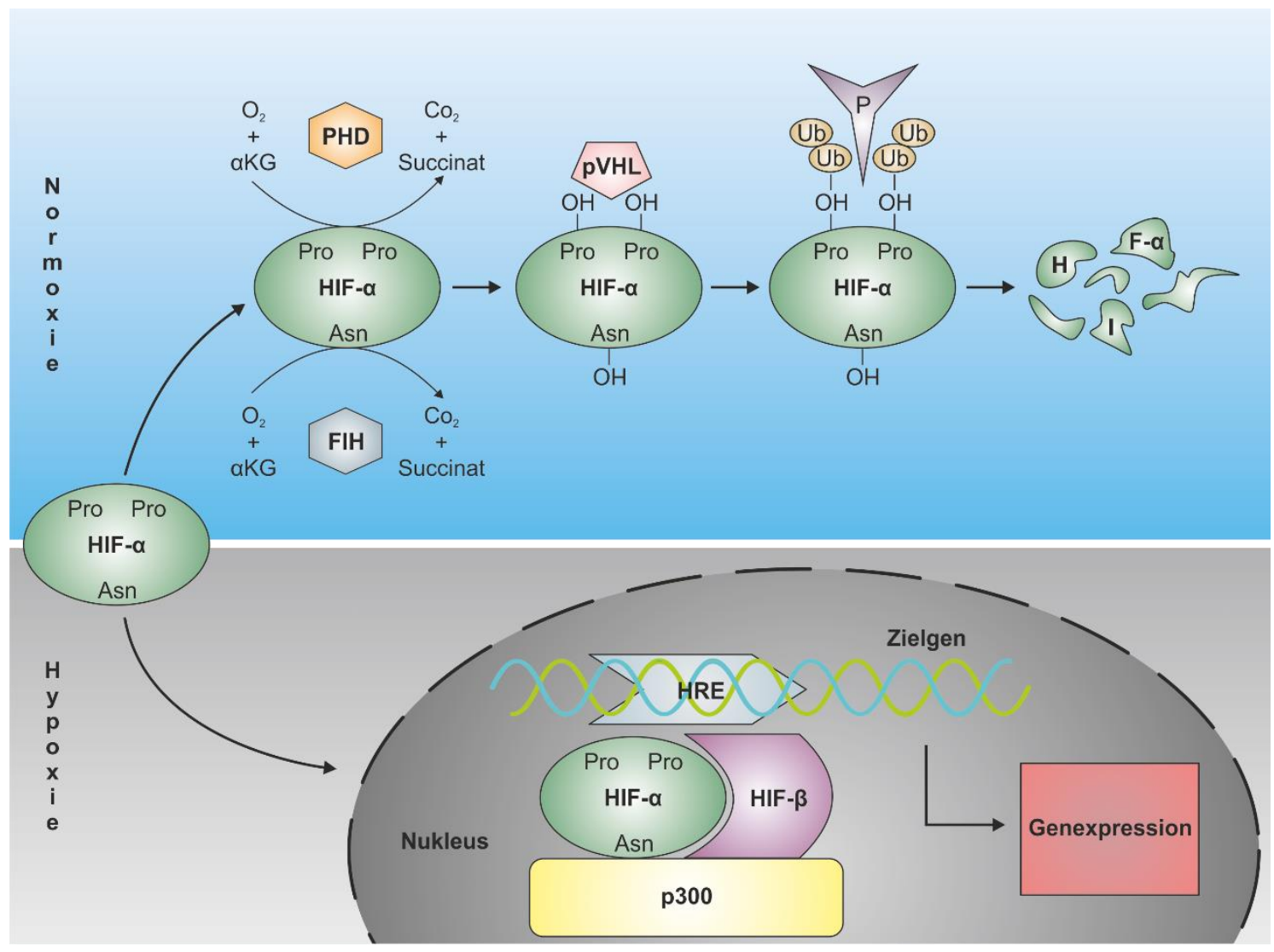

Abbildung 1: Sauerstoff-abhängige Regulation der HIF-Transkriptionsfaktoren. Die konstitutiv exprimierte $\alpha$-Untereinheit des Hypoxie-induzierbaren Faktors (HIF- $\alpha$ ) wird $\mathrm{O}_{2}$-abhängig durch ein oder mehrere Eisen-abhängige Prolylhydroxylase-Domäne enthaltende Enzyme (PHD1-3) an zwei Prolinresten hydroxyliert. Die hydroxylierten Prolinreste ermöglichen die Polyubiquitinylierung durch die von-Hippel-Lindau-Tumorsuppressor E3-Ubiquitinligase (pVHL) und nachfolgend die proteasomale Degradation. Die $\mathrm{O}_{2}$-abhängige Hydroxylierung eines Asparaginrestes durch den HIF-inhibierenden Faktor $(\mathrm{FIH})$ verhindert die Interaktion von HIF- $\alpha$ mit Transaktivatorproteinen wie $\mathrm{p} 300$. In beiden Hydroxylierungsreaktionen wird $\alpha$-Ketoglutarat als Cofaktor zu Succinat decarboxyliert. Unter Hypoxie akkumuliert HIF- $\alpha$, transloziert in den Nukleus, dimerisiert mit HIF- $\beta$ und bindet an Hypoxie-responsive Elemente (HRE) der DNA. Vermittelt durch Transaktivatorproteine reguliert HIF die Expression von Zielgenen. ASN: Asparaginrest; $\alpha \mathrm{KG}$ : $\alpha$-Ketoglutarat; $\mathrm{CO}_{2}$ : Kohlenstoffdioxid; $\mathrm{OH}$ : Hydroxylgruppe; Pro: Prolinrest; $\mathrm{O}_{2}$ : molekularer Sauerstoff; P: Proteasom; Ub: Ubiquitin. Abbildung modifiziert nach Eltzschig et al. (2014), mit freundlicher Genehmigung von Springer Nature.

\subsubsection{Prolylhydroxylase-Domäne enthaltende Enzyme}

PHDs werden als Hauptregulatoren der Hypoxie-Antwort bezeichnet (Myllyharju J. 2013). Sie dienen als $\mathrm{O}_{2}$-Sensor des HIF-Transkriptionssystems (Epstein et al. 2001) und gehören zur Klasse der Jelly-Roll-Motiv-enthaltenden Eisen- und $\alpha$-Ketoglutarat-abhängigen Dioxygenasen mit einem hoch konservierten Eisen-bindenden Histidin-XxxAsparaginsäure/Glutaminsäure...Histidin-Motiv (Loenarz und Schofield 2008). Im menschlichen Organismus umfasst diese Enzymklasse mehr als 60 Vertreter (Loenarz und Schofield 2011). Die Bindung des Enzymsubstrates und des Cofaktors $\alpha$-Ketoglutarat ermöglicht die Reaktion des zweiwertigen Eisens im aktiven Zentrum mit $\mathrm{O}_{2}$ und die Bildung einer aktiven Sauerstoffzwischenstufe. Das Substrat wird hydroxyliert, während $\alpha$ Ketoglutarat durch oxidative Decarboxylierung zu Succinat und $\mathrm{CO}_{2}$ reagiert (Zhou et al. 
1998; Zhang et al. 2000). Das Eisen im aktiven Zentrum wird durch Ascorbinsäure im für die Enzymfunktion notwendigen reduzierten Zustand gehalten (Knowles et al. 2003; Kuiper et al. 2010). Im menschlichen Organismus wurden mindestens drei PHD Isoformen identifiziert (Bruick und McKnight 2001). Diese werden als PHD1-3, Egg-Laying Defective Nine Homolog 2, 1 und 3 (EGLN2, 1 und 3) (Epstein et al. 2001) oder HIF-Prolylhydroxylase 3-1 (HPH-3, -2, -1) (Bruick und McKnight 2001) bezeichnet. Eine vierte Isoform ist ein Membranprotein, dessen biologische Funktion noch nicht vollständig charakterisiert ist (Koivunen et al. 2007a).

PHD1-3 werden nicht gewebespezifisch exprimiert. Es existieren jedoch zwischen verschiedenen Geweben Unterschiede in der relativen mRNA-Expression. PHD1 wird hauptsächlich im Hoden exprimiert, PHD3 im Herzen (Lieb et al. 2002; Willam et al. 2006). PHD2 ist die am stärksten exprimierte Isoform (Appelhoff et al. 2004; Takeda et al. 2008). In vitro- Daten zeigen eine differenzierte subzelluläre Kompartimentalisierung der PHDs. Während PHD1 ausschließlich im Zellkern lokalisiert ist, zeigt PHD2 eine vorwiegend zytoplasmatische Lokalisation. PHD3 ist gleichmäßig auf Nukleus und Zytoplasma verteilt (Metzen et al. 2003a). In vivo zeigt sich hingegen eine vorwiegend zytoplasmatische Lokalisation sowohl von endogenen PHD-Isoformen 1-3 als auch von FIH (Soilleux E J et al. 2005).

Der $\mathrm{O}_{2}-\mathrm{K}_{\mathrm{m}}$-Wert der PHD Isoformen 1-3 liegt oberhalb der intrazellulären $\mathrm{O}_{2}$ Konzentration bei Gewebenormoxie in den meisten Organen, sodass bereits geringe Verminderungen des $\mathrm{O}_{2}$-Angebotes die jeweilige Enzymaktivität beeinflussen (Koivunen et al. 2006; Ehrismann et al. 2007). Die Enzyme unterliegen alternativem Spleißen und unterscheiden sich in ihrer Affinität zu den Prolinresten der ODDD (Hirsilä et al. 2003) sowie zu den HIF- $\alpha$-Isoformen (Appelhoff et al. 2004).

Die Transkription von PHD2 und PHD3 wird durch HIF verstärkt (Berra et al. 2003; Appelhoff et al. 2004; Marxsen et al. 2004), sodass ein negativer Feedbackmechanismus unter Hypoxie und die schnelle Destabilisierung von HIF-1 $\alpha$ nach Reoxygenierung gewährleistet sind (D'Angelo et al. 2003; To und Huang 2005). Zudem ist hierdurch eine Adaptation der $\mathrm{HIF}-\alpha$ Induktionsschwelle an ein verändertes $\mathrm{O}_{2}$-Angebot möglich (Stiehl et al. 2006). Die Interaktion von HIF-1 $\alpha$ mit PHD2 und PHD3 wird durch das Protein OS-9 verstärkt (Baek et al. 2005).

Regulationsmechanismen der PHDs bestehen über eine Verminderung der PHD2Expression durch TGF- $\beta 1$ (McMahon et al. 2006), Regulation der Stabilität von PHD2 durch FK506-bindendes Protein 38 (FKBP38) (Barth et al. 2007) und die Degradation von PHD1 und 3 durch das Hypoxie-induzierte Protein Seven in absentia homolog 2 (Siah2) (Nakayama et al. 2004; Baba et al. 2013; Kokate et al. 2018). Die Hypoxie-induzierte Expression einer HIF$3 \alpha$-Spleißvariante mit dominant-negativer Regulatorfunktion auf HIF-Transkriptionsfaktoren bildet eine weitere negative Feedbackschleife für die HIF-1-aktivierte Genexpression (Makino et al. 2007). 
PHD2 ist in Normoxie der entscheidende $\mathrm{O}_{2}$-Sensor für den HIF-Transkriptionsweg (Berra et al. 2003; Appelhoff et al. 2004). PHD2 ist zudem von entscheidender Bedeutung für die Embryogenese. Im Mausmodell entwickeln sich Embryonen trotz Knockout von PHD1 und 3 normal, beim Knockout von PHD2 kommt es zu kardialen und plazentaren Fehlbildungen. Hierbei tritt in der Plazenta, nicht jedoch im Herzgewebe eine erhöhte HIF-1 $\alpha$-Stabilisierung auf (Takeda et al. 2006). PHD2 ist von zentraler Bedeutung für die Anpassung der Atmungsregulation unter chronischer Hypoxie (Bishop et al. 2013).

Sowohl für FIH (Cockman et al. 2006; Zheng et al. 2008; Yang et al. 2011) als auch für PHD1 und PHD2 (Cummins et al. 2006) wurden Hydroxylierungs-Substrate neben HIF- $\alpha$ identifiziert. Aufgrund der hohen Affinität der alternativen Targets zu FIH stellt dies einen möglichen weiteren Regulationsmechanismus für den HIF-Transkriptionsweg dar (Coleman et al. 2007). Die Hypoxie-induzierte Akkumulation von HIF-1 $\alpha$, nicht jedoch von HIF-2 $\alpha$ ist in vivo abhängig von einer basalen NFxB-Aktivität (Rius et al. 2008; van Uden et al. 2008). PHD2 und insbesondere PHD1 sind möglicherweise in der Lage, die I $\varkappa$ B Kinase an einem den HIF- $1 \alpha$-ODDD homologen Prolylrest zu hydroxylieren. Hierdurch wird NF $\varkappa B$ aktiviert (Cummins et al. 2006). Die Signifikanz dieses Mechanismus ist jedoch unklar (Semenza 2009).

PHDs werden nicht nur durch das $\mathrm{O}_{2}$-Angebot, sondern auch durch die Verfügbarkeit der Cofaktoren reguliert. Das $\alpha$-Ketoglutarat-Analog Dimethyloxaloglyzin (DMOG) bewirkt eine unspezifische Hemmung der $\alpha$-Ketoglutarat-abhängigen Dioxygenasen und eine Akkumulation von HIF- $\alpha$ (Epstein et al. 2001). Auch Zwischenprodukte des Zitratzyklus, insbesondere Fumarat, führen in vitro zu einer Hemmung der PHDs (Hewitson et al. 2007; Koivunen et al. 2007b).

\subsubsection{Modifikation des PHD/HIF-Signalweges}

In-vivo-Daten zeigen in verschiedenen Geweben eine Hypoxie-induzierte Akkumulation von HIF-1 $\alpha$-mRNA (Yu et al. 1998; Lee et al. 2000; Bergeron et al. 2008). Der Mechanismus hierfür ist ungeklärt (Prabhakar und Semenza 2012). In ischämischem Muskelgewebe ist die vermehrte Transkription von HIF-1 $\alpha$-mRNA abhängig von HIF-1 (Bosch-Marce et al. 2007).

Vor dem Hintergrund der unter Hypoxie reduzierten Proteinsynthese (Tinton und BucCalderon 1999; van den Beucken et al. 2006; Thomas und Johannes 2007) wurde eine präferentielle Translation von HIF-1 $\alpha$ diskutiert, um die Hypoxie-abhängige Transkription zu gewährleisten (Lang et al. 2002). Dieser Mechanismus wird jedoch nicht allgemein akzeptiert (Young et al. 2008). In Kardiomyozyten wird die Translation von HIF-1 $\alpha$ unter Normoxie durch die miR-199a antagonisiert. Über die Translationshemmung von der Histondeazetylase Sirtuin 1 (Sirt1) ist unter Hypoxie zudem eine Beeinflussung von PHD2 durch miR-199a möglich (Rane et al. 2009). Sirt1 verstärkt die Transkriptionswirkung von HIF-2 $\alpha$ (Dioum et al. 2009), sodass in Zusammenwirkung mit seiner HIF-abhängigen 
Expression ein positiver Feedbackmechanismus auf den HIF-2-Transkriptionsweg entsteht (Chen et al. 2011; Prabhakar und Semenza 2012). Sirt1 ist redox-sensitiv (Denu 2003).

Ein $\mathrm{O}_{2}$-unabhängiger Regulationsmechanismus des HIF-Transkriptionsweges ist die Induktion der Phosphoinositid-3-Kinase (PI3K)-abhängigen HIF-1 $\alpha$-Proteinsynthese durch Tyrosinkinasen wie HER2/neu (Zhong et al. 2000; Laughner et al. 2001; Treins et al. 2002). Unter diesen Bedingungen kann die pVHL-abhängige Degradation sättigen und zum geschwindigkeitsbestimmenden Schritt der Reaktion werden (Tanimoto et al. 2000). Die Hypoxie-abhängige Inhibition von mechanistic target of rapamycin (mTOR) (Arsham et al. 2003; Brugarolas et al. 2004), einem nachgeschalteten (downstream-) Effektor von PI3K (Laughner et al. 2001), ermöglicht ein komplexes Regulationssystem (Semenza 2009). Eine Induktion der HIF-1 $\alpha$-Translation ist zudem über die Aktivierung von PI3K und des Mitogenaktiviertes-Protein (MAP)-Kinase-Signaltransduktionsweges durch den Insulin-ähnlichen Wachstumsfaktor 1 (IGF1, insulin-like growth factor 1) (Fukuda et al. 2002), NO (Kasuno et al. 2004) und Prostaglandin $E_{2}$ möglich (Fukuda et al. 2003).

Thrombin (Gorlach et al. 2001) und NFxB (Kabe et al. 2005; Bonello et al. 2007) können ROS-abhängig die Expression von HIF-1 $\alpha$ induzieren. Auch die Aktivität von HIF-2 $\alpha$ wird durch NADPH-Oxidase-abhängige ROS-Produktion Hypoxie-unabhängig reguliert (Maranchie und Zhan 2005; Diebold et al. 2009).

NO ermöglicht durch Inhibition der mitochondrialen Atmungskette, insbesondere der Zytochrom-c-Oxidase, eine Regulation des mitochondrialen $\mathrm{O}_{2}$-Konsums und eine Induktion der mitochondrialen ROS-Produktion (Poderoso et al. 1996; Moncada und Erusalimsky 2002). Die Inhibition der PHDs durch NO (Metzen et al. 2003b) führt zu einer Stabilisierung von HIF- $1 \alpha$ und Induktion der HIF-1 $\alpha$-PHD2 Feedbackschleife (Sandau et al. 2001; Berchner-Pfannschmidt et al. 2007). Ein weiterer möglicher Mechanismus der NOinduzierten Akkumulation von HIF-1 $\alpha$ ist die S-Nitrosylierung der ODDD und verminderte Hypoxie-abhängige Degradation (Palmer et al. 2000; Li et al. 2007a). Demgegenüber wurde eine paradox erhöhte zelluläre $\mathrm{O}_{2}$-Verfügbarkeit nach Blockade der mitochondrialen Atmungskette unter Hypoxie durch $\mathrm{NO}$ beschrieben. Unter Bedingungen, in denen $\mathrm{O}_{2}$ der geschwindigkeitsbestimmende Faktor für die Prolylhydroxylierung von HIF-1 $\alpha$ ist, ermöglicht dies eine Modulation der Hypoxie-Antwort (Hagen et al. 2003).

Zum Einfluss von ROS auf die hypoxische Stabilisierung von HIF-1 $\alpha$ existieren widersprüchliche Daten (Kietzmann und Görlach 2005). Mitochondriale ROS-Produktion wurde als eine notwendige Voraussetzung der Hypoxie-induzierten Stabilisierung von HIF-1 $\alpha$ beschrieben (Chandel et al. 1998; Schroedl et al. 2002; Mansfield et al. 2005). Komplex III der mitochondrialen Atmungskette wurde als $\mathrm{O}_{2}$-Sensor für die ROSvermittelte HIF-1-Regulation unter Hypoxie identifiziert (Brunelle et al. 2005; Guzy et al. 2005; Bell et al. 2007). Die Verfügbarkeit von Eisen(II) limitiert die Aktivität der PHDs unabhängig vom $\mathrm{O}_{2}$-Angebot (Knowles et al. 2006) und ist daher mögliches Target für Modulation durch ROS (Gerald et al. 2004). Die Depletion von intrazellulärem Ascorbat 
durch die Oxidation von Eisen (II) führt zur Inhibition der PHDs (Gerald et al. 2004; Salnikow et al. 2004; Pan et al. 2007; Pagé et al. 2008). $\mathrm{H}_{2} \mathrm{O}_{2}$ übt eine ausgeprägte inhibierende Wirkung auf FIH und im geringerem Maße auch auf PHDs aus (Masson et al. 2012). Die mitochondriale ROS-Produktion wird als notwendige Voraussetzung zur Stabilisierung von HIF nicht allgemein akzeptiert (Bishop und Ratcliffe 2014). Daten anderer Untersuchungen zeigen eine Abhängigkeit der HIF-1 $\alpha$-Stabilisierung vom mitochondrialen $\mathrm{O}_{2}$-Konsum und weder einen Anstieg von mitochondrialer $\mathrm{O}_{2}{ }^{-}$-Produktion unter Hypoxie noch einen direkten Einfluss von ROS auf die PHD-Aktivität oder HIF-1 $\alpha$-Akkumulation (Vaux et al. 2001; Doege et al. 2005; Chua et al. 2010). Möglicherweise bedingen strukturelle Unterschiede der Substratbindungsstellen von FIH und PHD2 (Elkins et al. 2003; Chowdhury et al. 2009) die starke Substratbindung von PHD2 (McNeill et al. 2005) und die geringere Sensibilität gegenüber oxidativem Stress (Ratcliffe 2013). Oxidativer Stress dient durch Inaktivierung eines Anteils des exprimierten HIF-Hydroxylasesystems möglicherweise der Modulation (range finding) des Hypoxie-Schwellenwertes, der eine HIF-abhängige Reaktion induziert (Ratcliffe 2013).

Nach Ubiquitinylierung von HIF-1 $\alpha$ ist eine Regulation der Degradation durch enzymatische Deubiquitinylierung (Li et al. 2005) und Modifikation der pVHL-Aktivität durch das Protein Spermidin/Spermin-N ${ }^{1}$-Azetyltransferase 2 (SSAT2) möglich (Baek et al. 2007b). Das Protein SSAT1 verstärkt die Bindung von RACK1 an HIF-1 $\alpha$ und reduziert so den HSP90vermittelten Schutz vor Degradation (Baek et al. 2007a). Unter Hypoxie erfolgt unabhängig von Hydroxylierungsreaktionen die Konjugation von kleinen Ubiquitin-verwandten Modifikatorproteinen (SUMO, small ubiquitin-like modifier) an HIF-1 $\alpha$. Dies führt in vivo zur Ubiquitinylierung durch pVHL und proteasomaler Degradation (Cheng et al. 2007). SUMO1 ist Hypoxie-induzierbar (Comerford et al. 2003), sodass eine Modifikation der HypoxieAntwort naheliegt (Kaelin und Ratcliffe 2008). In vitro-Versuche zeigen im Gegensatz hierzu eine Stabilisierung von HIF-1 $\alpha$ durch SUMOylierung (Carbia-Nagashima et al. 2007). Die physiologische Relevanz dieser Daten ist nicht geklärt (Semenza 2009).

Die Expression eines Eisen-responsiven Elementes in der nicht translatierten mRNA reguliert die Proteinexpression von HIF- $2 \alpha$ in Abhängigkeit vom Eisenangebot (Sanchez et al. 2007). In embryonalen Mausfibroblasten wird HIF-2 $\alpha$ durch einen nicht identifizierten Mechanismus zytoplasmatisch kompartimentalisiert, sodass nukleäre Translokation und HIF-2 $\alpha$-abhängige Genexpression inhibiert werden (Park et al. 2003). Eine ähnliche Präferenz für die Induktion der Degradation von HIF-1 $\alpha$ im Vergleich zu HIF-2 $\alpha$ wurde für den Hypoxie-assoziierten Faktor (HAF) beschrieben (Koh et al. 2011). Unter prolongierter Hypoxie vermittelt Hitzeschockprotein 70 (HSP70) die Degradation von HIF-1 $\alpha$, nicht jedoch von HIF-2 $\alpha$, durch carboxyl terminus of Hsc70-interacting protein (CHIP). Dies ermöglicht die Reduktion HIF-1 $\alpha$-vermittelter Transkription (Luo et al. 2010). 


\subsection{Membranverkehr}

Das äußere Blatt der Plasmamembran ist die Oberfläche, über die eine Zelle mit ihrer Umgebung kommuniziert. Um ihre Umgebung zu modulieren und um auf Veränderungen ihrer Umgebung reagieren zu können, muss die Zelle die Zusammensetzung ihrer Plasmamembran regulieren. Endozytose beschreibt die de-novo Produktion interner Membranen aus der Plasmamembran-Lipiddoppelschicht, bei der Membranlipide, integrale Membranproteine und extrazelluläre Flüssigkeit vollständig internalisiert werden. Das morphologische Gegenstück hierzu ist die Exozytose, bei der intrazelluläre Membranen mit der Plasmamembran fusionieren. Hierbei werden spezifische chemische Substanzen an die Umgebung abgegeben und Lipide sowie Proteine der Plasmamembran zugeführt. Die Kontrolle dieser Vorgänge erlaubt eine präzise Regulation der Interaktion einer Zelle mit ihrer Umgebung (Doherty und McMahon 2009). Auch die meisten Organellen eukaryotischer Zellen sind von einer Lipid- und Proteinmembran umschlossen. Diese Membranen grenzen das Zytoplasma von einem topologisch getrennten wässrigen Lumen ab und dienen als Schnittstelle zwischen Organellen und dem Rest der Zelle. Ihre Proteinund Lipidzusammensetzung spielt somit eine zentrale Rolle in der Definition der Kompartimentfunktion (Diaz-Rohrer et al. 2014).

Die Lipid- und Proteinkomposition zellulärer Membranen ist komplex und in ihrer Interaktion, Regulation und Struktur sowie den hieraus entstehenden physiologischen Implikationen nur unzureichend verstanden (Engelman 2005; Shevchenko und Simons 2010). Membranproteine durchspannen entweder die Membran oder verfügen über eine Membranbindungsdomäne wie amphiphile $\alpha$-Helices oder Lipidanker. Protein-Lipid- und Protein-Protein-Interaktionen beeinflussen die Membranstruktur und die Bildung dynamischer Membrandomänen wie lipid rafts (Sieber et al. 2007; Shnyrova et al. 2009; Keren 2011).

Der Transport zwischen intrazellulären Membranen und der Plasmamembran durch Endound Exozytose ist der einzige Weg, auf dem Lipide und Transmembranproteine die Plasmamembran erreichen (Keren 2011). Veränderungen der Protein- und Lipidzusammensetzung, der Verteilung und luminalen Inhalte von Membranen sind zentrale Regulatoren von einer Vielzahl der extranukleären biologischen Prozesse innerhalb einer Zelle wie Mitose, Antigenpräsentation und Zellmigration (Doherty und McMahon 2009). Auch die epitheliale Polarisierung wird durch den Membranverkehr reguliert (Mrozowska und Fukuda 2016). Die Endozytose spielt eine zentrale Rolle in der Initiierung und Verbreitung von Signalen, der Aktivierung spezifischer sub-Signalwege und der Signalbeendigung (Andersson 2012). Durch seine Einbindung in nahezu alle zellulären Prozesse sind Defekte des Membranverkehrs mit einer Vielzahl von Pathologien wie Podozytenschädigung und glomerulären Erkrankungen (Swiatecka-Urban 2013), malignen Neoplasien (Lee et al. 1998; Thompson et al. 1999; Sunaga et al. 2004), Morbus Alzheimer (Cataldo et al. 2008), Autoimmun- (Delva et al. 2008) und metabolischen Erkrankungen 
(Garuti et al. 2005) assoziiert. Der Membranverkehr wird zudem von Viren und Bakterien zur Infektion des Wirtes genutzt (Veiga und Cossart 2005; Marsh und Helenius 2006; Mercer und Helenius 2009; Cossart und Helenius 2014).

\subsubsection{Endozytose}

Die Endozytose wurde als Hauptorganisator der Zellkommunikation bezeichnet (Sigismund et al. 2012). Von der Plasmamembran abgeschnürte Vesikel werden dem frühe-EndosomenSystem zugeführt, wo eine Sortierung stattfindet. Von dort aus kann endozytiertes Material späten Endosomen und Lysosomen zur Degradation zugeführt werden (Grant und Donaldson 2009). Nach intraluminaler Abschnürung von der Organellenmebran kann endozytiertes Material bei Fusion der späten Endosomen mit der Plasmamembran in Form von Exosomen nach extrazellulär abgegeben werden (Raposo und Stoorvogel 2013). Alternativ kann der Weitertransport zum trans-Golgi-Apparat (Johannes und Popoff 2008) oder zu Recycling-Endosomen erfolgen. Von Recycling-Endosomen aus erfolgt der Rücktransport zur Plasmamembran (Grant und Donaldson 2009). Durch diesen Recyclingvorgang wird ein Großteil der durch Endozytose internalisierten Membran und Fracht wieder der Zelloberfläche zugeführt. Dies ist ein sehr dynamischer Vorgang, in dem die Zelle das Äquivalent der gesamten Plasmamembran ein bis fünf Mal pro Stunde austauscht. Das Gleichgewicht zwischen Endozytose und Recycling reguliert die Plasmamembranzusammensetzung (Swiatecka-Urban 2013).

Die Endozytose, Vesikeltransport und die Endosomenverarbeitung werden durch kleine, monomere Guanosintriphosphat-bindende Proteine (G-Proteine) wie den Guanosintriphosphatasen (GTPasen) der Ras-related in brain (Rab)-Klasse (Hattula et al. 2006; Hutagalung und Novick 2011) oder Adenosindiphosphat-Ribosylierungsfaktoren (Arf) reguliert (D'Souza-Schorey und Chavrier 2006; Doherty und McMahon 2009; Grant und Donaldson 2009). Kleine G-Proteine werden durch die Bindung von Guanosintriphosphat (GTP) und Guanosindiphosphat (GDP) reguliert. Im GTP-gebundenen Zustand sind sie aktiv und interagieren mit einer Reihe von Zielmolekülen. GuaninnukleotidAustauschfaktoren (GEFs, guanine nucleotide exchange factors) katalysieren den Austausch von GDP gegen GTP und wirken somit als Aktivatoren. GTPase-aktivierende Proteine (GAPs) stimulieren die GTP-Hydrolyse und haben einen entgegengesetzten Effekt (EtienneManneville und Hall 2002; Ridley et al. 2003).

Die Induktion einer Membrankrümmung als Voraussetzung der Vesikelbildung ist je nach Organismus ein sehr komplexer Prozess (Johannes et al. 2014), der durch die Polymerisation dreidimensionaler Proteinaggregate (Dannhauser und Ungewickell 2012), der Insertion von keilartigen amphipathischen Proteindomänen in die Lipidmatrix (Ford et al. 2002; Zimmerberg und Kozlov 2006) oder der Akkumulation von bananenförmigen Proteinen, die eine Bin-Amphiphysin-Rvs (BAR)-Domäne enthalten (Peter et al. 2004; Henne et al. 2010), induziert wird. Auch eine asymmetrische Lipidverteilung zwischen dem äußeren und 
inneren Blatt der Membran (Zimmerberg und Kozlov 2006) oder eine lokale hohe Verdichtung unspezifischer Proteine (Stachowiak et al. 2012) können Membranen verformen. $\mathrm{Zu}$ endozytierende Moleküle können zudem direkt eine Krümmung der Plasmamembran induzieren (Römer et al. 2007). Die Membrankrümmung aktiviert daraufhin intrazelluläre Effektorproteine, die die Endozytose vorantreiben (Peter et al. 2004; Yoshida et al. 2004). Wichtige Funktionen in dem komplexen Protein- und Lipidnetzwerk, das den Membranverkehr ermöglicht, üben das Zytoskelett und Motorproteine aus (Aderem und Underhill 1999; Soldati und Schliwa 2006; Kapus und Janmey 2013). Das Aktin-Zytoskelett unterliegt hierbei der Regulation durch kleine G-Proteine der Rab-, Arf- und Rho-Klasse (Ridley 2006).

\subsubsection{Mechanismen der Endozytose}

Es wurde eine Vielzahl von Endozytosemechanismen beschrieben (Sigismund et al. 2012). Eine grobe Klassifikation kann anhand der initialen Membraninvagination vorgenommen werden. Partikel mit einer Größe von $>500 \mathrm{~nm}$, wie z. B. Bakterien, werden durch Phagozytose aufgenommen (Swanson 2008; Mao und Finnemann 2015). Die Aufnahme von Flüssigkeiten erfolgt durch Makropinozytose (Kerr und Teasdale 2009). Membraninvaginationen $<200 \mathrm{~nm}$ werden als Mikropinozytose bezeichnet und in Clathrin-vermittelte Endozytose (CME, clathrin-mediated endocytosis) und nicht-Clathrin-vermittelte Endozytose (NCE, non-clathrin endoytosis) unterteilt. Der relative Beitrag von CME und NCE zur Endozytose ist wahrscheinlich Zelltyp-abhängig. In Fibroblasten zeigen CME und NCE nach Schätzungen etwa die gleiche Prävalenz (Doherty und McMahon 2009).

Der am besten beschriebene Endozytosemechanismus ist die CME (Soldati und Schliwa 2006). In der CME werden verschiedene Transmembranrezeptoren und ihre Liganden vermittelt durch Adapterproteine in Clathrin-ummantelten Vesikeln aufgenommen. Aufgrund der großen Unterschiede zwischen den internalisierten Frachtmolekülen und beteiligten Proteinen wird die CME als eine Gruppe eng verwandter Endozytosemechanismen betrachtet, deren Gemeinsamkeit die Nutzung des Ummantelungsproteins Clathrin ist (Doherty und McMahon 2009). CME spielt eine zentrale Rolle in der Aufnahme von Lipoproteinen (Anderson et al. 1977), Epidermalem Wachstumsfaktor (EGF, epidermal growth factor) (Carpentier 1982), Transferrin (Neutra et al. 1985) und im Recycling synaptischer Vesikel (Cremona und De Camilli 1997; Brodin et al. 2000), aber auch im intrazellulären Transport, beispielsweise zwischen Endosomen und dem trans-Golgi-Apparat (Kirchhausen et al. 2014). Clathrin-ummantelte Vesikel entstehen an Clathrin-angereicherten Domänen der Plasmamembran (Ehrlich et al. 2004; Kirchhausen 2009; Cocucci et al. 2012).

Clathrin besteht aus drei leichten Ketten mit einem Molekulargewicht von 33 und 36 kDa sowie drei schweren Ketten mit einem Molekulargewicht von 180 kDa (Kirchhausen und Harrison 1981; Ungewickell und Branton 1981). Die drei schweren Ketten bilden eine dreibeinige Struktur, die Clathrin-Triskele (Fotin et al. 2004). Die Triskelen aggregieren pHabhängig zu käfigartigen dreidimensionalen Strukturen (Kirchhausen und Harrison 1981; 
Böcking et al. 2014), die eine Membrankrümmung und Vesikelabschnürung ermöglichen (Dannhauser und Ungewickell 2012; Kirchhausen 2012). Clathrin-assoziierte Sortierungsproteine (CLASP) wie Adapterprotein 1(AP-1) und insbesondere Adapterprotein 2 (AP-2) vermitteln die Interaktion von Clathrin und den jeweiligen Rezeptoren (Ohno et al. 1995) sowie Clathrin-Aggregation und Interaktion mit der Plasmamembran (Cocucci et al. 2012; Traub und Bonifacino 2013). Der Clathrin-Käfig kann eine Vielzahl unterschiedlicher Formen annehmen (Crowther et al. 1976).

Neben Clathrin und dem Adapterproteinkomplex ist ein komplexes Proteinnetzwerk für die Vesikelbildung und -funktion notwendig (Borner et al. 2006; Schmid und McMahon 2007; Borner et al. 2012). Die Vesikelabschnürung wird durch die GTPase Dynamin katalysiert (Shnyrova et al. 2013; Kirchhausen et al. 2014). Bei hoher Membranspannung und erschwertem Vesikelschluss werden Membraninvagination (Kaksonen et al. 2005), Membranabschnürung (Merrifield et al. 2005) und Endosomensortierung (Derivery et al. 2009) durch Aktinpolymerisierung vorangetrieben (Girao et al. 2008; Boulant et al. 2011; Kirchhausen et al. 2014). Die Clathrin-Ummantelung der Vesikel zerfällt unmittelbar nach der Abschnürung (Massol et al. 2006). Dieser Prozess wird durch die ATPase Hsc70 und das DnaJ-Homolog Auxilin vermittelt (Holstein 1996; Barouch et al. 1997; Xing et al. 2010).

Die Clathrin-Beschichtung der Membraninvaginationen ist elektronenmikroskopisch darstellbar (Roth und Porter 1964), sodass eine morphologische Differenzierung von CME und NCE möglich ist (Doherty und McMahon 2009). Unter den NCE wird die durch Caveolae vermittelte Endozytose besonders häufig beobachtet (Simionescu et al. 1974; Stan 2005; Parton und Pozo 2013).

Caveolae sind 60-80 nm große Einstülpungen der Plasmamembran, die Caveolin-Oligomere enthalten (Yamada 1955; Parton und Simons 2007). Abhängig von der Fixierung des Präparates zeigen sie eine flaschenähnliche Morphologie mit einer Verjüngung unterhalb der Plasmamembran oder eine Krater- bzw. Tassenform (Schlörmann et al. 2010). Insbesondere in glatten Muskelzellen, Adipozyten, Endothelzellen und Fibroblasten machen Caveolae einen Großteil der Plasmamembran aus (Thorn et al. 2003; Parton und Simons 2007). Im Gewebe des proximalen Tubulus sind Caveolae unter physiologischen Bedingungen hingegen nicht nachweisbar (Zhuang et al. 2011). Auch in Erythro-, Thrombo- (Parton und Simons 2007) und Lymphozyten (Fra et al. 1995) gibt es keine Caveolae. Die Lokalisation der Caveolae zeigt eine polarisierte Verteilung (Scheiffele et al. 1998; Parat et al. 2003). In Endothelzellen ist die Anzahl der Caveolae abhängig von der Scherbeanspruchung (shear stress) (Rizzo et al. 2003).

Die membranständigen Caveoline, insbesondere das ubiquitär exprimierte Caveolin-1 (Drab et al. 2001) und das muskelspezifische Caveolin-3 (Galbiati et al. 2001), sind zentrale Regulatorproteine der Caveolae (Rothberg et al. 1992; Scherer et al. 1996; Tang et al. 1996; Walser et al. 2012). Caveolin-1 ist darüber hinaus auch außerhalb von Caveolae nachweisbar (Echarri und Pozo 2015), unter anderem in Endosomen (Botos et al. 2008; Ritz et al. 2011) 
und stressinduziert in Mitochondrien (Fridolfsson et al. 2012). Die Morphologie und Funktion der Caveolae wird durch die zytoplasmatischen Proteine Cavin-1 und die gewebespezifisch exprimierten Cavin-Isoformen 2-4 moduliert (Hill et al. 2008; Bastiani et al. 2009; Hansen et al. 2013). Der Knockout von Cavin-1 führt zu einem Verlust der Caveolae und einer Reduktion von Caveolin-1 (Liu et al. 2008). Neben Caveolinen und Cavinen wurden weitere Proteine identifiziert, die die Funktion der Caveolae regulieren (Oh et al. 1998; Hansen et al. 2011; Morén et al. 2012; Parton und Pozo 2013). Caveolae sind mit Cholesterin- und Sphingolipid- angereicherten Mikrodomänen der Plasmamembran assoziiert (Echarri und Pozo 2012). Cholesterindepletion führt zur Dissoziation von Cavin-1 und Caveolin, dem proteasomalen Abbau von Cavin-2 und einem Abflachen der Caveolae (Breen et al. 2012). Caveolae zeigen eine komplexe Interaktion mit dem Zytoskelett (Mundy et al. 2002; Richter et al. 2008; Wickström et al. 2010) und sind über Stressfasern in der Plasmamembran verankert (Stahlhut und van Deurs 2000; Muriel et al. 2011).

Caveolin-1 und Caveolae sind von Bedeutung für die Mechanotransduktion (Sedding et al. 2005; Yu et al. 2006; Goetz et al. 2011). Zudem dienen Caveolae als Dehnungsreserve für die Plasmamembran (Dulhunty und Franzini-Armstrong 1975; Sinha et al. 2011). Durch die Kompartimentalisierung von Signalmolekülen und deren Interaktion mit Caveolin-1 spielen Caveolae eine Rolle in der Signaltransduktion (Weerd und Leeb-Lundberg 1997; Okamoto et al. 1998; Gosens et al. 2007; Sengupta et al. 2008; Blouin et al. 2010; Hezel et al. 2010).

Caveolae werden durch Dynamin von der Plasmamembran abgeschnürt (Henley et al. 1998; Oh et al. 1998) und fusionieren entweder mit frühen Endosomen (early endosomes) (Hayer et al. 2010) oder im Rahmen der Transzytose mit der gegenüberliegenden Plasmamembran (Oh et al. 2007). Die Endozytose von Caveolin-1 kann jedoch auch unabhängig von Caveolae beobachtet werden (Hayer et al. 2010). Nach Endozytose dissoziieren Caveoline nicht unmittelbar (Pelkmans und Zerial 2005), sodass die Protein- und Lipidstruktur der internalisierten Plasmamembran während der endosomalen Verarbeitung erhalten bleiben kann (Pelkmans et al. 2004). Caveoline und Caveolae sind durch die Regulation der Endozytose und des Abbaus von Membranproteinen (Pozo et al. 2005; Hernández-Deviez et al. 2008; González-Muñoz et al. 2009; Lee et al. 2009; Guo et al. 2012) sowie die Regulation des exozytotischen Transportes von Membranproteinen zur Plasmamembran (Gervásio et al. 2008; Langlois et al. 2008) an der Regulation der Plasmamembrankomposition beteiligt.

Neben der Caveolin-vermittelten Endozytose umfasst die NCE eine Vielzahl weiterer Mechanismen (Doherty und McMahon 2009). Die Flotillin-vermittelte Endozytose (Glebov et al. 2006; Frick et al. 2007) ist ein Caveolin-unabhängiger NCE-Mechanismus, der einen eigenständigen Endozytoseweg darstellt oder möglicherweise als Regulator anderer NCEMechanismen fungiert (Soldati und Schliwa 2006; Doherty und McMahon 2009). Glykosylphosphatidylinositol (GPI)-verankerte Proteine akkumulieren in Mikrodomänen der Plasmamembran außerhalb von Caveolae und Clathrin-angereicherten Bereichen und werden Cholesterin-abhängig über Clathrin-unabhängige Trägervesikel (CLICs, clathrin- 
independent carriers) internalisiert (Kirkham und Parton 2005). Die Aufnahme der GPIverankerten Proteine erfolgt über ein mit GPI-verankerten Proteinen angereichertes Kompartiment früher Endosomen (GEEC, GPI-anchored protein-enriched early endosomal compartment). Dieser Mechanismus wird durch Cdc42-induzierte Aktinpolymerisierung vermittelt (Chadda et al. 2007) und funktioniert unabhängig von Dynamin (Sabharanjak et al. 2002). Möglicherweise bedingt die Zusammensetzung der Lipid-Mikrodomänen eine Krümmung der Plasmamembran (Sarasij et al. 2007). B1-Integrine (Powelka et al. 2004) und Haupthistokompatibilitätskomplexe (MHCs, major histocompatibility complexes) werden über einen Arf6-abhängigen Mechanismus internalisiert (Naslavsky et al. 2004; Walseng et al. 2008). Die Endozytose des Interleukin (IL)-2-Rezeptors erfolgt über einen durch RhoGTPasen regulierten NCE-Mechanismus (Lamaze et al. 2001).

Die molekularen Mechanismen verschiedener Endozytosewege sind nicht immer klar voneinander abgrenzbar (Krauss et al. 2003; Kirkham und Parton 2005) und verschiedene NCE-Mechanismen interagieren miteinander (Chaudhary et al. 2014). Zudem existieren Zelltyp-spezifische Unterschiede in der endosomalen Verarbeitung internalisierter Vesikel (Fivaz et al. 2002).

\subsubsection{Einfluss von Hypoxie auf den Membranverkehr}

Aufgrund der fundamentalen Bedeutung des Membranverkehrs für die Funktion, Kommunikation und mechanische Interaktion von Zellen ist hier ein morphologisches Korrelat der zellulären Hypoxie-Adaptation zu erwarten. Eine wachsende Datengrundlage gibt Hinweise auf die Hypoxie-abhängige Regulation von Teilen des Vesikelverkehrs und die Internalisierung spezifischer Plasmamembranproteine.

Walmsley et al. (2006) beschreiben neben einer verminderten Apoptoserate eine verstärkte Phagozytoseaktivität nach hypoxischer Inkubation $\left(3 \% \mathrm{O}_{2}\right.$ für insgesamt zwei Stunden) gesunder und heterozygot VHL-defizienter humaner neutrophiler Granulozyten. Die Phagozytoseaktivität wurde durch den durchflusszytometrischen Nachweis der Aufnahme Fluoreszin-Isothiozyanat (FITC, fluorescein isothiocyanate)-markierter Bakterien bestimmt.

Eine Reihe von Untersuchungen zeigt eine HIF-unabhängige Regulation der Internalisierung und des Recyclings von Plasmamembranproteinen. Im Nematodenmodell zeigte sich eine verminderte Lokalisation der $\alpha$-amino-3-hydroxy-5-methyl-4-isoxazol-Proprionsäure (AMPA)-Rezeptor-Untereinheit GLR-1 an der Plasmamembran unter Hypoxie $\left(0,5 \% \mathrm{O}_{2}\right.$ für 24 Stunden) aufgrund der direkten Interaktion der Prolylhydroxylase EGL-9 mit LIN-10 (Park et al. 2012). LIN-10 reguliert das endosomale Recycling von GLR-1 (Glodowski et al. 2007). In Alveolarepithelzellen wurde unter akuter Hypoxie $\left(1,5 \% \mathrm{O}_{2}\right.$ für 60 Minuten bzw. $3 \% \mathrm{O}_{2}$ für 120 Minuten) eine spezifische Internalisierung der plasmamembranständigen Natrium (Na)/Kalium (K)-ATPase beschrieben. Der Effekt ist abhängig von mitochondrialer ROS-Produktion (Dada et al. 2003). Die verstärkte ROS-Produktion führt innerhalb von wenigen Minuten zu einer Aktivierung des kleinen, monomeren G-Proteins RhoA und 
einer Modifikation des Aktin-Zytoskeletts. Die Internalisierung der $\mathrm{Na} / \mathrm{K}$-ATPase ist abhängig vom Aktin-Zytoskelett (Dada et al. 2007) und von pVHL, nicht jedoch von HIF (Zhou et al. 2008).

Die Störung der Rezeptorendozytose, der fehlerhafte vesikuläre Transport von Wachstumsfaktoren und das unbalancierte Recycling von Integrin- und Cadherin-Adhäsionskomplexen ist ein Merkmal maligner Zellen (Mosesson et al. 2008). Vor dem Hintergrund der Prävalenz hypoxischer Areale in malignen Tumoren (Vaupel et al. 2007) und der prognostischen Relevanz von Tumorhypoxie (Harrison und Blackwell 2004) wurden in verschiedenen Studien Zusammenhänge zwischen Hypoxie und einer modifizierten Vesikeldynamik maligner Zellen hergestellt (Wang et al. 2009).

In MDA-MB-231 Brustkrebszellen wurde unter Hypoxie ( $3 \% \mathrm{O}_{2}$ für 24 Stunden) eine durch Rab11-vermittelte Induktion der Oberflächenexpression von Integrin $\alpha 6 \beta 4$ beschrieben. Damit einhergehend zeigten die Tumorzellen eine verstärkte Invasivität (Yoon et al. 2005). Rab11 ist von zentraler Bedeutung für die Regulation von Recycling-Endosomen (Maxfield und McGraw 2004), des Transportes von Recycling-Endosomen zum trans-Golgi-Netzwerk (Wilcke et al. 2000) und vom trans-Golgi-Netzwerk zur Plasmamembran (Chen et al. 1998). Es wurde spekuliert, dass Hypoxie Rab11-vermittelt weitere Proteine reguliert (Yoon et al. 2005). In primären VHL-defizienten klarzelligen Nierenzellkarzinomzellen und einer Reihe anderer Zellen konnte eine HIF-abhängige Störung der Fusion von frühen Endosomen nachgewiesen werden (Wang et al. 2009). Durch die verminderte Expression des Effektorproteins Rabaptin-5 kann die Rab5-vermittelte Fusion früher Endosomen nicht stattfinden (Bucci et al. 1992; Stenmark et al. 1995).

In klarzelligen Nierenzellkarzinomzellen konnte zudem eine Hypoxie-abhängige $\left(1 \% \mathrm{O}_{2}\right.$ für 12-48 Stunden), HIF-vermittelte Induktion von Caveolin-1 mit vermehrter Caveolenbildung gezeigt werden. Caveolin-1 ist unter diesen Bedingungen in der Lage, RezeptorTyrosinkinasen Liganden-unabhängig zu aktivieren (Wang et al. 2012). Bourseau-Guilmain et al. (2016) zeigten durchflusszytometrisch und in konfokaler Mikroskopie eine Reduktion der globalen Endozytoseaktivität von Tumorzelllinien unter Hypoxie $\left(1 \% \mathrm{O}_{2}\right.$ für zwei Stunden oder 20 Stunden). Die Autoren erklären dies durch eine HIF-unabhängige Induktion und zelluläre Umverteilung von Caveolin-1 und Hemmung der Dynaminvermittelten konstitutiven Endozytose. Im Kontrast zu dieser Beobachtung zeigte sich zugleich eine Induktion der Internalisierung von Transferrin und Choleratoxin als Marker der wichtigsten Endozytosemechanismen. Eine in der Untersuchung ebenfalls beschriebene Reduktion des Plasmamembranproteoms unter Hypoxie führen die Autoren auf eine verminderte Proteintranslation zurück. Die gleiche Arbeitsgruppe beschreibt in einer anderen Veröffentlichung eine Induktion der Lipoproteinaufnahme unter Hypoxie $\left(1 \% \mathrm{O}_{2}\right.$ für zwei und sechs Stunden) (Menard et al. 2016).

Die Regulation früher Endosomen durch die Hypoxie-aktivierbare p38 MAP-Kinase (Huang et al. 2004; An et al. 2005; Macé et al. 2005) und die hypoxische Induktion der Aktivität 
Endozytose-assoziierter kleiner, monomerer G-Proteine (Lamaze et al. 1996; Turcotte et al. 2004; Jin et al. 2006; Xue et al. 2006) legen weitere mögliche Zusammenhänge zwischen Hypoxie und Endozytose nahe (Wang und Ohh 2010).

Die Pathophysiologie einer Vielzahl von Erkrankungen umfasst die Kombination aus Hypoxie und nachfolgender Reoxygenierung (Yellon und Hausenloy 2007; Eltzschig und Eckle 2011). Zu den Effekten von alternierenden Hypoxie-Reoxygenierungszyklen auf die Vesikeldynamik gibt es nur wenige Daten. In primären Maus-Kardiomyozyten wurde durchflusszytometrisch und in konfokaler Mikroskopie eine Reduktion der Clathrinvermittelten Endozytose nach sechsstündiger Anoxie $\left(100 \% \mathrm{~N}_{2}\right)$ gezeigt. Dieser Effekt war nach einstündiger Reoxygenierung weitgehend reversibel. Die intrazelluläre Fluoreszenz durch rezeptorunabhängig endozytierte Polyethylenglykol-beschichtete Nanopartikel (Xiao et al. 2010) war unter Hypoxie und nach Reoxygenierung hingegen erhöht. Beide Effekte waren durch Transfer des Inkubationsmediums zumindest teilweise auf nicht-hypoxische Zellen übertragbar (Khaidakov et al. 2014).

Durch Exposition mit kurzen, sub-letalen Ischämieepisoden lässt sich eine ischämische Präkonditionierung von Geweben erreichen. Der Zellschaden durch eine nachfolgende prolongierte Hypoxie wird hierdurch reduziert (Murry et al. 1986; Azoulay et al. 2005; Eckle et al. 2008). Die anoxische Präkonditionierung von Hepatozyten $\left(95 \% \mathrm{~N}_{2}, 5 \% \mathrm{CO}_{2}\right.$ für zehn Minuten, gefolgt von $95 \% \mathrm{O}_{2}, 5 \% \mathrm{CO}_{2}$ für zehn Minuten) führt zur Exozytose von Endosomen und insbesondere von Lysosomen. Dieser Zytoskelett-abhängige Effekt korreliert mit einem Schutz vor anoxischem Zelltod $\left(95 \% \mathrm{O}_{2}, 5 \% \mathrm{CO}_{2}\right.$ für eine Stunde). Möglicherweise erlaubt die Exozytose der Lysosomen die Aufrechterhaltung der pHHomöostase unter anoxischem Stress. In dieser Untersuchung wurde die Kontrollbedingung jedoch unter sehr hohen $\mathrm{O}_{2}$-Partialdrücken $\left(95 \% \mathrm{O}_{2}, 5 \% \mathrm{CO}_{2}\right)$ inkubiert (Carini et al. 2004).

Eine Vielzahl von Daten deutet somit auf eine Hypoxie-induzierte Adaptation des Membranverkehrs hin. Die bisher durchgeführten Untersuchungen zeigen jedoch eine große Heterogenität hinsichtlich ihrer Methodik und zum Teil widersprüchliche Ergebnisse. Bisherige Untersuchungen zielten vornehmlich auf die Effekte von subakuter und chronischer Hypoxie-Exposition auf spezifische zelluläre Phänotypen ab. Die Auswirkungen von akuter Hypoxie auf den Gesamtmembranumsatz wurden im Detail bisher nicht untersucht.

\subsection{Kardiofibroblasten}

Fibroblasten sind spindelförmige Bindegewebszellen mesenchymalen Ursprungs, die an Plastik adhärieren und molekularbiologisch keiner anderen Zelllinie zuzuordnen sind. Sie verfügen über multiple Zellfortsätze und sind im Myokard als einziger Zelltyp nicht mit einer Basalmembran assoziiert. Fibroblasten werden über die Produktion von Komponenten der extrazellulären Matrix (EZM) definiert (Kalluri und Zeisberg 2006; Krenning et al. 2010; Driskell und Watt 2015). Fibroblasten entstehen aus unterschiedlichen Vorläuferzellen 
(Zeisberg und Kalluri 2010; Driskell et al. 2011) und lassen sich topographieabhängig mit molekulargenetischen Methoden in eine Vielzahl unterschiedlicher Zelltypen unterteilen (Chang et al. 2002). Im Herzen bilden Fibroblasten neben Kardiomyozyten die größte Zellpopulation. Je nach Alter, Topographie und Spezies wird der numerische Anteil mesenchymaler Zellen im Myokard zwischen $\sim 11 \%$ im Maus- und $\sim 60 \%$ im Rattenherzen angegeben (Camelliti et al. 2005; Banerjee et al. 2007; Bergmann et al. 2015; Pinto et al. 2016).

Kardiofibroblasten sind von zentraler Bedeutung für die Entwicklung des Myokards (Bowers et al. 2010; Kakkar und Lee 2010). Gemeinsam mit Kardiomyozyten erhalten Kardiofibroblasten die dreidimensionale Struktur sowie die elektrische, chemische und biomechanische Funktion des Myokards (Souders et al. 2009). Durch Sekretion und Degradation von EZM-Komponenten regulieren Kardiofibroblasten die EZMHomöostase. Die EZM bietet ein Gerüst für die Kardiomyozyten, verteilt die mechanische Belastung innerhalb des Gewebes und beeinflusst seine elektrische Leitfähigkeit (Spach und Boineau 1997; Baudino et al. 2008; Goldsmith et al. 2014). Darüber hinaus sezernieren Kardiofibroblasten Zytokine, Wachstumsfaktoren sowie andere Botenstoffe und sind selbst hormonsensitiv (Souders et al. 2009; Kakkar und Lee 2010). Kardiofibroblasten regulieren ein lokales Renin-Angiotensin-Aldosteron-System (Sanghi et al. 2005; Kumar et al. 2008). Untereinander sowie mit Kardiomyozyten sind Kardiofibroblasten über gap junctions verbunden. Hierdurch beeinflussen sie die elektrophysiologischen Eigenschaften des Myokards (Rook et al. 1989; Camelliti et al. 2004). Der hohe Membranwiderstand von Kardiofibroblasten begünstigt die Propagation von Aktionspotentialen über weite Distanzen (Kohl et al. 1999; Gaudesius 2003). Möglicherweise können Kardiofibroblasten durch die Expression mechanosensitiver Kationenkanäle die elektrische Aktivität der Kardiomyozyten modulieren (Stockbridge und French 1988; Kohl et al. 1994).

Kardiofibroblasten sind zudem von zentraler Bedeutung für das Remodeling nach myokardialer Schädigung (Hasenfuss 1998; Jiang et al. 2007; Travers et al. 2016). Aufgrund der geringen Proliferationsfähigkeit von Kardiomyozyten kann die strukturelle Integrität des Myokards nur durch Aktivierung, Migration und Proliferation von Kardiofibroblasten mit nachfolgender Modulation der EZM und Hypertrophie der Kardiomyozyten gewährleistet werden (Camelliti et al. 2005; Porter und Turner 2009; Fan et al. 2012). Auch die Induktion von Entzündungsreaktionen nach myokardialer Ischämie und Reperfusion wird durch Fibroblasten vermittelt (Kawaguchi et al. 2011). Ein dysreguliertes myokardiales Remodeling mit exzessiver Sekretion von EZM-Komponenten durch Fibroblasten ist zugleich Bestandteil der Ätiologie beinahe aller Herzerkrankungen (Travers et al. 2016). 


\subsection{Zielsetzung}

Während der Organentwicklung, in physiologischen Gewebenischen und unter verschiedenen pathologischen Bedingungen müssen sich Zellen an eine reduzierte Verfügbarkeit von $\mathrm{O}_{2}$ adaptieren. So ist Hypoxie ein zentrales Charakteristikum von akuter Myokardischämie. Kardiofibroblasten regulieren die Struktur, Funktion und das Remodeling des Myokards durch Prozesse, für die der zelluläre Membrantransport von herausragender Relevanz ist. Der Membranverkehr ermöglicht sowohl die Funktion individueller eukaryotischer Zellen als auch die interzelluläre Kommunikation. Die mechanische, chemische und elektrische Interaktion mit der Umgebung erfordert die präzise zelluläre Regulation von Rezeptorsignalen, der Abundanz und Lokalisation von Plasmamembranproteinen sowie der Aufnahme und Ausschüttung chemischer Verbindungen.

Eine quantitative Charakterisierung des Einflusses von akuter Hypoxie auf den Gesamtmembranverkehr von Kardiofibroblasten würde einen Beitrag zum besseren Verständnis der Hypoxie-Adaptation leisten und könnte darüber hinaus Optionen für die therapeutische Modulation der Hypoxie-Antwort aufzeigen. Bisherige Untersuchungen zum Einfluss von Hypoxie auf Membrantransport und Vesikeldynamik zeigten bei heterogener Methodik zum Teil widersprüchliche Ergebnisse. Mehrheitlich deuten die Ergebnisse auf eine Induktion spezifischer Membrantransportvorgänge hin. Ein Teil dieser Beobachtungen ist abhängig vom HIF-Transkriptionssystem. Die vollständige Reversibilität dieser Beobachtungen durch Reoxygenierung konnte nicht gezeigt werden und wurde bisher lediglich in einer Untersuchung geprüft. Die Auswirkungen von akuter Hypoxie auf den Gesamtmembrantransport primärer, nicht-maligner Zellen, bleiben trotz dieser bisher veröffentlichten Daten unklar. Diese Arbeit soll daher einen Beitrag zur Charakterisierung akuter Hypoxie-induzierter Veränderungen des Gesamtmembranverkehrs primärer Zellen leisten. Aufgrund der hohen pathophysiologischen Relevanz wurde ein KardiofibroblastenModell gewählt. 


\subsubsection{Fragestellungen}

Die folgenden Fragen sollen beantwortet werden:

1.) Gibt es einen Einfluss von akuter Hypoxie auf den Gesamtmembranverkehr? Die Gesamtmembranaufnahme und -abgabe von unter Normoxie und akuter Hypoxie inkubierten Kardiofibroblasten sollen quantifiziert werden.

2.) Sofern 1.) zutrifft: Ist dieser Effekt spezifisch für Kardiofibroblasten?

Der Einfluss von akuter Hypoxie auf den Gesamtmembranverkehr soll in Fibroblasten topographisch anderen Ursprungs analog zu 1.) quantifiziert werden.

3.) Sofern 1.) zutrifft: Ist der Einfluss von akuter Hypoxie auf den

Gesamtmembranverkehr von Kardiofibroblasten durch Reoxygenierung reversibel? Der Reversibilität des Effektes soll durch 30 Minuten bzw. zwei Stunden Reoxygenierung in Normoxie geprüft werden.

4.) Gibt es einen Einfluss von akuter Hypoxie auf die Plasmamembrankomposition von Kardiofibroblasten?

Die Protein-Plasmamembrankomposition von akut hypoxischen Kardiofibroblasten soll durch stabile Isotopenmarkierung mit Aminosäuren in Zellkultur (SILAC, stable isotope labeling with amino acids in cell culture) und massenspektrometrische Analyse auf Unterschiede zu der Protein-Plasmamembrankomposition von unter Normoxie inkubierten Kardiofibroblasten untersucht werden. 


\section{$2 \quad$ Material und Methoden}

Sofern nicht anders angegeben, sind Prozentangaben auf das Volumen bezogen. Aus Gründen der besseren Lesbarkeit werden anerkannte oder registrierte Warenmarken nur bei der ersten Nennung gekennzeichnet.

\subsection{Material}

\subsubsection{Reagenzien und Bestandteile von Zellkulturmedien}

Tabelle 1: Reagenzien

\begin{tabular}{|c|c|c|}
\hline Name & Hersteller & Katalognummer \\
\hline Agarose Broad Range & $\begin{array}{l}\text { Carl Roth GmbH, Karlsruhe, } \\
\text { Deutschland }\end{array}$ & T846.3 \\
\hline Ammoniumpersulfat (APS) & $\begin{array}{l}\text { Carl Roth GmbH, Karlsruhe, } \\
\text { Deutschland }\end{array}$ & 9592.2 \\
\hline$\beta$-Merkaptoethanol & $\begin{array}{l}\text { Carl Roth GmbH, Karlsruhe, } \\
\text { Deutschland }\end{array}$ & 4277.1 \\
\hline Benzoase Nuklease & $\begin{array}{l}\text { Novagen; Merck Millipore, } \\
\text { Darmstadt, Deutschland }\end{array}$ & 101654 \\
\hline Bovines Serumalbumin (BSA) & $\begin{array}{l}\text { AppliChem, Darmstadt, } \\
\text { Deutschland }\end{array}$ & A1391,0500 \\
\hline Bromphenolblau & $\begin{array}{l}\text { Carl Roth GmbH, Karlsruhe, } \\
\text { Deutschland }\end{array}$ & A512.1 \\
\hline $\begin{array}{l}\text { cOmplete }^{\mathrm{TM}} \text { Mini } \\
\text { Ethylendiamintetraazetat (EDTA)- } \\
\text { freier Proteaseinhibitor-Cocktail }\end{array}$ & $\begin{array}{l}\text { Roche Applied Science, } \\
\text { Mannheim, Deutschland }\end{array}$ & 04693159001 \\
\hline Kumarinsäure & $\begin{array}{l}\text { Sigma-Aldrich, St. Louis, } \\
\text { Vereinigte Staaten }\end{array}$ & C-9008 \\
\hline $\begin{array}{l}\text { Dinatriumhydrogenphosphat } \\
\left(\mathrm{Na}_{2} \mathrm{HPO}_{4}\right)\end{array}$ & $\begin{array}{l}\text { Carl Roth GmbH, Karlsruhe, } \\
\text { Deutschland }\end{array}$ & 4984.1 \\
\hline Dithiothreitol (DTT) & $\begin{array}{l}\text { Sigma-Aldrich, St. Louis, } \\
\text { Vereinigte Staaten }\end{array}$ & 43815 \\
\hline DNAse Typ I & $\begin{array}{l}\text { Merck Millipore, Darmstadt, } \\
\text { Deutschland }\end{array}$ & 260913 \\
\hline EDTA & $\begin{array}{l}\text { Carl Roth GmbH, Karlsruhe, } \\
\text { Deutschland }\end{array}$ & 8043.2 \\
\hline Essigsäure & $\begin{array}{l}\text { Carl Roth GmbH, Karlsruhe, } \\
\text { Deutschland }\end{array}$ & 3738.5 \\
\hline Fibronektin aus bovinem Plasma & $\begin{array}{l}\text { Sigma-Aldrich, St. Louis, } \\
\text { Vereinigte Staaten }\end{array}$ & F1141 \\
\hline $\begin{array}{l}\mathrm{FM}^{\mathrm{TM}} 1-43 \text { (N-(3- } \\
\text { (Triethylammoniumpropyl)-4-(4- } \\
\text { (Dibutylamino) Styryl) } \\
\text { Pyridiniumdibromid) } \\
\end{array}$ & $\begin{array}{l}\text { Thermo Fisher Scientific Inc., } \\
\text { Waltham, Vereinigte Staaten }\end{array}$ & T3163 \\
\hline Glukose & $\begin{array}{l}\text { AppliChem, Darmstadt, } \\
\text { Deutschland }\end{array}$ & A1349 \\
\hline Glyzerin & $\begin{array}{l}\text { Carl Roth GmbH, Karlsruhe, } \\
\text { Deutschland }\end{array}$ & 3783.2 \\
\hline
\end{tabular}




\begin{tabular}{|c|c|c|}
\hline Name & Hersteller & Katalognummer \\
\hline Glyzin & $\begin{array}{l}\text { Carl Roth GmbH, Karlsruhe, } \\
\text { Deutschland }\end{array}$ & 3908.2 \\
\hline Iodoazetamid & $\begin{array}{l}\text { Sigma-Aldrich, St. Louis, } \\
\text { Vereinigte Staaten }\end{array}$ & $\mathrm{I} 6125$ \\
\hline Isopropanol & $\begin{array}{l}\text { Carl Roth GmbH, Karlsruhe, } \\
\text { Deutschland }\end{array}$ & 6752.4 \\
\hline Kaliumchlorid (KCl) & $\begin{array}{l}\text { Carl Roth GmbH, Karlsruhe, } \\
\text { Deutschland }\end{array}$ & 6787.1 \\
\hline $\begin{array}{l}\text { Kaliumdihydrogenphosphat } \\
\left(\mathrm{KH}_{2} \mathrm{PO}_{4}\right)\end{array}$ & $\begin{array}{l}\text { Carl Roth GmbH, Karlsruhe, } \\
\text { Deutschland }\end{array}$ & 3904.1 \\
\hline Kollagenase Typ II & $\begin{array}{l}\text { Biochrom AG, Berlin, } \\
\text { Deutschland }\end{array}$ & C2-22 \\
\hline Luminol & $\begin{array}{l}\text { Carl Roth GmbH, Karlsruhe, } \\
\text { Deutschland }\end{array}$ & 4203.1 \\
\hline $\begin{array}{l}\text { Magnesiumsulfat Monohydrat } \\
\left(\mathrm{MgSO}_{4} \cdot \mathrm{H}_{2} \mathrm{O}\right)\end{array}$ & $\begin{array}{l}\text { Carl Roth GmbH, Karlsruhe, } \\
\text { Deutschland }\end{array}$ & 0261.2 \\
\hline Methanol & $\begin{array}{l}\text { Carl Roth GmbH, Karlsruhe, } \\
\text { Deutschland }\end{array}$ & 4627.5 \\
\hline Natriumchlorid $(\mathrm{NaCl})$ & $\begin{array}{l}\text { Carl Roth GmbH, Karlsruhe, } \\
\text { Deutschland }\end{array}$ & 9265.2 \\
\hline Natriumdodecylsulfat & $\begin{array}{l}\text { Carl Roth GmbH, Karlsruhe, } \\
\text { Deutschland }\end{array}$ & 4360.2 \\
\hline Natriumhydroxid $(\mathrm{NaOH})$ & $\begin{array}{l}\text { Carl Roth GmbH, Karlsruhe, } \\
\text { Deutschland }\end{array}$ & 6771.2 \\
\hline NuPAGE ${ }^{\circledR}$ LDS Probenpuffer $(4 \mathrm{x})$ & $\begin{array}{l}\text { Novex; Life Technologies, } \\
\text { Carlsbad, Vereinigte Staaten }\end{array}$ & NP0007 \\
\hline $\begin{array}{l}\text { NuPAGE }{ }^{\circledR} \text { Probenreduktionspuffer } \\
(10 \mathrm{x})\end{array}$ & $\begin{array}{l}\text { Novex; Life Technologies, } \\
\text { Carlsbad, Vereinigte Staaten }\end{array}$ & NP0004 \\
\hline PageRuler ${ }^{\mathrm{TM}}$ Prestained Protein Ladder & $\begin{array}{l}\text { Thermo Fisher Scientific Inc., } \\
\text { Waltham, Vereinigte Staaten }\end{array}$ & 26616 \\
\hline Paraformaldehyd (PFA) & $\begin{array}{l}\text { Carl Roth GmbH, Karlsruhe, } \\
\text { Deutschland }\end{array}$ & 0335.1 \\
\hline Ponceau & $\begin{array}{l}\text { Bio-Rad GmBH, München, } \\
\text { Deutschland }\end{array}$ & P7170 \\
\hline Roti ${ }^{\circledR}$ Safe Gel Stain & $\begin{array}{l}\text { Carl Roth GmbH, Karlsruhe, } \\
\text { Deutschland }\end{array}$ & 3865.1 \\
\hline Sucofin ${ }^{\circledR}$ Magermilchpulver & $\begin{array}{l}\text { TSI GmbH \& Co. KG, Zeven, } \\
\text { Deutschland }\end{array}$ & 120307 \\
\hline TRIS-Hydrochlorid (Tris-HCl) & $\begin{array}{l}\text { Carl Roth GmbH, Karlsruhe, } \\
\text { Deutschland }\end{array}$ & 9090.1 \\
\hline $\operatorname{Triton}^{\circledR}$ X 100 & $\begin{array}{l}\text { Carl Roth GmbH, Karlsruhe, } \\
\text { Deutschland }\end{array}$ & 3051.3 \\
\hline Trypsin Sequencing Grade & $\begin{array}{l}\text { Roche Diagnostics International } \\
\text { AG, Rotkreuz, Schweiz }\end{array}$ & 11047841001 \\
\hline Trypsin EDTA 0,05\% & $\begin{array}{l}\text { PAN-Biotech, Aidenbach, } \\
\text { Deutschland }\end{array}$ & P10-023100 \\
\hline Trypan Blau Lösung 0,4\% & $\begin{array}{l}\text { Sigma-Aldrich, St. Louis, } \\
\text { Vereinigte Staaten }\end{array}$ & 93595 \\
\hline Wasserstoffperoxid $\left(\mathrm{H}_{2} \mathrm{O}_{2}\right)$ & $\begin{array}{l}\text { Sigma-Aldrich, St. Louis, } \\
\text { Vereinigte Staaten }\end{array}$ & H1009 \\
\hline
\end{tabular}


Tabelle 2: Bestandteile von Zellkulturmedien

\begin{tabular}{|c|c|c|}
\hline Name & Hersteller & Katalognummer \\
\hline $\begin{array}{l}\text { 2-(4-(2-Hydroxyethyl)-1-piperazinyl)- } \\
\text { ethansulfonsäure (HEPES) }\end{array}$ & $\begin{array}{l}\text { Carl Roth GmbH, Karlsruhe, } \\
\text { Deutschland }\end{array}$ & 6763 \\
\hline $\begin{array}{l}\text { Dulbecco's modified Eagle medium } \\
\text { (DMEM) }\end{array}$ & $\begin{array}{l}\text { PAN-Biotech, Aidenbach, } \\
\text { Deutschland }\end{array}$ & P04-03590 \\
\hline Fetales Kälberserum (FKS) & $\begin{array}{l}\text { PAN-Biotech, Aidenbach, } \\
\text { Deutschland }\end{array}$ & P30-3302 \\
\hline \begin{tabular}{|l}
$\begin{array}{l}\text { Fetales Kälberserum (FKS), dialysiert, } \\
\text { steril filtriert }\end{array}$ \\
\end{tabular} & $\begin{array}{l}\text { PAN-Biotech, Aidenbach, } \\
\text { Deutschland }\end{array}$ & P30-2102 \\
\hline L-Glutamin & $\begin{array}{l}\text { PAN-Biotech, Aidenbach, } \\
\text { Deutschland }\end{array}$ & P04-82050 \\
\hline GlutaMAX $^{\mathrm{TM}}$ & $\begin{array}{l}\text { Thermo Fisher Scientific Inc., } \\
\text { Waltham, Vereinigte Staaten }\end{array}$ & 35050038 \\
\hline L-Arginin & \begin{tabular}{|l|} 
Sigma-Aldrich, St. Louis, \\
Vereinigte Staaten
\end{tabular} & A8094 \\
\hline L-Arginin, ,,schwer” $\left({ }^{13} \mathrm{C}_{6}^{15} \mathrm{~N}_{4}\right)$ & $\begin{array}{l}\text { Cambridge Isotope Laboratory } \\
\text { Inc, Tewksbury, Vereinigte } \\
\text { Staaten }\end{array}$ & $\begin{array}{l}\text { CNLM-539-H- } \\
\text { PK }\end{array}$ \\
\hline L-Lysin & $\begin{array}{l}\text { Sigma-Aldrich, St. Louis, } \\
\text { Vereinigte Staaten }\end{array}$ & 62840 \\
\hline L-Lysin „schwer” $\left({ }^{13} \mathrm{C}_{6}{ }^{15} \mathrm{~N}_{2}\right)$ & $\begin{array}{l}\text { Cambridge Isotope Laboratory } \\
\text { Inc, Tewksbury, Verinigte } \\
\text { Staaten }\end{array}$ & $\begin{array}{l}\text { CNLM-291-H- } \\
\text { PK }\end{array}$ \\
\hline L-Prolin & $\begin{array}{l}\text { Sigma-Aldrich, St. Louis, } \\
\text { Vereinigte Staaten }\end{array}$ & P5607 \\
\hline Natriumpyruvat & $\begin{array}{l}\text { PAN-Biotech, Aidenbach, } \\
\text { Deutschland }\end{array}$ & P04-43100 \\
\hline $\begin{array}{l}\text { Nicht-essentielle Aminosäuren } \\
\text { (MEM-NEAA, minimum essential media } \\
\text { non-essential amino acids) }\end{array}$ & $\begin{array}{l}\text { PAN-Biotech, Aidenbach, } \\
\text { Deutschland }\end{array}$ & P08-32100 \\
\hline $\begin{array}{l}\text { Penizillin/Streptomyzin } \\
(10000 \mathrm{U} / \mathrm{ml} \text { Penizillin, } 10000 \mu \mathrm{g} / \mathrm{ml} \\
\text { Streptomyzin) }\end{array}$ & $\begin{array}{l}\text { PAN-Biotech, Aidenbach, } \\
\text { Deutschland }\end{array}$ & P06-07100 \\
\hline SILAC-DMEM & $\begin{array}{l}\text { PAN-Biotech, Aidenbach, } \\
\text { Deutschland }\end{array}$ & P04-02505 \\
\hline
\end{tabular}

\subsubsection{Zellkulturmedien, Puffer- und Salzlösungen}

Tabelle 3: Zellkulturmedien, Puffer- und Salzlösungen

\begin{tabular}{|l|l|}
\hline Bezeichnung der Lösung & Zusammensetzung \\
\hline \multirow{5}{*}{ PBS } & $137 \mathrm{mM} \mathrm{NaCl}$ \\
& $4,3 \mathrm{mM} \mathrm{Na} \mathrm{HPO}_{4} \cdot 7 \mathrm{H}_{2} \mathrm{O}$ \\
& $2,7 \mathrm{mM} \mathrm{KCl}$ \\
& $1,4 \mathrm{mM} \mathrm{KH}_{2} \mathrm{PO}_{4}$ \\
& in steril filtriertem $\mathrm{H}_{2} \mathrm{O}$ \\
& $\mathrm{pH} 7,4$ \\
\hline
\end{tabular}




\begin{tabular}{|c|c|}
\hline Bezeichnung der Lösung & Zusammensetzung \\
\hline \multicolumn{2}{|l|}{ Isolierung neonataler Kardiofibroblasten } \\
\hline $\begin{array}{l}\text { Kalzium- und bikarbonatfreie Hanks- } \\
\text { Lösung mit HEPES (CBFHH) }\end{array}$ & $\begin{array}{l}137 \mathrm{mM} \mathrm{NaCl} \\
0,81 \mathrm{mM} \mathrm{MgSO}_{4} \cdot 7 \mathrm{H}_{2} \mathrm{O} \\
0,44 \mathrm{mM} \mathrm{KH}_{2} \mathrm{PO}_{4} \\
0,34 \mathrm{mM} \mathrm{Na}_{2} \mathrm{HPO}_{4} \cdot 7 \mathrm{H}_{2} \mathrm{O} \\
5,55 \mathrm{mM} \mathrm{Glukose} \\
20,06 \mathrm{mM} \mathrm{HEPES} \mathrm{pH} \mathrm{7,4} \\
\text { in steril filtriertem } \mathrm{H}_{2} \mathrm{O} \\
\mathrm{pH} 7,4 \text { mit } \mathrm{NaOH}\end{array}$ \\
\hline DNAse I Stammlösung & $\begin{array}{l}100 \mathrm{mg} \text { DNAse I Typ V } \\
\text { in } 100 \mathrm{ml} \text { steril filtriertem } \mathrm{H}_{2} \mathrm{O}\end{array}$ \\
\hline DNAse I Arbeitslösung & $\begin{array}{l}\text { 1\% Penizillin/Streptomyzin } \\
1,7 \mathrm{ml} \text { FKS } \\
0,2 \mathrm{ml} \text { DNAse I Stammlösung } \\
\text { mit CBFHH auf } 50 \mathrm{ml} \text { aufgefüllt }\end{array}$ \\
\hline $\begin{array}{l}\text { Hitze-inaktiviertes Fetales Kälberserum } \\
\text { (FKS) }\end{array}$ & $\begin{array}{l}50 \mathrm{ml} \text { FKS } \\
\text { im Wasserbad bei } 56^{\circ} \mathrm{C} \text { für } 30 \text { Minuten } \\
\text { inkubiert }\end{array}$ \\
\hline Nicht-Kardiomyozyten (NKM) Medium & $\begin{array}{l}\text { DMEM 1g/l Glukose } \\
\text { 10\% FKS, Hitze-inaktiviert } \\
1 \% \text { GlutaMAX } \\
1 \% \text { Penizillin/Streptomyzin } \\
\end{array}$ \\
\hline Trypsin-Stammlösung 50x & $\begin{array}{l}\text { 1g Trypsin } \\
\text { in } 10 \mathrm{ml} \mathrm{CBFHH} \text {, bei } 4{ }^{\circ} \mathrm{C} \text { über Nacht gelöst, } \\
\text { steril filtriert }\end{array}$ \\
\hline Trypsin-Arbeitslösung & $\begin{array}{l}\text { 1\% Penizillin/Streptomyzin } \\
1,3 \mathrm{ml} \text { Trypsin Stammlösung } \\
0,2 \mathrm{ml} \text { DNAse I Stammlösung } \\
\text { mit CBFHH auf } 50 \mathrm{ml} \text { aufgefüllt }\end{array}$ \\
\hline \multicolumn{2}{|l|}{ Isolierung neonataler Schwanzfibroblasten } \\
\hline Schwanzfibroblasten-Medium & $\begin{array}{l}\text { DMEM } \\
10 \% \text { FKS } \\
1 \% \text { Penizillin/Streptomyzin }\end{array}$ \\
\hline Dissoziationsmedium & $\begin{array}{l}\text { DMEM } \\
400 \mathrm{U} / \mathrm{ml} \text { Kollagenase Typ II }\end{array}$ \\
\hline \multicolumn{2}{|c|}{ Kultivierung von Kardio- und Schwanzfibroblasten } \\
\hline Fibroblasten-Wachstumsmedium (FWM) & $\begin{array}{l}\text { DMEM 4,5 g/l Glukose } \\
10 \% \text { FKS } \\
1 \% \text { NEAA } \\
1 \% \text { GlutaMAX } \\
1 \% \text { Penizillin/Streptomyzin }\end{array}$ \\
\hline Trypsin-EDTA & $\begin{array}{l}\text { 1x Trypsin-EDTA } \\
1 \text { mM EDTA }\end{array}$ \\
\hline \multicolumn{2}{|l|}{ FM 1-43-Färbung } \\
\hline Fibronektinlösung & $\begin{array}{l}10 \mu \mathrm{g} / \mathrm{ml} \text { Fibronektin } \\
\text { in PBS }\end{array}$ \\
\hline FM 1-43-Färbemedium & $\begin{array}{l}5 \mu \mathrm{M} \text { FM 1-43 } \\
\text { in FWM }\end{array}$ \\
\hline Quenchlösung & $\begin{array}{l}50 \mathrm{mM} \mathrm{NH}_{4} \mathrm{Cl} \\
\text { in Phosphat-gepufferter Salzlösung (PBS) }\end{array}$ \\
\hline
\end{tabular}




\begin{tabular}{|c|c|}
\hline Bezeichnung der Lösung & Zusammensetzung \\
\hline \multicolumn{2}{|c|}{ Proteinextraktion, Auftrennung und Western-Blot-Analyse } \\
\hline Ponceau-S-Lösung & $\begin{array}{l}0,1 \% \text { Ponceau } \\
5 \% \text { Essigsäure }\end{array}$ \\
\hline $\begin{array}{l}5 \times \text { Natriumdodecylsulfat (SDS, sodium } \\
\text { dodecyl sulfate) Elektrophoresepuffer }\end{array}$ & $\begin{array}{l}125 \mathrm{mM} \text { TRIS } \\
1,25 \mathrm{M} \text { Glyzin } \\
0,5 \% \text { SDS } \\
\text { in } \mathrm{H}_{2} \mathrm{O}, \mathrm{pH} 8,3\end{array}$ \\
\hline $2 \times$ SDS Probenpuffer & $\begin{array}{l}100 \mathrm{mM} \text { Tris- } \mathrm{HCl}, \mathrm{pH} 6,8 \\
4 \% \text { SDS } \\
0,2 \% \text { Bromphenolblau } \\
20 \% \text { Glyzerin } \\
5 \% \beta \text {-Merkaptoethanol } \\
\text { in } \mathrm{H}_{2} \mathrm{O}\end{array}$ \\
\hline Transferpuffer & $\begin{array}{l}25 \mathrm{mM} \text { Tris } \\
192 \mathrm{mM} \text { Glyzin } \\
20 \% \text { Methanol } \\
10 \% \text { SDS } \\
\text { in } \mathrm{H}_{2} \mathrm{O} . \\
\end{array}$ \\
\hline $\begin{array}{l}\text { Verstärkte Chemilumineszenz (ECL, } \\
\text { enhanced chemiluminescence)-Lösung }\end{array}$ & $\begin{array}{l}100 \mathrm{mM} \text { Tris- } \mathrm{HCl}, \mathrm{pH} 8,5 \\
90 \mathrm{mM} \text { Kumarinsäure } \\
250 \mathrm{mM} \text { Luminol in DMSO } \\
2,65 \mathrm{mM}(0,009 \%) \mathrm{H}_{2} \mathrm{O}_{2} \\
\mathrm{pH} 8,8\end{array}$ \\
\hline Zelllysepuffer & $\begin{array}{l}400 \text { mM NaCl } \\
10 \text { mM Tris- } \mathrm{HCl}, \mathrm{pH} 8,0 \\
1 \text { mM EDTA, } \mathrm{pH} 8,0 \\
0,1 \% \text { Triton-X } 100 \\
\text { Proteaseinhibitor-Cocktail } \\
\text { in aqua dest. }\end{array}$ \\
\hline \multicolumn{2}{|l|}{ SILAC-Markierung und Proteomanalyse } \\
\hline NuPAGE ${ }^{\circledR}$ Probenpuffer & $\begin{array}{l}\text { 1x NuPAGE LDS Probenpuffer } \\
\text { 1x NuPAGE Probenreduktionspuffer } \\
\text { in } \mathrm{H}_{2} \mathrm{O}\end{array}$ \\
\hline SILAC-Kulturmedium „leicht“ & $\begin{array}{l}\text { SILAC-DMEM } \\
10 \% \text { dialysiertes FKS } \\
1 \% \text { Penizillin/Streptomyzin } \\
100 \mathrm{mM} \text { Natriumpyruvat } \\
600 \mathrm{mM} \text { L-Prolin } \\
42 \mathrm{mg} / 1 \text { L-Arginin } \\
146 \mathrm{mg} / 1 \text { L-Lysin } \\
\text { steril filtriert }\end{array}$ \\
\hline SILAC-Kulturmedium „schwer“ & $\begin{array}{l}\text { SILAC-DMEM } \\
10 \% \text { dialysiertes FKS } \\
1 \% \text { Penizillin/Streptomyzin } \\
100 \mathrm{mM} \text { Natriumpyruvat } \\
600 \mathrm{mM} \text { L-Prolin } \\
42 \mathrm{mg} / \mathrm{L} \text {-Arginin }\left({ }^{13} \mathrm{C}_{6}{ }^{15} \mathrm{~N}_{4}\right) \\
146 \mathrm{mg} / 1 \mathrm{~L}-\mathrm{Lysin}\left({ }^{13} \mathrm{C}_{6}{ }^{15} \mathrm{~N}_{2}\right) \\
\text { steril filtriert }\end{array}$ \\
\hline
\end{tabular}




\subsubsection{Verbrauchsmaterialien}

Tabelle 4: Verbrauchsmaterialien

\begin{tabular}{|c|c|c|}
\hline Verbrauchsmaterial & Spezifikation & Hersteller \\
\hline Deckgläschen & Rund, $15 \mathrm{~mm}$ Durchmesser & $\begin{array}{l}\text { Thermo Fisher Scientific Inc., } \\
\text { Waltham, Vereinigte Staaten }\end{array}$ \\
\hline Eppendorf Röhrchen & $1,5 \mathrm{ml}$ & $\begin{array}{l}\text { Sarstedt AG \& Co, } \\
\text { Nümbrecht, Deutschland) }\end{array}$ \\
\hline Mikrotiterplatte & Mikrotestplatte 96 Well & $\begin{array}{l}\text { Sarstedt AG \& Co, } \\
\text { Nümbrecht, Deutschland) }\end{array}$ \\
\hline Nitrozellulosemembran & Amersham $^{\mathrm{TM}} \operatorname{Protran}^{\circledR}$ & $\begin{array}{l}\text { GE Healthcare, Little Chalfont, } \\
\text { Vereinigtes Königreich }\end{array}$ \\
\hline $\begin{array}{l}\text { NuPAGE }{ }^{\circledR} \text { Bis-Tris } \\
\text { Minigel }\end{array}$ & $8 \mathrm{~cm} \times 8 \mathrm{~cm}, 1 \mathrm{~mm}, 4-12 \%$ & $\begin{array}{l}\text { Invitrogen; Life Technologies, } \\
\text { Waltham, Vereinigte Staaten }\end{array}$ \\
\hline Nylon Zellsiebe & Falcon $^{\mathrm{TM}}$, Porengröße $70 \mu \mathrm{m}$ & $\begin{array}{l}\text { Thermo Fisher Scientific Inc., } \\
\text { Waltham, Vereinigte Staaten }\end{array}$ \\
\hline Pipettenspitzen & $10 \mu \mathrm{l}, 200 \mu \mathrm{l}, 1000 \mu \mathrm{l}$ & $\begin{array}{l}\text { Sarstedt AG \& Co, } \\
\text { Nümbrecht, Deutschland }\end{array}$ \\
\hline Spritzenfilter & Porengröße $0,2 \mu \mathrm{m}$ & $\begin{array}{l}\text { Sarstedt AG \& Co, } \\
\text { Nümbrecht, Deutschland) }\end{array}$ \\
\hline Zellschaber & $1,7 \mathrm{~cm}$ & $\begin{array}{l}\text { Sarstedt AG \& Co, } \\
\text { Nümbrecht, Deutschland }\end{array}$ \\
\hline Zellkulturflaschen & T175 & $\begin{array}{l}\text { Sarstedt AG \& Co, } \\
\text { Nümbrecht, Deutschland }\end{array}$ \\
\hline Zellkulturschale & $10 \mathrm{~cm}, 15 \mathrm{~cm}$ & $\begin{array}{l}\text { Greiner Bio-One, } \\
\text { Kremsmünster, Österreich }\end{array}$ \\
\hline Zentrifugenröhrchen & $15 \mathrm{ml}, 50 \mathrm{ml}$ & $\begin{array}{l}\text { Sarstedt AG \& Co, } \\
\text { Nümbrecht, Deutschland }\end{array}$ \\
\hline Sechslochplatte & Zellkulturplatte 6 Well & $\begin{array}{l}\text { Sarstedt AG \& Co, } \\
\text { Nümbrecht, Deutschland }\end{array}$ \\
\hline
\end{tabular}

\subsubsection{Geräte}

Tabelle 5: Geräte

\begin{tabular}{|c|c|c|}
\hline Gerät & Typ & Hersteller \\
\hline Blottingapparat & $\begin{array}{l}\text { PerfectBlue }{ }^{\mathrm{TM}} \text { Semi Dry- } \\
\text { Elektroblotter }\end{array}$ & $\begin{array}{l}\text { PEQLAB Biotechnologie } \\
\text { GmbH, Erlangen, Deutschland }\end{array}$ \\
\hline \begin{tabular}{|l} 
Dounce \\
Handhomogenisator
\end{tabular} & $2 \mathrm{ml}$ & $\begin{array}{l}\text { Sigma-Aldrich, St. Louis, } \\
\text { Vereinigte Staaten }\end{array}$ \\
\hline $\begin{array}{l}\text { Gelsystem für } \\
\text { Gelelektrophorese }\end{array}$ & $\begin{array}{l}\text { PerfectBlue }{ }^{\mathrm{TM}} \text { Doppelgelsystem } \\
\text { Twin M }\end{array}$ & $\begin{array}{l}\text { PEQLAB Biotechnologie } \\
\text { GmbH, Erlangen, Deutschland }\end{array}$ \\
\hline Hypoxie-Werkbank & InvivO $_{2} 300$ & $\begin{array}{l}\text { Ruskin Technology, Bridgend, } \\
\text { Vereinigtes Königreich }\end{array}$ \\
\hline Imaging System & $\begin{array}{l}\text { LAS-3000 Luminescent Image } \\
\text { Analyzer }\end{array}$ & $\begin{array}{l}\text { Fuijifilm, Düsseldorf, } \\
\text { Deutschland }\end{array}$ \\
\hline Massenspektrometer & $\begin{array}{l}\text { Q Exactive }{ }^{\mathrm{TM}} \text { Hybrid- } \\
\text { Quadrupol-Orbitrap } \\
\text { Massenspektrometer }\end{array}$ & $\begin{array}{l}\text { Thermo Fisher Scientific Inc., } \\
\text { Waltham, Vereinigte Staaten }\end{array}$ \\
\hline Microplate Reader & Microplate Reader Model 680 & $\begin{array}{l}\text { Bio-Rad GmBH, München, } \\
\text { Deutschland }\end{array}$ \\
\hline
\end{tabular}




\begin{tabular}{|c|c|c|}
\hline Gerät & Typ & Hersteller \\
\hline Mikroskop & TCS SP5 STED & $\begin{array}{l}\text { Leica Microsystems, Wetzlar, } \\
\text { Deutschland }\end{array}$ \\
\hline Objektiv (Mikroskopie) & HCX PL APO 63x/1,4 Oil & $\begin{array}{l}\text { Leica Microsystems, Wetzlar, } \\
\text { Deutschland }\end{array}$ \\
\hline Photospektrometer & SmartSpec ${ }^{\mathrm{TM}}$ Plus & $\begin{array}{l}\text { Bio-Rad, München, } \\
\text { Deutschland }\end{array}$ \\
\hline $\begin{array}{l}\text { Quelle am } \\
\text { Massenspektrometer }\end{array}$ & FlexIon nanoSpray & $\begin{array}{l}\text { Thermo Fisher Scientific Inc., } \\
\text { Waltham, Vereinigte Staaten }\end{array}$ \\
\hline Reinwassersystem & Arium $^{\circledR} 611 \mathrm{VF}$ & $\begin{array}{l}\text { Sartorius, Göttingen, } \\
\text { Deutschland }\end{array}$ \\
\hline Sicherheitswerkbank & HERAsafe ${ }^{\circledR}$ HS 12 & $\begin{array}{l}\text { Thermo Fisher Scientific Inc., } \\
\text { Waltham, Vereinigte Staaten }\end{array}$ \\
\hline Zählkammer & Neubauer & $\begin{array}{l}\text { Marienfeld Superior, Lauda- } \\
\text { Königshofen, Deutschland }\end{array}$ \\
\hline Zellkultur-Brutschrank & CB 150 & $\begin{array}{l}\text { Binder, Tuttlingen, } \\
\text { Deutschland } \\
\end{array}$ \\
\hline Zellkultur-Brutschrank & C200 & $\begin{array}{l}\text { Labotect Labor-Technik- } \\
\text { Göttingen GmbH, Rosdorf, } \\
\text { Deutschland }\end{array}$ \\
\hline Zellsieb & $\begin{array}{l}\text { Cell dissociation sieve-tissue } \\
\text { grinder kit (Porengröße } 250 \mu \mathrm{m} \text { ) }\end{array}$ & $\begin{array}{l}\text { Sigma-Aldrich, St. Louis, } \\
\text { Vereinigte Staaten }\end{array}$ \\
\hline Zentrifuge & 5810R, 5415R & $\begin{array}{l}\text { Eppendorf, Hamburg, } \\
\text { Deutschland }\end{array}$ \\
\hline
\end{tabular}

\subsubsection{Kits}

Tabelle 6: Verwendete kommerzielle Kits

\begin{tabular}{|l|l|l|l|}
\hline Name & Inhalt & Hersteller & Katalognummer \\
\hline $\begin{array}{l}\text { DC } \\
\text { II }\end{array}$ & $\begin{array}{l}\text { Reagenz A } \\
\text { Reagenz B } \\
\text { Reagenz S }\end{array}$ & $\begin{array}{l}\text { Biorad, München, } \\
\text { Deutschland }\end{array}$ & 500-0112 \\
\hline Plasma Membrane \\
Protein Extraction Kit & $\begin{array}{l}\text { Homogenisierungspuffer } \\
\text { Oberphaselösung } \\
\begin{array}{l}\text { Unterphaselösung } \\
\text { Proteaseinhibitor- } \\
\text { Cocktail (lyophilisiert) }\end{array}\end{array}$ & $\begin{array}{l}\text { Abcam, Cambridge, } \\
\text { Vereinigtes } \\
\text { Königreich }\end{array}$ & Ab65400 \\
\hline
\end{tabular}

\subsubsection{Antikörper}

Tabelle 7: Primäre Antikörper

\begin{tabular}{|l|l|l|l|}
\hline Primärer Antikörper gegen & Verdünnung & Seriennummer/Hersteller & Spezies \\
\hline HIF-1 $\alpha$ & $1: 1000$ & NB 100-479/Novus Biologicals & Kaninchen \\
\hline$\beta$-Aktin & $1: 10.000$ & A5441/Sigma-Aldrich & Maus \\
\hline$\alpha$-glatte-Muskulatur-Aktin & $1: 1000$ & ab5694/Abcam & Kaninchen \\
\hline$\beta$-Tubulin & $1: 1000$ & ab6046/Abcam & Kaninchen \\
\hline
\end{tabular}


Tabelle 8: Sekundäre Antikörper

\begin{tabular}{|l|l|l|l|}
\hline Sekundärer Antikörper gegen & Verdünnung & Seriennummer/Hersteller & Spezies \\
\hline Kaninchen & $1: 10.000$ & $\begin{array}{l}\text { SC-2004/Santa Cruz } \\
\text { Biotechnology }\end{array}$ & Ziege \\
\hline Maus & $1: 1000$ & $\begin{array}{l}\text { SC-2005/Santa Cruz } \\
\text { Biotechnology }\end{array}$ & Ziege \\
\hline
\end{tabular}

\subsubsection{Software}

Tabelle 9: Software und PC-Anwendungen

\begin{tabular}{|c|c|c|}
\hline Software & Anwendung & Hersteller \\
\hline CorelDRAW $^{\circledR}$ V.15.2.0.661 & Grafikerstellung & $\begin{array}{l}\text { Corel Corporation, Ottawa, } \\
\text { Kanada }\end{array}$ \\
\hline $\begin{array}{l}\text { GraphPad Prism }{ }^{\circledR} \text { V.4.0; V. } \\
5.01\end{array}$ & Statistische Datenanalyse & $\begin{array}{l}\text { GraphPad Software, San } \\
\text { Diego, Vereinigte Staaten }\end{array}$ \\
\hline ImageJ V.1.50b & Bildanalyse & $\begin{array}{l}\text { National Institute of Health, } \\
\text { Vereinigte Staaten }\end{array}$ \\
\hline LAS AF V.2.7.3.9723 & Mikroskopbedienung & $\begin{array}{l}\text { Leica Microsystems, Wetzlar, } \\
\text { Deutschland }\end{array}$ \\
\hline Matlab R2013a & $\begin{array}{l}\text { Auswertung der } \\
\text { Fluoreszenzmikroskopie }\end{array}$ & $\begin{array}{l}\text { The MathWorks }{ }^{\circledR} \text {, Inc., Natick, } \\
\text { Vereinigte Staaten }\end{array}$ \\
\hline MaxQuandt V.1.4.1.13 & $\begin{array}{l}\text { Massenspektrometrie } \\
\text { Datenanalyse }\end{array}$ & $\begin{array}{l}\text { Max-Planck-Institut für } \\
\text { Biochemie, Martinsried, } \\
\text { Deutschland }\end{array}$ \\
\hline $\begin{array}{l}\left.\text { Microplate Manager }^{(}\right) \\
\text {V.5.2.1 }\end{array}$ & Mikrotiterplatten Messungen & $\begin{array}{l}\text { Bio-Rad GmBH, München, } \\
\text { Deutschland }\end{array}$ \\
\hline $\begin{array}{l}\text { Microsoft Office } 365^{\circledR} \\
\text { ProPlus V.1803 }\end{array}$ & $\begin{array}{l}\text { Datenmanagement, } \\
\text { Texterstellung }\end{array}$ & $\begin{array}{l}\text { Microsoft, Redmond, } \\
\text { Vereinigte Staaten }\end{array}$ \\
\hline MultiGauge V.3.0 & Analyse der Western Blots & $\begin{array}{l}\text { Fujifilm Corporation, } \\
\text { Düsseldorf, Deutschland }\end{array}$ \\
\hline Perseus V.1.5.0.8 & $\begin{array}{l}\text { Massenspektrometrie } \\
\text { statistische Analyse }\end{array}$ & $\begin{array}{l}\text { Max-Planck-Institut für } \\
\text { Biochemie, Martinsried, } \\
\text { Deutschland }\end{array}$ \\
\hline Xcalibur $^{\mathrm{TM}}$ V.2.2 & $\begin{array}{l}\text { Steuerung des nanoLC- } \\
\text { MS/MS Systems }\end{array}$ & $\begin{array}{l}\text { Thermo Fisher Scientific Inc., } \\
\text { Waltham, Vereinigte Staaten }\end{array}$ \\
\hline Zotero V.5.0.55 & Literaturverwaltung & $\begin{array}{l}\text { Roy Rosenzweig Center for } \\
\text { History and New Media der } \\
\text { George Mason University, } \\
\text { Fairfax, Vereinigte Staaten }\end{array}$ \\
\hline
\end{tabular}

V.: Version 


\subsection{Methoden}

\subsubsection{Zellisolierung}

\subsubsection{Kardiofibroblasten von neonatalen Ratten}

Kardiofibroblasten neonataler Ratten (Rattus norvegicus) wurden in Kooperation mit der Arbeitsgruppe von Prof. Dr. S. Lutz (Institut für Pharmakologie und Toxikologie, Universitätsmedizin Göttingen) isoliert. Hierfür wurde ein modifiziertes Protokoll von Simpson und Savion angewendet (Simpson und Savion 1982). Die Präparation erfolgte auf Eis. Die Ratten wurden im Alter von ein bis drei Tagen dekapitiert. Der Brustkorb wurde eröffnet, das Herz mit Gefäßstumpf entfernt und in eine $10 \mathrm{~cm}$ Zellkulturschale mit kalziumund bikarbonatfreier Hanks-Lösung mit HEPES (CBFHH) überführt. Gefäßstumpf, Vorhöfe und verbliebenes Bindegewebe wurden entfernt. Um Blutreste zu entfernen, wurde das Ventrikelgewebe zweimal mit CBFHH gewaschen, danach in $1 \mathrm{~mm}^{3}$ kleine Teile geschnitten und erneut zweimal mit CBFHH gewaschen. Die Kardiofibroblasten wurden durch enzymatische Zersetzung der EZM aus dem Zellverband herausgelöst. Hierzu wurde das Ventrikelgewebe bei Raumtemperatur in Trypsin-Arbeitslösung für ein bis vier Minuten inkubiert, bis die Lösung begann, sich zu trüben. Der Überstand wurde in ein Röhrchen mit fetalem Kälberserum (FKS) überführt. DNAse I-Arbeitslösung wurde zu dem Ventrikelgewebe gegeben. Das Gewebe wurde mehrfach auf- und abpipettiert, um die Zellen mechanisch aus dem Verband zu lösen. Der Überstand wurde ebenfalls in das Röhrchen mit FKS überführt. Diese Schritte wurden so lange wiederholt, bis sich keine Zellen mehr aus dem Ventrikelgewebe lösten. Anschließend wurden die Röhrchen für 15 Minuten bei 60x g, $4{ }^{\circ} \mathrm{C}$ zentrifugiert. Die Pellets wurden in Nicht-Kardiomyozyten Medium (NKM, Tabelle 3) aufgenommen, die Zellen aus den verschiedenen Röhrchen gepoolt und durch ein befeuchtetes Zellsieb mit der Porengröße $250 \mu \mathrm{m}$ in ein neues $50 \mathrm{ml}$ Röhrchen überführt. $10 \mu \mathrm{l}$ der Zellsuspension wurden im Verhältnis 1:1 mit einer 0,4\% Trypanblau Lösung gemischt. Die Zellzahl und -vitalität wurde mit einer Neubauer-Zählkammer ermittelt.

Die Selektion der Kardiofibroblasten aus der Zellsuspension erfolgte über ihre im Vergleich zu Kardiomyozyten und anderen Zelltypen schnellere Adhäsion an Plastikoberflächen. $8 \times 10^{6}$ Zellen wurden in eiskaltem NKM Medium auf einer $15 \mathrm{~cm}$ Zellkulturschale ausgesät und für 45 Minuten in einem Zellkulturbrutschrank bei $37{ }^{\circ} \mathrm{C}, 20 \% \mathrm{O}_{2}, 5 \% \mathrm{CO}_{2}$ und Wasserdampfsättigung inkubiert. Danach wurde das NKM Medium mit den nicht adhärierenden Zellen entfernt und durch Fibroblasten-Wachstumsmedium (FWM, Tabelle 3) ersetzt. Die adhärierenden Fibroblasten wurden als Passage 0 (P0) definiert und in FWM inkubiert, bis sie eine $70-80 \%$ Konfluenz erreichten. 


\subsubsection{Schwanzfibroblasten neonataler Ratten}

Schwanzfibroblasten neonataler Ratten (Rattus norvegicus) wurden in Kooperation mit der Arbeitsgruppe von Prof. Dr. S. Lutz (Institut für Pharmakologie und Toxikologie, Universitätsmedizin Göttingen) isoliert. Die Ratten wurden im Alter von ein bis drei Tagen dekapitiert und die Schwänze proximal abgetrennt. Hiernach wurden die Schwänze für 60 Minuten in Schwanzfibroblasten-Medium auf Eis inkubiert. Nach Waschen mit phosphatgepufferter Salzlösung (PBS) +2\% Penizillin/Streptomyzin wurden die Schwänze in $70 \%$ Ethanol getaucht und mit einem sterilen Skalpell zerkleinert. Das Gewebe wurde in $25 \mathrm{ml}$ Dissoziationsmedium über Nacht bei $37^{\circ} \mathrm{C}$ lysiert. Am Folgetag wurde die Suspension durch mehrmaliges Pipettieren gemischt, durch ein Nylon-Zellsieb mit einer Porengröße von $70 \mu \mathrm{m}$ in ein 25-ml-Zentrifugenröhrchen überführt und bei 1000 Umdrehungen pro Minute (rpm, revolutions per minute) für fünf Minuten zentrifugiert. Der Überstand wurde verworfen, das Zell-Pellet in Zellkulturmedium resuspendiert und in Zellkulturflaschen ausgesät.

\subsubsection{Zellkultur in Normoxie und Hypoxie}

Kardio- und Schwanzfibroblasten wurden in FWM kultiviert. Die Kultivierung der Zellen erfolgte in einem Zellkultur-Brutschrank bei $37{ }^{\circ} \mathrm{C}, 20 \% \mathrm{O}_{2}, 5 \% \mathrm{CO}_{2}$ und Wasserdampfsättigung. Hypoxie-Experimente wurden an einer Hypoxie-Werkbank bei $37^{\circ} \mathrm{C}, 1 \% \mathrm{O}_{2}, 5 \%$ $\mathrm{CO}_{2}, 94 \% \mathrm{~N}_{2}$ und Wasserdampfsättigung durchgeführt. Das Zellkulturmedium wurde jeden zweiten Tag erneuert.

\subsubsection{Passagieren und Aussäen der Zellen}

Sofern nicht anders angegeben, wurden für alle Versuche Zellen in P1 genutzt. Die Passagierung der Zellen erfolgte, indem das Kulturmedium entfernt und verbliebene Reste mit PBS abgewaschen wurden. Die Zellen wurden mit $4 \mathrm{ml}$ Trypsin-EDTA für fünf Minuten bei $37{ }^{\circ} \mathrm{C}$ inkubiert und in $16 \mathrm{ml}$ DMEM $+10 \%$ FKS aufgenommen. Die Zellen wurden entweder im Verhältnis 1:2-1:6 (in der Regel 1:4) passagiert oder nach der Bestimmung der Zellzahl unter Verwendung einer Neubauer-Zählkammer in der benötigten Konzentration ausgesät. Je nach Größe der Zellkulturflaschen (75 bzw. $\left.175 \mathrm{~cm}^{2}\right)$ wurde das Volumen mit dem entsprechenden Zellkulturmedium auf 15 oder $25 \mathrm{ml}$ aufgefüllt.

\subsubsection{FM 1-43-Färbung und konfokale Mikroskopie}

\subsubsection{FM 1-43-Färbung}

Zur Analyse des Gesamtmembranumsatzes von Kardio- und Schwanzfibroblasten wurde eine Färbung mit dem Styryl-Fluoreszenzfarbstoff FM 1-43 (N-(3-(Triethylammoniumpropyl)-4-(4-(Dibutylamino) Styryl) Pyridiniumdibromid) durchgeführt (Betz et al. 1992). Fluoreszenzfarbstoffe sind organische Verbindungen, die konjugierte alternierende Doppelbindungen enthalten, die die Delokalisierung von Elektronen innerhalb des Moleküls ermöglichen. Bei Absorption von Photonen mit der geeigneten Energie werden Elektronen 
im Fluorophor angeregt. Bei Rückkehr in den Ausgangszustand wird die Energie in Form von Photonen abgegeben. Die emittierten Photonen sind hierbei von niedrigerer Energie, sodass das emittierte Licht eine größere Wellenlänge hat als das zur Anregung genutzte. Das Verhältnis der Anzahl absorbierter Photonen zur Anzahl emittierter Photonen wird als Quantenausbeute bezeichnet (Ghiran 2011). Aufgrund seiner hydrophoben Schwanzdomäne hat FM 1-43 eine hohe Affinität zu Lipidstrukturen. Die aromatischen Ringe in der Brückenregion des Farbstoffs bilden den Fluorophor (Abbildung 2). Die Quantenausbeute ist abhängig von der Polarität des Lösungsmittels und im unpolaren Milieu, wie Lipidmembranen, um mehr als zwei Größenordnungen höher als in polaren Lösungsmitteln wie z. B. Wasser. Die positiv geladene Kopfdomäne des Moleküls verhindert das Durchwandern der Lipidmembran, sodass endozytotisch aufgenommener Farbstoff nur durch Exozytose wieder abgegeben werden kann (Gaffield und Betz 2006).

A

Kopf Brücke Schwanz

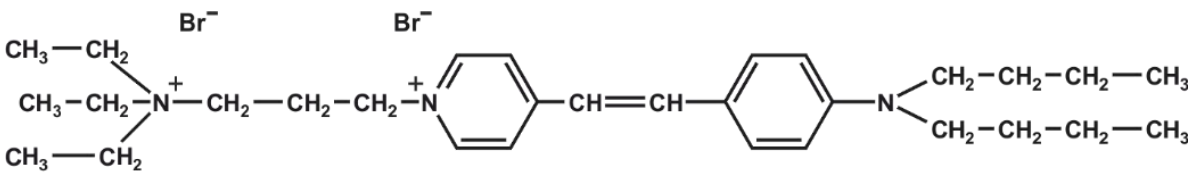

B

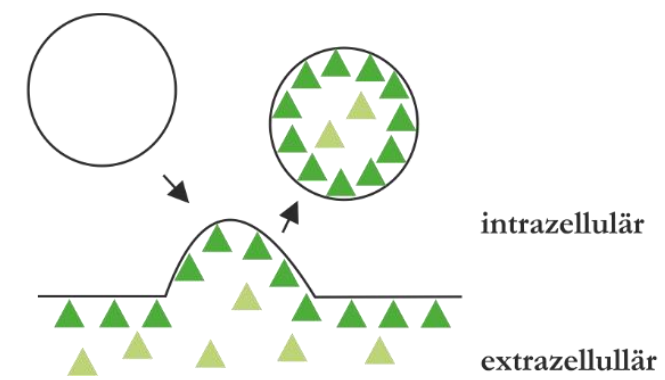

C

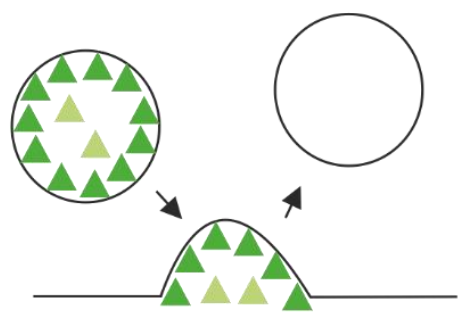

Abbildung 2: Struktur und Kinetik von FM 1-43. (A) Strukturformel von FM 1-43 (N-(3(Triethylammoniumpropyl)-4-(4-(Dibutylamino) Styryl) Pyridiniumdibromid); (B) Die Inkorporation von FM 1-43 erfolgt durch Einlagerung des Farbstoffes in die Zellmembran. Ungefärbte intrazelluläre Vesikel fusionieren in Exozytosevorgängen mit der Zellmembran, bei der Bildung von Endozytosevesikeln werden angefärbte Membranabschnitte in die Zelle aufgenommen. Es erfolgt keine Membran-unabhängige Aufnahme. (C) Die Abgabe des Farbstoffs erfolgt durch Verschmelzung gefärbter intrazellulärer Vesikel mit der entfärbten Zellmembran. Bei endozytotischer Vesikelbildung wird kein neues FM 1-43 inkorporiert. Dunkelgrüne Dreiecke stellen in Lipidmembranen eingelagerte stark fluoreszierende FM 1-43-Moleküle dar. Blassgrüne Dreiecke entsprechen schwach fluoreszierenden FM 1-43-Molekülen in polarer Umgebung. Abbildung adaptiert nach Betz et al. (1992), mit freundlicher Genehmigung der Society for Neuroscience. 
Die Zellfärbung erfolgte auf kollagenbeschichteten runden Glasdeckgläschen mit einem Durchmesser von $15 \mathrm{~mm}$. Die Deckgläschen wurden vor Gebrauch durch Abflammen sterilisiert. Je ein Deckgläschen wurde in die Vertiefungen einer Sechslochplatte gelegt und für fünf Minuten bei $37^{\circ} \mathrm{C}$ mit $10 \mu \mathrm{g} / \mathrm{ml}$ Fibronektin in PBS benetzt. Die Fibronektinlösung wurde anschließend mit PBS abgewaschen. Hiernach wurden die Zellen in einer Konzentration von $5 \times 10^{4}-10^{5}$ pro Vertiefung in $2 \mathrm{ml}$ FWM ausgesät und über Nacht bei $37^{\circ} \mathrm{C}$ und $20 \% \mathrm{O}_{2}$ inkubiert. Pro analysierter Bedingung wurden drei Vertiefungen vorbereitet. Am Folgetag wurden die Zellen für sechs Stunden entweder bei Hypoxie oder Normoxie inkubiert. Für Reoxygenierungsexperimente wurden weitere Zellen nach sechs Stunden Hypoxie für 30 Minuten bzw. zwei Stunden in den Normoxie-Brutschrank überführt (Abbildung 3). Zur Analyse der Endozytoseaktivität wurde das FWM 30 Minuten vor ihrer Fixierung durch FM 1-43-Färbemedium ersetzt (Tabelle 3). Nach Ablauf der sechsstündigen Inkubation und ggf. der Reoxygenierungszeit wurde das Färbemedium entfernt, die Zellen dreimal mit DMEM gewaschen und in 4\% Paraformaldehyd (PFA) in PBS über 30 Minuten fixiert. Das PFA wurde anschließend durch zweimaliges Waschen mit PBS entfernt. Um die Autofluoreszenz des verbliebenen PFA zu unterdrücken, wurden die fixierten Zellen für 15 Minuten mit Quenchlösung (Tabelle 3) inkubiert. Die Zellen wurden zweimal mit PBS gewaschen, dunkel gelagert und am selben Tag in PBS mikroskopiert.

Zur Analyse der Exozytoseaktivität wurde das FWM eine Stunde vor Zellfixierung durch FM 1-43-Färbemedium ersetzt. Nach 30 Minuten Inkubation in FM 1-43-Färbemedium wurden die Zellen dreimal mit DMEM gewaschen. Für die verbliebenen 30 Minuten bis zur Fixierung erfolgte die Inkubation in FWM, um die Abgabe des Fluoreszenzfarbstoffs durch Exozytose zu ermöglichen. Anschließend wurden die Zellen dreimal mit DMEM gewaschen, über 30 Minuten mit 4\% PFA in PBS fixiert und erneut zweimal mit PBS gewaschen. Hiernach wurden die Zellen für 15 Minuten bei Raumtemperatur in Quenchlösung inkubiert, zweimal mit PBS gewaschen, dunkel gelagert und am selben Tag in PBS mikroskopiert. 
A

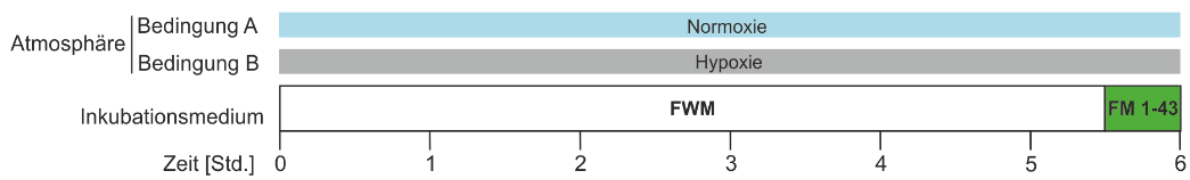

B

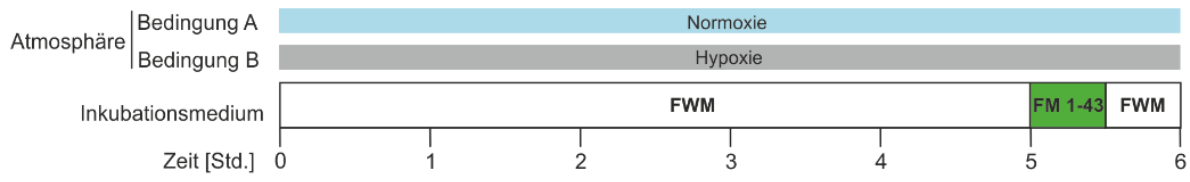

C

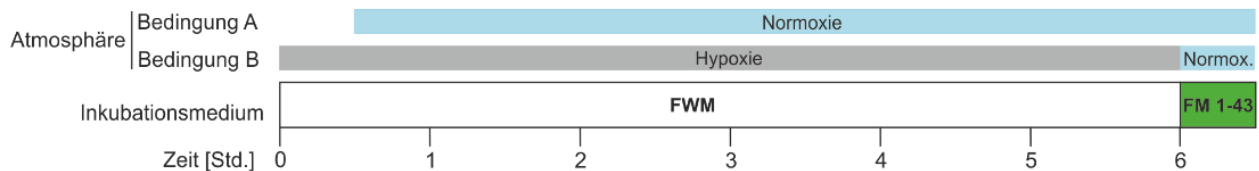

D

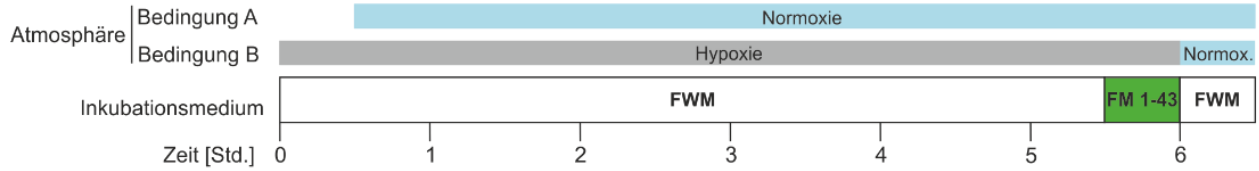

E

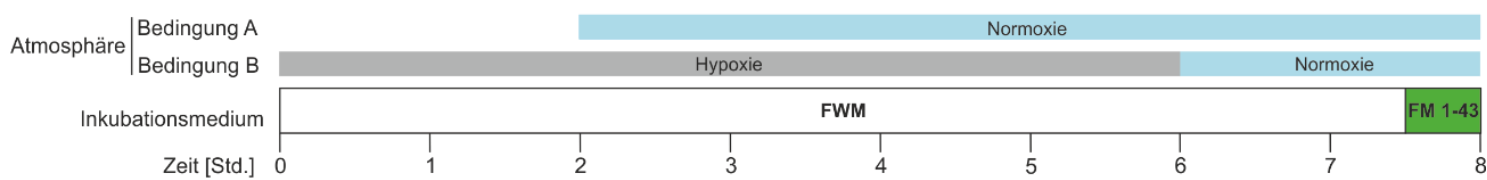

$\mathbf{F}$

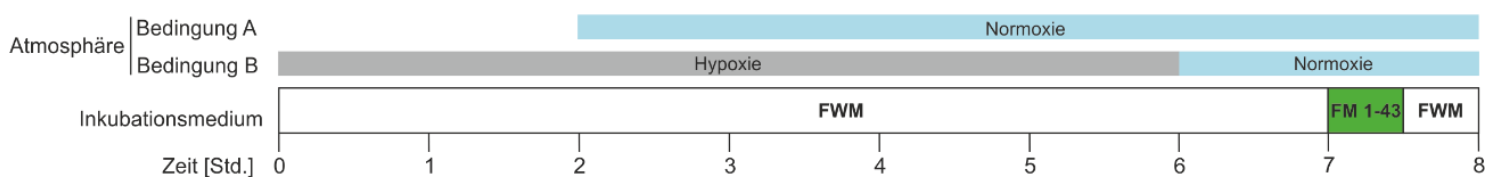

Abbildung 3: Ablauf des FM 1-43-Färbeversuchs. Primäre neonatale Kardio- oder Schwanzfibroblasten wurden in Normoxie (Bedingung A, 20\% $\mathrm{O}_{2}, 5 \% \mathrm{CO}_{2}, 37^{\circ} \mathrm{C}$ ) oder für sechs Stunden in Hypoxie (Bedingung B, $1 \% \mathrm{O}_{2}, 5 \% \mathrm{CO}_{2}, 37^{\circ} \mathrm{C}$ ) inkubiert. (A) Zur Analyse der Endozytoseaktivität wurden die Zellen 30 Minuten vor Fixierung mit FM 1-43 angefärbt. (B) Zur Analyse der Exozytoseaktivität erfolgte die Färbung mit FM 1-43 eine Stunde vor Zellfixierung für 30 Minuten. Anschließend wurden die Zellen 30 Minuten in Fibroblasten-Wachstumsmedium inkubiert; (C) Analyse der Endozytoseaktivität nach sechs Stunden Hypoxie gefolgt von 30 Minuten Reoxygenierung in Normoxie; (D) Analyse der Exozytoseaktivität nach sechs Stunden Hypoxie gefolgt von 30 Minuten Reoxygenierung; (E) Analyse der Endozytoseaktivität nach sechs Stunden Hypoxie und zwei Stunden Reoxygenierung; (F) Analyse der Exozytoseaktivität nach sechs Stunden Hypoxie und zwei Stunden Reoxygenierung; FM 1-43: FM 1-43-Färbemedium, FWM: FibroblastenWachstumsmedium, Normox.: Normoxie, Std.: Stunden.

\subsubsection{Konfokale Mikroskopie}

Die mit FM 1-43 markierten Proben wurden durch konfokale Mikroskopie ausgewertet. Zur Exzitation wurde das $488 \mathrm{~nm}$ Spektrum eines Argon-Lasers verwendet. Die Intensität des akusto-optischen durchstimmbaren Filters (AOTF, acousto-optical tunable filter) wurde auf 30\% eingestellt. Die Leistung des Argon Lasers betrug 20\%. Emittiertes Licht der Wellenlänge 539-563 nm wurde mit einem Photoelektronenverfielfacher (PMT, photomultiplier tube) detektiert. Die Lochblende wurde auf 151,6 $\mu \mathrm{m}$ eingestellt, die Vergrößerung auf 2,5. Die 
Zeilenmittelung (line average) wurde auf 16 festgelegt, sodass jede Bildzeile 16 Mal abgelesen und anschließend gemittelt wurde, bevor die folgende Bildzeile analysiert wurde. Die Ablesegeschwindigkeit betrug $1000 \mathrm{~Hz}$, die Auflösung 8 Bit. Die PMT-Verstärkung (gain) wurde auf 927 V festgelegt. Formatbreite und Formathöhe betrugen jeweils 1024 Pixel. Bei einer Bildbreite (size-width) und Bildhöhe (size-height) von $62 \mu \mathrm{m}$ ergab sich daraus für einzelne Pixel eine Kantenlänge von 60,6 nm und eine Fläche von 3672,36 nm². Pro untersuchter Bedingung wurden mindestens zehn Bilder analysiert.

\subsubsection{Datenanalyse der Mikroskopiebilder}

Die Bilder wurden im Tagged Image File Format (TIFF) gespeichert und mit einer von Prof. Dr. Silvio O. Rizzoli (Institut für Neuro- und Sinnesphysiologie, Universitätsmedizin Göttingen) zur Verfügung gestellten Matlab-Anwendung analysiert (Revelo et al. 2014). Es wurde manuell so viel Zellfläche wie möglich zur Analyse ausgewählt. Hierbei wurde der Nukleus ausgelassen und die Bereiche von Interesse (ROI, regions of interest) streng auf intrazellulär liegende Bildabschnitte begrenzt. Die Mittelwerte der erhobenen Parameter aus allen ROI innerhalb einer Zellgruppe wurden berechnet. Analysiert wurde die Gesamtfluoreszenz FM 1-43-markierter Vesikel innerhalb einer Zelle. Diese wurden als Pixel definiert, deren FM 1-43-Fluoreszenzintensität über dem durchschnittlichen FM 1-43Fluoreszenzwert des Hintergrundes lag. Der Wert wurde in beliebigen Einheiten angegeben. Die Fluoreszenzintensität innerhalb einer Experimentgruppe wurde auf die Fluoreszenzstärke der jeweiligen Normoxiebedingung normiert. Zur Berechnung der durchschnittlichen Vesikelgröße wurde die Anzahl der Pixel innerhalb eines Vesikels berechnet. Durch Multiplikation mit der bekannten Pixelgröße von 3672,36 nm² ergab sich die Vesikelgröße in der Mikroskopie-Ebene.

\subsubsection{Statistische Analyse der FM 1-43-Färbung}

Die statistische Analyse der Daten und die Erstellung der Graphen erfolgte mit GraphPad Prism. Es sind die Mittelwerte \pm Standardfehler des Mittelwertes (SEM, standard error of the mean) angegeben. Zur Signifikanzprüfung wurden gepaarte t-Tests durchgeführt. Ergebnisse fehlerhaft durchgeführter Experimente (z. B. bei abweichenden Mikroskop-Einstellungen) wurden bei der Analyse ausgeschlossen. Eine Verblindung der Daten fand nicht statt, da Versuchsdurchführung, Mikroskopie und Datenauswertung von derselben Person durchgeführt wurden. 


\subsubsection{Proteinextraktion, Auftrennung und Western-Blot-Analyse}

\subsubsection{Proteinextraktion}

Die Zellen wurden in einer Dichte von $1,4 \times 10^{5}$ Zellen pro Vertiefung einer Sechslochplatte in Zellkulturmedium ausgesät. Am folgenden Tag wurden die Zellen in Normoxie oder Hypoxie inkubiert. Anschließend wurde das Zellkulturmedium verworfen und die Vertiefungen mit eiskaltem PBS gewaschen. Die Zellen wurden mit jeweils $100 \mu \mathrm{l}$ Zelllysepuffer pro Vertiefung lysiert und abgeschabt. Das Lysat wurde für fünf Minuten bei $4{ }^{\circ} \mathrm{C}$ und $14000 \mathrm{rpm}$ zentrifugiert. Der Überstand wurde in ein neues Reaktionsgefäß überführt.

\subsubsection{Isolierung von Membranproteinen}

Die Isolierung der Plasmamembranproteine erfolgte mithilfe des Plasma Membrane Extraction Kit der Firma Abcam weitgehend nach Herstellerprotokoll. Die adhärenten Zellen wurden zweimal mit PBS gewaschen und danach mit einem Zellschaber vom Boden der Zellkulturflasche gelöst. Nachfolgend wurde die Zellsuspension bei $3000 \mathrm{rpm}$ für fünf Minuten zentrifugiert. Das Pellet wurde mit PBS gewaschen, in $1 \mathrm{ml}$ Homogenisierungspuffer resuspendiert und mit einem eiskalten Dounce Handhomogenisatior zermahlen. Die erfolgreiche Homogenisierung wurde unter einem Lichtmikroskop durch das Verschwinden des hellen Ringes um den Zellkern in mehr als 70\%-80\% der Zellen verifiziert. Das Homogenisat wurde in ein 1,5-ml-Eppendorf-Röhrchen überführt. Abweichend vom Herstellerprotokoll wurde das Homogenisat mit $8 \mu \mathrm{l} 25 \mathrm{U} / \mu \mathrm{l}$ Benzoase bei Raumtemperatur für zehn Minuten inkubiert, um verbliebene DNA und RNA zu hydrolysieren. Anschließend wurde das Homogenisat bei $700 x$ g und $4{ }^{\circ} \mathrm{C}$ zentrifugiert. Der Überstand wurde in ein neues Eppendorf-Röhrchen (A) überführt und durch Zentrifugation für 30 Minuten bei 10.000x g und $4{ }^{\circ} \mathrm{C}$ in zytosolisches und zelluläres Membranprotein aufgetrennt. Das im Pellet abgesetzte Membranproteom wurde in $200 \mu$ l Oberphaselösung resuspendiert. Hiernach wurden $200 \mu \mathrm{l}$ Unterphaselösung hinzugegeben, die Suspension wurde vermischt und für fünf Minuten auf Eis inkubiert. In einem zweiten Eppendorf-Röhrchen (B) wurden $200 \mu \mathrm{l}$ Oberphaselösung mit $200 \mu \mathrm{l}$ Unterphaselösung vermischt. Beide Eppendorf Röhrchen wurden bei $1000 \mathrm{x}$ g, $4{ }^{\circ} \mathrm{C}$ für fünf Minuten zentrifugiert. Die Oberphase vom ersten Eppendorf Röhrchen (A) wurde in ein drittes Eppendorf Röhrchen (C) überführt und auf Eis gelagert. $100 \mu \mathrm{l}$ der Oberphase von Eppendorf Röhrchen B wurden in Eppendorf Röhrchen A überführt, mit dessen Inhalt vermischt und bei 1000x g, $4{ }^{\circ} \mathrm{C}$ für fünf Minuten zentrifugiert. Die Oberphase von Eppendorf Röhrchen A sowie $100 \mu$ der Unterphase von Eppendorf Röhrchen B wurden in Eppendorf Röhrchen C überführt. Dieses wurde hiernach bei $1000 \mathrm{x} g, 4{ }^{\circ} \mathrm{C}$ für fünf Minuten zentrifugiert. Die Oberphase wurde in ein neues Eppendorf Röhrchen (D) überführt, mit fünf Volumina $\mathrm{H}_{2} \mathrm{O}$ verdünnt und für fünf Minuten auf Eis inkubiert. Anschließend wurde Eppendorf Röhrchen D für zehn Minuten bei 
Maximalgeschwindigkeit und $4^{\circ} \mathrm{C}$ zentrifugiert. Die im Pellet abgesetzten Plasmamembranproteine wurden in $50 \mu \mathrm{l}$ PBS mit 10\% SDS resuspendiert. Die Proteinkonzentration wurde gemessen und der NuPAGE-Probenpuffer hinzugegeben.

Gleiche Mengen leicht markierten Membranproteoms bei Normoxie inkubierter Zellen und schwer markierter Zellen, die Hypoxie ausgesetzt waren, wurden gepoolt. Als Kontrollexperiment wurden identische Mengen schwer markierter Membranproteine aus Normoxiebedingungen mit leicht markierten Membranproteinen, die bei Hypoxie inkubiert wurden, zusammengegeben.

\subsubsection{Bestimmung der Proteinkonzentration}

Für die Bestimmung der Proteinkonzentration des Zelllysats wurde das DC Protein Assay Kit II (Bio-Rad GmbH, München, Deutschland) entsprechend den Herstellerangaben verwendet. Das Verfahren basiert auf dem Lowry-Assay (Lowry et al. 1951). Das Prinzip der Messung ist die Reduktion von Kupfer-(II)-Ionen zu Kupfer-(I) durch Peptidbindungen unter alkalischen Bedingungen. In einem zweiten Schritt reduziert Kupfer-(I) das FolinCiocalteau-Reagenz. Die entstehenden Reaktionsprodukte haben ein Absorptionsmaximum bei einer Wellenlänge von $\lambda=750 \mathrm{~nm}$. Die Proteinkonzentration der Probe kann daher photometrisch bezogen auf eine bovines Serumalbumin (BSA)-Standardreihe ermittelt werden. Die verwendeten Mengen der Reagenzien sind in Tabelle 10 aufgeführt. Reagenz A' wird hergestellt, indem Reagenz A und Reagenz C im Verhältnis 1:0,02 zusammengegeben werden.

Tabelle 10: Benötigte Mengen der Reagenzien zur Bestimmung der Proteinkonzentration

\begin{tabular}{|l|l|l|l|l|}
\hline Probenanzahl & $\begin{array}{l}\text { Reagenz A } \\
{[\mathrm{ml}]}\end{array}$ & $\begin{array}{l}\text { Reagenz S } \\
{[\mathrm{ml}]}\end{array}$ & $\begin{array}{l}\text { Reagenz A' } \\
{[\mathrm{ml}]}\end{array}$ & $\begin{array}{l}\text { Reagenz B } \\
{[\mathrm{ml}]}\end{array}$ \\
\hline 2 & 0,5882 & 0,0118 & 0,6 & 4,8 \\
\hline 4 & 0,6862 & 0,0137 & 0,7 & 5,6 \\
\hline 8 & 0,8824 & 0,0176 & 0,9 & 7,2 \\
\hline
\end{tabular}

Die Berechnung der Proteinkonzentration erfolgte bezogen auf eine Standardreihe von 0,5 bis $5 \mu \mathrm{g}$ BSA. Standardreihe und $2 \mu \mathrm{l}$ Zelllysat wurden in Duplikaten auf eine Mikrotiterplatte ausgebracht. Pro Vertiefung wurden $25 \mu \mathrm{l}$ von Reagenz A' sowie $200 \mu \mathrm{l}$ von Reagenz B hinzugegeben. Die Proben wurden mit der Mixfunktion des Microplate Readers für fünf Sekunden gemischt. Nach 15 Minuten wurde die Photoabsorption bei $750 \mathrm{~nm}$ gemessen.

\subsubsection{Natriumdodecylsulfat Polyacrylamid-Gelelektrophorese}

Die Natriumdodecylsulfat Polyacrylamid-Gelelektrophorese (SDS PAGE, sodium dodecyl sulfate polyacrylamide gel electrophoresis) ist ein Verfahren, um Proteine im elektrischen Feld beim Durchwandern eines Polyacrylamid-Maschenwerks der Größe nach zu trennen (Laemmli 1970). Das negativ geladene Detergens SDS wird verwendet, um durch Interaktion mit den nicht-kovalenten Bindungen die Sekundärstruktur der Proteine aufzubrechen, die entfalteten 
Moleküle zu ummanteln und mit einer homogenen Negativladung zu versehen. Disulphidbrücken können durch Zugabe von 2-Merkaptoethanol aufgebrochen werden.

Die Verwendung eines diskontinuierlichen Gels, bestehend aus einem Sammel- und einem Trenngel, verbessert die räumliche Auftrennung der Proteine. Während das Sammelgel mit einer 1,5-molaren Tris(hydroxymethyl)-aminomethan (TRIS)-HCL Pufferlösung auf einen $\mathrm{pH}$ von 6,8 eingestellt wird, liegt der $\mathrm{pH}$ des Trenngels durch Zugabe eines 1-molaren TRISHCL Puffers bei 8,8. Die Gelzusammensetzungen sind in Tabelle 11 aufgeführt.

Tabelle 11: Bestandteile eines Polyacrylamid-Gels

\begin{tabular}{|l|l|l|l|}
\hline \multirow{2}{*}{ Bestandteile } & \multicolumn{2}{|l|}{ Trenngel } & Sammelgel \\
\cline { 2 - 4 } & $\begin{array}{l}\mathbf{1 0 \%} \text { Acrylamid } \\
{[\mathbf{m l}]}\end{array}$ & $\begin{array}{l}\mathbf{1 2} \% \text { Acrylamid } \\
{[\mathbf{m l}]}\end{array}$ & $\begin{array}{l}\mathbf{5 \%} \text { Acrylamid } \\
{[\mathbf{m l}]}\end{array}$ \\
\hline $\mathrm{H}_{2} \mathrm{O}$ & 11,9 & 9,9 & 6,8 \\
\hline $30 \%$ Acrylamid/Bisacrylamid & 10 & 12 & 1,7 \\
\hline $10 \%$ SDS & 0,3 & 0,3 & 0,1 \\
\hline $10 \%$ APS & 0,3 & 0,3 & 0,1 \\
\hline TEMED & 0,012 & 0,012 & 0,01 \\
\hline 1,5 M TRIS $(\mathrm{pH} 8,8)$ & 7,5 & 7,5 & \\
\hline 1,0 TRIS $(\mathrm{pH} 6,8)$ & & & 1,25 \\
\hline Gesamtvolumen & $\mathbf{3 0 , 0 1 2}$ & $\mathbf{3 0 , 0 1 2}$ & $\mathbf{9 , 9 6}$ \\
\hline
\end{tabular}

APS: Ammoniumpersulfat, SDS: Natriumdodecylsulfat, TEMED: Tetraethylmethyldiamin

Durch den niedrigeren $\mathrm{pH}$-Wert liegen Glyzinmoleküle im Ladegel überwiegend in ihrer ungeladenen Form vor und wandern im elektrischen Feld langsamer als die Protein-SDS Komplexe. Diese werden durch die erhöhte elektrische Spannung in Richtung Anode beschleunigt und an der Grenze zur vorauslaufenden Chlorid-Ionenfront zu einer scharfen Bande konzentriert. Mit Erreichen des Trenngels geben die Glyzinmoleküle im basischen Milieu überwiegend Protonen ab und überholen als Glyzinat-Ionen aufgrund ihrer geringeren Größe die Protein-SDS Komplexe. Diese bewegen sich abhängig von ihrer Größe unterschiedlich schnell zur Anode, sodass eine räumliche Auftrennung erreicht wird.

Es wurde ein diskontinuierliches Gel aus einem 5\% Acrylamid Sammelgel und einem 10\% oder 12\% Acrylamid Trenngel verwendet. 10\% Acrylamid Gele wurden für den Nachweis von HIF1- $\alpha$ genutzt. Je 70-100 $\mu$ g Protein wurden in 2 x SDS Probenpuffer aufgenommen, durch fünfminütiges Erhitzen auf $95{ }^{\circ} \mathrm{C}$ denaturiert und auf das sich in $1 \mathrm{x}$ SDS Elektrophoresepuffer befindende Gel aufgetragen. Zur Größenbestimmung der Proteine wurde der PageRuler-Proteinmarker in eine separate Geltasche aufgetragen. Die SDS PAGE wurde durch Anlegen von Gleichstrom mit 40-60 mA pro Gel und maximal $300 \mathrm{~V}$ durchgeführt. Membranproteine wurden für zehn Minuten auf $75{ }^{\circ} \mathrm{C}$ erhitzt und auf 4-12\% NuPAGE BisTris Minigelen aufgetrennt. 


\subsubsection{Western Blot}

Beim Western Blot handelt es sich um ein Protein-Immunoblotverfahren. Es wird durchgeführt, um die Expression eines Proteins in einer Probe nachzuweisen und relativ zu anderen Proteinen zu quantifizieren (Towbin et al. 1979; Burnette 1981). Hierfür werden die zuvor in einer SDS PAGE der Größe nach aufgetrennten Proteine vom Polyacrylamid-Gel auf eine Nitrozellulosemembran übertragen, wo sie durch Antikörper-Konjugate gebunden werden können. Die Übertragung erfolgte durch Elektrotransfer (semi-dry Elektroblotting) bei $2 \mathrm{~mA} / \mathrm{cm}^{2}$ über 60 Minuten. Das Polyacrylamidgel, Filterpapier und Nitrozellulosemembran wurden in Transferpuffer getränkt und zwischen Kathode und Anode eines PerfectBlue Semi Dry-Blotters gestapelt. Die durch SDS-Ummantelung mit einer negativen Ladung versehenen Proteine wanderten im elektrischen Feld aus dem Gel zur Anode und ließen sich so auf die Nitrozellulosemembran übertragen. Die Membran wurde hiernach für fünf Minuten mit Ponceau-S-Färbelösung inkubiert, um den erfolgreichen Proteintransfer zu verifizieren. Durch Waschen mit PBS wurde die reversibel bindende Ponceau-SFärbelösung von der Membran entfernt. Um unspezifische Bindungsstellen auf der Nitrozellulosemembran vor der Anwendung von Antikörpern zu blockieren, wurde diese für 60 Minuten bei Raumtemperatur in einer 5\% Milchpulverlösung in PBS inkubiert.

Der primäre Antikörper wurde in einer Lösung von 5\% Milchpulver in PBS in der angegebenen Konzentration (Tabelle 7) mit $125 \mu \mathrm{l}$ 2\% Natriumazid bei $4{ }^{\circ} \mathrm{C}$ über Nacht inkubiert. Nicht bindende Antikörper wurden am nächsten Morgen durch drei je zehnminütige Waschschritte mit PBS entfernt. Hiernach wurde die Membran mit dem in der angegeben Konzentration (Tabelle 8) in 5\% Milchpulver in PBS gelösten sekundären Antikörper für zwei Stunden bei Raumtemperatur inkubiert. Der sekundäre Antikörper ist gegen den primären Antikörper gerichtet und an Meerrettich-Peroxidase konjugiert. Die Membran wurde dreimal für jeweils zehn Minuten mit PBS gewaschen für weitere zehn Minuten in ECL-Lösung inkubiert.

Die Meerrettich-Peroxidase katalysiert in Anwesenheit von Wasserstoffperoxid die Chemilumineszenzreaktion von Luminol und anderen Bestandteilen der ECL-Lösung. Die Bildauswertung erfolgte mit dem LAS-3000 Imager. 


\subsubsection{SILAC-Markierung, Zellmembranisolierung und Proteomanalyse}

\subsubsection{SILAC-Markierung}

SILAC ist ein Verfahren zur Quantifizierung unterschiedlicher Proteinexpression unter verschiedenen Inkubationsbedingungen (Ong et al. 2002). Es umfasst einen Markierungsschritt, in dem isotopenmarkierte Aminosäuren in die Zellen inkorporiert werden, die Extraktion des markierten Zellproteoms, die Auftrennung durch gepoolte Gelelektrophorese sowie die massenspektrometrische Identifikation der extrahierten Proteine und Quantifizierung der unterschiedlichen Expressionsmuster. Die selektive Inkorporation von schwer bzw. leicht markierten Aminosäuren in Proben der Versuchs- und Kontrollbedingung führt zu einer messbaren und bekannten Massendifferenz der markierten Proteine, ohne deren chemische Eigenschaften zu verändern.

Verglichen wurde das Membranproteom von Kardiofibroblasten neonataler Ratten, die bei Normoxie $\left(20 \% \mathrm{O}_{2}\right)$ bzw. für sechs Stunden bei Hypoxie $\left(1 \% \mathrm{O}_{2}\right)$ inkubiert wurden. Hierzu wurden mit primären Kardiofibroblasten bewachsene $25 \mathrm{~cm}$ Zellkulturplatten verwendet. Die Kultivierung erfolgte mit SILAC-Medium, das entweder normales, „leichtes“ ${ }^{12} \mathrm{C}_{6}{ }^{14} \mathrm{~N}_{4}$ L-Arginin und ${ }^{12} \mathrm{C}_{6}{ }^{14} \mathrm{~N}_{2}$ L-Lysin oder mit stabilen Isotopen markiertes ${ }^{13} \mathrm{C}_{6}{ }^{15} \mathrm{~N}_{4} \mathrm{~L}$-Arginin und ${ }^{13} \mathrm{C}_{6}{ }^{15} \mathrm{~N}_{2}$ L-Lysin enthielt (Tabelle 2). Um Kontamination mit unmarkierten Aminosäuren auszuschließen, wurde für SILAC-Versuche dialysiertes FKS verwendet. Durch die Zugabe von Prolin wurde die Konversion von Arginin zu Prolin verhindert (Lössner et al. 2011). Die Zellen wurden bei Konfluenz in $175 \mathrm{~cm}$ Zellkulturflaschen passagiert und danach so gesplittet, dass nach der dritten Passagierung je 40 Zellkulturflaschen mit schwer bzw. leicht markierten Zellen für den Versuch verwendet werden konnten. Nach Erreichen von 70\% Konfluenz wurden die Zellen für je sechs Stunden in Normoxie bzw. Hypoxie inkubiert. Das Experiment wurde doppelt ausgeführt, sodass leicht markierte Zellen, die unter Normoxie inkubiert wurden, mit schwer markierten Zellen verglichen wurden, die Hypoxie ausgesetzt waren. Umgekehrt wurden schwer markierte Zellen, die unter Normoxie inkubiert wurden, mit leicht markierten Zellen verglichen, die Hypoxie ausgesetzt waren. Nach der sechsstündigen Inkubation wurden die Plasmamembranproteine isoliert (Abbildung 4). 


\title{
Primäre Kardiofibroblasten von neonatalen Ratten
}

\author{
$\sum_{\text {leicht }} \sum_{\text {schwer }}$ \\ 3 Passagen $\quad \begin{array}{ll}{ }^{14} \mathrm{~N}_{2}{ }^{12} \mathrm{C}_{6} \text { - Lysin } & { }^{15} \mathrm{~N}_{2}{ }^{13} \mathrm{C}_{6} \text { - Lysin (Lys8) } \\ { }^{14} \mathrm{~N}_{4}{ }^{12} \mathrm{C}_{6} \text { - Arginin }{ }^{15} \mathrm{~N}_{4}{ }^{13} \mathrm{C}_{6} \text { - Arginin (Arg10) }\end{array}$
}

$20 \% \mathrm{O}_{2}$ für 6 Std. $1 \% \mathrm{O}_{2}$ für 6 Std

Isolierung von Membranproteinen und Membran-assoziierten Proteinen

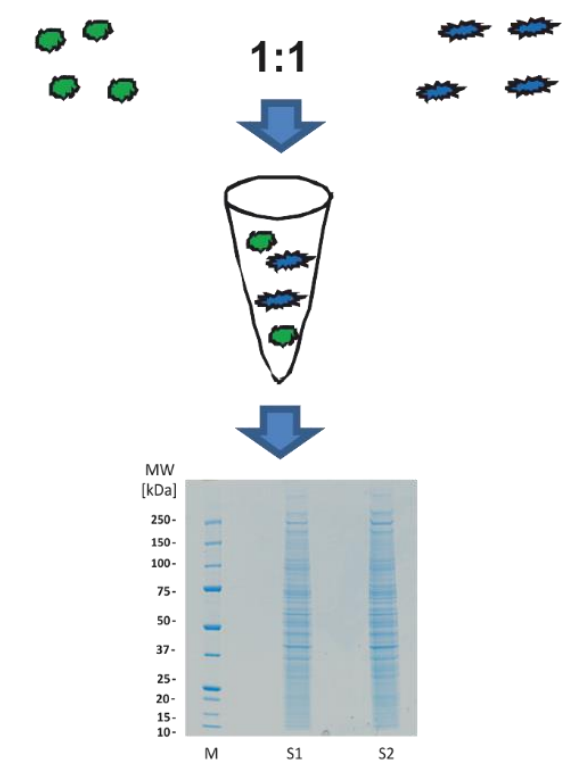

Trypsinierung im Gel

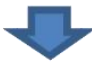

Nano LC-MS/MS

\section{Analysierte Bedingungen}

$20 \% \mathrm{O}_{2}$ vs. $1 \% \mathrm{O}_{2}, 6 \mathrm{Std}$.

\begin{abstract}
Abbildung 4: Versuchsaufbau der quantitativen Proteom-Analyse mittels SILACMarkierung. Primäre Kardiofibroblasten neonataler Ratten (Rattus norvegicus) wurden für die SILACMarkierung (stable isotope labeling with amino acids in cell culture, stabile Isotopenmarkierung mit Aminosäuren in Zellkultur) über drei Passagen mit den schwer oder leicht markierten Aminosäuren Lysin und Arginin inkubiert. Die Zellmembranfraktion der Zellen wurde nach sechs Stunden Inkubation bei Hypoxie $\left(1 \% \mathrm{O}_{2}\right)$ bzw. Normoxie $\left(20 \% \mathrm{O}_{2}\right)$ isoliert. Gleiche Mengen schwer markierter Proteine aus hypoxischen Zellen und leicht markierten Proteinen aus bei Normoxie inkubierten Zellen wurden gepoolt durch Gelelektrophorese aufgetrennt. Jede Spur des Gels wurde in 23 Stücke unterteilt und im Gel trypsiniert. Die Identifikation der Proteine erfolgte mittels Flüssigchromatographie mit Tandem-Massenspektrometrie Kopplung (LC-MS/MS). M: Marker des Molekulargewichtes; MW: molecular weight (Molekulargewicht); S1: Spur 1; S2: Spur 2.
\end{abstract}




\subsubsection{Massenspektrometrische Proteomanalyse}

Um Unterschiede in der Membranproteinexpression zu quantifizieren, wurde durch die Arbeitsgruppe „Bioanalytische Massenspektrometrie“ von Prof. Dr. H. Urlaub (Max-PlanckInstitut für biophysikalische Chemie, Göttingen) eine gelverstärkte Flüssigchromatographie mit Tandem-Massenspektrometrie (GeLC-MS/MS, gel-enhanced liquid chromatography-tandem mass spectrometry) durchgeführt. Zunächst wurden die gepoolten, unterschiedlich markierten Proteine aus Hypoxie und Normoxie in einer eindimensionalen SDS PAGE auf 4-12\% NuPAGE Bis-Tris Minigelen anhand ihrer Größe aufgetrennt (Abbildung 5).

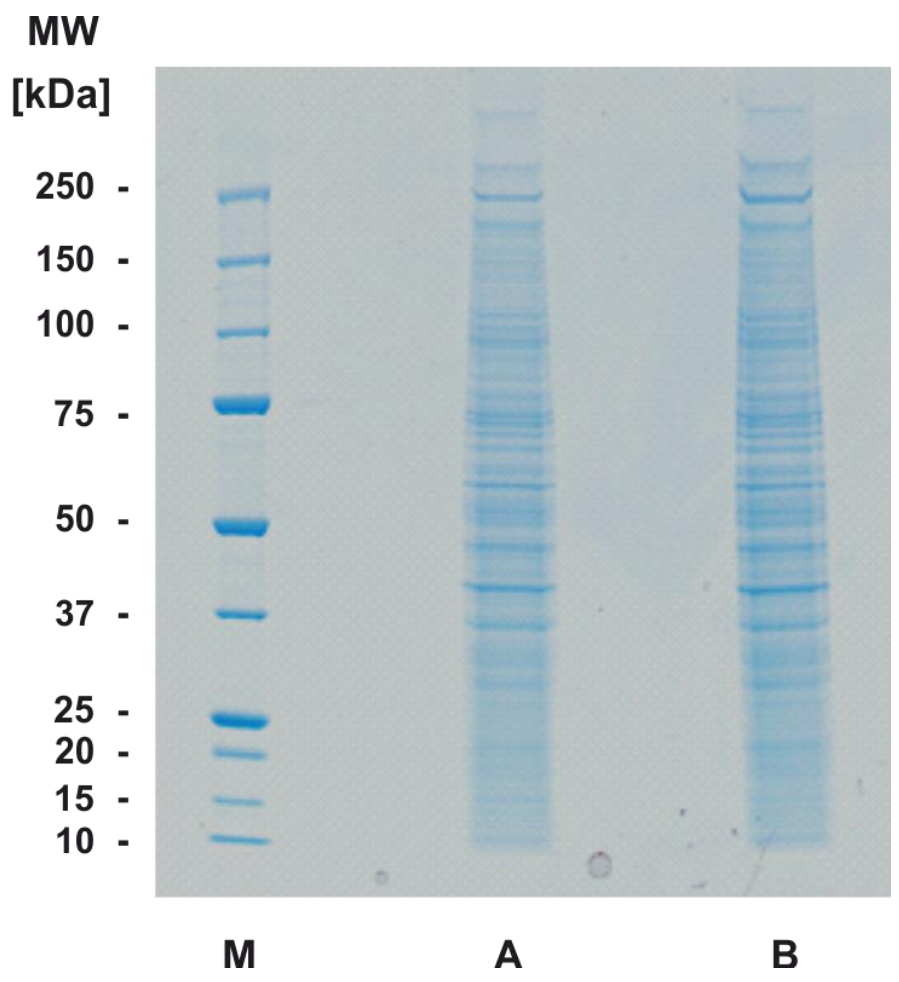

Abbildung 5: Coomassie-Brillant-Blau-Färbung der aufgetrennten Membranproteine und Membran-assoziierten Proteine nach SILAC-Markierung. Spur A enthielt im Verhältnis 1:1 gepoolte Zellmembranproteine aus mit schweren Aminosäuren markierten Zellen, die für sechs Stunden bei Hypoxie inkubiert wurden, und aus mit leichten Aminosäuren markierten Zellen, die unter normoxischen Bedingungen inkubiert wurden. Spur B enthielt gepoolte Zellmembranproteine aus mit leichten Aminosäuren markierten Zellen, die für sechs Stunden bei Hypoxie inkubiert wurden, und aus mit schweren Aminosäuren markierten Zellen, die bei Normoxie inkubiert wurden. M bezeichnet eine Spur mit einem Indikator des Molekulargewichts. MW: molecular weight (Molekulargewicht), SILAC: stable isotope labeling with amino acids in cell culture (stabile Isotopenmarkierung mit Aminosäuren in Zellkultur).

Die Gele wurden nach einem Protokoll von Schmidt und Urlaub (2009) zur Visualisierung der aufgetrennten Proteine mit Coomassie-Brillant-Blau gefärbt und jede Proteinspur in 23 gleich große Stücke zerteilt. Die Zerteilung erfolgte unabhängig vom Färbungsmuster der jeweiligen Spur. Hiernach wurde das Gel gewaschen. Um die SH-Gruppen der Proteine vor Oxidation zu schützen, wurde das Gel mit Dithiothreitol (DT'T) reduziert. Ribonukleasen und Enzyme mit Zystein im aktiven Zentrum wurden durch Alkylierung mit Iodoazetamid irreversibel inhibiert. Die Proteine wurden durch Zugabe von Trypsin über Nacht gespalten. 
Trypsin ist eine Endoprotease mit Serin im aktiven Zentrum, die hinter den basischen Aminosäuren Lysin und Arginin spaltet, sodass sich am C-terminalen Ende der entstehenden Peptide eine markierte Aminosäure befindet, die zudem im sauren Milieu Protonen akzeptiert und die Ionisierung begünstigt. Die trypsinierten Peptide wurden anschließend extrahiert, in einem SpeedVac-Konzentrator getrocknet, in 2\% Azetonitril/1\% Ameisensäure rekonstituiert und durch nanoLC-MS/MS analysiert (Atanassov und Urlaub 2013). Hierzu wurden die Peptide in einer selbst gepackten Säule mithilfe eines Umkehrphasemechanismus (reversed phase) angereichert (Tabelle 12). Die stationäre Phase bestand dabei aus mit langkettigen Alkylgruppen beschichteten Kieselerdepartikeln, die die Elution polarer Bestandteile begünstigten. Die Auftrennung erfolgte an einer analytischen Umkehrphase-Säule mithilfe eines 37-minütigen linearen Gradienten von 5-35\% Azetonitril/0,1\% Ameisensäure bei $300 \mathrm{nl} / \mathrm{min}$.

Tabelle 12: Säulen in der nanoLC

\begin{tabular}{|l|l|l|l|l|}
\hline Säule & $\begin{array}{l}\text { Höhe } \\
{[\mathbf{c m}]}\end{array}$ & $\begin{array}{l}\text { Innendurchmesser } \\
{[\mu \mathrm{m}]}\end{array}$ & Stationäre Phase & $\begin{array}{l}\text { Partikelgröße } \\
{[\mu \mathrm{m}]}\end{array}$ \\
\hline Sammelsäule & 2 & 150 & $\begin{array}{l}\text { Reprosil-Pur120 } \\
\text { C18-AQ, Dr. Maisch, } \\
\text { Deutschland }\end{array}$ & 5 \\
\hline $\begin{array}{l}\text { Trennsäule Picofrit } \\
\text { 360-20-10-N, New } \\
\text { Objective }\end{array}$ & 20 & 75 & $\begin{array}{l}\text { Reprosil-Pur120 } \\
\text { C18-AQ, Dr. Maisch, } \\
\text { Deutschland }\end{array}$ & 3 \\
\hline
\end{tabular}

LC: liquid chromatograpby (Dünnschichtchromatographie)

Das Eluat wurde mit einem Q Exactive Hybrid-Quadrupol-Orbitrap Massenspektrometer analysiert, das mit einer FlexIon nanoSpray Quelle ausgestattet war. Die Datensammlung erfolgte als Daten-abhängige Akquise (DDA, data-dependent acquisition). Bei der DDA wird eine feste Anzahl von Peptidfragmenten mit bekannten Verhältnissen von Masse zu Ladung (m/z-Verhältnissen) weiter analysiert (Mann et al. 2001). In jedem Durchgang wurde ein gesamter MS-Scan über den Bereich 350-1600 m/z bei einer Auflösung von 70.000 Halbwertsbreiten und einem automatischen Gain Kontrollziel von $10 \mathrm{e}^{6}$ durchgeführt. Bei einer maximalen Füllungszeit von 60 Millisekunden wurden die bis zu zehn häufigsten Peptidvorstufen mit einer Ladung von zwei bis fünf über einer $10 \mathrm{e}^{4}$ Intensitätsschwelle mit einer Isolationsbreite von 2,0 m/z selektiert. Die Peptidvorstufen wurden durch higher energy collision dissociation (HCD, durch Kollisionen mit höherer Energie induzierte Dissoziation) mit Stickstoff bei einer normierten Kollisionsenergie von $25 \%$ fragmentiert. Ihre Produktionsspektra wurden ab einer Masse von $100 \mathrm{~m} / \mathrm{z}$, einer Auflösung von 17.500 Halbwertsbreiten, einem Gain Ziel von $2 \times 10 e^{5}$ und einer maximalen Füllungszeit von 60 Millisekunden registriert. Ausgewählte $\mathrm{m} / \mathrm{z}$ Werte der Vorstufen wurden danach für die folgenden 15 Sekunden ausgeschlossen. Je Probe wurden drei technische Replikate durchgeführt. 


\subsubsection{Datenanalyse des SILAC-Screens}

Die Identifikation und Quantifizierung des Proteoms erfolgte mithilfe der MaxQuandt Software. Die Proteinidentifikation erfolgte mit dem UniProtKB Swiss-Prot Referenzproteom und der MaxQuandt Datenbank häufiger Verunreinigungen. Die Enzymspezifität wurde bei maximal zwei ausgelassenen Schnittstellen auf Trypsin/P festgelegt. Als variable Modifikationen wurden N-terminale Azetylierung des Proteins sowie Oxidation von Methionin bestimmt. Aufgrund der Probenaufbereitung wurden K und R SILAC-Markierungen sowie Zystein-Carbamidomethylierung als feste Modifizierungen festgelegt. Der Instrumententyp wurde auf „Orbitrap“ eingestellt. Hieraus folgte eine Suchtoleranz von 20 Millionstel (ppm, parts per million) in der ersten Peptidsuche, 4,5 ppm in der zentralen Peptidsuche und 0,6 Da in der MS/MS Suche. Zusätzlich wurde die Requantifizierungsoption (requantify) für die SILAC-Quantifizierung genutzt. Die Datenbanksuchergebnisse wurden mit einem Filter von 1\% Falschpositivrate (FDR, false discovery rate) sowohl auf Peptid- als auch auf Proteinebene belegt. Alle Datenpakete von jeder biologischen Probe wurden für die Verarbeitung als einzelne Experimente zusammengefasst. Die quantitative und statistische Auswertung erfolgte mit der Anwendung Perseus. Aus dem MaxQuandt Proteingruppen-Ordner wurden mit Microsoft Excel die auf die jeweils andere Markierungsgruppe normierten Signalintensitäten ausgelesen. Nach Ausschluss doppelt gezählter und kontaminierter Messwerte wurden die Ergebnisse auf Kongruenz zwischen den beiden spiegelbildlichen Versuchsanordnungen geprüft. Hierzu wurden die Daten in GraphPad Prism $\log _{2}$-transformiert und in einem zweidimensionalen Streudiagramm gegeneinander aufgetragen. Durch Berechnung der Pearson-Korrelation wurden die Ergebnisse aus beiden Versuchen auf Kongruenz geprüft.

Die Intensität, die für ein Proteinspektrum gemessen wird, repräsentiert die jeweilige Expressionshäufigkeit in der Probe. Da jede Proteinspur im Gel unterschiedlich markierte Proteine sowohl aus hypoxischen Zellen als auch aus der Normoxie-Kontrollgruppe enthielt, reflektiert der Quotient der Signalintensität korrespondierender leicht und schwer markierter Proteinspektren Unterschiede in ihrer jeweiligen Expression. Zur Identifikation der unter Hypoxie vermehrt vorhandenen Membranproteine wurde ein doppelter Intensitätsquotienten-Schwellenwert angesetzt. Als unter Hypoxie vermehrt vorhanden galten Proteine bei einem Quotienten von $>1,5$ in Experiment A und parallel <0,67 in Experiment B. Als unter Hypoxie vermindert vorhanden galten Proteine bei einem Intensitätsquotienten von $>1,5$ in Experiment B und <0,67 in Experiment A. Proteine, die dieser Definition entsprachen, wurden anhand des Protein ANalysis Through Evolutionary RelationshipsKlassifikationssystems (PANTHER, Proteinanalyse durch evolutionäre Verbindungen) eingeordnet (Thomas et al. 2003; Mi et al. 2013; Mi et al. 2017). Zur manuellen Auswertung der unterschiedlich häufig vorhandenen Proteine wurde die UniProtKB-Datenbank genutzt (Bateman et al. 2017). Die Suche nach den Proteinen erfolgte anhand ihrer jeweiligen UniProt-Zugangsnummer. Als G-Proteine und mit G-Proteinen interagierend wurden Proteine klassifiziert, deren molekulare Funktion in der Genontologie (GO)-Datenbank 
(Ashburner et al. 2000; The Gene Ontology Consortium 2017) mit den in Tabelle 13 aufgeführten Begriffen verschlagwortet waren.

Tabelle 13: Schlagworte, die in der manuellen Auswertung des SILAC-Screens zur Einordnung der unterschiedlich häufig vorhandenen Proteine als G-Proteine oder mit G-Proteinen interagierend verwendet wurden.

\begin{tabular}{|l|l|}
\hline Schlagwort & Deutsche Übersetzung \\
\hline Rab-guanyl nucleotide exchange factor activity & Rab-Guanyl-Austauschfaktoraktivität \\
\hline Rac GTPase-binding & Rac GTPase-bindend \\
\hline G-protein beta-subunit-binding & G-Protein beta-Untereinheit-bindend \\
\hline G-protein coupled receptor-binding & G-Protein-gekoppelten Rezeptor-bindend \\
\hline GDP-binding & GDP-bindend \\
\hline GTP-binding & GTP-bindend \\
\hline GTPase activator activity & GTPase Aktivatoraktivität \\
\hline GTPase activity & GTPase Aktivität \\
\hline Rho guanyl-nucleotide exchange factor activity & Rho-Guanyl-Austauschfaktoraktivität \\
\hline
\end{tabular}

GDP: Guanosindiphosphat, GTP: Guanosintriphosphat, Rab: Ras-related in Brain, Rac: Ras-related C3 botulinum toxin substrate 


\section{Ergebnisse}

Kardiofibroblasten bilden im Herzen gemeinsam mit Kardiomyozyten die numerisch größte Zellpopulation. Durch Sekretion und Abbau von Bestandteilen der extrazellulären Matrix, autokriner und parakriner Sekretion von Wachstumsfaktoren sowie direkten Zell-ZellInteraktionen sind sie von zentraler Bedeutung für Entwicklung, Funktion und Remodeling des Myokards. Diese Vorgänge sind abhängig vom zellulären Membranverkehr und werden durch die Plasmamembran vermittelt. Diese Arbeit soll den Einfluss verminderter $\mathrm{O}_{2}{ }^{-}$ Verfügbarkeit auf den Gesamtmembranverkehr von Kardiofibroblasten untersuchen.

\subsection{Analyse des Gesamtmembranverkehrs von Fibroblasten unter Hypoxie}

\subsubsection{Inkubation von Kardiofibroblasten bei Hypoxie für sechs Stunden führt zur Stabilisierung von HIF-1 $\alpha$}

Die zelluläre Adaptation an verminderte $\mathrm{O}_{2}$-Verfügbarkeit wird wesentlich durch HIFTranskriptionsfaktoren reguliert. HIF-Transkriptionsfaktoren sind heterodimere Proteine, die aus einer konstitutiv exprimierten $\beta$-Untereinheit (HIF- $\beta$ ) und einer $\mathrm{O}_{2}$-regulierten $\alpha$-Untereinheit $(\mathrm{HIF}-\alpha)$ bestehen. Bei hohem $\mathrm{O}_{2}$-Angebot wird HIF- $\alpha$ durch PHD-Enzyme hydroxyliert und proteasomal abgebaut. Bei $\mathrm{O}_{2}$-Mangel unterbleibt der Abbau von HIF- $\alpha$. Nach Heterodimerisierung mit HIF- $\beta$ erfolgt die Bindung an HRE der DNA und die Transkription der Zielgene. Unter den drei Isoformen von HIF- $\alpha$ wird nur HIF-1 $\alpha$ in allen kernhaltigen Zellen exprimiert. Gleichzeitig ist HIF-1 $\alpha$ in der kurzfristigen Anpassung an $\mathrm{O}_{2}$-Mangel von zentraler Bedeutung.

In einer Proteinanalyse mittels Western Blot zeigte sich eine vermehrte Stabilisierung von HIF-1 $\alpha$ in Kardiofibroblasten nach Inkubation in Hypoxie $\left(1 \% \mathrm{O}_{2}\right)$ für sechs Stunden (Abbildung 6).

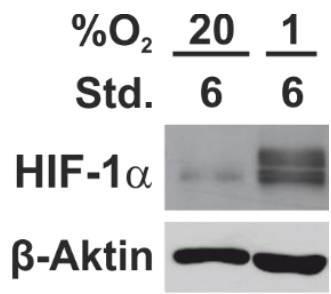

Abbildung 6: Nachweis von HIF-1 $\alpha$ in Kardiofibroblasten durch Western-Blot-Analyse nach sechsstündiger Inkubation unter Hypoxie. Primäre Kardiofibroblasten wurden für sechs Stunden bei Normoxie $\left(20 \% \mathrm{O}_{2}\right)$ bzw. Hypoxie $\left(1 \% \mathrm{O}_{2}\right)$ inkubiert. HIF-1 $\alpha$ wurde durch Western Blot im Proteinlysat der Zellen nachgewiesen. Die Ladungskontrolle erfolgte durch den Nachweis von $\beta$-Aktin. Std.: Stunden. 


\subsubsection{Kardiofibroblasten zeigen unter Hypoxie in der Analyse der Endozytose eine verstärkte FM 1-43-Fluoreszenz und eine veränderte Morphologie intrazellulärer Vesikel}

Um die Auswirkungen eines verminderten $\mathrm{O}_{2}$-Angebots auf den Membranverkehr von Kardiofibroblasten zu untersuchen, wurden Membranfärbungen mit FM 1-43 bei Normoxie $\left(20 \% \mathrm{O}_{2}\right)$ und Hypoxie $\left(1 \% \mathrm{O}_{2}\right)$ durchgeführt. Der Farbstoff inkorporiert in das äußere Blatt der Plasmamembran und wird durch Endozytose unabhängig von spezifischen Mechanismen aufgenommen. Alle Organellen, die in diesen Membranfluss eingebunden sind, werden hierdurch angefärbt. Der Farbstoff zeigt im unpolaren Milieu einer Lipidmembran eine um mehr als zwei Größenordnungen stärkere Fluoreszenz als in einem polaren Lösungsmittel wie dem Zytosol. Eine positiv geladene Kopfdomäne verhindert das Durchwandern von Lipidmembranen und somit die Akkumulation in nicht am Membranverkehr beteiligten Kompartimenten. Die Abgabe des Farbstoffes kann somit nur im Rahmen der Exozytose durch den Transport markierter intrazellulär Membranabschnitte zur Plasmamembran erfolgen. Nicht internalisierter Farbstoff wurde nach der Inkubation durch Waschen entfernt, sodass die analysierte Zellfluoreszenz das Gleichgewicht endozytotischer und exozytotischer Prozesse widerspiegelt.

Nach sechsstündiger Inkubation unter Hypoxie zeigte sich in der Darstellung der Endozytose eine verstärkte FM 1-43-Fluoreszenz im Vergleich zu bei Normoxie inkubierten Zellen (Abbildung 7 A und B). Zum Ausschluss unspezifischer Farbstoffakkumulation und zum Nachweis der Zellvitalität wurde die Exozytoseaktivität analysiert. Hierzu wurde die Zellen nach Anfärbung in farbstofffreiem Zellkulturmedium inkubiert. Es zeigte sich in diesem Ansatz sowohl in Hypoxie als auch in Normoxie eine geringere FM 1-43-Fluoreszenz als in der Analyse der Endozytose.

Unter Hypoxie zeigte sich in der Endozytose zudem eine veränderte Vesikelmorphologie mit vermehrten tubulären Strukturen und durchschnittlich um etwa 38\% größeren Vesikeln (Abbildung 7 A und $\mathbf{C}$ ). 


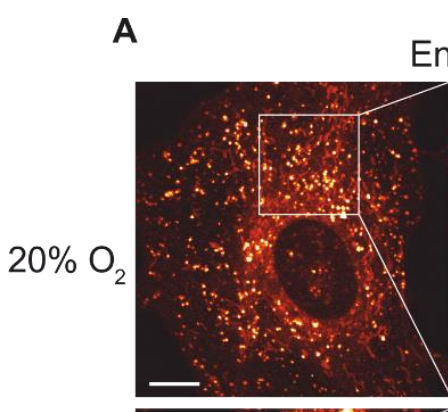

Endo

Exo
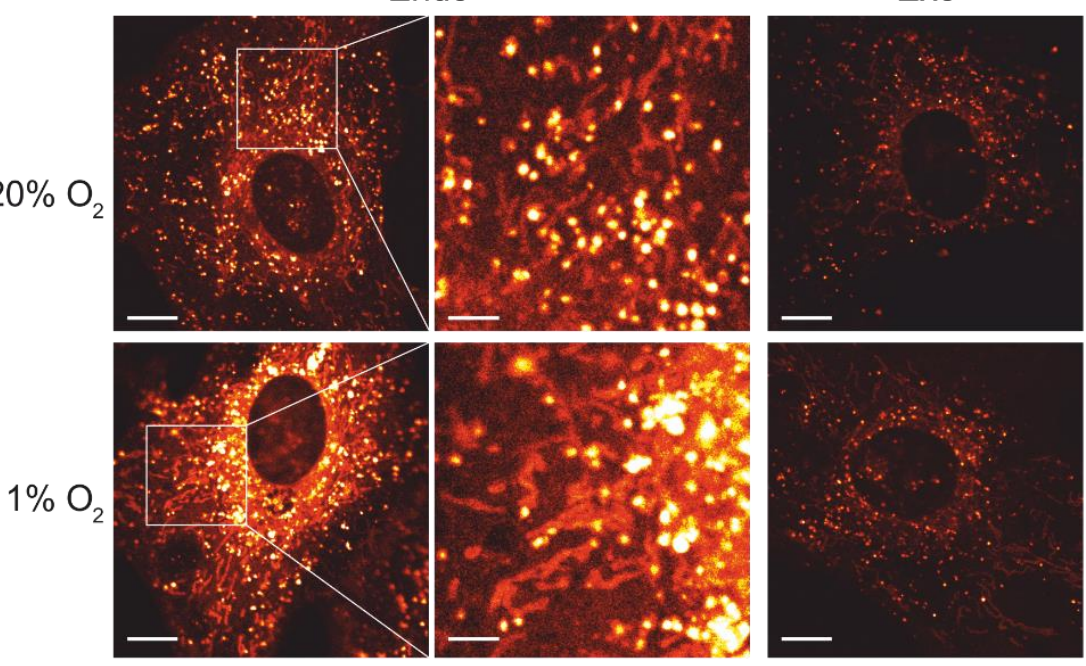

B
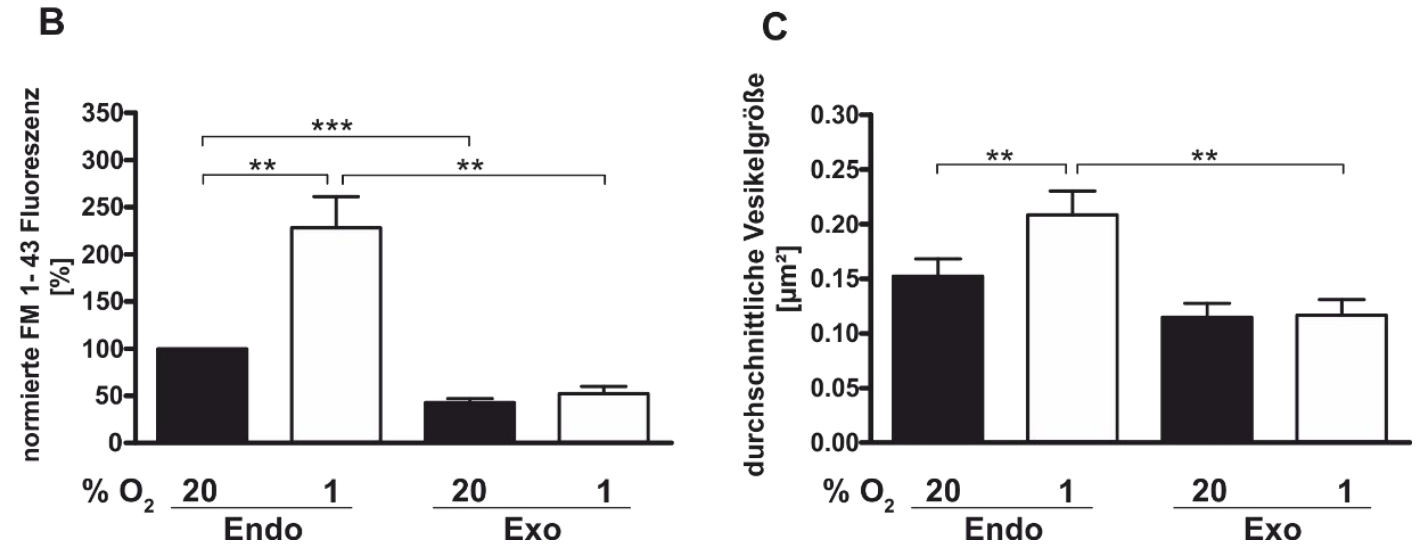

Abbildung 7: FM 1-43-Färbung von Kardiofibroblasten unter Normoxie und Hypoxie. Kardiofibroblasten neonataler Ratten wurden für sechs Stunden bei Normoxie $\left(20 \% \mathrm{O}_{2}\right)$ oder Hypoxie $\left(1 \% \mathrm{O}_{2}\right)$ inkubiert. Endo- und Exozytose wurden durch Membranfärbungen mit FM 1-43 quantifiziert. (A) Repräsentative Fluoreszenzbilder. (B) Fluoreszenz der Zellen normiert auf Fluoreszenz bei Endozytose in Normoxie. (C) Durchschnittliche Vesikelgröße. Sieben unabhängige Versuche. Skala: $10 \mu \mathrm{m}$; $1 \mu \mathrm{m}$ in Vergrößerung. Endo: Endozytose, Exo: Exozytose. Abhängiger tTest; * $\mathrm{p}<0,05$; ** $\mathrm{p}<0,005$; *** $\mathrm{p}<0,001$. Fehlerbalken entsprechen dem Standardfehler des Mittelwertes. 


\subsubsection{Inkubation von Schwanzfibroblasten bei Hypoxie für sechs Stunden führt zur Stabilisierung von HIF-1 $\alpha$}

Fibroblasten zeigen je nach topographischer Herkunft heterogene Genexpressionsmuster und damit einhergehend unterschiedliche Differenzierungen. Um zu untersuchen, ob der bei Kardiofibroblasten beobachtete Phänotyp spezifisch für diesen Zelltyp ist oder sich auch bei Fibroblasten aus anderen Geweben nachweisen lässt, wurden aus Rattenschwänzen gewonnene Fibroblasten untersucht.

In der Western Blot Analyse zeigte sich eine vermehrte Stabilisierung von HIF-1 $\alpha$ nach sechsstündiger Inkubation unter Hypoxie $\left(1 \% \mathrm{O}_{2}\right)$ verglichen mit der Normoxiekontrolle (20\% $\mathrm{O}_{2}$, Abbildung 8).

$\% \mathrm{O}_{2} \underline{20} \frac{1}{6}$

Std. $6 \quad 6$

HIF-1 $\alpha$

$\beta$-Aktin

Abbildung 8: Nachweis von HIF-1 $\alpha$ in Schwanzfibroblasten durch Western-Blot-Analyse nach sechsstündiger Inkubation unter Hypoxie. Primäre Schwanzfibroblasten wurden für sechs Stunden bei Normoxie $\left(20 \% \mathrm{O}_{2}\right)$ bzw. Hypoxie $\left(1 \% \mathrm{O}_{2}\right)$ inkubiert. HIF-1 $\alpha$ wurde durch Western Blot im Proteinlysat der Zellen nachgewiesen. Die Ladungskontrolle erfolgte durch den Nachweis von $\beta$-Aktin. Std.: Stunden. 


\subsubsection{Schwanzfibroblasten zeigen unter Hypoxie in der Analyse der Endozytose eine erhöhte FM 1-43-Fluoreszenz und eine veränderte Morphologie intrazellulärer Vesikel}

Zur Analyse des Gesamtmembranverkehrs bei aus Rattenschwänzen isolierten Fibroblasten wurden FM 1-43-Färbungen durchgeführt. Verglichen mit bei Normoxie $\left(\begin{array}{lll}20 \% & \mathrm{O}_{2}\end{array}\right)$ inkubierten Zellen zeigte sich in der Analyse der Endozytose nach sechsstündiger Inkubation unter Hypoxie $\left(1 \% \mathrm{O}_{2}\right)$ eine verstärkte Farbstofffluoreszenz (Abbildung 9 A und $\left.\mathbf{B}\right)$. In der Analyse der Exozytose war die FM 1-43-Fluoreszenz im Vergleich zur Endozytose in beiden Gruppen vermindert.

Unter Hypoxie zeigte sich in der Endozytose auch bei Schwanzfibroblasten eine veränderte Morphologie der intrazellulären Vesikel (Abbildung 9 A und C). Es traten vermehrt tubuläre Strukturen auf, und die Vesikel waren im Durchschnitt etwa 33\% größer als unter Normoxie. In der Exozytoseanalyse war die Vesikelgröße sowohl unter Normoxie als auch unter Hypoxie geringer als in der Endozytose.

A

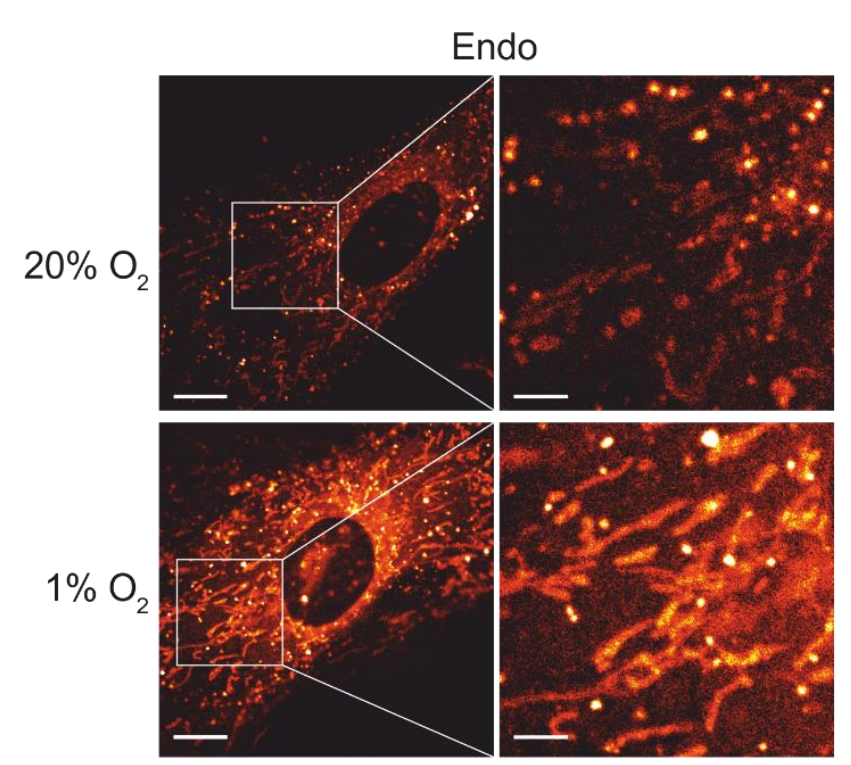

B

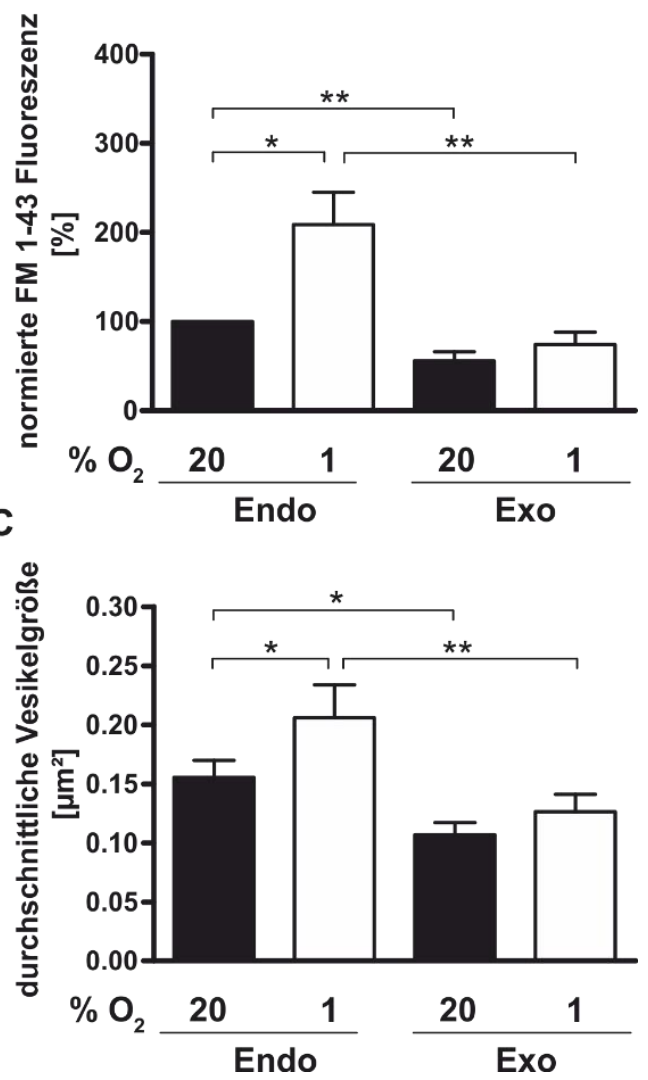

Abbildung 9: FM 1-43-Färbung von Schwanzfibroblasten in Normoxie und Hypoxie. Schwanzfibroblasten neonataler Ratten wurden für sechs Stunden bei Normoxie $\left(20 \% \mathrm{O}_{2}\right)$ oder Hypoxie $\left(1 \% \mathrm{O}_{2}\right)$ inkubiert. Endo- und Exozytose wurden durch Membranfärbungen mit FM 1-43 analysiert. (A) Repräsentative Fluoreszenzbilder. (B) Fluoreszenz der Zelle normiert auf Fluoreszenz bei Endozytose in Normoxie. (C) Durchschnittliche Vesikelgröße. Sieben unabhängige Versuche. Skala: $10 \mu \mathrm{m}, 1 \mu \mathrm{m}$ in Vergrößerung. Endo: Endozytose, Exo: Exozytose. Abhängiger t-Test; ${ }^{*} \mathrm{p}<0,05 ;{ }^{* *} \mathrm{p}<0,005$. Fehlerbalken entsprechen dem Standardfehler des Mittelwertes. 


\subsubsection{Die Stabilisierung von HIF-1 $\alpha$ ist in Kardiofibroblasten durch Reoxygenierung reversibel}

Um die Reversibilität des beobachteten Hypoxie-induzierten Phänotyps zu prüfen, wurden Kardiofibroblasten nach sechsstündiger Inkubation unter Hypoxie $\left(1 \% \mathrm{O}_{2}\right)$ für 30 Minuten bzw. zwei Stunden bei Normoxie $\left(20 \% \mathrm{O}_{2}\right)$ reoxygeniert.

In der Western Blot Analyse war HIF-1 $\alpha$ nach 30 Minuten Reoxygenierung nicht nachweisbar und somit in geringerer Menge stabilisiert als bei Zellen der Hypoxiebedingung (Abbildung 10). Nach zwei Stunden Reoxygenierung war eine etwas geringere Menge HIF$1 \alpha$ als in der Normoxiekontrolle nachweisbar.

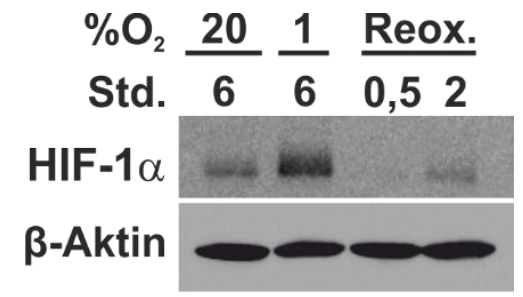

Abbildung 10: Nachweis von HIF-1 $\alpha$ in Kardiofibroblasten durch Western-Blot-Analyse nach sechsstündiger Inkubation unter Hypoxie und nach anschließender Reoxygenierung. Primäre Kardiofibroblasten wurden für sechs Stunden bei Normoxie $\left(20 \% \mathrm{O}_{2}\right)$ bzw. Hypoxie $(1 \%$ $\mathrm{O}_{2}$ ) inkubiert und entweder sofort für die Analyse aufbereitet oder für 30 Minuten bzw. zwei Stunden bei Normoxie reoxygeniert. HIF-1 $\alpha$ wurde durch Western Blot im Proteinlysat der Zellen nachgewiesen. Die Ladungskontrolle erfolgte durch den Nachweis von $\beta$-Aktin. Reox.: Reoxygenierung, Std.: Stunden.

\subsubsection{Veränderungen der unter Hypoxie beobachteten FM 1-43-Fluoreszenz und Vesikelgröße sind in Kardiofibroblasten nach Reoxygenierung vollständig reversibel}

Die Reversibilität der unter Hypoxie beobachteten Veränderungen von FM 1-43Fluoreszenz und Vesikelmorphologie wurde in FM 1-43-Membranfärbungen von Kardiofibroblasten geprüft. Hierzu wurden zusätzlich zur Untersuchung von unter Normoxie $\left(20 \% \mathrm{O}_{2}\right)$ und für sechs Stunden unter Hypoxie (1\% O2) inkubierten Zellen zwei Versuchsgruppen im Anschluss an eine sechsstündige Hypoxie für 30 Minuten bzw. zwei Stunden bei Normoxie reoxygeniert.

Hierbei zeigte sich bereits nach 30 Minuten Reoxygenierung ein Rückgang der in der Analyse der Endozytose unter Hypoxie vermehrten FM 1-43-Fluoreszenz auf einen nicht signifikant von der Normoxiekontrolle verschiedenen Wert (Abbildung 11 A und B). Spätestens nach zwei Stunden Reoxygenierung lag die Fluoreszenz auf dem Niveau der Normoxiekontrolle.

Die in der Analyse der Endozytose unter Hypoxie beobachtete Größenzunahme intrazellulärer Vesikel war ebenfalls nach 30 Minuten Reoxygenierung nicht mehr nachweisbar (Abbildung 11 A und C). Auch nach zwei Stunden Reoxygenierung war die durchschnittliche Vesikelgröße auf dem Niveau der Normoxiekontrolle. 

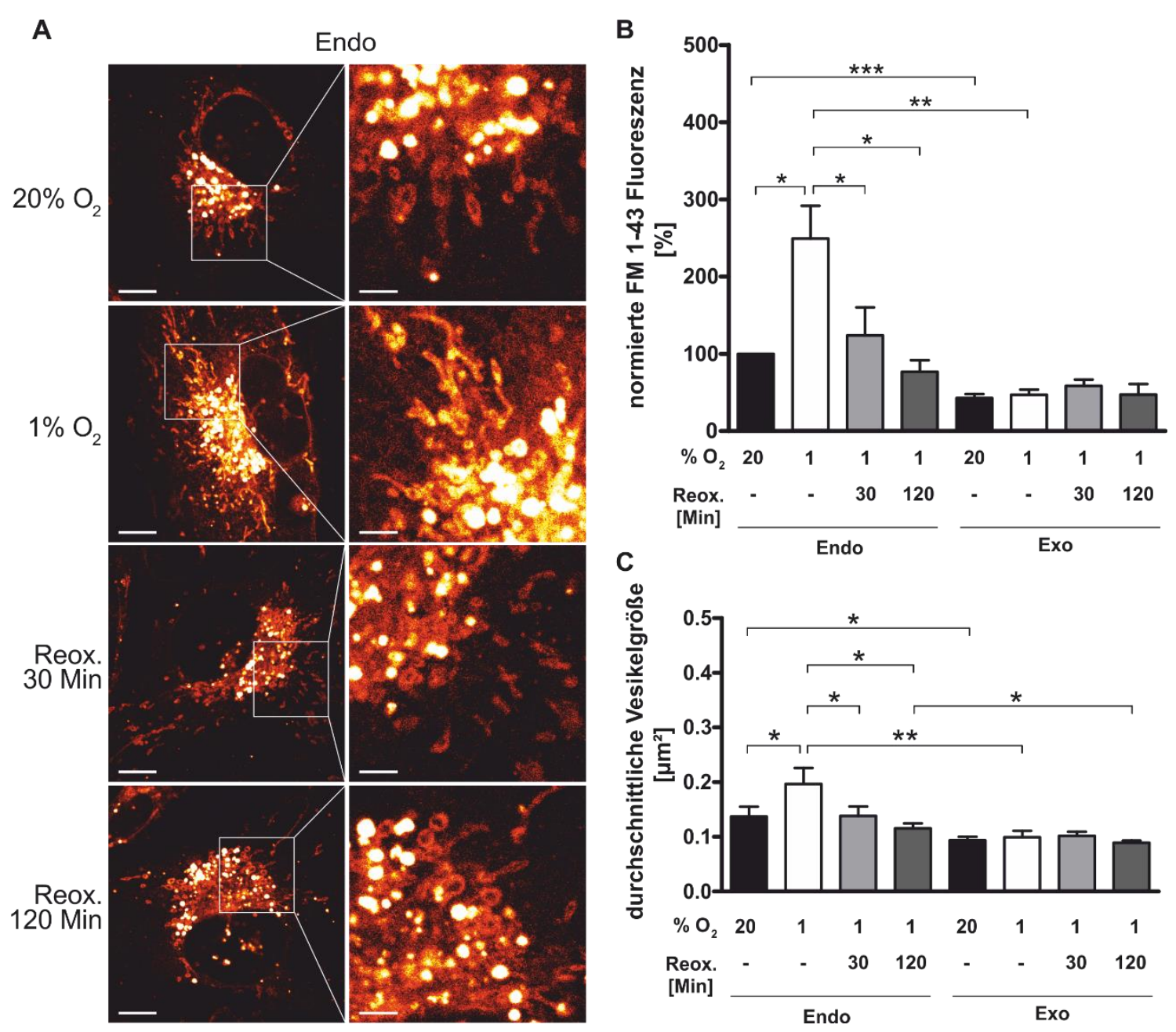

Abbildung 11: FM 1-43-Färbung von Kardiofibroblasten in Normoxie, Hypoxie und nach Reoxygenierung. Kardiofibroblasten von neonatalen Ratten wurden für sechs Stunden bei Normoxie $\left(20 \% \mathrm{O}_{2}\right)$ oder Hypoxie $\left(1 \% \mathrm{O}_{2}\right)$ inkubiert. Die Zellen wurden entweder direkt fixiert oder für 30 Minuten bzw. zwei Stunden bei $20 \% \mathrm{O}_{2}$ reoxygeniert. Endo- und Exozytose wurden durch Membranfärbung mit FM 1-43 analysiert. (A) Repräsentative Fluoreszenzbilder. (B) Fluoreszenz der Zellen normiert auf Fluoreszenz bei Endozytose in Normoxie. (C) Durchschnittliche Vesikelgröße. Fünf unabhängige Versuche. Skala: $10 \mu \mathrm{m}, 1 \mu \mathrm{m}$ in Vergrößerung. Endo: Endozytose, Exo: Exozytose, Reox.: Reoxygenierung. Abhängiger t-Test; ${ }^{*} \mathrm{p}<0,05$; ${ }^{* *} \mathrm{p}<0,005$; ${ }^{* * *} \mathrm{p}<0,001$. Fehlerbalken entsprechen dem Standardfehler des Mittelwertes. 


\subsection{Analyse des Plasmamembranproteoms von Kardiofibroblasten unter Normoxie und Hypoxie}

Vor dem Hintergrund der in FM 1-43-Versuchen beobachteten erhöhten Farbstofffluoreszenz von Fibroblasten unter Hypoxie wurde das Membranproteom von primären Kardiofibroblasten mithilfe eines SILAC-Screens analysiert. Hierzu wurden isotopenmarkierte Aminosäuren während der Wachstumspassagen in die Zellen inkorporiert. Die Fibroblasten wurden unter Normoxie $\left(20 \% \mathrm{O}_{2}\right)$ bzw. für sechs Stunden unter Hypoxie $(1 \%$ $\mathrm{O}_{2}$ ) inkubiert. Anschließend wurden die Zellmembranproteine isoliert, gleiche Mengen schwer markierter Membranproteine aus hypoxischen Zellen mit leicht markierten Membranproteinen unter Normoxie inkubierter Zellen zusammengegeben und durch SDS PAGE gemeinsam aufgetrennt (Experiment A). In einem parallelen Versuch wurden schwer markierte Membranproteine von bei Normoxie inkubierten Zellen mit leicht markierten Proteinen von bei Hypoxie inkubierten Zellen zusammengegeben und gemeinsam durch SDS PAGE aufgetrennt (Experiment B). Nach Trypsinierung der Proteine im Gel wurden die entstandenen Peptide massenspektrometrisch analysiert und bioinformatisch identifiziert. Da in beiden Experimenten Membranproteine aus Hypoxie und Normoxie analysiert wurden, die anhand ihrer Markierung der jeweiligen Inkubationsbedingung zuzuordnen waren, konnte eine Normierung auf die jeweils andere Gruppe erfolgen. Die Intensitätsverhältnisse von schwer zu leicht markierten Proteinen wurden analysiert.

\subsubsection{Ergebnisse des SILAC-Screens}

In den beiden parallelen Versuchen wurden 3.501 bzw. 3.430 Proteine identifiziert. Hiervon wurden 2.645 in beiden Versuchen übereinstimmend gefunden. Die normierten Signalintensitäten der übereinstimmend identifizierten Proteine in Experiment A wurden gegen die normierten Signalintensitäten der entsprechenden Proteine in Experiment B aufgetragen (Abbildung 12 A). Zur besseren Übersicht wurden die Werte vorher logarithmisch transformiert. Aufgrund des spiegelbildlichen Versuchsaufbaus war in dieser Auftragung eine negative inverse Korrelation der normierten Signalintensitäten der schwer zu leicht markierten Peptide eines Proteins in den beiden Experimenten zu erwarten. Es wurden eine lineare Regressionsgerade mit einer Steigung von -0,17 berechnet und zur Analyse der Korrelation beider Experimente Pearsons R (Korrelationskoeffizient nach Pearson) mit 0,25 bestimmt. Zudem wurde die Gesamtsignalintensität aller Peptide eines Proteins unabhängig von der jeweiligen Isotopenmarkierung gegen die normierte Signalintensität des Proteins in Experiment A und Experiment B aufgetragen (Abbildung 12 B). Auch diese Daten wurden zur besseren Lesbarkeit zuvor logarithmisch transformiert. Es zeigte sich eine grob symmetrische Verteilung der normierten Signalintensitäten in Experiment A und B mit den meisten Werten zwischen $2^{-1}$ und $2^{1}$. Die größte Verdichtung der normierten Signalintensitätswerte lag nach visueller Abschätzung etwa im Bereich zwischen $2^{-0,6}$ und $2^{0,6}$. Die Werte der Gesamtsignalintensität waren über vier Zehnerpotenzen verteilt. 


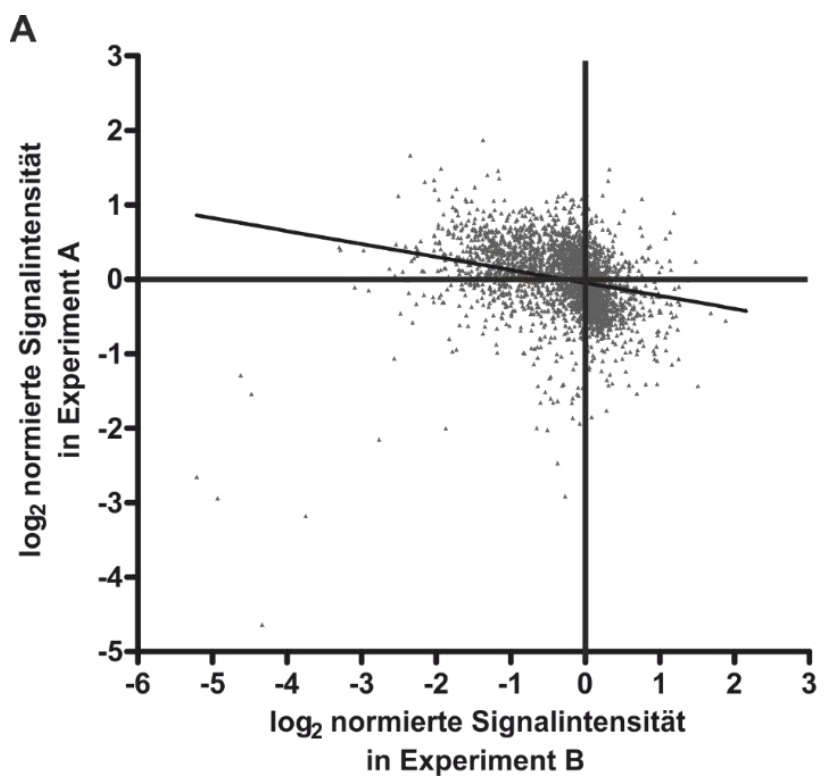

B

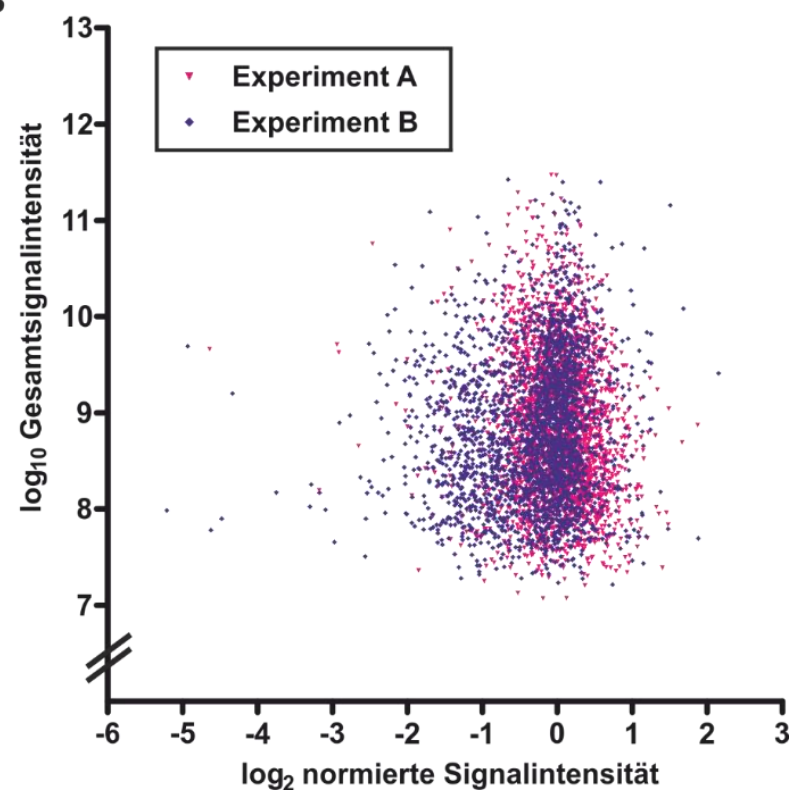

Abbildung 12: Ergebnisse des SILAC-Screens. Isotopenmarkierte Aminosäuren wurden in primäre Kardiofibroblasten neonataler Ratten inkorporiert. Die Zellen wurden für sechs Stunden bei Hypoxie $\left(1 \% \mathrm{O}_{2}\right)$ oder Normoxie $\left(20 \% \mathrm{O}_{2}\right)$ inkubiert. Anschließend wurden die Plasmamembranproteine extrahiert. Gleiche Mengen schwer markierter Membranproteinfraktion aus bei Hypoxie inkubierten Zellen und leicht markierter Membranproteinfraktion aus bei Normoxie inkubierten Zellen wurden zusammengegeben und durch SDS PAGE gemeinsam aufgetrennt (Experiment A). Parallel wurden schwer markierte Membranproteine von bei Normoxie inkubierten Zellen mit leicht markierten Proteinen von bei Hypoxie inkubierten Zellen zusammengegeben und gemeinsam durch SDS PAGE aufgetrennt (Experiment B). Nach Trypsinierung im Gel wurden die Peptide massenspektrometrisch analysiert und bioinformatisch identifiziert. 2645 in beiden Experimenten identifizierte Proteine wurden weiter analysiert. (A) Das Verhältnis der Signalintensitäten der schwer bzw. leicht markierten Proteine in Experiment A zu den Signalintensitäten der Proteine in Experiment B wurde logarithmisch transformiert gegeneinander aufgetragen. Es wurde eine lineare Regressionsgerade mit Steigung von $-0,17$ berechnet, $\mathrm{p}<0,0001$. Zur Prüfung der Korrelation der Daten wurde Pearsons R (Korrelationskoeffizient nach Pearson) mit -0,25 berechnet, $\mathrm{p}<0,001$. (B) Die logarithmisch transformierten Werte der Signalintensitäten wurden gegen die Gesamtsignalintensität aller Peptide eines Proteins jeweils in Experiment A und Experiment B aufgetragen. 
Die logarithmisch transformierten normierten Signalintensitäten schwer und leicht markierter Membranproteine in Experiment A und B wurden gemeinsam in einem Histogramm dargestellt (Abbildung 13). Es war eine Normalverteilung des $\log _{2}$ der normierten Signalintensität um null zu erwarten. Im D'Agostino-Pearson-Test konnte eine Normalverteilung jedoch nicht bestätigt werden. Eine mögliche Erklärung war die scheinbar linksschiefe Verteilung der Daten. Aufgrund der spiegelbildlichen Versuchsanordnung von Experiment A und Experiment B wäre eine symmetrische Verteilung der ermittelten Werte zu erwarten gewesen. Bei perfekter Symmetrie beträgt die Schiefe der Daten annähernd null. Für das Experiment wurde eine Schiefe von -1,339 berechnet.

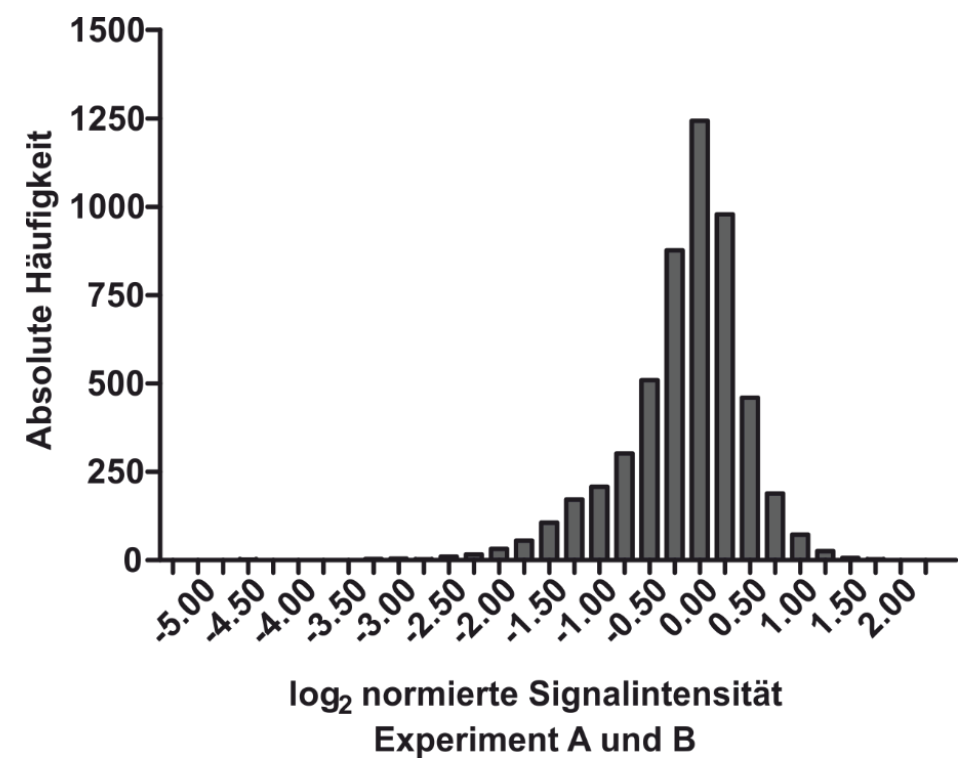

\begin{abstract}
Abbildung 13: Histogramm der normierten Signalintensitäten im SILAC-Screen identifizierter Proteine. Isotopenmarkierte Plasmamembranproteine von für sechs Stunden bei Normoxie $\left(20 \%\right.$ O2) oder Hypoxie $\left(1 \% \mathrm{O}_{2}\right)$ inkubierten Kardiofibroblasten wurden gepoolt durch SDS PAGE aufgetrennt und massenspektrometrisch analysiert. Experiment A: Schwer markierte Proteine von bei Hypoxie inkubierten Zellen und leicht markierte Proteine bei Normoxie inkubierter Zellen. Experiment B: schwer markierte Proteine bei Normoxie inkubierter Zellen und leicht markierte Proteine bei Hypoxie inkubierter Zellen. Die Signalintensität schwer markierter Proteine wurde auf die Signalintensität leicht markierter Proteine normiert und logarithmisch transformiert. 2.645 in beiden Experimenten übereinstimmend identifizierte Proteine. 5.290 Werte, Median: -0,05, Minimum: -5,21, Maximum: 2,15, 25\% Perzentile: -0,42, 75\% Perzentile: 0,21; D'Agostino-PearsonTest ohne Nachweis einer Normalverteilung ( $p<0,0001)$, Schiefe: $-1,339$.
\end{abstract}

Zur Analyse des Effektes von Hypoxie auf das Plasmamembranproteom der Fibroblasten wurde ein doppelter Schwellenwert für die normierte Signalintensität definiert. In Übereinstimmung mit der beobachteten Häufung von Werten im Bereich von $2^{-0,6}$ und $2^{0,6}$ (Abbildung 12) wurden Proteine bei einer normierten Signalintensität von $>1,5$ in Experiment A und parallel $<0,67$ in Experiment B als Hypoxie-abhängig vermehrt in der Zellmembran vorhanden definiert. Als unter Hypoxie vermindert vorhanden galten Proteine bei einem Intensitätsquotienten von $>1,5$ in Experiment B und $<0,67$ in Experiment A. 140 Proteine galten nach dieser Definition als unter Hypoxie vermehrt vorhanden, 29 als unter Hypoxie reduziert (Abbildung 14, Anhang 1, Anhang 2). 
A

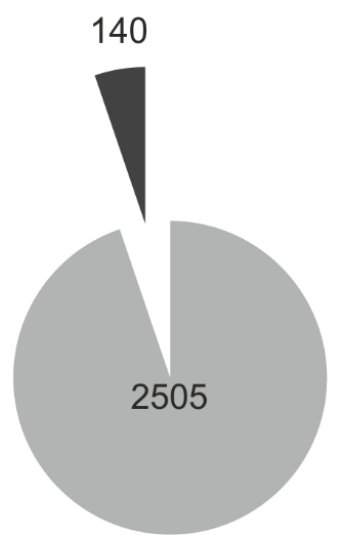

B

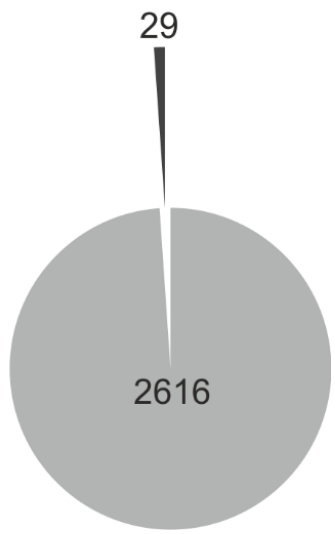

Abbildung 14: Im SILAC-Screen Hypoxie-abhängig differenziell identifizierte Proteine. Plasmamembranproteine von Kardiofibroblasten neonataler Ratten wurden nach sechsstündiger Inkubation unter Normoxie $\left(20 \% \mathrm{O}_{2}\right)$ oder Hypoxie $\left(\begin{array}{lll}1 \% & \mathrm{O}_{2}\end{array}\right)$ in einem SILAC-Screen massenspektrometrisch analysiert. In zwei parallelen Versuchen wurden schwer markierte Membranproteine aus bei Hypoxie inkubierten Zellen gemeinsam mit leicht markierten Proteinen aus der Normoxiekontrolle (Experiment A) sowie schwer markierte Proteine aus bei Normoxie inkubierten Zellen gemeinsam mit leicht markierten Proteinen aus hypoxischen Zellen analysiert (Experiment B). Als unter Hypoxie vermehrt in der Plasmamembran vorhanden wurden Proteine mit einem Quotienten von schwer zu leicht markierten Proteinen $>1,5$ in Experiment A und gleichzeitig $<0,67$ in Experiment B definiert. Proteine mit einem Signalintensitätsquotienten schwer zu leicht markierter Proteine $<0,67$ in Experiment A und $>1,5$ in Experiment B wurden als unter Hypoxie in der Plasmamembran vermindert vorhanden betrachtet. Es wurden 2.645 Proteine übereinstimmend in beiden Experimenten identifiziert. (A) 140 Proteine waren unter Hypoxie in der Membran vermehrt vorhanden. (B) 29 Proteine waren unter Hypoxie in der Plasmamembran vermindert vorhanden. 


\subsubsection{Klassifikation im SILAC-Screen Hypoxie-abhängig differenziell identifizierter Proteine}

3.2.2.1 PANTHER-Datenbank-Klassifikation unter Hypoxie vermehrt identifizierter Proteine

Um die unter Hypoxie vermehrt identifizierten Proteine näher einzuordnen, wurden sie anhand ihrer UniProt-Zugangsnummer mit der Datenbank des PANTHERKlassifikationssystems abgeglichen. Von 140 unter Hypoxie vermehrt identifizierten Proteinen waren 111 (79\%) in der PANTHER-Datenbank verzeichnet. 73 Proteine (52\%) konnten einer Proteinklasse zugeordnet werden (Abbildung 15). Es wurden 20 verschiede Proteinklassen identifiziert. Die größten Gruppen waren hierbei die Hydrolasen, Zytoskelettproteine, Enzymmodulatoren und Chaperons, denen mehr als ein Drittel der Proteine zugeordnet wurde.

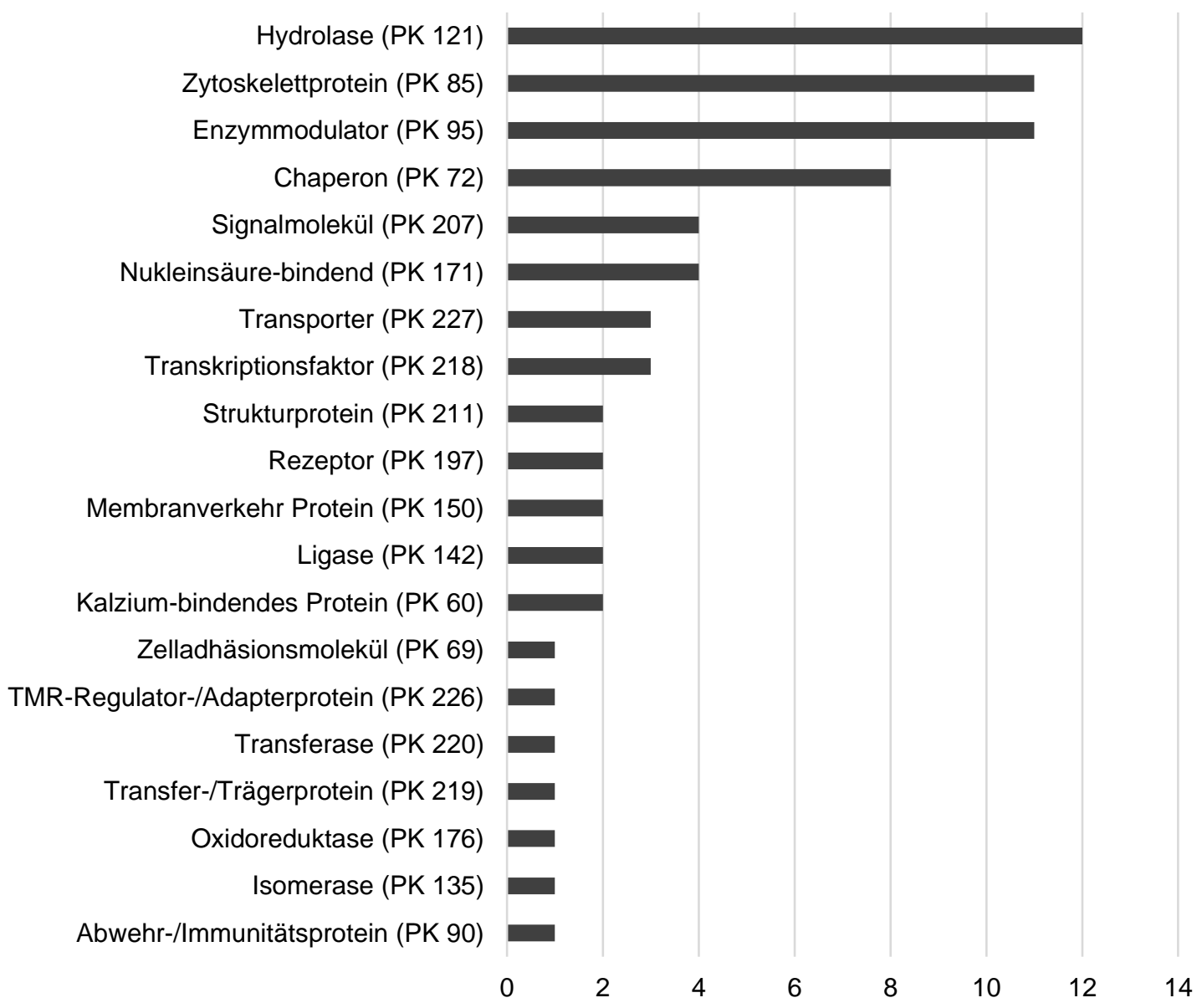

Abbildung 15: PANTHER-Datenbank-Klassifikation der im SILAC-Screen unter Hypoxie vermehrt identifizierten Proteine. $140 \mathrm{im}$ SILAC-Screen unter Hypoxie vermehrt identifizierte Proteine wurden über die PANTHER (Protein ANalysis THrough Evolutionary Relationships)-Datenbank klassifiziert. 111 Proteine wurden in der Datenbank anhand ihrer UniProt-Zugangsnummer gefunden, 73 hiervon konnten einer Proteinklasse zugeordnet werden. Die absolute Anzahl der Proteine einer Klasse sind im Diagramm angegeben. PK: PANTHER-Klassifikationsnummer, TMR: Transmembranrezeptor. 
3.2.2.2 PANTHER-Klassifikation unter Hypoxie vermindert identifizierter Membranproteine

Die im SILAC-Screen als unter Hypoxie vermindert identifizierten Proteine wurden anhand ihrer UniProt-Zugangsnummer mit der Datenbank des PATHER-Klassifikationssystems abgeglichen (Abbildung 16). Von 29 Proteinen waren 23 (79\%) in der PANTHERDatenbank verzeichnet. 16 (55\%) dieser Proteine konnten einer Proteinklasse zugeordnet werden.

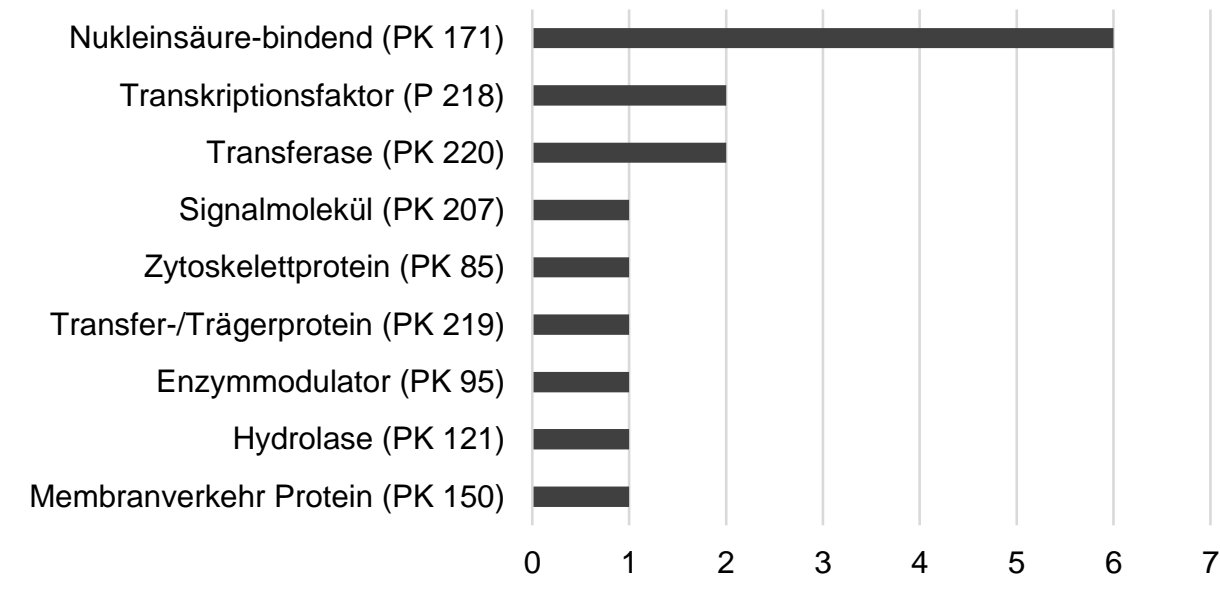

Abbildung 16: PANTHER-Datenbank-Klassifikation der im SILAC-Screen unter Hypoxie vermindert identifizierten Proteine. 29 im SILAC-Screen unter Hypoxie vermindert identifizierte Proteine wurden über die PANTHER (Protein ANalysis THrough Evolutionary Relationships)-Datenbank klassifiziert. 23 Proteine wurden in der Datenbank anhand ihrer UniProt-Zugangsnummer gefunden, 16 hiervon konnten einer Proteinklasse zugeordnet werden. Die absolute Anzahl der Proteine einer Klasse sind im Diagramm angegeben. PK: PANTHER-Klassifikationsnummer.

3.2.2.3 Manuelle Auswertung der im SILAC-Screen unter Hypoxie vermehrt identifizierten Proteine

Aufgrund der unvollständigen Klassifikation der identifizierten Proteine mithilfe der PANTHER-Datenbank erfolgte eine manuelle Auswertung der nachgewiesenen Proteine. In der Durchsicht der nicht in der Datenbank verzeichneten unter Hypoxie häufiger identifizierten Proteine fiel ein großer Anteil von im Zusammenhang mit dem intrazellulären Vesikelverkehr beschriebenen kleinen, monomeren G-Proteinen wie Arf4 und Arf5 auf. Hiervon ausgehend wurden die Hypoxie-abhängig vermehrt identifizierten Proteine mithilfe der UniProtKB-Datenbank manuell eingeordnet. Von den 140 unter Hypoxie vermehrt identifizierten Proteinen waren $79(56 \%)$ als mit Membranen assoziierte Proteine verzeichnet, davon 45 als mit der Plasmamembran assoziiert. Dies entspricht 32\% der unter Hypoxie vermehrt identifizierten Proteine. Insgesamt 27 der 140 Proteine (19\%) konnten anhand ihrer zugeordneten molekularen Funktion als G-Proteine oder mit G-Proteinen interagierend eingeordnet werden (Tabelle 14). 
Tabelle 14: G-Proteine und mit G-Proteinen interagierende Proteine, die im SILAC-Screen konsistent unter Hypoxie um mindestens 50\% vermehrt in bzw. assoziiert mit der Plasmamembran von Kardiofibroblasten neonataler Ratten nachgewiesen wurden

\begin{tabular}{|c|c|c|c|c|}
\hline Protein & $\begin{array}{l}\text { Gen- } \\
\text { Name }\end{array}$ & $\begin{array}{l}\text { UniProt- } \\
\text { Zugangsnr. }\end{array}$ & $\begin{array}{l}\text { Normierte } \\
\text { Signal- } \\
\text { intensität } \\
\text { in Exp. A }\end{array}$ & $\begin{array}{l}\text { Normierte } \\
\text { Signal- } \\
\text { intensität } \\
\text { in Exp. B }\end{array}$ \\
\hline $\begin{array}{l}\text { Arf-GAP domain and FG repeat-containing } \\
\text { protein } 1\end{array}$ & Agfg1 & Q4KLH5 & 1,527 & 0,569 \\
\hline A-kinase Ankerprotein 5 & Akap5 & P24587 & 1,754 & 0,387 \\
\hline ADP-Ribosylierungsfaktor 4 & Arf4 & P84083 & 2,357 & 0,358 \\
\hline ADP-Ribosylierungsfaktor 5 & Arf5 & P84083 & 1,515 & 0,362 \\
\hline Arf-GAP 1 Herz-Isoform & Arfgap1 & Q3S4A4 & 2,091 & 0,471 \\
\hline Rho GEF 40 & Arhgef40 & A0A0G2JZE7 & 1,671 & 0,612 \\
\hline T-Komplex Protein 1 Untereinheit $\varepsilon$ & Cct5 & Q68FQ0 & 1,893 & 0,303 \\
\hline $\begin{array}{l}\text { Guaninnukleotid-bindendes Protein } \\
\text { G(i) Untereinheit } \alpha-1\end{array}$ & Gnai1 & P10824 & 1,61 & 0,319 \\
\hline $\begin{array}{l}\text { Guaninnukleotid-bindendes Protein } \\
G(q) \text { Untereinheit } \alpha\end{array}$ & Gnaq & D4AE68 & 1,575 & 0,494 \\
\hline $\begin{array}{l}\text { Guaninnukleotid-bindendes Protein } \\
G(\mathrm{I}) / \mathrm{G}(\mathrm{S}) / \mathrm{G}(\mathrm{T}) \text { Untereinheit } \beta-1\end{array}$ & Gnb1 & P54311 & 1,578 & 0,377 \\
\hline G Protein Untereinheit $\beta-2$ & Gnb2 & P54313 & 1,537 & 0,391 \\
\hline $\begin{array}{l}\text { Guaninnukleotid-bindendes Protein } \\
\text { Untereinheit } \gamma\end{array}$ & Gng12 & G3V6P8 & 1,815 & 0,306 \\
\hline Myosin phosphatase Rho-interacting protein & Mprip & Q9ERE6 & 1,923 & 0,3667 \\
\hline $\begin{array}{l}\text { Interferon-induziertes GTP-bindendes } \\
\text { Protein Mx2 }\end{array}$ & Mx2 & P18589 & 3,166 & 0,196 \\
\hline Ras-ähnliches Protein Rab1B & Rab1b & G3V6H0 & 1,518 & 0,617 \\
\hline Ras-ähnliches Protein Rab18 & Rab18 & Q5EB77 & 1,546 & 0,641 \\
\hline Ras-ähnliches Protein Rab23 & Rab23 & D3ZRM5 & 1,729 & 0,337 \\
\hline Ras-ähnliches Protein Rab2b & Rab2b & Q3B7V5 & 1,768 & 0,626 \\
\hline Ras-ähnliches Protein Rab30 & Rab30 & Q5BK72 & 1,867 & 0,596 \\
\hline Ras-ähnliches Protein Rab34 & Rab34 & Q5U1Y1 & 1,565 & 0,5 \\
\hline GTP-bindendes Protein Rheb & Rheb & Q62639 & 2,301 & 0,247 \\
\hline Ras homolog family member $C$ & Rhoc & B2RYP0 & 2,312 & 0,302 \\
\hline Ras-ähnliches Protein R-Ras & Rras & D3Z8L7 & 1,535 & 0,403 \\
\hline Ras-ähnliches Protein R-Ras2 & Rras2 & Q5BJU0 & 1,596 & 0,35 \\
\hline Secretion-associated, Ras-related GTPase 1A & Sar1a & Q6AY18 & 2,521 & 0,245 \\
\hline $\begin{array}{l}\text { Stip1 homology and U-Box containing protein } \\
\text { 1, Isoform CRA_b }\end{array}$ & Stub1 & D4A4T0 & 1,614 & 0,591 \\
\hline Thy-1 Zelloberflächenantigen & Thy1 & P01830 & 1,55 & 0,422 \\
\hline
\end{tabular}

Normierte Signalintensität in Exp. A: Signalintensität mit schweren Isotopen markierter Membranproteine von Kardiofibroblasten, die für sechs Stunden bei Hypoxie $\left(1 \% \mathrm{O}_{2}\right)$ inkubiert wurden, normiert auf die Signalintensität der mit leichten Isotopen markierten korrespondierenden Membranproteine von Fibroblasten, die bei Normoxie $\left(20 \% \mathrm{O}_{2}\right)$ inkubiert wurden; Schwellenwert $>1,5$. Normierte Signalintensität in Exp. B: Verhältnis der Signalintensitäten mit schweren Isotopen markierter Membranproteine, die bei Normoxie inkubiert wurden, zur Signalintensität von mit leichten Isotopen markierten korrespondierenden Proteinen, die für sechs Stunden unter Hypoxie inkubiert wurden; Schwellenwert <0,67. Sortierung alphabetisch nach Gen-Name. Arf-GAP: Adenosyl-Ribosylierungsfaktor-GTPase aktivierendes Protein, Exp.: Experiment, GEF: Guaninnukleotid-Austauschfaktor, GTP: Guanosintriphosphat, Rab: Ras-related in Brain, Rheb: Ras bomolog enriched in brain, Stip: Stressinduziertes Phosphoprotein, Zugangsnr.: Zugangsnummer. 
3.2.2.4 Manuelle Auswertung der im SILAC-Screen unter Hypoxie vermindert identifizierten Proteine

Die 29 im SILAC-Screen unter Hypoxie vermindert nachgewiesenen Proteine wurden mithilfe der UniProtKB-Datenbank analysiert. Hiervon waren acht (28\%) als membranassoziiert verzeichnet, vier davon mit der Plasmamembran. Dies entspricht 14\% der unter Hypoxie vermindert nachgewiesenen Proteine. Zwei Proteine (7\%) wurden als G-Proteine oder Interaktionspartner von G-Proteinen eingeordnet. Es wurden keine kleinen, monomeren G-Proteine identifiziert.

Tabelle 15: G-Proteine und mit G-Proteinen interagierende Proteine, die im SILAC-Screen konsistent unter Normoxie um mindestens 50\% vermehrt in bzw. assoziiert mit der Plasmamembran von Kardiofibroblasten neonataler Ratten nachgewiesen wurden

\begin{tabular}{|l|l|l|l|l|}
\hline Protein & $\begin{array}{l}\text { Gen- } \\
\text { Name }\end{array}$ & $\begin{array}{l}\text { UniProt- } \\
\text { Zugangsnr. }\end{array}$ & $\begin{array}{l}\text { Normierte } \\
\text { Signalintensität } \\
\text { in Experiment A }\end{array}$ & $\begin{array}{l}\text { Normierte } \\
\text { Signalintensität } \\
\text { in Experiment B }\end{array}$ \\
\hline $\begin{array}{l}\text { Nucleolar and coiled-body } \\
\text { phosphoprotein 1 }\end{array}$ & Nolc1 & P41777 & 0,518 & 1,624 \\
\hline Septin-2 & Sept2 & Q91Y81 & 0,615 & 1,618 \\
\hline
\end{tabular}

Normierte Signalintensität in Experiment A: Signalintensität mit schweren Isotopen markierter Membranproteine von Kardiofibroblasten, die für sechs Stunden bei Hypoxie $\left(1 \% \mathrm{O}_{2}\right)$ inkubiert wurden, normiert auf die Signalintensität der mit leichten Isotopen markierten korrespondierenden Membranproteine von Kardiofibroblasten, die bei Normoxie $\left(\begin{array}{lll}20 & \mathrm{O}_{2}\end{array}\right)$ inkubiert wurden; Schwellenwert $<0,67$. Normierte Signalintensität in Experiment B: Verhältnis der Signalintensitäten mit schweren Isotopen markierter Membranproteine, die bei Normoxie inkubiert wurden, zu der Signalintensität von mit leichten Isotopen markierten korrespondierenden Proteinen, die für sechs Stunden unter Hypoxie inkubiert wurden; Schwellenwert $>1,5$. Sortierung alphabetisch nach GenName. Zugangsnr.: Zugangsnummer. 


\section{Diskussion}

Während der intrauterinen Entwicklung (Simon und Keith 2008), in physiologischen Nischen (Suda et al. 2011; Spencer et al. 2014) und unter einer Vielzahl von pathologischen Bedingungen (Vaupel et al. 2007; Eltzschig und Carmeliet 2011; Handley et al. 2011; Hossmann 2012) charakterisiert Hypoxie die zelluläre Umgebung. Das Myokard ist in besonderem Maße von einer konstanten $\mathrm{O}_{2}$-Versorgung abhängig (Giordano 2005) und zelluläre Adaptationen an Hypoxie prägen die Pathophysiologie von myokardialer Ischämie und belastungsinduziertem myokardialen Remodeling (Lee et al. 2000; Semenza 2014). Unter diesen Umständen vermitteln Kardiofibroblasten strukturelle und funktionelle Veränderungen des Myokards (Souders et al. 2009; Kakkar und Lee 2010).

Eukaryotische Zellen verfügen über eine Reihe von Mechanismen, durch die sie auf Hypoxie reagieren und sich an ein vermindertes $\mathrm{O}_{2}$-Angebot adaptieren können (Ward 2008; Prabhakar und Semenza 2015). Auf Transkriptionsebene werden viele Hypoxie-induzierte Adaptationen durch HIF, den Hauptregulator der $\mathrm{O}_{2}$-Homöostase, kontrolliert (Bishop und Ratcliffe 2014). Die $\mathrm{O}_{2}$-abhängige Degradation von HIF- $\alpha$ wird durch PHDs induziert. (Bruick und McKnight 2001; Epstein et al. 2001). Unter den drei Isoformen von HIF- $\alpha$ reguliert HIF-1 $\alpha$ die größte Anzahl von Genen (Elvidge et al. 2006; Forristal et al. 2010). PHD2 ist die quantitativ am stärksten exprimierte Isoform und für die Regulation von HIF-1 $\alpha$ funktionell am bedeutsamsten (Appelhoff et al. 2004).

Die Interaktion einer Zelle mit ihrer Umgebung, die interzelluläre Kommunikation und die zelluläre Signalverarbeitung sind vom zellulären Membranverkehr abhängig (Doherty und McMahon 2009). Endo- und Exozytose sind der einzige Weg, auf dem Membranlipide und Plasmamembranproteine zur Plasmamembran transportiert und von dort entfernt werden können (Keren 2011). Aufgrund seiner Relevanz für nahezu alle extranukleären zellulären Prozesse sind Veränderungen des Membranverkehrs mit einer großen Anzahl von heterogenen Erkrankungen assoziiert (Garuti et al. 2005; Cataldo et al. 2008; Delva et al. 2008; Mosesson et al. 2008).

Eine wachsende Datengrundlage zeigt eine Modifikation des Membranverkehrs und der Plasmamembranprotein-Expression durch Hypoxie (Dada et al. 2003; Carini et al. 2004; Yoon et al. 2005; Walmsley et al. 2006; Zhou et al. 2008; Wang et al. 2009; Park et al. 2012; Khaidakov et al. 2014; Bourseau-Guilmain et al. 2016; Menard et al. 2016). Einige dieser Effekte werden durch den HIF-Transkriptionsweg vermittelt (Wang et al. 2009), andere durch eine direkte PHD-abhängige Regulation des endosomalen Recyclings (Park et al. 2012). Weitere Mechanismen sind abhängig von mitochondrialer ROS-Produktion und werden durch eine Modifikation des Aktin-Zytoskeletts vermittelt (Dada et al. 2003; Dada et al. 2007). Die Auswirkungen von akuter Hypoxie auf den Gesamtmembranverkehr wurden im Detail bisher jedoch nicht untersucht. Ziel dieser Arbeit ist daher, den Einfluss von akuter Hypoxie auf den Gesamtmembranumsatz von Kardiofibroblasten zu untersuchen. 


\subsection{Hypoxie induziert in Kardiofibroblasten eine Zunahme der endozytotischen Membraninternalisierung}

Der Gesamtmembranverkehr primärer Kardiofibroblasten von neonatalen Ratten wurde mithilfe des Styryl-Fluoreszenzfarbstoffs FM 1-43 analysiert. FM 1-43 hat eine hohe Affinität zu Lipidstrukturen (Henkel et al. 1996) und zeigt eine Lösungsmittel-abhängige Quantenausbeute. Im unpolaren Milieu von Lipidmembranen ist diese um mehr als zwei Größenordnungen höher als in polaren Lösungsmitteln wie dem Zytosol. FM 1-43 kann Membranen im physiologischen $\mathrm{pH}$-Bereich aufgrund einer polaren Kopfdomäne nicht durchwandern, sodass es nur durch Endozytose in eine Zelle gelangen und durch Exozytose wieder abgegeben werden kann. Die Aufnahme des Farbstoffes erfolgt unabhängig von spezifischen Endozytosemechanismen. Die Fluoreszenzintensität der untersuchten Zellen ist proportional zur Menge der internalisierten FM 1-43-markierten Plasmamembran, sodass eine Analyse des Gesamtmembranumsatzes ermöglicht wird. (Betz et al. 1996; Gaffield und Betz 2006; Hoopmann et al. 2012).

Nach sechsstündiger Inkubation unter hypoxischen Bedingungen war die FM 1-43Fluoreszenz in Kardiofibroblasten im Vergleich zu unter Normoxie inkubierten Zellen signifikant um $\sim 100 \%$ erhöht (Abbildung 7). Dies deutet auf eine verstärkte Internalisierung der FM 1-43-markierten Plasmamembran hin. Die im Verhältnis zur Endozytosebedingung reduzierte Zellfluoreszenz nach anschließender Inkubation in farbstofffreiem Medium schließt eine unspezifische Akkumulation von FM 1-43 aus und beweist die Funktionsfähigkeit des Vesikelverkehrs unter Hypoxie. Die Wirksamkeit der hypoxischen Inkubation spiegelt sich in der Stabilisierung von HIF-1 $\alpha$ wider (Abbildung 6). Die Nachweisbarkeit von HIF-1 $\alpha$ in Normoxie ist durch den hohen $\mathrm{O}_{2}-\mathrm{K}_{\mathrm{m}}$-Wert der PHDs bedingt und war so zu erwarten (Stroka et al. 2001; Koivunen et al. 2006; Ehrismann et al. 2007). In der Zusammenschau deuten diese Daten auf eine Induktion der Endozytoseaktivität von Kardiofibroblasten unter akuter Hypoxie hin.

Diese Beobachtung deckt sich mit der von einer anderen Gruppe berichteten Induktion der Internalisierung fluoreszierender Nanopartikel durch Kardiomyozyten nach sechsstündiger Anoxie (Khaidakov et al. 2014), steht jedoch scheinbar im Widerspruch zu der von Bourseau-Guilmain et al. (2016) beschriebenen Reduktion der globalen Endozytoseaktivität nach zwei bzw. 20 Stunden Hypoxie. Die Autoren zeigten in HeLa-Zellen durchflusszytometrisch und in konfokaler Mikroskopie eine Reduktion der Aufnahme des für die Analyse biotinylierten Plasmamembranproteoms von $\sim 18 \%$ auf $\sim 13 \%$ bereits nach zweistündiger Hypoxie. Zudem demonstrierten sie in Immunoblots eine absolute Reduktion des endozytierten Plasmamembranproteoms. Gleichzeitig zeigten sie eine Hypoxieabhängige Reduktion der Plasmamembranproteine um 27\% nach zweistündiger Hypoxie. Diesen Befund führten sie auf eine reduzierte Proteintranslation zurück. Überraschenderweise zeigten die Autoren keine Veränderung der makropinozytotischen 
Dextranaufnahme und sogar eine signifikante Induktion der wichtigsten Mikropinozytosemechanismen in Form einer gesteigerten Aufnahme von Transferrin als Marker der CME sowie von Choleratoxin als Marker der lipid raft-assoziierten Endozytosewege. Vergleichbare Befunde fanden sich in weiteren Tumorzelllinien (ebd.). Die hypoxische Induktion der Clathrin-vermittelten Endozytose von Transferrin steht hierbei scheinbar im Widerspruch zum von Khaidakov et al. (2014) beschriebenen Zusammenbruch der Clathrin-vermittelten Endozytose unter Anoxie. Bourseau-Guilmain et al. (2016) demonstrierten somit eine Hypoxie-abhängige Reduktion des Membranproteinumsatzes. Dies ist nicht unbedingt mit dem im Rahmen der vorliegenden Arbeit untersuchten Gesamtmembranverkehr gleichzusetzen. Zudem gilt der von Bourseau-Guilmain et al. (2016) beschriebene Phänotyp nicht für das gesamte Plasmamembranproteom sondern steht im Kontrast zur verstärkten Internalisierung spezifischer Membranproteine (ebd.).

Neben einer verstärkten Internalisierung der Plasmamembran zeigte sich unter Hypoxie eine signifikante Größenzunahme FM 1-43-gefärbter intrazellulärer Vesikel von 15 auf 20 $\mu \mathrm{m}^{2}$ (Abbildung 7). Dieser Parameter wurde in der Literatur mit einer vergleichbaren Methodik bisher nicht untersucht. Die Beobachtung deckt sich scheinbar nicht mit der von Wang et al. (2009) beschriebenen HIF-abhängigen Reduktion der Endosomenfusion. Aufgrund der spezifischen Untersuchung von frühen Endosomen nach mindestens 24-stündiger Hypoxie und der Abhängigkeit des Effektes von der HIF-Transkriptionswirkung stehen diese Beobachtungen jedoch nicht im unauflösbaren Widerspruch zu den Ergebnissen der vorliegenden Arbeit. Zwar zeigte sich auch in den im Rahmen der hier vorgelegten Arbeit durchgeführten Untersuchungen an Kardiofibroblasten nach sechsstündiger Inkubation unter Hypoxie eine Stabilisierung von HIF-1 $\alpha$ (Abbildung 6), diese beweist jedoch weder die veränderte Aktivität nachgeschalteter Effektoren noch die mechanistische Abhängigkeit des beobachteten Phänotyps vom HIF-Transkriptionsweg.

\subsection{Die Hypoxie-induzierte Zunahme der endozytotischen Membraninternalisierung ist nicht spezifisch für Kardiofibroblasten}

Fibroblasten sind eine Zellart, die Topographie-abhängig eine große Heterogenität aufweist (Chang et al. 2002). Um zu prüfen, ob es sich bei den Veränderungen des Membranverkehrs um für Kardiofibroblasten spezifische Effekte handelt, wurde ein FM 1-43-Färbeversuch bei aus den Schwänzen neonataler Ratten isolierten Fibroblasten durchgeführt. Wie in den Kardiofibroblasten zeigte sich im Endozytoseversuch eine Verdopplung der FM 1-43Fluoreszenz nach sechsstündiger Hypoxie im Vergleich zu unter Normoxie inkubierten Zellen. Auch die in Kardiofibroblasten unter Hypoxie beobachtete Zunahme der durchschnittlichen endozytotischen Vesikelgröße von $\sim 15$ auf $\sim 20 \mu \mathrm{m}^{2}$ konnte in Schwanzfibroblasten demonstriert werden. Die Schwanzfibroblasten zeigten im Exozytoseversuch eine gegenüber der Endozytose signifikant reduzierte 
Fluoreszenzintensität. Dies beweist die Funktionsfähigkeit des exozytotischen Vesikelverkehrs unter Hypoxie (Abbildung 9). Die Wirksamkeit der hypoxischen Inkubation wurde durch den Nachweis der Stabilisierung von HIF-1 $\alpha$ gezeigt (Abbildung 8). Die in Kardiofibroblasten unter akuter Hypoxie beobachteten Veränderungen des Membranverkehrs sind somit zumindest auch in Fibroblasten anderen topographischen Ursprungs zu beobachten. Der hypoxischen Induktion der Endozytoseaktivität und der veränderten Größe endozytotischer Vesikel liegt daher möglicherweise ein genereller zellulärer Adaptationsmechanismus zugrunde.

\subsection{Die Hypoxie-induzierte Zunahme der endozytotischen Membraninternalisierung ist durch Reoxygenierung vollständig reversibel}

Um die Reversibilität der hypoxischen Induktion der Endozytoseaktivität zu prüfen, wurden Kardiofibroblasten nach sechsstündiger Inkubation in Hypoxie für 30 Minuten bzw. zwei Stunden bei Normoxie reoxygeniert und die Membraninternalisierung in einem FM 1-43Färbeversuch quantifiziert. Die hypoxische Induktion der Endozytoseaktivität war bereits nach 30 Minuten voll reversibel. Auch die Veränderung der Vesikelmorphologie zeigte eine vollständige Reversibilität (Abbildung 11). Wie aufgrund der hypoxischen Induktion von PHD2 und PHD3 erwartet (Jewell et al. 2001; D’Angelo et al. 2003; To und Huang 2005) war HIF-1 $\alpha$ nach 30 Minuten Reoxygenierung nicht nachweisbar. Dies entspricht der in HeLa-Zellen beobachteten Kinetik (Jewell et al. 2001). Zwei Stunden nach Reoxygenierung zeigte sich eine etwas geringere Stabilisierung von HIF-1 $\alpha$ als in der Normoxiekontrolle (Abbildung 10). Dies beweist die Wirksamkeit der Reoxygenierung und ist ein Hinweis auf die Vitalität der Zellen. Eine vergleichbar schnelle Degradation der HIF-1-induzierten Proteine ist nicht $\mathrm{zu}$ erwarten, sodass eine mechanistische Rolle von HIF-1 $\alpha$ für die beobachteten Veränderungen unwahrscheinlich erscheint.

Die Reversibilität der Beobachtungen steht scheinbar im Widerspruch zu den Ergebnissen von Khaidakov et al. (2014). Allerdings benutzten die Autoren Polyethylenglykolbeschichtete nicht-zielgerichtete (non-targeted) Nanopartikel mit neutraler Oberflächenladung, um die Rezeptor-unabhängige Endozytose zu untersuchen (ebd.). Dies entspricht nicht der in dieser Arbeit durchgeführten Färbung der internalisierten Zellmembran. Zudem sind der Aufnahmemechanismus und die Interaktion der beschichteten Nanopartikel mit intrazellulären biologischen Mechanismen nicht vollständig geklärt (Xiao et al. 2010). Polyethylenglykol-Beschichtungen werden verwendet, um die unspezifische Interaktion von Nanopartikeln mit Proteinen des Organismus zu vermindern (Bentzen et al. 2005). Sie führen daher insbesondere bei neutraler Oberflächenladung zu einer reduzierten endozytotischen Aufnahme der Partikel (Chang et al. 2005; Zhang und Monteiro-Riviere 2009; Kelf et al. 2010). Für die verwendeten Nanopartikel wurde bei zwölfstündiger Inkubation sowohl in der nicht-neoplastischen humanen Mammaepithel-Zelllinie MCF-10A 
als auch der Adenokarzinomzelllinie MCF-7 keine zelluläre Internalisierung beobachtet (Xiao et al. 2010). In menschlichen Keratinozyten zeigte sich zwar nach 24-stündiger Inkubation eine Aufnahme der Nanopartikel, jedoch auch eine reduzierte Zellvitalität (Ryman-Rasmussen et al. 2007). Die extrazelluläre Diffusion nicht-zielgerichtete Nanopartikel mit neutraler Oberflächenladung wurden zudem für die Vermessung des zerebralen Extrazellularraums verwendet (Thorne und Nicholson 2006). Möglicherweise erschwert daher eine unzuverlässige Internalisierung des verwendeten Endozytosemarkers die Interpretation der Diskrepanz zu den hier berichteten Ergebnissen. Die von Khaidakov et al. (2014) berichteten signifikanten Unterschiede in der Fluoreszenzintensität von in Normoxie inkubierten Kardiomyozyten gegenüber hypoxischen und reoxygenierten Zellen bedürfen vor diesem Hintergrund weiterer Klärung.

Zusammenfassend konnte gezeigt werden, dass sechsstündige Inkubation unter Hypoxie in Fibroblasten unterschiedlicher topographischer Herkunft eine Zunahme der endozytotischen Plasmamembraninternalisierung und Veränderung der Endosomenmorphologie bewirkt, die nach Reoxygenierung rasch reversibel ist. Die Kinetik des Phänotyps deutet auf das Zugrundeliegen eines HIF-unabhängigen Mechanismus hin. Es sind weitere Untersuchungen notwendig, um den zugrundeliegenden Mechanismus und die möglichen resultierenden physiologischen Konsequenzen dieses Phänotyps zu differenzieren. Neben den vielfältigen biologischen Prozessen, die vom Membranverkehr abhängig sind (Doherty und McMahon 2009) beeinflusst eine verstärkte endozytotische Internalisierung möglicherweise die Zusammensetzung, Fläche und biophysikalischen Eigenschaften der Plasmamembran.

Für die Analyse des Gesamtmembranverkehrs wurde eine Färbung mit dem Styryl-Farbstoff FM 1-43 durchgeführt. Dies ermöglicht zwar die zuverlässige Darstellung intrazellulärer Vesikel und die relative Quantifizierung der Membraninternalisierung, erlaubt jedoch keine Aussage über den zugrundeliegenden Endozytosemechanismus und die Identität der angefärbten endosomalen Strukturen (Betz et al. 1996; Hao und Maxfield 2000; Gaffield und Betz 2006; Opazo und Rizzoli 2010; Hoopmann et al. 2012). Zudem erlaubt die Beschränkung auf nur eine Färbemethode nicht den Ausschluss einer für den beobachteten Effekt relevanten Interaktion des Farbstoffs mit der Zelle.

FM-Farbstoffe sind nicht toxisch (Gaffield und Betz 2006) und können von Neuronen noch mehrere Stunden nach Markierung auf Stimulation hin abgegeben werden (Richards et al. 2000). Sie können jedoch biologische Wirkungen ausüben und nikotinerge (Bewick und Betz 1994) sowie muskarinerge Azetylcholinrezeptoren blockieren (Mazzone et al. 2006). Jelínková et al. (2010) zeigten in Pflanzenzellen eine transiente Störung der Lokalisation und Aktivität integraler Plasmamembranproteine durch verschiedene FM-Farbstoffe, allerdings nicht durch FM 1-43. Alle untersuchten FM-Farbstoffe beeinflussten jedoch den Phospholipidstoffwechsel (ebd.). Auch wenn FM-Markierungen der zellulären Membranen eine etablierte Methode zur Untersuchung des Membranverkehrs sind (Cochilla et al. 1999; 
Bolte et al. 2004; Gaffield und Betz 2006), wurden für einige Zelltypen Endozytoseunabhängige Aufnahmemechanismen beschrieben. FM-Farbstoffe können über mechanosensitive Ionenkanäle in neuronale Zellen gelangen (Meyers et al. 2003; Kamin et al. 2014) und dort Ionenkanäle blockieren (Gale et al. 2001; Drew und Wood 2007; Breunig et al. 2011). Auch durch Liganden-abhängige Ionenkanäle ist unter Stimulation durch Agonisten eine Aufnahme in sensorische Zellen möglich (Meyers et al. 2003). In Astrozyten konnten eine Aufnahme von FM-Farbstoffen durch kationische Ionenkanäle sowie eine Veränderung des intrazellulären Kalziumhaushaltes gezeigt werden (Li et al. 2009). Aufgrund der untersuchten Zelltypen und der gewählten Methodik sind diese Interaktionen jedoch mutmaßlich von untergeordneter Relevanz für die Ergebnisse dieser Arbeit. Die hier beschriebenen Unterschiede in der Zellfluoreszenz wären zudem auch bei nichtendozytotischer Farbstoffaufnahme als Hinweis auf Hypoxie-induzierte strukturelle oder funktionelle Veränderungen der Plasmamembran zu interpretieren.

Im Rahmen der Endozytose werden gemeinsam mit Teilen der Plasmamembran auch extrazelluläre Flüssigkeit mit den darin gelösten Stoffen sowie mit der Plasmamembran assoziierte Moleküle aufgenommen (Doherty und McMahon 2009). Der Nachweis einer unter Hypoxie verstärkten Internalisierung dieser Verbindungen könnte daher den Einfluss von Hypoxie auf die endozytotische Aktivität von Fibroblasten bestätigen.

Für die Darstellung der Internalisierung von Plasmamembran-assoziierten Molekülen ist eine Zellfärbung mit fluoreszenzmarkiertem Weizenkeim-Agglutinin (WGA, wheat germ agglutinin) möglich (Liu et al. 2011). WGA bindet an Silainsäure- sowie N-Azetylglukosaminresteenthaltende Glykoproteine und Glykolipide des äußeren Blattes der Plasmamembran (Chazotte 2011). Somit besteht eine völlig andere Interaktion des Farbstoffes mit der Plasmamembran als im Fall von FM 1-43. WGA wird Rezeptor-abhängig, vermutlich Clathrin-vermittelt, internalisiert (Gabor et al. 2004; Ranftler et al. 2012). Darüber hinaus ist die Aufnahme über weitere Mechanismen wahrscheinlich (Vetterlein et al. 2002). Zum Nachweis der Internalisierung von extrazellulärer Flüssigkeit ist ein Färbeversuch mit fluoreszenzmarkierten Dextranen möglich (Berlin und Oliver 1980; Lencer et al. 1990; Chazotte 2009). Dextrane sind verzweigte Polysaccharide, die kaum Interaktion mit der Zellmembran zeigen. Je nach Größe werden Dextrane vorwiegend durch Makropinozytose oder NCE aufgenommen (Saeed et al. 2010; Li et al. 2015). Die konjugierten Fluorophore sind jedoch pH-sensibel, sodass die Darstellung azider Organellen im unterschiedlichen Ausmaß eingeschränkt ist. Darüber hinaus verleihen sie den Dextranen adsorptive Eigenschaften, die eine Interaktion mit der Plasmamembran begünstigen. Fluoreszenzmarkierte Dextrane sind somit nicht uneingeschränkt spezifisch für die Aufnahme extrazellulärer Flüssigkeit (Swanson 1988). Abhängig von ihrer Größe können sie zudem Membranporen passieren (Chazotte 2009; Samudram et al. 2016).

Der Nachweis einer verstärkten Internalisierung von Markern spezifischer Endozytosewege würde neben der Bestätigung des Einflusses von Hypoxie auf den Membranverkehr auch 
eine Identifikation der beteiligten Mechanismen erlauben. Eine alternative Möglichkeit zur Identifikation des unter Hypoxie induzierten Endozytoseweges ist die selektive Inhibition einzelner Mechanismen vor einem FM-Färbeversuch. Aufgrund von Interaktionen zwischen den einzelnen Endozytosemechanismen (Krauss et al. 2003; Kirkham und Parton 2005; Chaudhary et al. 2014) wäre die Interpretation der Ergebnisse jedoch kompliziert.

Für die für die Identifikation der im FM-Färbeversuch dargestellten Strukturen ist eine Kofärbung der Membranstrukturen und spezifischer Markerproteine intrazellulärer Vesikelstrukturen notwendig. FM 1-43 und Dextranpartikel sind für die gleichzeitige Anwendung von fluoreszenzmarkierten Antikörpern nicht optimal geeignet, da sie im Rahmen der notwendigen Fixationsschritte aus den intrazellulären Membranen gelöst werden und möglicherweise sogar in ursprünglich nicht markierten Strukturen wie Mitochondrien akkumulieren (Revelo et al. 2014). Zudem liegen intrazelluläre Organellen in großer räumlicher Nähe zueinander vor, sodass die Differenzierung mithilfe der konventionellen, diffraktionslimitierten Lichtmikroskopie eventuell nicht möglich ist (Hell 2007). Beide Einschränkungen gelten nicht für den Membranfarbstoff Mebran-bindendeFluorophor-Zystein-Lysin-Palmitoylgruppe (mCLING, membrane-binding fluorophore-cysteinelysine-palmitoyl group). Der Farbstoff wird durch Endozytose aufgenommen und zeigt ein zu FM 1-43 identisches Markierungsmuster. Er lässt sich im Rahmen von Immunfärbungen effektiv fixieren und ist neben der konfokalen Mikroskopie auch für die hochauflösende Stimulierte-Emission-Depletion (STED)-Mikroskopie geeignet (Revelo et al. 2014). Somit ist mCLING als Membranfarbstoff bei simultaner Immunmarkierung endosomaler Markerproteine für die mikroskopische Identifikation der im FM-Färbeversuch dargestellten Strukturen geeignet. Als FM 1-43-vergleichbarer lipophiler Farbstoff ist mCLING jedoch nur von begrenztem Nutzen für die Bestätigung der in dieser Arbeit beschriebenen hypoxischen Induktion der Plasmamembraninternalisierung.

\subsection{Hypoxie beeinflusst die Plasmamembrankomposition von Kardiofibroblasten}

Aufgrund der Abhängigkeit der Plasmamembrankomposition vom Gesamtmembranverkehr (Keren 2011) und der Regulation der Endozytose durch membranständige und temporär über hydrophobe, elektrostatische oder andere nicht-kovalente Bindungen mit der Membran assoziierte Proteine (Doherty und McMahon 2009; Stenmark 2009; Hutagalung und Novick 2011) wurde das Plasmamembranproteom von primären Kardiofibroblasten unter Normoxie nach sechsstündiger Hypoxie verglichen. Hierzu wurden die zellulären Proteine in einem SILAC-Screen mit unterschiedlich schweren Isotopen markiert (Abbildung 4). Die durch die Isotopenmarkierung verliehene Massedifferenz erlaubt nach gepoolter elektrophoretischer Auftrennung die Differenzierung des Proteoms unterschiedlich behandelter Zellen (Ong et al. 2002). Die Proteinbanden wurden im Gel trypsiniert und die enthaltenen Proteine massenspektrometrisch identifiziert. Die relative Abundanz der 
differenziell markierten Proteine entspricht der unterschiedlichen Expression in der Plasmamembran. Um isotopenvermittelte Einflüsse auszuschließen, wurde das Experiment doppelt ausgeführt: Leicht markierte Zellen wurden unter Normoxie inkubiert und mit schwer markierten Zellen verglichen, die für sechs Stunden unter Hypoxie inkubiert wurden. Parallel wurden leicht markierte Zellen, die Hypoxie ausgesetzt waren, mit schwer markierten Zellen verglichen, die unter Normoxie inkubiert wurden. In den beiden Experimenten konnten jeweils 3.501 bzw. 3.430 Proteine quantifizierbar identifiziert werden. Hiervon wurden 2.645 in beiden Experimenten übereinstimmend gefunden und für die weitere Analyse berücksichtigt.

Bei idealer Übereinstimmung der Experimente sollte sich nach Auftragung der relativen Abundanz der differenziell markierten Proteine in dem ersten Experiment gegen die relative Abundanz der differenziell markierten Proteine im spiegelbildlichen zweiten Experiment eine lineare Korrelation ergeben. Bei nicht optimaler Korrelation der Daten (Pearsons $R=-0,25, p<0,001)$ ergab sich eine Steigung der linearen Regressionsgerade von $-0,17$ $(\mathrm{p}<0,0001 ;$ Abbildung 12 A). Das Ausmaß der Korrelation dient als Maß der Reproduzierbarkeit der Summe mehrerer Versuchsschritte wie Zellkultivierung und Isotopenmarkierung, Probenaufbereitung und Proteinidentifikation (Xu et al. 2010). Die nicht optimale Korrelation spiegelt somit die Komplexität biologischer Systeme (Bruce et al. 2013; Gatto und Christoforou 2014) und die methodische Schwierigkeit der Untersuchung von Plasmamembranproteinen (Rabilloud 2003; Helbig et al. 2010) wider. Die geringe Abweichung der linearen Regressionsgerade von null deutet auf einen großen Anteil nicht durch Hypoxie regulierter Proteine hin. Dies wurde in der Auftragung der Gesamtsignalintensitäten aller zu einem Protein gehörenden Peptide gegen die normierten Signalintensitäten als Parameter der relativen Proteinabundanz aus beiden spiegelbildlichen Experimenten (Abbildung 12 B) sowie im Histogramm der normierten Signalintensitäten bestätigt (Abbildung 13). Dem spiegelbildlichen Versuchsaufbau entsprechend war im Idealfall eine um null zentrierte Normalverteilung der Daten zu erwarten. Bei einer deutlichen Linksschiefe (skewness) von -1,34 konnte eine Normalverteilung im D'AgostinoPearson-Test nicht bestätigt werden $(\mathrm{p}<0,0001)$. Dies entspricht jedoch den anhand der Daten anderer Untersuchungen erwartbaren Abweichungen im Rahmen dieser Methode (Xu et al. 2010; Hara et al. 2013). Die größte Häufung der relativen Proteinabundanzen lag näherungsweise im Bereich von $2^{-0,6}$ bzw. 1,5 und $2^{0,6}$ bzw. 0,67 (Abbildung 12 B).

Eine hypoxische Induktion wurde daher angenommen, wenn ein schwer markiertes Protein unter Hypoxie eine im Verhältnis 3:2 erhöhte Abundanz gegenüber seinem leicht markierten Gegenstück aus normoxischen Zellen zeigte, und gleichzeitig im spiegelbildlichen Parallelexperiment eine im Verhältnis 2:3 verminderte Abundanz des schwer markierten Proteins gegenüber dem aus hypoxischen Zellen stammenden leicht markierten Gegenstück nachweisbar war. Im umgekehrten Fall wurde eine Hypoxie-abhängige Reduktion angenommen. Es wurden 140 Hypoxie-induzierte Proteine identifiziert. Dies entspricht 5,3\% der in beiden Experimenten überlappend gefundenen Proteine. Unter Hypoxie 
vermindert waren lediglich 29 Proteine (1,1\%; Abbildung 14, Anhang 1, Anhang 2). Dies steht im Kontrast zu Untersuchungen an MDA-MB-231 Brustkrebszellen, bei denen ein deutlich größerer Anteil der Membranproteine unter kurzfristiger Hypoxie negativ als positiv reguliert ist (Wottawa et al. 2017).

\subsubsection{Klassifikation der in der Plasmamembran Hypoxie-abhängig differenziell exprimierten Proteine}

Die Hypoxie-abhängig regulierten Plasmamembran- und membranassoziierten Proteine wurden anhand ihrer UniProt-Zugangsnummer mit der Datenbank des PANTHERKlassifikationssystems (Mi et al. 2013; Mi et al. 2017) abgeglichen. Unter den Hypoxieabhängig vermehrt in der Plasmamembran identifizierten Proteinen wurde der überwiegende Teil als Hydrolase, Zytoskelettprotein, Enzymmodulator oder Chaperon klassifiziert (Abbildung 15). Von den unter Hypoxie vermindert identifizierten Proteinen stellten Nukleinsäure-bindende Proteine die größte Gruppe (Abbildung 16). Diese Zuordnung deutete auf einen relevanten Anteil nicht an der Plasmamembran lokalisierter Proteine hin. Unter den 140 in Hypoxie vermehrt an der Plasmamembran identifizierten Proteinen waren jedoch nur 111 (79\%) in der PANTHER-Datenbank verzeichnet. Nur 73 der 140 Proteine (52\%) konnten einer Proteinklasse zugeordnet werden. Von den 29 unter Hypoxie vermindert an der Plasmamembran identifizierten Proteinen waren 23 (79\%) in der PANTHER-Datenbank verzeichnet. 16 der 29 Proteine (55\%) konnten einer Proteinklasse zugeordnet werden. Unter den in der PANTHER-Datenbank verzeichneten, jedoch keiner Proteinklasse zugeordneten unter Hypoxie vermehrt identifizierten Proteinen fielen bei manueller Durchsicht kleine, monomere G-Proteine wie Arf4 , Arf5, Rab1b und Rab2b auf, die im Zusammenhang mit dem Vesikeltransport beschrieben wurden (Volpicelli-Daley et al. 2005; Hutagalung und Novick 2011; Nakai et al. 2013). Die Expression bzw. die Aktivität einzelner Vertreter dieser Proteinklasse wird durch die $\mathrm{O}_{2}$-Verfügbarkeit modifiziert (Turcotte et al. 2004; Jin et al. 2006; Xue et al. 2006; Dada et al. 2007). Aufgrund der zentralen Funktion von kleinen, monomeren G-Proteinen in der Regulation des Membranverkehrs (Doherty und McMahon 2009; Grant und Donaldson 2009) wurden die $\mathrm{O}_{2}$-abhängig regulierten Proteine mithilfe der UniProtKB-Datenbank (Bateman et al. 2017) im Hinblick auf diese Regulatoren manuell ausgewertet (Tabelle 13).

Von den 140 unter Hypoxie vermehrt identifizierten Proteinen waren 79 (56\%) anhand ihrer GO-Annotation (Ashburner et al. 2000; The Gene Ontology Consortium 2017) als mit Membranen assoziierte Proteine verzeichnet, 45 davon mit der Plasmamembran. Unter den $29 \mathrm{O}_{2}$-abhängig vermindert identifizierten Proteinen waren lediglich acht $(28 \%)$ als mit Membranen assoziiert verzeichnet. Für einen Teil der Proteine waren jedoch nur unvollständige Informationen verfügbar. Proteine wie trafficking protein particle complex 6B (Trappc6b), die bei anderen Organismen nach ihrer GO-Annotation mit Membranen assoziiert sind, wurden bei fehlender entsprechender Verschlagwortung für Rattus norvegicus trotz ansonsten weitgehender Übereinstimmung hierbei nicht als membranassoziiert 
gewertet. Somit ist der Anteil von Membran- und membranassoziierten Proteinen möglicherweise höher als die hier angegebenen 56\% bzw. 28\%. Aufgrund der im Verhältnis zu zytosolischen Proteinen geringen Expression von Membranproteinen, ihrer schlechten Extrahierbarkeit und der durch hydrophobe Domänen erschwerten Trypsinierung (Rabilloud 2003; Eichacker et al. 2004; Helbig et al. 2010; Vit und Petrak 2017) ist die ausschließliche Erfassung von Plasmamembranproteinen jedoch unwahrscheinlich.

Unter den Hypoxie-abhängig vermehrt identifizierten Proteinen ließen sich 27 (19\%) anhand ihrer in der GO-Annotation verzeichneten molekularen Funktion als G-Proteine oder mit G-Proteinen interagierende Proteine einordnen (Tabelle 14). Aufgrund der ausschließlichen Berücksichtigung der molekularen und nicht der biologischen Funktion wurden mit GTPasen interagierende Proteine wie Trappc6b, der Dynein-Leichtkette Tctex-Typ 1 (Chuang et al. 2005; Pavlos et al. 2011) und Regulatoren der Rac-Signaltransduktion wie der Kalzium/Kalmodulin-abhängige Proteinkinase Typ II Untereinheit $\delta$ (Camk2d) (Mercure et al. 2008; Penzes et al. 2008) nicht berücksichtigt. Von diesen 27 Proteinen waren 19 monomere G-Proteine oder Interaktionspartner von monomeren G-Proteinen. Hierunter waren mit dem Membranverkehr assoziierte Proteine wie Rab34, das sowohl im antegraden Vesikeltransport innerhalb des Golginetzwerkes (Goldenberg et al. 2007) als auch in der Regulation von Makropinozytose (Sun et al. 2003; Coyne et al. 2007) und der räumlichen Anordnung von Lysosomen (Wang und Hong 2002) eine Rolle spielt. Auch Proteine wie Arf-GAP 1 (Antonny et al. 2005) und secretion-associated, Ras-related GTPase 1A (Sar1 a) (Loftus et al. 2012), die die für eine Vesikelabschnürung notwendige Membrankrümmung (Zimmerberg und Kozlov 2006; Johannes et al. 2014) induzieren können, waren unter den Hypoxie-abhängig vermehrt identifizierten Proteinen. Die ebenfalls vermehrt identifizierten Proteine Arf4 (Nakai et al. 2013; Wang et al. 2017), Arf5 (Volpicelli-Daley et al. 2005; Sadakata et al. 2010; Manavski et al. 2014), Rab1b (Slavin et al. 2011; Guo und Linstedt 2014), Rab2b (Aizawa und Fukuda 2015), Rab18 (Gerondopoulos et al. 2014; Zhang et al. 2016a), Rab23 (Evans et al. 2003; Zheng et al. 2017), Rab30 (Kelly et al. 2012), Rab34 (Sun et al. 2003; Goldenberg et al. 2007; Zhang et al. 2016a) und R-Ras (Conklin et al. 2010; Sandri et al. 2012) sind ebenfalls an der Regulation des Membranverkehrs oder der Morphologie intrazellulärer Organellen beteiligt (Stenmark 2009).

Unter den Hypoxie-abhängig vermehrt identifizierten Proteinen (Anhang 1) waren zudem Endozytose-assoziierte Proteine wie Caveolin-1 (Oh et al. 2007; Parton und Simons 2007; Doherty und McMahon 2009; Hayer et al. 2010; Walser et al. 2012), Cavin-3 (McMahon et al. 2009; Hernandez et al. 2013; Zhu et al. 2017) und Clathrin-Leichtkette B (Kirchhausen und Harrison 1981; Ungewickell und Branton 1981; Dannhauser und Ungewickell 2012; Kirchhausen 2012). Eine Hypoxie-abhängige Induktion von Caveolin-1 deckt sich mit den Beobachtungen anderer Autoren (Wang et al. 2012; Bourseau-Guilmain et al. 2016). Die auffällige Häufung in den Membranverkehr involvierter Proteine spiegelt möglicherweise die Hypoxie-abhängige Induktion des Vesikelverkehrs wider. Im Rahmen des SILAC-Screens konnte allerdings nicht unterschieden werden, ob der vermehrten Identifikation dieser 
Proteine eine verstärkte Synthese oder eine vermehrte Rekrutierung an die Plasmamembran zugrunde liegt.

Von den 29 in Hypoxie vermindert identifizierten Proteinen (Anhang 2) wurden nur zwei (7\%) als G-Protein oder mit G-Proteinen interagierend eingeordnet (Tabelle 15). Mit dem Clathrin-Adapterprotein Disabled 2 (Dab 2) wurde lediglich ein Endozytose-assoziiertes Protein identifiziert (Chetrit et al. 2009), dies entspricht 3\% der vermindert identifizierten Proteine. Auffällig war die unter Hypoxie verminderte Identifikation der EZM-Proteine Kollagen I $\alpha 1$, Kollagen I $\alpha 2$, Kollagen XII $\alpha 1$ sowie Fibronektin. Kollagen I ist der vorherrschende Kollagen-Subtyp im Myokard (Medugorac und Jacob 1983; Porter und Turner 2009; Fan et al. 2012). Kollagen und Fibronektin sind keine Membranproteine, dienen jedoch als Gerüst für die Integrin-vermittelte zelluläre Adhäsion (Pankov und Yamada 2002; Astrof und Hynes 2009; Bowers et al. 2010).

Die unter Hypoxie verminderte Identifikation dieser Proteine steht scheinbar im Widerspruch zur unter prolongierter Hypoxie verstärkten Kollagenexpression und Ablagerung in der EZM von verschiedenen Geweben (Horino et al. 2002; Gabrielsen et al. 2007; Gilkes et al. 2013; Rozen-Zvi et al. 2013; Gilkes et al. 2014; Watson et al. 2014). Auch die Abundanz von extrazellulärem Fibronektin ist nach prolongierter Inkubation unter Hypoxie erhöht (Lee et al. 2011; Rana et al. 2015). Die Induktion der Kollagenexpression erfolgt jedoch erst nach einer Hypoxiedauer von mindestens zwölf Stunden. Unter akuter Hypoxie zeigt sich sogar eine Reduktion der mRNA von Kollagen I $\alpha 1$ (Falanga et al. 1993). Aufgrund der langen Halbwertzeit von etwa 100 Tagen (Brown et al. 2005) erscheint eine unter kurzfristiger Hypoxie verringerte Expression von Kollagen jedoch als Erklärung für die verminderte Identifikation unwahrscheinlich.

Neben einer veränderten Abundanz könnte möglicherweise auch eine unter Hypoxie verringerte Interaktion der Kardiofibroblasten mit der EZM die verminderte Identifikation dieser Proteine erklären. Hierfür spricht, dass bei endothelialen Vorläuferzellen bereits unter kurzfristiger Hypoxie (1\% $\mathrm{O}_{2}$ für 1,5-18 Stunden) eine reduzierte Adhäsion an Fibronektin gezeigt werden konnte (Kaiser et al. 2012). Auch in glatten Gefäßmuskelzellen konnte eine HIF-abhängige Reduktion von Migration und Adhäsion gezeigt werden (Corley et al. 2005). Hingegen wurde in embryonalen Stammzellen (Lee et al. 2011) und extravillösen Trophoblastenzellen (Arimoto-Ishida et al. 2009) eine unter Hypoxie verstärkte Adhäsion an Fibronektin bei gleichzeitig erhöhter Migration gezeigt. Auch Tumorzellen zeigen unter Hypoxie eine erhöhte Abundanz von Integrinen an der Zelloberfläche (Yoon et al. 2005; Bourseau-Guilmain et al. 2016) sowie eine durch Integrine vermittelt erhöhte EZMAdhäsion (Ren et al. 2013).

Für Fibroblasten existieren widersprüchliche Daten. Mogford et al. (2002) und Li et al. (2007) zeigten eine Hypoxie-abhängig verstärkte Migration von Fibroblasten. Neuere Untersuchungen demonstrierten hingegen eine unter Hypoxie reduzierte Zellmigration (Breit et al. 2011; Vogler et al. 2013). Allerdings erklärten Vogler et al. (2013) die verminderte 
Migration im Widerspruch zu Corley et al. (2005), in diesem Aspekt jedoch in Übereinstimmung mit Lee et al. (2011) sowie mit Ren et al. (2013), durch eine verstärkte Integrin-vermittelte Zelladhäsion. Im Rahmen einer Dissertation am Institut für Herz- und Kreislaufphysiologie der Universitätsmedizin Göttingen konnte hiermit übereinstimmend eine verminderte Adhäsionsfähigkeit von embryonalen Mausfibroblasten nach dem Knockout von HIF-1 $\alpha$ gezeigt werden (Schnelle 2012).

Es wurde eine Reduktion der Zell-Matrix-Interaktion durch die Arf6- und Arf5-vermittelte Endozytose von Integrinen beschrieben (Dunphy et al. 2006; Manavski et al. 2014; D’Souza und Casanova 2016). Zwar wurde Arf5 im Rahmen der in dieser Arbeit durchgeführten Versuche unter Hypoxie vermehrt identifiziert (Tabelle 14), gegen eine Hypoxie-abhängig reduzierte Interaktion von Kardiofibroblasten mit der EZM als Erklärung für die verminderte Identifikation von EZM-Bestandteilen spricht jedoch auch der fehlende Nachweis einer differenziellen Regulation der die Interaktion vermittelnden Integrine (Astrof und Hynes 2009; Bowers et al. 2010) in den hier gezeigten Ergebnissen. Eine Analyse der Interaktion von Kardiofibroblasten mit der EZM unter Hypoxie könnte vor diesem Hintergrund wichtige Ergebnisse zeigen.

Bei der Interpretation der Ergebnisse des SILAC-Screens ist zu beachten, dass in der Analyse ausschließlich Proteine berücksichtigt wurden, die in zwei spiegelbildlichen Experimenten übereinstimmend identifiziert wurden. Diese 2.645 Proteine entsprechen jedoch nur $\sim 76 \%$ bzw. $\sim 77 \%$ des innerhalb jeweils eines Experimentes quantifizierbar identifizierten Proteoms. Der Anteil übereinstimmend in beiden Experimenten gefundener Proteine liegt in einer Größenordnung, die in vergleichbaren Experimenten berichtet wurde (Xu et al. 2010; Peláez-García et al. 2015). In der Analyse fehlen somit jedoch 856 Proteine aus Experiment A und 785 Proteine aus Experiment B. Dies entspricht einem Vielfachen der Hypoxie-abhängig differenziell an der Plasmamembran exprimierten Proteine. Möglicherweise sind neben Artefakten hierunter auch einzelne funktionell relevante $\mathrm{O}_{2}$ abhängig regulierte Proteine, die aufgrund von Messungenauigkeiten in jeweils einem der Experimente (Chen et al. 2014) nicht erfasst wurden.

Zudem induziert die Kultivierung von Fibroblasten auf starren Plastikoberflächen (Goffin et al. 2006; Galie et al. 2011) ebenso wie Hypoxie (Short et al. 2004) oder die Exposition gegenüber dem supraphysiologischem $\mathrm{pO}_{2}$ der Atmosphärenluft (Roy et al. 2003) die Differenzierung zu unter physiologischen Bedingungen im Myokard nicht vorhanden Myofibroblasten (Rohr 2011). Dieser Effekt ist bereits nach 48 Stunden nachweisbar und verstärkt sich über die subsequenten Passagierungen (Wang et al. 2000). Um ausreichende Isotopenmarkierung zu ermöglichen, mussten die Kardiofibroblasten über mehrere Passagen kultiviert werden. Die Repräsentativität der beobachteten Veränderungen für die in vivo stattfindenden Adaptationen ist somit möglicherweise beeinträchtigt. Auch Rückschlüsse auf einen Zusammenhang der im SILAC-Screen beobachteten Veränderungen der Plasmamembrankomposition mit der im FM 1-43-Färbeversuch dargestellten Zunahme 
der endozytotischen Membraninternalisierung sind nicht uneingeschränkt möglich. Zwar wurden im Rahmen dieser Arbeit auch Analysen des Gesamtmembranverkehrs in über mehrere Generationen kultivierten Kardiofibroblasten durchgeführt, die eine Induktion der Endozytose nahelegen (Anhang 3), aufgrund der höheren physiologischen Relevanz wurden für die in der vorliegenden Arbeit beschriebenen FM 1-43-Färbeversuche jedoch Zellen der P1-Generation verwendet.

\subsection{Schlussfolgerung und Ausblick}

Es konnte gezeigt werden, dass akute Hypoxie in Fibroblasten unterschiedlichen topographischen Ursprungs eine Induktion der endozytotischen Membranaufnahme und eine Veränderung der Morphologie intrazellulärer Membrankompartimente induziert. Dieser Effekt ist nach Reoxygenierung rasch reversibel. Dies deutet möglicherweise auf einen generellen, HIF-unabhängigen Adaptationsmechanismus des zellulären Membranverkehrs an Hypoxie hin. Eine Analyse des Plasmamembranproteoms ergab hierzu komplementär eine vermehrte Abundanz von kleinen, monomeren G-Proteinen sowie Interaktionspartnern dieser Proteine. Monomere G-Proteine sind zentrale Regulatoren der Endozytose, des Vesikeltransportes und der Endosomenverarbeitung (D'Souza-Schorey und Chavrier 2006; Doherty und McMahon 2009; Grant und Donaldson 2009; Hutagalung und Novick 2011).

Die in dieser Arbeit beschriebene Hypoxie-abhängige Induktion der endozytotischen Plasmamembran-Internalisierung und die Veränderung der intrazellulären Vesikelmorphologie konnten durch Stephanie Naas im Rahmen ihrer medizinischen Dissertation am Institut für Herz- und Kreislaufphysiologie der Universitätsmedizin Göttingen auch in embryonalen Mausfibroblasten und in einer humanen Adenokarzinom-Zelllinie demonstriert werden (Wottawa et al. 2017). Dies unterstützt die Hypothese, dass ein Speziesund Zelltyp-unabhängiger Phänotyp vorliegt. Durch den Knockdown bzw. Knockout von HIF-1 $\alpha$ konnte keine Veränderung der Hypoxie-abhängigen FM 1-43-Internalisierung erreicht werden. Auch der Knockdown von PHD2 beeinflusste den Phänotyp nicht (ebd.). Hierdurch konnte ein Einfluss des für die Hypoxie-Adaptation zentralen PHD2-HIF-1 $\alpha$ Transkriptionsweges (Berra et al. 2003; Bishop und Ratcliffe 2014) ausgeschlossen werden (Fandrey J. 2017; Wottawa et al. 2017).

Darüber hinaus konnte die Hypoxie-abhängige Induktion der Plasmamembraninternalisierung in WGA- und mCLING-Färbeversuchen bestätigt werden (Wottawa et al. 2017). Durch Kofärbungen mit fluoreszenzmarkierten Antikörpern gegen endosomale Markerproteine wurde ein verstärkter retrograder Membrantransport zum trans-GolgiNetzwerk nachgewiesen (ebd.). In Übereinstimmung mit den Beobachtungen von BourseauGuilmain et al. (2016) konnte eine Hypoxie-abhängige Induktion der Internalisierung von Choleratoxin-Untereinheit B nachgewiesen werden (Wottawa et al. 2017). Die Aufnahme von fluoreszenzmarkiertem Transferrin und Transferrin-Aptamer war im Gegensatz hierzu unter Hypoxie reduziert (ebd.). Dies steht in Übereinstimmung mit den Ergebnissen von 
Wang et al. (2009) und Khaidakov et al. (2014), jedoch im Widerspruch zur von BourseauGuilmain et al. (2016) beschriebenen verstärkten Transferrin-Aufnahme hypoxischer Zellen. Die differenzielle Aufnahme unterschiedlicher Verbindungen deutet auf die $\mathrm{O}_{2}$-abhängige Regulation spezifischer Endozytosemechanismen hin. Der fehlende Einfluss von Hypoxie auf die Aufnahme von Calcein als Marker der Aufnahme von extrazellulärer Flüssigkeit spricht für eine gezielte Internalisierung von Plasmamembranproteinen (Wottawa et al. 2017).

Ausgehend von den Ergebnissen einer SILAC-basierten Analyse des Einflusses von Hypoxie auf die Plasmamembrankomposition von Adenokarzinomzellen wurde das Aktin-bündelnde Protein T-Plastin als Regulator der Hypoxie-abhängigen Endozytose-Induktion identifiziert (Wottawa et al. 2017). Eine Regulation der endozytotischen Aufnahme extrazellulärer Flüssigkeit war bereits zuvor beschrieben worden (Hagiwara et al. 2011; Hosseinibarkooie et al. 2016). Es konnte gezeigt werden, dass T-Plastin unter Hypoxie bei unveränderter Expression vermehrt an die Plasmamembran rekrutiert wird (Wottawa et al. 2017). Nach Knockdown von T-Plastin war unter Hypoxie keine signifikant höhere FM 1-43-Aufnahme als unter Normoxie nachweisbar (ebd.).

Der Knockdown von T-Plastin verhinderte zudem die Hypoxie-induzierte Reorganisation von Aktinfilamenten (ebd.). Dies unterstreicht den engen Zusammenhang des Membranverkehrs mit dem Zytoskelett (Soldati und Schliwa 2006; Kapus und Janmey 2013). Der Mechanismus, über den der $\mathrm{pO}_{2}$ die Lokalisation und Aktivität von T-Plastin reguliert, ist jedoch unklar. Kleine, monomere G-Proteine der Rho-Familie kontrollieren die Dynamik des AktinZytoskeletts (Ridley 2006; Hall 2012). Die Expression und die Aktivität einiger Proteine dieser Familie ist abhängig vom $\mathrm{pO}_{2}$ (Zieseniss 2014). Zumindest ein Teil dieser Effekte ist abhängig von Hypoxie-induzierter ROS-Produktion (Turcotte et al. 2003). Der Nachweis einer ROS-abhängigen regulatorischen Funktion von RhoA in der Hypoxie-induzierten Internalisierung der Na/K-ATPase (Dada et al. 2007) legt einen ROS-vermittelten Zusammenhang zwischen G-Protein-vermittelten Veränderungen des Zytoskeletts und der endozytotischen Membranprotein-Internalisierung unter Hypoxie nahe. Zukünftige Untersuchungen des möglicherweise ROS-abhängigen Einflusses der Rho-Proteine auf den Gesamtmembranverkehr könnten daher neue Erkenntnisse über den zugrundeliegenden Mechanismus bringen.

Die Ausbildung des Aktin-Zytoskeletts ist abhängig von der Zellumgebung und die Kultivierungsbedingungen von Zellen können die Rolle von Aktin in der Endozytose modulieren (Fujimoto et al. 2000; Boulant et al. 2011). Darüber hinaus unterliegen primäre Zellen in vivo einer Vielzahl weiterer Einflüsse, die in Zellkultur nicht abgebildet werden und deren Fehlen phänotypische und funktionelle Abweichungen bedingt (Yeh et al. 1991; Dini et al. 2008; Rohr 2011; Zhuang et al. 2011; Weigert 2014). Auch wenn die Ergebnisse dieser Arbeit auf einen Zelltyp-unabhängigen Effekt von Hypoxie auf den Membranverkehr hindeuten, wäre aufgrund der komplexen Interaktion von Fibroblasten mit ihrer Umgebung 
die Analyse des Einflusses von Hypoxie auf den Gesamtmembranverkehr im physiologischen Gewebe von Interesse. Dies wäre möglicherweise durch ex vitro- oder intravitale Mikroskopie zu erreichen (Masedunskas und Weigert 2008; Pittet und Weissleder 2011; Weigert 2014).

Die in der vorliegenden Arbeit beschriebenen Ergebnisse geben Hinweise auf HIFunabhängige Adaptationsmechanismen des zellulären Membranverkehrs an Hypoxie. Aufgrund der Beteiligung des Membranverkehrs an einer Vielzahl extranukleärer zellulärer Prozesse (Doherty und McMahon 2009) impliziert dies Konsequenzen für eine unüberschaubare Vielfalt biologischer Vorgänge. Die Hypoxie-abhängige Induktion der Endozytoseaktivität geht mit Veränderungen der Plasmamembran-Proteinkomposition einher. Weiterführende Untersuchungen (Wottawa et al. 2017) legen ebenso wie die Daten anderer Arbeitsgruppen (Dada et al. 2003; Bourseau-Guilmain et al. 2016) eine spezifische Regulation der Proteininternalisierung unter Hypoxie nahe. Obwohl sie weniger als 8\% der Proteinmasse von HeLa-Zellen (Nagaraj et al. 2011) und nur ein Drittel der im menschlichen Genom kodierten Proteine ausmachen (Wallin und von Heijne 1998; Rabilloud 2003), wirkt die überwiegende Mehrheit von Medikamenten über die Interaktion mit Plasmamembranproteinen (Hopkins und Groom 2002; Rabilloud 2003). Aufgrund der zentralen Rolle von Hypoxie in der Pathophysiologie vieler Erkrankungen (Vaupel et al. 2007; Handley et al. 2011; Hossmann 2012; Bandarra et al. 2014) eröffnet die Charakterisierung des Einflusses von Hypoxie auf die zelluläre Membranprotein-Komposition möglicherweise vielfältige therapeutisch relevante medikamentöse Interventionsmöglichkeiten. 


\section{$5 \quad$ Zusammenfassung}

Hypoxie ist von zentraler Bedeutung für die Pathophysiologie von ischämischen, entzündlichen und malignen neoplastischen Erkrankungen, kennzeichnet jedoch auch Stammzellnischen sowie die intrauterine Umgebung während der embryonalen Entwicklung. Die Oxygenierung des Blutes und der Gewebe können sich in vivo schnell verändern, sodass Zellen in der Lage sein müssen, sich rasch an Einschränkungen des Sauerstoffangebotes zu adaptieren. Insbesondere das Myokard ist von einer konstanten Sauerstoffversorgung abhängig. Entwicklung, Struktur und Funktion, aber auch Remodeling des Herzgewebes werden durch Kardiofibroblasten reguliert. Die hierzu notwendige Interaktion einer Zelle mit ihrer Umgebung wird durch die Plasmamembran vermittelt. Deren Zusammensetzung ist ebenso wie eine große Vielzahl biologischer Prozesse abhängig vom zellulären Membranverkehr. Ziel dieser Arbeit war daher die Untersuchung des Einflusses von kurzfristiger Hypoxie auf den zellulären Membranverkehr und die Zusammensetzung der Plasmamembran.

$\mathrm{Zu}$ diesem Zweck wurde durch Membranmarkierung mit dem lipophilen Fluoreszenzfarbstoff FM 1-43 der Gesamtmembranumsatz von primären Fibroblasten unterschiedlicher topographischer Herkunft nach sechsstündiger Inkubation in Hypoxie mit dem Membranumsatz in Normoxie inkubierter Zellen verglichen. Hypoxie führte zu einer Steigerung der endozytotischen Membraninternalisierung und einer Größenzunahme der endosomalen Strukturen. Der Effekt war bereits nach kurzer Reoxygenierung vollständig reversibel. Diese Kinetik deutet möglicherweise auf einen HIF-unabhängigen zugrundeliegenden Mechanismus hin. Frühere Untersuchungen des Einflusses von Hypoxie auf spezifische Teilbereiche des Membranverkehrs und die Expression einzelner Proteine an der Plasmamembran zeigten bei heterogener Methodik zum Teil widersprüchliche Ergebnisse. Eine Analyse des Gesamtmembranumsatzes von primären Zellen wurde bisher nicht durchgeführt.

Ausgehend von der Hypoxie-abhängig verstärkten endozytotischen Membraninternalisierung wurde ein SILAC-Screen des Plansmamembranproteoms von Kardiofibroblasten durchgeführt, um die Membranprotein-Komposition in Normoxie und nach sechsstündiger Hypoxie zu analysieren. Unter Hypoxie wurden auffallend viele kleine, monomere G-Proteine vermehrt an der Plasmamembran identifiziert. Diese Proteine sind zentrale Regulatoren des Membranverkehrs.

Diese Ergebnisse ermöglichen neue Einblicke in die Adaptation zentraler zellulärer Prozesse an Hypoxie. Weiterführende Analysen der Kinetik und der physiologischen Konsequenzen des Einflusses von Hypoxie auf den Membranverkehr sowie der zugrundeliegenden molekularen Mechanismen könnten zukünftig für die Therapie Hypoxie-assoziierter Erkrankungen nutzbare Erkenntnisse bringen. 


\section{$6 \quad$ Anhang}

\subsection{Anhangsverzeichnis}

Anhang 1: Proteine, die im SILAC-Screen unter Hypoxie vermehrt in bzw. assoziiert mit der Plasmamembran nachgewiesen wurden.

Anhang 2: Proteine, die im SILAC-Screen unter Hypoxie vermindert in bzw. assoziiert mit der Plasmamembran nachgewiesen wurden.

Anhang 3: FM 1-43-Färbung von über drei Passagierungen kultivierten Kardiofibroblasten unter Normoxie und Hypoxie.

\subsection{Im SILAC-Screen als Hypoxie-abhängig differenziell reguliert identifizierte Proteine}

Anhang 1: Proteine, die im SILAC-Screen konsistent unter Hypoxie um mindestens 50\% vermehrt in bzw. assoziiert mit der Plasmamembran von Kardiofibroblasten neonataler Ratten nachgewiesen wurden

\begin{tabular}{|c|c|c|c|c|}
\hline Protein & $\begin{array}{l}\text { Gen- } \\
\text { Name }\end{array}$ & $\begin{array}{l}\text { UniProt- } \\
\text { Zugangsnr. }\end{array}$ & \begin{tabular}{|l|} 
Normierte \\
Signal- \\
intensität \\
in Exp. A
\end{tabular} & $\begin{array}{l}\text { Normierte } \\
\text { Signal- } \\
\text { intensität } \\
\text { in Exp. B }\end{array}$ \\
\hline Peflin & Pef1 & Q641Z8 & 3,661 & 0,386 \\
\hline $\begin{array}{l}\text { Interferon-induziertes GTP-bindendes } \\
\text { Protein } \mathrm{Mx} 2\end{array}$ & Mx2 & P18589 & 3,166 & 0,196 \\
\hline Hitzeschockprotein $\beta-1$ & Hspb1 & P42930 & 2,797 & 0,262 \\
\hline Mikrotubuli-assoziiertes Protein 1B & Map1b & F1LRL9 & 2,745 & 0,444 \\
\hline E3 Ubiquitin-Proteinligase PDZRN3 & Pdzrn3 & P68907 & 2,638 & 0,402 \\
\hline LHFPL tetraspan subfamily member 6 protein & Lhfp & Q5BJS2 & 2,556 & 0,449 \\
\hline Secretion-associated, Ras-related GTPase 1A & Sar1a & Q6AY18 & 2,521 & 0,245 \\
\hline Tropomyosin $1, \alpha$, Isoform CRA_h & Tpm1 & Q91XN6 & 2,479 & 0,225 \\
\hline ADP-Ribosylierungsfaktor 4 & Arf4 & P61751 & 2,357 & 0,358 \\
\hline Ras homolog family member $C$ & Rhoc & B2RYP0 & 2,312 & 0,302 \\
\hline GTP-bindendes Protein Rheb & Rheb & Q62639 & 2,301 & 0,247 \\
\hline PDZ and LIM domain 3, Isoform CRA_b & Pdlim3 & D3ZFR7 & 2,173 & 0,176 \\
\hline Trk-fused gene & Tfg & Q6AYR1 & 2,161 & 0,29 \\
\hline Transmembranprotein 47 & Tmem47 & D3ZBB3 & 2,109 & 0,329 \\
\hline$\alpha$-Kristallin B Kette & Cryab & P23928 & 2,1 & 0,256 \\
\hline Arf-GAP 1 Herz-Isoform & Arfgap1 & Q3S4A4 & 2,091 & 0,471 \\
\hline E3 Ubiquitin-Proteinligase UBR4 & Ubr4 & Q2TL32 & 2,077 & 0,426 \\
\hline $\begin{array}{l}\text { Peptidyl-Prolyl cis-trans Isomerase } \\
\text { FKBP1A }\end{array}$ & Fkbp1a & Q62658 & 2,073 & 0,348 \\
\hline Serin/Threonin-Proteinkinase Nek6 & Nek6 & P59895 & 2,063 & 0,331 \\
\hline $\begin{array}{l}\text { Carbamoyl-Phosphat Synthetase 2, } \\
\text { Aspartat Transcarbamylase und } \\
\text { Dihydroorotase }{ }^{\text {a }}\end{array}$ & Cad & D4A8A0 & 1,949 & 0,291 \\
\hline
\end{tabular}




\begin{tabular}{|c|c|c|c|c|}
\hline Protein & $\begin{array}{l}\text { Gen- } \\
\text { Name }\end{array}$ & $\begin{array}{l}\text { UniProt- } \\
\text { Zugangsnr. }\end{array}$ & $\begin{array}{l}\text { Normierte } \\
\text { Signal- } \\
\text { intensität } \\
\text { in Exp. A } \\
\end{array}$ & $\begin{array}{l}\text { Normierte } \\
\text { Signal- } \\
\text { intensität } \\
\text { in Exp. B } \\
\end{array}$ \\
\hline Glypikan $6^{\text {b }}$ & Gpc6 $^{b}$ & $\begin{array}{l}\text { A0A096MJY } \\
1^{\text {b }}\end{array}$ & 1,941 & 0,573 \\
\hline Kinesin-1 schwere Kette & Kif5b & Q2PQA9 & 1,934 & 0,607 \\
\hline Myosin phosphatase Rho-interacting protein & Mprip & G3V9F3 & 1,923 & 0,367 \\
\hline Perilipin & Plin3 & M0RA08 & 1,91 & 0,299 \\
\hline C-type lectin domain family 2 member D11 & Clec2d11 & Q0H8B9 & 1,909 & 0,431 \\
\hline Phosphoinositid-Phospholipase C & Plcb4 & D4A8C5 & 1,909 & 0,553 \\
\hline T-Komplex Protein 1 Untereinheit $\varepsilon$ & Cct5 & Q68FQ0 & 1,893 & 0,303 \\
\hline Neudesin & Nenf & Q6IUR5 & 1,886 & 0,583 \\
\hline $\begin{array}{l}\text { 3'-Phosphoadenosin 5'- } \\
\text { Phosphosulfatsynthase } 2\end{array}$ & Papss2 & B5DFH4 & 1,885 & 0,512 \\
\hline $\begin{array}{l}\text { Zytoplasmatische Dynein } 1 \text { leichte } \\
\text { Intermediärkette } 2\end{array}$ & Dync1li2 & Q62698 & 1,883 & 0,389 \\
\hline Proteinkinase C $\delta$-bindendes Protein & Prkcdb & Q9Z1H9 & 1,87 & 0,541 \\
\hline Ras-ähnliches Protein Rab30 & Rab30 & Q5BK72 & 1,867 & 0,597 \\
\hline Glypikan 4 & Gpc4 & Q642B0 & 1,858 & 0,34 \\
\hline Tripeptidyl-Peptidase 2 & Tpp2 & Q64560 & 1,853 & 0,458 \\
\hline T-Komplex Protein 1 Untereinheit $\alpha$ & Tcp1 & P28480 & 1,831 & 0,268 \\
\hline Programmed cell death protein 6 & Pdcd6 & G3V7W1 & 1,829 & 0,618 \\
\hline Visinin-ähnliches Protein 1 & Vsnl1 & P62762 & 1,828 & 0,492 \\
\hline $\begin{array}{l}\text { Guaninnukleotid-bindendes Protein } \\
\text { Untereinheit } \gamma\end{array}$ & Gng12 & G3V6P8 & 1,815 & 0,306 \\
\hline Kinesin Leichtkette 1 & Klc1 & P37285 & 1,811 & 0,417 \\
\hline DnaJ homolog subfamily A member 2 & Dnaja2 & O35824 & 1,81 & 0,411 \\
\hline Elongationsfakor $1-\delta$ & Eef1d & Q68FR9 & 1,808 & 0,558 \\
\hline $\begin{array}{l}\text { Kalzium/Kalmodulin-abhängige } \\
\text { Proteinkinase Typ II Untereinheit } \delta\end{array}$ & Camk2d & P15791 & 1,806 & 0,41 \\
\hline Hebp1 Protein & Hebp1 & B4F7C7 & 1,802 & 0,573 \\
\hline Trafficking protein particle complex 6B & Trappc6b & D3ZES2 & 1,796 & 0,663 \\
\hline $\begin{array}{l}\text { Connector enhancer of kinase suppressor of Ras } \\
3\end{array}$ & Cnksr3 & Q5SGD7 & 1,776 & 0,485 \\
\hline Ras-ähnliches Protein Rab2b & Rab2b & Q3B7V5 & 1,768 & 0,626 \\
\hline Neuronaler Kalziumsensor 1 & Ncs1 & P62168 & 1,767 & 0,638 \\
\hline Myeloid-derived growth factor ${ }^{\mathrm{c}}$ & $\operatorname{Mydgf}^{c}$ & M0R3V4 & 1,759 & 0,669 \\
\hline Retinol-bindendes Protein 1 & Rbp1 & P02696 & 1,758 & 0,359 \\
\hline A-kinase Ankerprotein 5 & Akap5 & P24587 & 1,754 & 0,387 \\
\hline $\begin{array}{l}\text { Large neutral amino acids transporter small } \\
\text { subunit } 1\end{array}$ & Slc7a5 & Q63016 & 1,744 & 0,424 \\
\hline Canopy 4 Homolog (Zebrafish) & Cnpy4 & B1WC84 & 1,742 & 0,53 \\
\hline Four and a half LIM domains 1 & Fhl1 & Q6P792 & 1,74 & 0,599 \\
\hline Eukaryotic translation elongation factor $1 \beta 2$ & Eef1b2 & B5DEN5 & 1,732 & 0,481 \\
\hline Chaperonin-containing TCP1 subunit 7 & Cct7 & D4AC23 & 1,732 & 0,29 \\
\hline Ras-ähnliches Protein Rab23 & Rab23 & D3ZRM5 & 1,73 & 0,337 \\
\hline Protein Numb Homolog & Numb & F1LNZ2 & 1,718 & 0,524 \\
\hline Inositol Polyphosphate-5-Phosphatase A & Inpp5a & D3ZZX1 & 1,69 & 0,355 \\
\hline T-Komplex Protein 1 Untereinheit $\gamma$ & Cct3 & Q6P502 & 1,684 & 0,315 \\
\hline
\end{tabular}




\begin{tabular}{|c|c|c|c|c|}
\hline Protein & $\begin{array}{l}\text { Gen- } \\
\text { Name }\end{array}$ & $\begin{array}{l}\text { UniProt- } \\
\text { Zugangsnr. }\end{array}$ & \begin{tabular}{|l|} 
Normierte \\
Signal- \\
intensität \\
in Exp. A
\end{tabular} & $\begin{array}{l}\text { Normierte } \\
\text { Signal- } \\
\text { intensität } \\
\text { in Exp. B }\end{array}$ \\
\hline Rho GEF 40 & Arhgef40 & $\begin{array}{l}\text { A0A0G2JZ } \\
\text { E7 }^{\text {d }}\end{array}$ & 1,671 & 0,612 \\
\hline DCN1-like protein 3 & Dcun1d3 & Q4V8B2 & 1,666 & 0,331 \\
\hline $\begin{array}{l}\text { PTB domain-containing engulfment adapter } \\
\text { protein } 1\end{array}$ & Gulp1 & Q5PQS4 & 1,666 & 0,4 \\
\hline Tropomyosin $\alpha-4$ Kette & Tpm4 & P09495 & 1,663 & 0,256 \\
\hline Nukleobindin-2 & Nucb2 & Q9JI85 & 1,659 & 0,606 \\
\hline Ac1288 & $-^{\mathrm{e}}$ & Q7TQ77 & 1,655 & 0,565 \\
\hline Neutral amino acid transporter ASCT1 & Slc1a4 & Q76GL9 & 1,654 & 0,329 \\
\hline Hämoxygenase 1 & Hmox1 & P06762 & 1,652 & 0,619 \\
\hline \begin{tabular}{|l|} 
Interferon-induziertes \\
Transmembranprotein 3 \\
\end{tabular} & ifitm3 & P26376 & 1,65 & 0,599 \\
\hline Latexin & Lxn & Q64361 & 1,642 & 0,302 \\
\hline T-Komplex Protein 1 Untereinheit $\delta$ & Cct4 & Q7TPB1 & 1,64 & 0,297 \\
\hline $\begin{array}{l}\text { Phosphatidylinositol Transferprotein } \beta \\
\text { Isoform }\end{array}$ & Pitpnb & P53812 & 1,637 & 0,397 \\
\hline Trafficking protein particle complex subunit 3 & Trappc3 & Q5U1Z2 & 1,631 & 0,467 \\
\hline Phospholipid-phosphatase 3 & Plpp3 & P97544 & 1,63 & 0,389 \\
\hline Thioredoxin domain-containing protein 12 & Txndc12 & Q498E0 & 1,629 & 0,598 \\
\hline CD151 Antigen & Cd151 & Q9QZA6 & 1,629 & 0,377 \\
\hline CD59 Glykoprotein & $\mathrm{Cd} 59$ & P27274 & 1,623 & 0,499 \\
\hline PDZ and LIM domain protein 5 & Pdlim5 & Q62920 & 1,623 & 0,474 \\
\hline $\begin{array}{l}\text { Interferon-induziertes } \\
\text { Transmembranprotein } 2\end{array}$ & Ifitm2 & Q9R175 & 1,623 & 0,547 \\
\hline Phospholipidphosphatase 1 & Ppap2a & O08564 & 1,617 & 0,471 \\
\hline $\begin{array}{l}\text { CKLF-like MARVEL transmembrane } \\
\text { domain-containing } 7\end{array}$ & $\mathrm{Cmtm} 7$ & D4A768 & 1,614 & 0,591 \\
\hline Calponin-1 & Cnn1 & Q08290 & 1,614 & 0,254 \\
\hline $\begin{array}{l}\text { Guaninnukleotid-bindendes Protein G(i) } \\
\text { Untereinheit } \alpha-1\end{array}$ & Gnai1 & P10824 & 1,61 & 0,319 \\
\hline Chaperonin containing Tcp1, subunit 6A (ל 1) & Cct6a & Q3MHS9 & 1,61 & 0,298 \\
\hline $\begin{array}{l}\text { Transforming growth factor beta-1-induced } \\
\text { transcript } 1 \text { protein }\end{array}$ & Tgfb1i1 & Q99PD6 & 1,605 & 0,265 \\
\hline $\begin{array}{l}\text { Hepatocyte growth factor-regulated tyrosine } \\
\text { kinase substrate }\end{array}$ & Hgs & Q9JJ50 & 1,602 & 0,522 \\
\hline LDLR Chaperon MESD & Mesd & Q5U2R7 & 1,602 & 0,561 \\
\hline Ras-ähnliches Protein R-Ras2 & Rras2 & Q5BJU0 & 1,596 & 0,35 \\
\hline Golgin subfamily $A$ member 7 & Golga7 & Q6AYQ1 & 1,594 & 0,357 \\
\hline Epsin 2 & Epn2 & F1LQ45 & 1,59 & 0,579 \\
\hline Proteasom Untereinheit $\alpha$ Typ 1 & Psma1 & P18420 & 1,586 & 0,381 \\
\hline Apoptoseregulator BAX & Bax & G3V8T9 & 1,584 & 0,437 \\
\hline Sulfatase-modifying factor 2 & Sumf2 & D3ZTR4 & 1,583 & 0,609 \\
\hline Dihydropyrimidinase-related protein 3 & Dpysl3 & Q62952 & 1,582 & 0,315 \\
\hline Myristoylated alanine-rich C-kinase substrate & Marcks & P30009 & 1,582 & 0,352 \\
\hline $\begin{array}{l}\text { Guaninnukleotid-bindendes Protein } \\
G(\mathrm{I}) / \mathrm{G}(\mathrm{S}) / \mathrm{G}(\mathrm{T}) \text { Untereinheit } \beta-1\end{array}$ & Gnb1 & P54311 & 1,578 & 0,377 \\
\hline RNA-bindendes Protein 3 & Rbm3 & Q925G0 & 1,576 & 0,55 \\
\hline
\end{tabular}




\begin{tabular}{|c|c|c|c|c|}
\hline Protein & $\begin{array}{l}\text { Gen- } \\
\text { Name }\end{array}$ & $\begin{array}{l}\text { UniProt- } \\
\text { Zugangsnr. }\end{array}$ & \begin{tabular}{|l} 
Normierte \\
Signal- \\
intensität \\
in Exp. A
\end{tabular} & $\begin{array}{l}\text { Normierte } \\
\text { Signal- } \\
\text { intensität } \\
\text { in Exp. B }\end{array}$ \\
\hline \begin{tabular}{|l} 
Interferon-induziertes \\
Transmembranprotein 1
\end{tabular} & Ifitm1 & F1M3Q1 & 1,576 & 0,53 \\
\hline $\begin{array}{l}\text { Guaninnukleotid-bindendes Protein } \mathrm{G}(\mathrm{q}) \\
\text { Untereinheit } \alpha\end{array}$ & Gnaq & D4AE68 & 1,575 & 0,493 \\
\hline Dibydropyrimidinase-related protein 2 & Dpysl2 & P47942 & 1,574 & 0,28 \\
\hline Elongin-C & Eloc & P83941 & 1,574 & 0,536 \\
\hline Endophilin-B1 & Sh3glb1 & Q6AYE2 & 1,566 & 0,407 \\
\hline Pkp2 Protein & Pkp2 & Q562C0 & 1,566 & 0,419 \\
\hline Ras-ähnliches Protein Rab34 & Rab34 & Q5U1Y1 & 1,565 & 0,45 \\
\hline Gewebefaktor & F3 & P42533 & 1,564 & 0,362 \\
\hline $\begin{array}{l}\text { DnaJ (Hsp40) bomolog, subfamily B, member } \\
4\end{array}$ & Dnajb4 & Q5XIP0 & 1,564 & 0,634 \\
\hline Asparaginyl-tRNA Synthetase & Nars & Q4KLM9 & 1,562 & 0,415 \\
\hline Galektin-1 & Lgals1 & P11762 & 1,558 & 0,423 \\
\hline $\begin{array}{l}\text { Death domain-containing membrane protein } \\
N R A D D\end{array}$ & Nradd & Q8K5A9 & 1,557 & 0,448 \\
\hline Spg20 Protein & Spg20 & Q4FZR7 & 1,557 & 0,41 \\
\hline $\begin{array}{l}\text { Microtubule-associated proteins } 1 A / 1 B \text { light } \\
\text { chain 3A }\end{array}$ & Map1lc3a & Q6XVN8 & 1,556 & 0,594 \\
\hline$V$-type proton ATPase subunit F & Atp6v1f & P50408 & 1,554 & 0,628 \\
\hline Calcium homeostasis modulator protein 2 & Calhm2 & Q5RJQ8 & 1,551 & 0,396 \\
\hline Four and a half LIM domains 1 & Fhl2 & O35115 & 1,55 & 0,489 \\
\hline Thy-1 Membranglykoprotein & Thy1 & P01830 & 1,55 & 0,422 \\
\hline Clathrin Leichtkette B & Cltb & P08082 & 1,549 & 0,439 \\
\hline Ras-ähnliches Protein Rab18 & Rab18 & Q5EB77 & 1,546 & 0,641 \\
\hline $\begin{array}{l}\text { Proteasome (Prosome, macropain) 26S subunit, } \\
\text { non-ATPase, } 7\end{array}$ & Psmd7 & D4AEH3 & 1,541 & 0,616 \\
\hline T-Komplex Protein 1 Untereinheit $\beta$ & Cct2 & Q5XIM9 & 1,541 & 0,284 \\
\hline G Protein Untereinheit $\beta-2$ & Gnb2 & P54313 & 1,537 & 0,391 \\
\hline $\begin{array}{l}\text { Stip1 homology and U-Box containing protein } \\
\text { 1, Isoform CRA_b }\end{array}$ & Stub1 & D4A4T0 & 1,537 & 0,376 \\
\hline C2 calcium-dependent domain-containing 2 & $\mathrm{C} 2 \mathrm{~cd} 2$ & Q6P691 & 1,536 & 0,528 \\
\hline Ras-ähnliches Protein R-Ras & Rras & D3Z8L7 & 1,535 & 0,403 \\
\hline $\begin{array}{l}\text { Arf-GAP domain and FG repeat-containing } \\
\text { protein } 1\end{array}$ & Agfg1 & Q4KLH5 & 1,527 & 0,569 \\
\hline $\begin{array}{l}\text { Proteasome (Prosome, macropain) activator } \\
\text { subunit } 1\end{array}$ & Psme1 & Q6P9V7 & 1,524 & 0,294 \\
\hline RELT-like 1 & Rell1 & B0BNL7 & 1,524 & 0,279 \\
\hline Acid sphingomyelinase-like phosphodiesterase & Smpdl3b & Q4V7D9 & 1,522 & 0,376 \\
\hline $\begin{array}{l}\text { V acuolar protein sorting-associated protein } 28 \\
\text { homolog }\end{array}$ & Vps28 & B5DEN9 & 1,518 & 0,549 \\
\hline Ras-ähnliches Protein Rab1B & Rab1b & P10536 & 1,518 & 0,617 \\
\hline Caveolin-1 & Cav1 & P41350 & 1,518 & 0,603 \\
\hline ADP-Ribosylierungsfaktor 5 & Arf5 & P84083 & 1,515 & 0,362 \\
\hline Dynein Leichtkette Tctex-Typ 1 & Dynlt1 & Q9Z336 & 1,512 & 0,508 \\
\hline Oxidized low-density lipoprotein receptor 1 & Olr1 & O70156 & 1,509 & 0,394 \\
\hline Elongin-B & Elob & P62870 & 1,508 & 0,524 \\
\hline
\end{tabular}




\begin{tabular}{|l|l|l|l|l|}
\hline Protein & Gen- & UniProt- & $\begin{array}{l}\text { Normierte } \\
\text { Signal- } \\
\text { Zugangsnr. } \\
\text { intensität } \\
\text { in Exp. A } \\
\text { Signal- } \\
\text { intensität } \\
\text { in Exp. B }\end{array}$ \\
\hline LIM and cysteine-rich domains 1 & Lmcd1 & Q6AYF2 & 1,508 & 0,246 \\
\hline Tetraspanin & Cd81 & Q6P9V1 & 1,507 & 0,401 \\
\hline Hypothetisches Protein LOC681410 & Hnrnpa0 & F1M3H8 & 1,507 & 0,653 \\
\hline Supervillin & Svil & F1M155 & 1,507 & 0,338 \\
\hline $\begin{array}{l}\text { Phosphatidylsäurephosphatase 2a, } \\
\text { Isoform CRA_b }\end{array}$ & Ppap2a & G3V9Y2 & 1,505 & 0,46 \\
\hline RCG55706 & Stam & B5DF55 & 1,503 & 0,549 \\
\hline Choline transporter-like protein 2 & Slc44a2 & B4F795 & 1,503 & 0,372 \\
\hline
\end{tabular}

Normierte Signalintensität in Exp. A: Signalintensität mit schweren Isotopen markierter Membranproteine von Kardiofibroblasten, die für sechs Stunden bei Hypoxie $\left(1 \% \mathrm{O}_{2}\right)$ inkubiert wurden, normiert auf die Signalintensität der mit leichten Isotopen markierten korrespondierenden Membranproteine von Kardiofibroblasten, die bei Normoxie $\left(\begin{array}{lll}20 \% & \mathrm{O}_{2}\end{array}\right)$ inkubiert wurden; Schwellenwert $>1,5$. Normierte Signalintensität in Exp. B: Verhältnis der Signalintensitäten mit schweren Isotopen markierter Membranproteine, die bei Normoxie inkubiert wurden, zu der Signalintensität von mit leichten Isotopen markierten korrespondierenden Proteinen, die für sechs Stunden unter Hypoxie inkubiert wurden; Schwellenwert <0,67. Sortierung nach normierter Signalintensität in Experiment A. Arf-GAP: Adenosyl-Ribosylierungsfaktor-GTPase aktivierendes Protein, Exp: Experiment, GEF: Guaninnukleotid-Austauschfaktor, Zugangsnr.: Zugangsnummer.

a ehemals (ehm.) DNA-Fragmentierungsfaktor Untereinheit B; b ehm. uncharakterisiertes Protein, UniProt-Zugangsnr. D4AA04; c ehm. Protein LOC501282, Genn-Name LOC501282; d ehm. F1LZN; e ehm. Hook3

Anhang 2: Proteine, die im SILAC-Screen konsistent unter Hypoxie um mindestens 50\% vermindert in bzw. assoziiert mit der Plasmamembran von Kardiofibroblasten neonataler Ratten nachgewiesen wurden

\begin{tabular}{|c|c|c|c|c|}
\hline Protein & Gen-Name & $\begin{array}{l}\text { UniProt- } \\
\text { Zugangsnr. }\end{array}$ & $\begin{array}{l}\text { Normierte } \\
\text { Signal- } \\
\text { intensität } \\
\text { in Exp. A }\end{array}$ & $\begin{array}{l}\text { Normierte } \\
\text { Signal- } \\
\text { intensität } \\
\text { in Exp. B }\end{array}$ \\
\hline Kollagen $\alpha$-1(I) Kette & Col1a1 & P02454 & 0,37 & 2,846 \\
\hline $\begin{array}{l}\text { High density lipoprotein binding protein } \\
\text { (Vigilin) }\end{array}$ & Hdlbp & Q3KRF2 & 0,475 & 2,378 \\
\hline 605 ribosomal protein L29 & Rpl29 & P25886 & 0,626 & 2,355 \\
\hline Kollagen Typ I $\alpha 2$ Kette & Col1a2 & F1LS40 & 0,453 & 2,235 \\
\hline $\begin{array}{l}\text { Eukaryotic translation initiation factor } 3 \\
\text { subunit B }\end{array}$ & Eif3b & Q4G061 & 0,645 & 2,197 \\
\hline Kollagen $\alpha$-1(XII) Kette & Col12a1 & P70560 & 0,61 & 2,13 \\
\hline Uncharakterisiertes Protein $^{a}$ & Gigyf2 $^{a}$ & B2RYE6 $^{a}$ & 0,52 & 2,114 \\
\hline Endothelial differentiation-related factor 1 & Edf1 & P69736 & 0,582 & 2,101 \\
\hline $40 S$ ribosomal protein $S A$ & Rpsa & P38983 & 0,619 & 1,975 \\
\hline Fibronektin & Fn1 & F1LST1 & 0,594 & 1,957 \\
\hline $\begin{array}{l}\text { Glycylpeptid N- } \\
\text { Tetradekanoyltransferase } 1\end{array}$ & Nmt1 & Q8K1Q0 & 0,613 & 1,95 \\
\hline HEAT repeat-containing protein 1 & Heatr1 & D3ZL86 & 0,377 & 1,949 \\
\hline RNA Cytidin Azetyltransferase & RGD1306717 & B5DFI0 & 0,468 & 1,947 \\
\hline Dpy-19-like 2 & Dyp1912 & M0RC58 & 0,535 & 1,934 \\
\hline $\begin{array}{l}N(\text { alpha)-acetyltransferase } 15, \text { NatA } \\
\text { auxiliary subunit }{ }^{\text {b }}\end{array}$ & Naa15 & D3ZD89 & 0,476 & 1,9 \\
\hline
\end{tabular}




\begin{tabular}{|l|l|l|l|l|}
\hline Protein & Gen-Name & $\begin{array}{l}\text { UniProt- } \\
\text { Zugangsnr. }\end{array}$ & $\begin{array}{l}\text { Normierte } \\
\text { Signal- } \\
\text { intensität } \\
\text { in Exp. A }\end{array}$ & $\begin{array}{l}\text { Sormierte } \\
\text { Signal- } \\
\text { intensität } \\
\text { in Exp. B }\end{array}$ \\
\hline Ubiquitin-associated protein 2-like & Ubap2l & E9PTR4 & 0,49995 & 1,899 \\
\hline Disabled homolog 2 & Dab2 & O88797 & 0,515 & 1,884 \\
\hline Programmed cell death 11 & Pdcd11 & D3ZNI3 & 0,376 & 1,753 \\
\hline Procollagen C-endopeptidase enhancer 1 & Pcolce & O08628 & 0,539 & 1,717 \\
\hline Ribosomal RNA-processing 12 homolog & LOC679127 & M0R3M8 & 0,568 & 1,691 \\
\hline Methionin Aminopeptidase & Metap1 & D3ZE72 & 0,559 & 1,653 \\
\hline $\begin{array}{l}\text { Nucleolar and coiled-body phosphoprotein } \\
1\end{array}$ & Nolc1 & P41777 & 0,518 & 1,624 \\
\hline Septin-2 & Sept2 & Q91Y81 & 0,615 & 1,618 \\
\hline $\begin{array}{l}\text { U3 small nucleolar RNA-associated } \\
\text { protein 15 homolog }\end{array}$ & Utp15 & A2RRU3 & 0,499 & 1,615 \\
\hline Myb-bindendes Protein 1A & Mybbp1a & O35821 & 0,346 & 1,612 \\
\hline Basischer Transkriptionsfaktor 3 & Btf3 & Q5U3Y8 & 0,662 & 1,575 \\
\hline Golgin subfamily A member 4 & Golga4 & Q5U4E6 & 0,622 & 1,544 \\
\hline Fibronectin type III domain-containing 3B & Fndc3b & D4A0W7 & 0,573 & 1,524 \\
\hline WD repeat domain 36 & Wdr36 & M0RAY7 & 0,508 & 1,517 \\
\hline
\end{tabular}

Normierte Signalintensität in Exp. A: Signalintensität mit schweren Isotopen markierter Membranproteine von Kardiofibroblasten, die für sechs Stunden bei Hypoxie $\left(1 \% \mathrm{O}_{2}\right)$ inkubiert wurden, normiert auf die Signalintensität der mit leichten Isotopen markierten korrespondierenden Membranproteine von Kardiofibroblasten, die bei Normoxie $\left(20 \% \mathrm{O}_{2}\right)$ inkubiert wurden; Schwellenwert $>1,5$. Normierte Signalintensität in Exp. B: Verhältnis der Signalintensitäten mit schweren Isotopen markierter Membranproteine, die bei Normoxie inkubiert wurden, zu der Signalintensität von mit leichten Isotopen markierten korrespondierenden Proteinen, die für sechs Stunden unter Hypoxie inkubiert wurden; Schwellenwert <0,67. Sortierung nach normierter Signalintensität in Experiment B. Exp.: Experiment, Zugangsnr.: Zugangsnummer.

a ehm. ehm. Protein LOC100362458, Genn-Name LOC100362458, UniProt-Zugangsnr. D3ZXW6;

b ehm. NMDA-Rezeptor reguliertes Gen 1 Isoform CRA_b 


\subsection{FM 1-43-Färbung von über drei Passagierungen kultivierten Kardiofibroblasten unter Normoxie und Hypoxie}

A

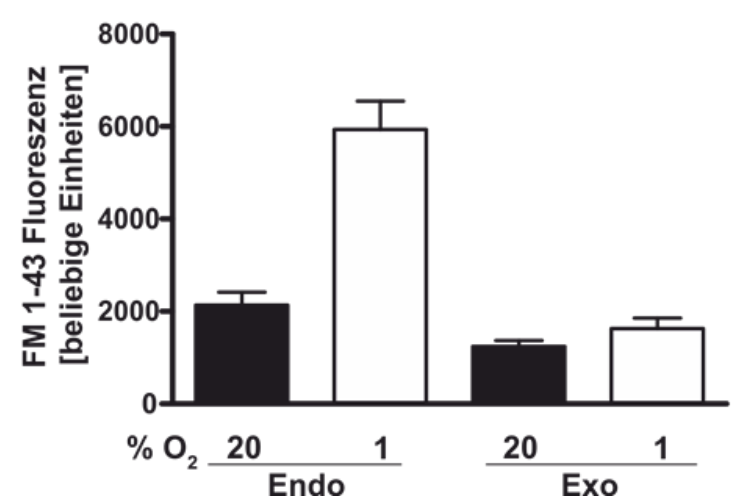

B

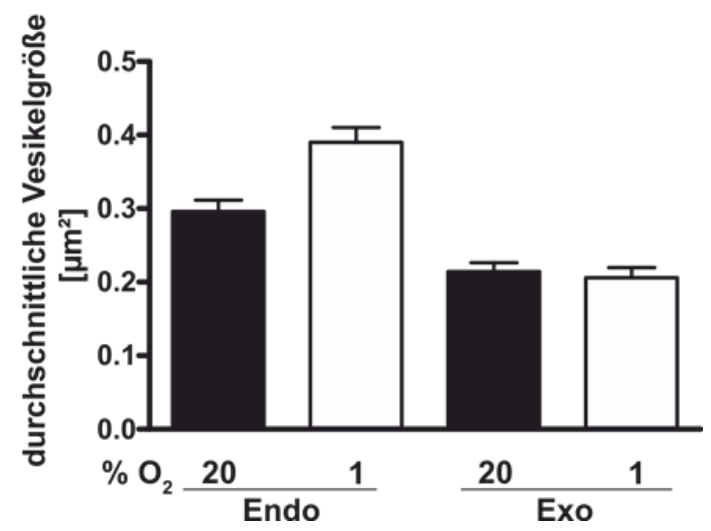

Anhang 3: FM 1-43-Färbung von über drei Passagierungen kultivierten Kardiofibroblasten unter Normoxie und Hypoxie. Kardiofibroblasten neonataler Ratten wurden über drei Passagierungen in Normoxie kultiviert. Anschließend erfolgte eine sechsstündige Inkubation in Normoxie $\left(20 \% \mathrm{O}_{2}\right)$ oder Hypoxie $\left(1 \% \mathrm{O}_{2}\right)$. Endo- und Exozytose wurden durch Membranfärbungen mit FM 1-43 quantifiziert. (A) Fluoreszenz der Zellen in beliebigen Einheiten. (B) Durchschnittliche Vesikelgröße. Ein Versuch. Pro Bedingung wurden jeweils mindestens 19 Zellen analysiert. Endo: Endozytose, Exo: Exozytose. Fehlerbalken entsprechen dem Standardfehler des Mittelwertes. 


\section{$7 \quad$ Literaturverzeichnis}

Aderem A, Underhill DM (1999): Mechanisms of Phagocytosis in Macrophages. Annu Rev Immunol $\underline{17}$, 593-623

Aizawa M, Fukuda M (2015): Small GTPase Rab2B and Its Specific Binding Protein Golgi-associated Rab2B Interactor-like 4 (GARI-L4) Regulate Golgi Morphology. J Biol Chem 290, 22250-22261

Aldosari S, Awad M, Harrington EO, Sellke FW, Abid MR (2018): Subcellular Reactive Oxygen Species (ROS) in Cardiovascular Pathophysiology. Antioxidants $\underline{7}, 14$

An SS, Pennella CM, Gonnabathula A, Chen J, Wang N, Gaestel M, Hassoun PM, Fredberg JJ, Kayyali US (2005): Hypoxia alters biophysical properties of endothelial cells via p38 MAPK- and Rho kinasedependent pathways. Am J Physiol-Cell Physiol 289, C521-C530

Anderson RG, Goldstein JL, Brown MS (1977): A mutation that impairs the ability of lipoprotein receptors to localise in coated pits on the cell surface of human fibroblasts. Nature 270, 695-699

Andersson ER (2012): The role of endocytosis in activating and regulating signal transduction. Cell Mol Life Sci $\underline{69}, 1755-1771$

Antonny B, Bigay J, Casella J-F, Drin G, Mesmin B, Gounon P (2005): Membrane curvature and the control of GTP hydrolysis in Arf1 during COPI vesicle formation. Biochem Soc Trans $\underline{33}$, 619-622

Appelhoff RJ, Tian Y-M, Raval RR, Turley H, Harris AL, Pugh CW, Ratcliffe PJ, Gleadle JM (2004): Differential Function of the Prolyl Hydroxylases PHD1, PHD2, and PHD3 in the Regulation of Hypoxia-inducible Factor. J Biol Chem $\underline{279}$, 38458-38465

Arany Z, Huang LE, Eckner R, Bhattacharya S, Jiang C, Goldberg MA, Bunn HF, Livingston DM (1996): An essential role for p300/CBP in the cellular response to hypoxia. Proc Natl Acad Sci U S A 93, 1296912973

Archer SL, Reeve HL, Michelakis E, Puttagunta L, Waite R, Nelson DP, Dinauer MC, Weir EK (1999): O2 sensing is preserved in mice lacking the gp91 phox subunit of NADPH oxidase. Proc Natl Acad Sci U S A $\underline{96}, 7944-7949$

Arimoto-Ishida E, Sakata M, Sawada K, Nakayama M, Nishimoto F, Mabuchi S, Takeda T, Yamamoto T, Isobe A, Okamoto Y, et al. (2009): Up-Regulation of $\alpha 5$-Integrin by E-Cadherin Loss in Hypoxia and Its Key Role in the Migration of Extravillous Trophoblast Cells during Early Implantation. Endocrinology 150, 4306-4315

Arsham AM, Howell JJ, Simon MC (2003): A Novel Hypoxia-inducible Factor-independent Hypoxic Response Regulating Mammalian Target of Rapamycin and Its Targets. J Biol Chem 278, 29655-29660

Ashburner M, Ball CA, Blake JA, Botstein D, Butler H, Cherry JM, Davis AP, Dolinski K, Dwight SS, Eppig JT, et al. (2000): Gene Ontology: tool for the unification of biology. Nat Genet 25, 25-29

Astrof S, Hynes RO (2009): Fibronectins in Vascular Morphogenesis. Angiogenesis 12, 165-175

Atanassov I, Urlaub H (2013): Increased proteome coverage by combining PAGE and peptide isoelectric focusing: Comparative study of gel-based separation approaches. Proteomics $\underline{13}$, 2947-2955

Azoulay D, Del Gaudio M, Andreani P, Ichai P, Sebag M, Adam R, Scatton O, Min BY, Delvard V, Lemoine A, et al. (2005): Effects of 10 Minutes of Ischemic Preconditioning of the Cadaveric Liver on the Graft's Preservation and Function. Ann Surg 242, 133-139

Baba K, Muraguchi T, Imaoka S (2013): Role of the hypoxia response pathway in lens formation during embryonic development of Xenopus laevis. FEBS Open Bio $\underline{3}, 490-495$ 
Baba M, Hirai S, Yamada-Okabe H, Hamada K, Tabuchi H, Kobayashi K, Kondo K, Yoshida M, Yamashita A, Kishida T, et al. (2003): Loss of von Hippel-Lindau protein causes cell density dependent deregulation of CyclinD1 expression through Hypoxia-inducible factor. Oncogene 22, 2728-2738

Baek JH, Mahon PC, Oh J, Kelly B, Krishnamachary B, Pearson M, Chan DA, Giaccia AJ, Semenza GL (2005): OS-9 Interacts with Hypoxia-Inducible Factor $1 \alpha$ and Prolyl Hydroxylases to Promote OxygenDependent Degradation of HIF-1 $\alpha$. Mol Cell $\underline{17}, 503-512$

Baek JH, Liu YV, McDonald KR, Wesley JB, Zhang H, Semenza GL (2007a): Spermidine/Spermine N1Acetyltransferase-1 Binds to Hypoxia-inducible Factor- $1 \alpha(\mathrm{HIF}-1 \alpha)$ and RACK1 and Promotes Ubiquitination and Degradation of HIF-1 $\alpha$. J Biol Chem 282, 33358-33366

Baek JH, Liu YV, McDonald KR, Wesley JB, Hubbi ME, Byun H, Semenza GL (2007b): Spermidine/Spermine-N1-Acetyltransferase 2 Is an Essential Component of the Ubiquitin Ligase Complex That Regulates Hypoxia-inducible Factor 1 $\alpha$. J Biol Chem 282, 23572-23580

Bandarra D, Biddlestone J, Mudie S, Muller HA, Rocha S (2014): Hypoxia activates IKK-NF-xB and the immune response in Drosophila melanogaster. Biosci Rep $\underline{34}$, 429-440

Banerjee I, Fuseler JW, Price RL, Borg TK, Baudino TA (2007): Determination of cell types and numbers during cardiac development in the neonatal and adult rat and mouse. Am J Physiol-Heart Circ Physiol 293, H1883-H1891

Barouch W, Prasad K, Greene L, Eisenberg E (1997): Auxilin-Induced Interaction of the Molecular Chaperone Hsc70 with Clathrin Baskets. Biochemistry $\underline{36}$, 4303-4308

Barth S, Nesper J, Hasgall PA, Wirthner R, Nytko KJ, Edlich F, Katschinski DM, Stiehl DP, Wenger RH, Camenisch G (2007): The Peptidyl Prolyl cis/trans Isomerase FKBP38 Determines Hypoxia-Inducible Transcription Factor Prolyl-4-Hydroxylase PHD2 Protein Stability. Mol Cell Biol 27, 3758-3768

Bastiani M, Liu L, Hill MM, Jedrychowski MP, Nixon SJ, Lo HP, Abankwa D, Luetterforst R, FernandezRojo M, Breen MR, et al. (2009): MURC/Cavin-4 and cavin family members form tissue-specific caveolar complexes. J Cell Biol 185, 1259-1273

Bateman A, Martin MJ, O’Donovan C, Magrane M, Alpi E, Antunes R, Bely B, Bingley M, Bonilla C, Britto R, et al. (2017): UniProt: the universal protein knowledgebase. Nucleic Acids Res $\underline{45}$, D158-D169

Bateman RM, Sharpe MD, Ellis CG (2003): Bench-to-bedside review: Microvascular dysfunction in sepsis hemodynamics, oxygen transport, and nitric oxide. Crit Care 7, 359-373

Baudino TA, McFadden A, Fix C, Hastings J, Price R, Borg TK (2008): Cell Patterning: Interaction of Cardiac Myocytes and Fibroblasts in Three-Dimensional Culture. Microsc Microanal 14, 117-125

Baumgärtl H, Leichtweiss HP, Lübbers DW, Weiss C, Huland H (1972): The oxygen supply of the dog kidney: measurements of intrarenal pO 2. Microvasc Res $\underline{4}, 247-257$

Beall CM, Cavalleri GL, Deng L, Elston RC, Gao Y, Knight J, Li C, Li JC, Liang Y, McCormack M, et al. (2010): Natural selection on EPAS1 (HIF2 $\alpha$ ) associated with low hemoglobin concentration in Tibetan highlanders. Proc Natl Acad Sci U S A $\underline{107}, 11459-11464$

Bell EL, Klimova TA, Eisenbart J, Moraes CT, Murphy MP, Budinger GRS, Chandel NS (2007): The Qo site of the mitochondrial complex III is required for the transduction of hypoxic signaling via reactive oxygen species production. J Cell Biol 177, 1029-1036

Bentzen EL, Tomlinson ID, Mason J, Gresch P, Warnement MR, Wright D, Sanders-Bush E, Blakely R, Rosenthal SJ (2005): Surface Modification To Reduce Nonspecific Binding of Quantum Dots in Live Cell Assays. Bioconjug Chem 16, 1488-1494 
Berchner-Pfannschmidt U, Yamac H, Trinidad B, Fandrey J (2007): Nitric Oxide Modulates Oxygen Sensing by Hypoxia-inducible Factor 1-dependent Induction of Prolyl Hydroxylase 2. J Biol Chem 282, 17881796

Bergeron M, Yu AY, Solway KE, Semenza GL, Sharp FR (2008): Induction of hypoxia-inducible factor-1 (HIF-1) and its target genes following focal ischaemia in rat brain. Eur J Neurosci $\underline{11}, 4159-4170$

Bergmann O, Zdunek S, Felker A, Salehpour M, Alkass K, Bernard S, Sjostrom SL, Szewczykowska M, Jackowska T, dos Remedios C, et al. (2015): Dynamics of Cell Generation and Turnover in the Human Heart. Cell $\underline{161}, 1566-1575$

Berlin RD, Oliver JM (1980): Surface functions during mitosis. II. Quantitation of pinocytosis and kinetic characterization of the mitotic cycle with a new fluorescence technique. J Cell Biol $\underline{85}, 660-671$

Berra E, Benizri E, Ginouvès A, Volmat V, Roux D, Pouysségur J (2003): HIF prolyl-hydroxylase 2 is the key oxygen sensor setting low steady-state levels of HIF-1 $\alpha$ in normoxia. EMBO J 22, $4082-4090$

Betz WJ, Mao F, Bewick GS (1992): Activity-dependent fluorescent staining and destaining of living vertebrate motor nerve terminals. J Neurosci 12 , 363-375

Betz WJ, Mao F, Smith CB (1996): Imaging exocytosis and endocytosis. Curr Opin Neurobiol $\underline{6}$, 365-371

van den Beucken T, Koritzinsky M, Wouters BG (2006): Translational control of gene expression during hypoxia. Cancer Biol Ther $\underline{5}, 749-755$

Bewick GS, Betz WJ (1994): Illumination Partly Reverses the Postsynaptic Blockade of the Frog Neuromuscular Junction by the Styryl Pyridinium Dye RH414. Proc R Soc B Biol Sci 258, 201-207

Bhattacharya S, Michels CL, Leung M-K, Arany ZP, Kung AL, Livingston DM (1999): Functional role of p35srj, a novel p300/CBP binding protein, during transactivation by HIF-1. Genes Dev 13, 64-75

Bishop T, Ratcliffe PJ (2014): Signaling hypoxia by hypoxia-inducible factor protein hydroxylases: a historical overview and future perspectives. Hypoxia Auckl NZ 2, 197-213

Bishop T, Talbot NP, Turner PJ, Nicholls LG, Pascual A, Hodson EJ, Douglas G, Fielding JW, Smith TG, Demetriades M, et al. (2013): Carotid body hyperplasia and enhanced ventilatory responses to hypoxia in mice with heterozygous deficiency of PHD2. J Physiol 591, 3565-3577

Black AM, McCloskey DI, Torrance RW (1971): The responses of carotid body chemoreceptors in the cat to sudden changes of hypercapnic and hypoxic stimuli. Respir Physiol 13, 36-49

Blouin CM, Prado C, Takane KK, Lasnier F, Garcia-Ocana A, Ferré P, Dugail I, Hajduch E (2010): Plasma Membrane Subdomain Compartmentalization Contributes to Distinct Mechanisms of Ceramide Action on Insulin Signaling. Diabetes $\underline{59}$, 600-610

Böcking T, Aguet F, Rapoport I, Banzhaf M, Yu A, Zeeh JC, Kirchhausen T (2014): Key Interactions for Clathrin Coat Stability. Structure 22, 819-829

Bolte S, Talbot C, Boutte Y, Catrice O, Read ND, Satiat-Jeunemaitre B (2004): FM-dyes as experimental probes for dissecting vesicle trafficking in living plant cells. J Microsc 214, 159-173

Bonello S, Zahringer C, BelAiba RS, Djordjevic T, Hess J, Michiels C, Kietzmann T, Gorlach A (2007): Reactive Oxygen Species Activate the HIF-1 Promoter Via a Functional NF B Site. Arterioscler Thromb Vasc Biol 27, 755-761 
Bonnet S, Michelakis ED, Porter CJ, Andrade-Navarro MA, Thébaud B, Bonnet S, Haromy A, Harry G, Moudgil R, McMurtry MS, et al. (2006): An Abnormal Mitochondrial-Hypoxia Inducible Factor-1 $\alpha-\mathrm{Kv}$ Channel Pathway Disrupts Oxygen Sensing and Triggers Pulmonary Arterial Hypertension in Fawn Hooded Rats: Similarities to Human Pulmonary Arterial Hypertension. Circulation 113, 2630-2641

Borner GHH, Harbour M, Hester S, Lilley KS, Robinson MS (2006): Comparative proteomics of clathrincoated vesicles. J Cell Biol $\underline{175}, 571-578$

Borner GHH, Antrobus R, Hirst J, Bhumbra GS, Kozik P, Jackson LP, Sahlender DA, Robinson MS (2012): Multivariate proteomic profiling identifies novel accessory proteins of coated vesicles. J Cell Biol 197 , $141-160$

Bosch-Marce M, Okuyama H, Wesley JB, Sarkar K, Kimura H, Liu YV, Zhang H, Strazza M, Rey S, Savino L, et al. (2007): Effects of Aging and Hypoxia-Inducible Factor-1 Activity on Angiogenic Cell Mobilization and Recovery of Perfusion After Limb Ischemia. Circ Res 101, 1310-1318

Botos E, Klumperman J, Oorschot V, Ígyártó B, Magyar A, Oláh M, Kiss AL (2008): Caveolin-1 is transported to multi-vesicular bodies after albumin-induced endocytosis of caveolae in HepG2 cells. J Cell Mol Med 12, 1632-1639

Boulant S, Kural C, Zeeh J-C, Ubelmann F, Kirchhausen T (2011): Actin dynamics counteract membrane tension during clathrin-mediated endocytosis. Nat Cell Biol 13, 1124-1131

Bourseau-Guilmain E, Menard JA, Lindqvist E, Chandran VI, Christianson HC, Magaña MC, Lidfeldt J, Marko-Varga G, Welinder C, Belting M (2016): Hypoxia regulates global membrane protein endocytosis through caveolin-1 in cancer cells. Nat Commun $\underline{7}, 11371$

Bowers SLK, Banerjee I, Baudino TA (2010): The Extracellular Matrix: At the Center of it All. J Mol Cell Cardiol $\underline{48}, 474-482$

Bracken CP, Fedele AO, Linke S, Balrak W, Lisy K, Whitelaw ML, Peet DJ (2006): Cell-specific Regulation of Hypoxia-inducible Factor (HIF)- $1 \alpha$ and HIF- $2 \alpha$ Stabilization and Transactivation in a Graded Oxygen Environment. J Biol Chem 281, 22575-22585

Brandes RP, Weissmann N, Schröder K (2014): Redox-mediated signal transduction by cardiovascular Nox NADPH oxidases. J Mol Cell Cardiol $\underline{73}$, 70-79

Breen MR, Camps M, Carvalho-Simoes F, Zorzano A, Pilch PF (2012): Cholesterol Depletion in Adipocytes Causes Caveolae Collapse Concomitant with Proteosomal Degradation of Cavin-2 in a Switch-Like Fashion. PLoS ONE 7 , e 34516

Breit S, Bubel M, Pohlemann T, Oberringer M (2011): Erythropoietin ameliorates the reduced migration of human fibroblasts during in vitro hypoxia. J Physiol Biochem $\underline{67}, 1-13$

Breunig E, Kludt E, Czesnik D, Schild D (2011): The Styryl Dye FM1-43 Suppresses Odorant Responses in a Subset of Olfactory Neurons by Blocking Cyclic Nucleotide-gated (CNG) Channels. J Biol Chem 286, 28041-28048

Brizel DM, Scully SP, Harrelson JM, Layfield LJ, Bean JM, Prosnitz LR, Dewhirst MW (1996): Tumor oxygenation predicts for the likelihood of distant metastases in human soft tissue sarcoma. Cancer Res $\underline{56}, 941-943$

Brodin L, Löw P, Shupliakov O (2000): Sequential steps in clathrin-mediated synaptic vesicle endocytosis. Curr Opin Neurobiol 10, 312-320

Brown RD, Ambler SK, Mitchell MD, Long CS (2005): The Cardiac Fibroblast: Therapeutic Target in Myocardial Remodeling and Failure. Annu Rev Pharmacol Toxicol 45, 657-687 
Brown ST, Kelly KF, Daniel JM, Nurse CA (2009): Hypoxia inducible factor (HIF)-2 $\alpha$ is required for the development of the catecholaminergic phenotype of sympathoadrenal cells. J Neurochem $\underline{110}, 622-630$

Brown ST, Buttigieg J, Nurse CA (2010): Divergent roles of reactive oxygen species in the responses of perinatal adrenal chromaffin cells to hypoxic challenges. Respir Physiol Neurobiol 174, 252-258

Bruce C, Stone K, Gulcicek E, Williams K (2013): Proteomics and the Analysis of Proteomic Data: 2013 Overview of Current Protein-Profiling Technologies. Curr Protoc Bioinformatics $\underline{41}$, 13.21.1-13.21.17

Brugarolas J, Lei K, Hurley RL, Manning BD, Reiling JH, Hafen E, Witters LA, Ellisen LW, Kaelin WG (2004): Regulation of mTOR function in response to hypoxia by REDD1 and the TSC1/TSC2 tumor suppressor complex. Genes Dev 18, 2893-2904

Bruick RK, McKnight SL (2001): A Conserved Family of Prolyl-4-Hydroxylases That Modify HIF. Science 294, $1337-1340$

Brunelle JK, Bell EL, Quesada NM, Vercauteren K, Tiranti V, Zeviani M, Scarpulla RC, Chandel NS (2005): Oxygen sensing requires mitochondrial ROS but not oxidative phosphorylation. Cell Metab $1,409-414$

Bucci C, Parton RG, Mather IH, Stunnenberg H, Simons K, Hoflack B, Zerial M (1992): The small GTPase rab5 functions as a regulatory factor in the early endocytic pathway. Cell $\underline{70}, 715-728$

Buckler KJ, Turner PJ (2013): Oxygen sensitivity of mitochondrial function in rat arterial chemoreceptor cells. J Physiol 591, 3549-3563

Burnette WN (1981): „Western blotting“: electrophoretic transfer of proteins from sodium dodecyl sulfate-polyacrylamide gels to unmodified nitrocellulose and radiographic detection with antibody and radioiodinated protein A. Anal Biochem 112, 195-203

Camelliti P, Green CR, LeGrice I, Kohl P (2004): Fibroblast network in rabbit sinoatrial node: structural and functional identification of homogeneous and heterogeneous cell coupling. Circ Res 94, 828-835

Camelliti P, Borg T, Kohl P (2005): Structural and functional characterisation of cardiac fibroblasts. Cardiovasc Res $\underline{65}, 40-51$

Camps C, Saini HK, Mole DR, Choudhry H, Reczko M, Guerra-Assunção JA, Tian Y-M, Buffa FM, Harris AL, Hatzigeorgiou AG, et al. (2014): Integrated analysis of microRNA and mRNA expression and association with HIF binding reveals the complexity of microRNA expression regulation under hypoxia. Mol Cancer $\underline{13}, 28$

Carabelli V, Marcantoni A, Comunanza V, Luca AD, Díaz J, Borges R, Carbone E (2007): Chronic hypoxia up-regulates $\alpha 1 \mathrm{H}$ T-type channels and low-threshold catecholamine secretion in rat chromaffin cells. J Physiol 584, 149-165

Carbia-Nagashima A, Gerez J, Perez-Castro C, Paez-Pereda M, Silberstein S, Stalla GK, Holsboer F, Arzt E (2007): RSUME, a Small RWD-Containing Protein, Enhances SUMO Conjugation and Stabilizes HIF$1 \alpha$ during Hypoxia. Cell 131, 309-323

Carini R, Castino R, Cesaris MGD, Splendore R, Démoz M, Albano E, Isidoro C (2004): Preconditioninginduced cytoprotection in hepatocytes requires Ca2+-dependent exocytosis of lysosomes. J Cell Sci 117 , 1065-1077

Carmeliet P, Dor Y, Herbert J-M, Fukumura D, Brusselmans K, Dewerchin M, Neeman M, Bono F, Abramovitch R, Maxwell P, et al. (1998): Role of HIF-1 $\alpha$ in hypoxia-mediated apoptosis, cell proliferation and tumour angiogenesis. Nature $\underline{394}, 485-490$ 
Carpentier JL (1982): Co-localization of 125I-epidermal growth factor and ferritin-low density lipoprotein in coated pits: a quantitative electron microscopic study in normal and mutant human fibroblasts. J Cell Biol $\underline{95}, 73-77$

Carreau A, Hafny-Rahbi BE, Matejuk A, Grillon C, Kieda C (2011): Why is the partial oxygen pressure of human tissues a crucial parameter? Small molecules and hypoxia. J Cell Mol Med 15, 1239-1253

Cash TP, Pan Y, Simon MC (2007): Reactive Oxygen Species and Cellular Oxygen Sensing. Free Radic Biol Med $\underline{43}, 1219-1225$

Cataldo AM, Mathews PM, Boiteau AB, Hassinger LC, Peterhoff CM, Jiang Y, Mullaney K, Neve RL, Gruenberg J, Nixon RA (2008): Down Syndrome Fibroblast Model of Alzheimer-Related Endosome Pathology: Accelerated Endocytosis Promotes Late Endocytic Defects. Am J Pathol 173, 370-384

Chadda R, Howes MT, Plowman SJ, Hancock JF, Parton RG, Mayor S (2007): Cholesterol-Sensitive Cdc42 Activation Regulates Actin Polymerization for Endocytosis via the GEEC Pathway. Traffic $\underline{8}, 702-717$

Chandel NS, Budinger GR, Choe SH, Schumacker PT (1997): Cellular respiration during hypoxia. Role of cytochrome oxidase as the oxygen sensor in hepatocytes. J Biol Chem $\underline{272}, 18808-18816$

Chandel NS, Maltepe E, Goldwasser E, Mathieu CE, Simon MC, Schumacker PT (1998): Mitochondrial reactive oxygen species trigger hypoxia-induced transcription. Proc Natl Acad Sci U S A $\underline{95}$, 1171511720

Chang AJ, Ortega FE, Riegler J, Madison DV, Krasnow MA (2015): Oxygen control of breathing by an olfactory receptor activated by lactate. Nature $\underline{527}, 240-244$

Chang E, Yu WW, Colvin VL, Drezek R (2005): Quantifying the Influence of Surface Coatings on Quantum Dot Uptake in Cells. J Biomed Nanotechnol 1, 397-401

Chang HY, Chi J-T, Dudoit S, Bondre C, Rijn M van de, Botstein D, Brown PO (2002): Diversity, topographic differentiation, and positional memory in human fibroblasts. Proc Natl Acad Sci U S A $\underline{99}$, 12877-12882

Chaudhary N, Gomez GA, Howes MT, Lo HP, McMahon K-A, Rae JA, Schieber NL, Hill MM, Gaus K, Yap AS, Parton RG (2014): Endocytic Crosstalk: Cavins, Caveolins, and Caveolae Regulate ClathrinIndependent Endocytosis. PLoS Biol 12, e1001832

Chazotte B (2009): Labeling Pinocytotic Vesicles and Cytoplasm with Fluorescent Dextrans or Ficolls for Imaging. Cold Spring Harb Protoc 2009, pdb.prot4951

Chazotte B (2011): Labeling Membrane Glycoproteins or Glycolipids with Fluorescent Wheat Germ Agglutinin. Cold Spring Harb Protoc 2011, pdb.prot5623

Chen LS, Prentice RL, Wang P (2014): A penalized EM algorithm incorporating missing data mechanism for Gaussian parameter estimation. Biometrics $\underline{70}, 312-322$

Chen R, Dioum EM, Hogg RT, Gerard RD, Garcia JA (2011): Hypoxia Increases Sirtuin 1 Expression in a Hypoxia-inducible Factor-dependent Manner. J Biol Chem 286, 13869-13878

Chen W, Feng Y, Chen D, Wandinger-Ness A, Pfeffer SR (1998): Rab11 Is Required for Trans-Golgi Network-to-Plasma Membrane Transport and a Preferential Target for GDP Dissociation Inhibitor. Mol Biol Cell $\underline{9}, 3241-3257$

Cheng J, Kang X, Zhang S, Yeh ETH (2007): SUMO-Specific Protease 1 Is Essential for Stabilization of HIF1 $\alpha$ during Hypoxia. Cell $131,584-595$

Chetrit D, Ziv N, Ehrlich M (2009): Dab2 regulates clathrin assembly and cell spreading. Biochem J $\underline{418}$, $701-715$ 
Chowdhury R, McDonough MA, Mecinović J, Loenarz C, Flashman E, Hewitson KS, Domene C, Schofield CJ (2009): Structural Basis for Binding of Hypoxia-Inducible Factor to the Oxygen-Sensing Prolyl Hydroxylases. Structure 17, 981-989

Chua YL, Dufour E, Dassa EP, Rustin P, Jacobs HT, Taylor CT, Hagen T (2010): Stabilization of Hypoxiainducible Factor- $1 \alpha$ Protein in Hypoxia Occurs Independently of Mitochondrial Reactive Oxygen Species Production. J Biol Chem 285, 31277-31284

Chuang J-Z, Yeh T-Y, Bollati F, Conde C, Canavosio F, Caceres A, Sung C-H (2005): The Dynein Light Chain Tctex-1 Has a Dynein-Independent Role in Actin Remodeling during Neurite Outgrowth. Dev Cell $\underline{9}, 75-86$

Chun Y-S, Choi E, Yeo E-J, Lee JH, Kim M-S, Park J-W (2001): A new HIF-1 alpha variant induced by zinc ion suppresses HIF-1-mediated hypoxic responses. J Cell Sci $\underline{114}$, 4051-4061

Chun Y-S, Choi E, Kim T-Y, Kim M-S, Park J-W (2002): A dominant-negative isoform lacking exons 11 and 12 of the human hypoxia-inducible factor-1alpha gene. Biochem J $\underline{362}, 71-79$

Clambey ET, McNamee EN, Westrich JA, Glover LE, Campbell EL, Jedlicka P, de Zoeten EF, Cambier JC, Stenmark KR, Colgan SP, Eltzschig HK (2012): Hypoxia-inducible factor-1 alpha-dependent induction of FoxP3 drives regulatory T-cell abundance and function during inflammatory hypoxia of the mucosa. Proc Natl Acad Sci U S A 109, E2784-E2793

Cochilla AJ, Angleson JK, Betz WJ (1999): Monitoring secretory membrane with FM1-43 fluorescence. Annu Rev Neurosci 22, $1-10$

Cockman ME, Masson N, Mole DR, Jaakkola P, Chang G-W, Clifford SC, Maher ER, Pugh CW, Ratcliffe PJ, Maxwell PH (2000): Hypoxia Inducible Factor- $\alpha$ Binding and Ubiquitylation by the von Hippel-Lindau Tumor Suppressor Protein. J Biol Chem 275, 25733-25741

Cockman ME, Lancaster DE, Stolze IP, Hewitson KS, McDonough MA, Coleman ML, Coles CH, Yu X, Hay RT, Ley SC, et al. (2006): Posttranslational hydroxylation of ankyrin repeats in I $x$ B proteins by the hypoxia-inducible factor (HIF) asparaginyl hydroxylase, factor inhibiting HIF (FIH). Proc Natl Acad Sci U S A $\underline{103}, 14767-14772$

Cocucci E, Aguet F, Boulant S, Kirchhausen T (2012): The First Five Seconds in the Life of a ClathrinCoated Pit. Cell $\underline{150}, 495-507$

Coleman ML, McDonough MA, Hewitson KS, Coles C, Mecinović J, Edelmann M, Cook KM, Cockman ME, Lancaster DE, Kessler BM, et al. (2007): Asparaginyl Hydroxylation of the Notch Ankyrin Repeat Domain by Factor Inhibiting Hypoxia-inducible Factor. J Biol Chem 282, 24027-24038

Comerford KM, Leonard MO, Karhausen J, Carey R, Colgan SP, Taylor CT (2003): Small ubiquitin-related modifier-1 modification mediates resolution of CREB-dependent responses to hypoxia. Proc Natl Acad Sci U S A $\underline{100}$, 986-991

Compernolle V, Brusselmans K, Acker T, Hoet P, Tjwa M, Beck H, Plaisance S, Dor Y, Keshet E, Lupu F, et al. (2002): Loss of HIF-2 $\alpha$ and inhibition of VEGF impair fetal lung maturation, whereas treatment with VEGF prevents fatal respiratory distress in premature mice. Nat Med $\underline{8}, 702-710$

Conklin MW, Ada-Nguema A, Parsons M, Riching KM, Keely PJ (2010): R-Ras regulates $\beta 1$-integrin trafficking via effects on membrane ruffling and endocytosis. BMC Cell Biol $\underline{11}, 14$

Corley KM, Taylor CJ, Lilly B (2005): Hypoxia-inducible factor $1 \alpha$ modulates adhesion, migration, and FAK phosphorylation in vascular smooth muscle cells. J Cell Biochem 무, 971-985 
Cossart P, Helenius A (2014): Endocytosis of Viruses and Bacteria. Cold Spring Harb Perspect Biol $\underline{6}$, a016972

Covello KL, Kehler J, Yu H, Gordan JD, Arsham AM, Hu C-J, Labosky PA, Simon MC, Keith B (2006): HIF-2alpha regulates Oct-4: effects of hypoxia on stem cell function, embryonic development, and tumor growth. Genes Dev 20, 557-570

Coyne CB, Shen L, Turner JR, Bergelson JM (2007): Coxsackievirus Entry across Epithelial Tight Junctions Requires Occludin and the Small GTPases Rab34 and Rab5. Cell Host Microbe 2, 181-192

Cramer T, Yamanishi Y, Clausen BE, Förster I, Pawlinski R, Mackman N, Haase VH, Jaenisch R, Corr M, Nizet V, et al. (2003): HIF-1 $\alpha$ Is Essential for Myeloid Cell-Mediated Inflammation. Cell 112, 645-657

Cremona O, De Camilli P (1997): Synaptic vesicle endocytosis. Curr Opin Neurobiol 7, 323-330

Crowther RA, Pinch JT, Pearse BMF (1976): On the structure of coated vesicles. J Mol Biol $\underline{103}$, 785-798

Cummins EP, Berra E, Comerford KM, Ginouves A, Fitzgerald KT, Seeballuck F, Godson C, Nielsen JE, Moynagh P, Pouyssegur J, et al. (2006): Prolyl hydroxylase-1 negatively regulates I $\varkappa$ B kinase- $\beta$, giving insight into hypoxia-induced NFxB activity. Proc Natl Acad Sci U S A $\underline{103}, 18154-18159$

Dada LA, Chandel NS, Ridge KM, Pedemonte C, Bertorello AM, Sznajder JI (2003): Hypoxia-induced endocytosis of $\mathrm{Na}, \mathrm{K}$-ATPase in alveolar epithelial cells is mediated by mitochondrial reactive oxygen

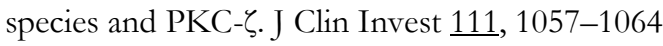

Dada LA, Novoa E, Lecuona E, Sun H, Sznajder JI (2007): Role of the small GTPase RhoA in the hypoxiainduced decrease of plasma membrane Na,K-ATPase in A549 cells. J Cell Sci 120, 2214-2222

Dang EV, Barbi J, Yang H-Y, Jinasena D, Yu H, Zheng Y, Bordman Z, Fu J, Kim Y, Yen H-R, et al. (2011): Control of TH17/Treg Balance by Hypoxia-inducible Factor 1. Cell 146, 772-784

D’Angelo G, Duplan E, Boyer N, Vigne P, Frelin C (2003): Hypoxia up-regulates prolyl hydroxylase activity: a feedback mechanism that limits HIF-1 responses during reoxygenation. J Biol Chem $\underline{278}$, 3818338187

Dannhauser PN, Ungewickell EJ (2012): Reconstitution of clathrin-coated bud and vesicle formation with minimal components. Nat Cell Biol 14, 634-639

Del Pozo MA, Balasubramanian N, Alderson NB, Kiosses WB, Grande-García A, Anderson RGW, Schwartz MA (2005): Phospho-caveolin-1 mediates integrin-regulated membrane domain internalization. Nat Cell Biol 7, 901-908

Delva E, Jennings JM, Calkins CC, Kottke MD, Faundez V, Kowalczyk AP (2008): Pemphigus Vulgaris IgGinduced Desmoglein-3 Endocytosis and Desmosomal Disassembly Are Mediated by a Clathrin- and Dynamin-independent Mechanism. J Biol Chem 283, 18303-18313

Dempsey JA, Veasey SC, Morgan BJ, O’Donnell CP (2010): Pathophysiology of Sleep Apnea. Physiol Rev $\underline{90}$, 47-112

Denko NC, Fontana LA, Hudson KM, Sutphin PD, Raychaudhuri S, Altman R, Giaccia AJ (2003): Investigating hypoxic tumor physiology through gene expression patterns. Oncogene 22, 5907-5914

Denu JM (2003): Linking chromatin function with metabolic networks: Sir2 family of NAD1-dependent deacetylases. Trends Biochem Sci $\underline{28}, 41-48$

Depping R, Hägele S, Wagner KF, Wiesner RJ, Camenisch G, Wenger RH, Katschinski DM (2004): A dominant-negative isoform of hypoxia-inducible factor-1 alpha specifically expressed in human testis. Biol Reprod 71, 331-339 
Derivery E, Sousa C, Gautier JJ, Lombard B, Loew D, Gautreau A (2009): The Arp2/3 Activator WASH Controls the Fission of Endosomes through a Large Multiprotein Complex. Dev Cell 17, 712-723

Diaz-Rohrer B, Levental KR, Levental I (2014): Rafting through traffic: Membrane domains in cellular logistics. Biochim Biophys Acta BBA - Biomembr 1838, 3003-3013

Diebold I, Flügel D, Becht S, BelAiba RS, Bonello S, Hess J, Kietzmann T, Görlach A (2009): The HypoxiaInducible Factor- $2 \alpha$ Is Stabilized by Oxidative Stress Involving NOX4. Antioxid Redox Signal 13, 425 436

Dini L, Ruzittu M, Carlà EC, Falasca L (2008): Relationship between cellular shape and receptor-mediated endocytosis: an ultrastructural and morphometric study in rat Kupffer cells. Liver 18, 99-109

Dioum EM, Chen R, Alexander MS, Zhang Q, Hogg RT, Gerard RD, Garcia JA (2009): Regulation of Hypoxia-Inducible Factor $2 \alpha$ Signaling by the Stress-Responsive Deacetylase Sirtuin 1. Science $\underline{324}$, 1289-1293

Doege K, Heine S, Jensen I, Jelkmann W, Metzen E (2005): Inhibition of mitochondrial respiration elevates oxygen concentration but leaves regulation of hypoxia-inducible factor (HIF) intact. Blood 106, 23112317

Doherty GJ, McMahon HT (2009): Mechanisms of Endocytosis. Annu Rev Biochem 므, 857-902

Drab M, Verkade P, Elger M, Kasper M, Lohn M, Lauterbach B, Menne J, Lindschau C, Mende F, Luft FC, et al. (2001): Loss of Caveolae, Vascular Dysfunction, and Pulmonary Defects in Caveolin-1 GeneDisrupted Mice. Science 293, 2449-2452

Drew LJ, Wood JN (2007): FM1-43 is a permeant blocker of mechanosensitive ion channels in sensory neurons and inhibits behavioural responses to mechanical stimuli. Mol Pain $\underline{3}, 1$

Driskell RR, Watt FM (2015): Understanding fibroblast heterogeneity in the skin. Trends Cell Biol 25, 92-99

Driskell RR, Clavel C, Rendl M, Watt FM (2011): Hair follicle dermal papilla cells at a glance. J Cell Sci $\underline{124}$, 1179-1182

D’Souza RS, Casanova JE (2016): The BRAG/IQSec family of Arf GEFs. Small GTPases ㄱ, 257-264

D'Souza-Schorey C, Chavrier P (2006): ARF proteins: roles in membrane traffic and beyond. Nat Rev Mol Cell Biol ㄱ, 347-358

Dulhunty AF, Franzini-Armstrong C (1975): The relative contributions of the folds and caveolae to the surface membrane of frog skeletal muscle fibres at different sarcomere lengths. J Physiol 250, 513-539

Dunham-Snary KJ, Wu D, Sykes EA, Thakrar A, Parlow LRG, Mewburn JD, Parlow JL, Archer SL (2017): Hypoxic Pulmonary Vasoconstriction. Chest $\underline{151}, 181-192$

Dunphy JL, Moravec R, Ly K, Lasell TK, Melancon P, Casanova JE (2006): The Arf6 GEF GEP100/BRAG2 Regulates Cell Adhesion by Controlling Endocytosis of $\beta 1$ Integrins. Curr Biol CB $\underline{16}, 315-320$

Dunwoodie SL (2009): The Role of Hypoxia in Development of the Mammalian Embryo. Dev Cell 17, 755773

Ebert BL, Bunn HF (1998): Regulation of Transcription by Hypoxia Requires a Multiprotein Complex That Includes Hypoxia-Inducible Factor 1, an Adjacent Transcription Factor, and p300/CREB Binding Protein. Mol Cell Biol 18, 4089-4096

Ebert BL, Firth JD, Ratcliffe PJ (1995): Hypoxia and Mitochondrial Inhibitors Regulate Expression of Glucose Transporter-1 via Distinct Cis-acting Sequences. J Biol Chem 270, 29083-29089 
Echarri A, Del Pozo MA (2012): Caveolae. Curr Biol 22, R114-R116

Echarri A, Pozo MAD (2015): Caveolae - mechanosensitive membrane invaginations linked to actin filaments. J Cell Sci $\underline{128}, 2747-2758$

Eckle T, Kohler D, Lehmann R, El Kasmi KC, Eltzschig HK (2008): Hypoxia-Inducible Factor-1 Is Central to Cardioprotection: A New Paradigm for Ischemic Preconditioning. Circulation 118, 166-175

Ehrismann D, Flashman E, Genn DN, Mathioudakis N, Hewitson KS, Ratcliffe PJ, Schofield CJ (2007): Studies on the activity of the hypoxia-inducible-factor hydroxylases using an oxygen consumption assay. Biochem J 401, 227-234

Ehrlich M, Boll W, van Oijen A, Hariharan R, Chandran K, Nibert ML, Kirchhausen T (2004): Endocytosis by Random Initiation and Stabilization of Clathrin-Coated Pits. Cell $\underline{118}, 591-605$

Eichacker LA, Granvogl B, Mirus O, Müller BC, Miess C, Schleiff E (2004): Hiding behind hydrophobicity. Transmembrane segments in mass spectrometry. J Biol Chem 279, 50915-50922

Elkins JM, Hewitson KS, McNeill LA, Seibel JF, Schlemminger I, Pugh CW, Ratcliffe PJ, Schofield CJ (2003): Structure of Factor-inhibiting Hypoxia-inducible Factor (HIF) Reveals Mechanism of Oxidative Modification of HIF-1 $\alpha$. J Biol Chem 278, 1802-1806

Eltzschig HK, Carmeliet P (2011): Hypoxia and Inflammation. N Engl J Med 364, 656-665

Eltzschig HK, Eckle T (2011): Ischemia and reperfusion—from mechanism to translation. Nat Med $\underline{17}$, $1391-1401$

Eltzschig HK, Bratton DL, Colgan SP (2014): Targeting hypoxia signalling for the treatment of ischaemic and inflammatory diseases. Nat Rev Drug Discov $\underline{13}$, 852-869

Elvidge GP, Glenny L, Appelhoff RJ, Ratcliffe PJ, Ragoussis J, Gleadle JM (2006): Concordant regulation of gene expression by hypoxia and 2-oxoglutarate-dependent dioxygenase inhibition: the role of HIF1alpha, HIF-2alpha, and other pathways. J Biol Chem 281, 15215-15226

Ema M, Taya S, Yokotani N, Sogawa K, Matsuda Y, Fujii-Kuriyama Y (1997): A novel bHLH-PAS factor with close sequence similarity to hypoxia-inducible factor $1 \alpha$ regulates the VEGF expression and is

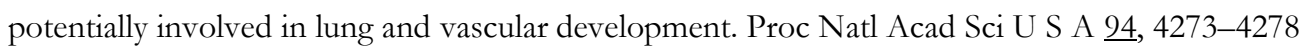

Engelman DM (2005): Membranes are more mosaic than fluid. Nature 438, 578-580

Epstein ACR, Gleadle JM, McNeill LA, Hewitson KS, O’Rourke J, Mole DR, Mukherji M, Metzen E, Wilson MI, Dhanda A, et al. (2001): C. elegans EGL-9 and Mammalian Homologs Define a Family of Dioxygenases that Regulate HIF by Prolyl Hydroxylation. Cell 107, 43-54

Etienne-Manneville S, Hall A (2002): Rho GTPases in cell biology. Nature 420, 629-635

Evans AM, Hardie DG, Peers C, Wyatt CN, Viollet B, Kumar P, Dallas ML, Ross F, Ikematsu N, Jordan HL, et al. (2009): Ion channel regulation by AMPK: the route of hypoxia-response coupling in thecarotid body and pulmonary artery. Ann N Y Acad Sci 1177, 89-100

Evans TM, Ferguson C, Wainwright BJ, Parton RG, Wicking C (2003): Rab23, a Negative Regulator of Hedgehog Signaling, Localizes to the Plasma Membrane and the Endocytic Pathway. Traffic $\underline{4}$, 869-884

Falanga V, Martin TA, Takagi H, Kirsner RS, Helfman T, Pardes J, Ochoa MS (1993): Low oxygen tension increases mRNA levels of alpha 1 (I) procollagen in human dermal fibroblasts. J Cell Physiol 157,408 412

Fan D, Takawale A, Lee J, Kassiri Z (2012): Cardiac fibroblasts, fibrosis and extracellular matrix remodeling in heart disease. Fibrogenesis Tissue Repair $\underline{5}, 15$ 
Fandrey J. (2017): Membrane traffic control by hypoxia. Acta Physiol 221, 8-10

Fandrey J, Gorr TA, Gassmann M (2006): Regulating cellular oxygen sensing by hydroxylation. Cardiovasc Res $\underline{71}$, 642-651

Fernández-Agüera MC, Gao L, González-Rodríguez P, Pintado CO, Arias-Mayenco I, García-Flores P, García-Pergañeda A, Pascual A, Ortega-Sáenz P, López-Barneo J (2015): Oxygen Sensing by Arterial Chemoreceptors Depends on Mitochondrial Complex I Signaling. Cell Metab 22, 825-837

Firth JD, Ebert BL, Ratcliffe PJ (1995): Hypoxic regulation of lactate dehydrogenase A: Interaction between hypoxia-inducible factor 1 and cAMP response elements. J Biol Chem 270, 21021-21027

Fivaz M, Vilbois F, Thurnheer S, Pasquali C, Abrami L, Bickel PE, Parton RG, Goot FG van der (2002):

Differential sorting and fate of endocytosed GPI-anchored proteins. EMBO J 21, 3989-4000

Flamme I, Fröhlich T, von Reutern M, Kappel A, Damert A, Risau W (1997): HRF, a putative basic helixloop-helix-PAS-domain transcription factor is closely related to hypoxia-inducible factor- $1 \alpha$ and developmentally expressed in blood vessels. Mech Dev $\underline{63}, 51-60$

Ford MGJ, Mills IG, Peter BJ, Vallis Y, Praefcke GJK, Evans PR, McMahon HT (2002): Curvature of clathrin-coated pits driven by epsin. Nature 419, 361-366

Forristal CE, Wright KL, Hanley NA, Oreffo ROC, Houghton FD (2010): Hypoxia inducible factors regulate pluripotency and proliferation in human embryonic stem cells cultured at reduced oxygen tensions. Reprod Camb Engl 139, 85-97

Forsythe JA, Jiang BH, Iyer NV, Agani F, Leung SW, Koos RD, Semenza GL (1996): Activation of vascular endothelial growth factor gene transcription by hypoxia-inducible factor 1. Mol Cell Biol 16, 4604-4613

Fotin A, Cheng Y, Sliz P, Grigorieff N, Harrison SC, Kirchhausen T, Walz T (2004): Molecular model for a complete clathrin lattice from electron cryomicroscopy. Nature $432,573-579$

Fra AM, Williamson E, Simons K, Parton RG (1995): De novo formation of caveolae in lymphocytes by expression of VIP21-caveolin. Proc Natl Acad Sci U S A 2, 8655-8659

Freedman SJ, Sun Z-YJ, Kung AL, France DS, Wagner G, Eck MJ (2003): Structural basis for negative regulation of hypoxia-inducible factor- $1 \alpha$ by CITED2. Nat Struct Mol Biol $\underline{10}, 504-512$

Frick M, Bright NA, Riento K, Bray A, Merrified C, Nichols BJ (2007): Coassembly of Flotillins Induces Formation of Membrane Microdomains, Membrane Curvature, and Vesicle Budding. Curr Biol 17, 1151-1156

Fridolfsson HN, Kawaraguchi Y, Ali SS, Panneerselvam M, Niesman IR, Finley JC, Kellerhals SE, Migita MY, Okada H, Moreno AL, et al. (2012): Mitochondria-localized caveolin in adaptation to cellular stress and injury. FASEB J 26, 4637-4649

Fu XW, Wang D, Nurse CA, Dinauer MC, Cutz E (2000): NADPH oxidase is an O2 sensor in airway chemoreceptors: Evidence from $\mathrm{K}+$ current modulation in wild-type and oxidase-deficient mice. Proc Natl Acad Sci U S A $\underline{97}, 4374-4379$

Fujimoto LM, Roth R, Heuser JE, Schmid SL (2000): Actin Assembly Plays a Variable, but not Obligatory Role in Receptor-Mediated Endocytosis: Actin and Receptor Mediated Endocytosis. Traffic 1, 161-171

Fukuda R, Hirota K, Fan F, Jung YD, Ellis LM, Semenza GL (2002): Insulin-like Growth Factor 1 Induces Hypoxia-inducible Factor 1-mediated Vascular Endothelial Growth Factor Expression, Which is Dependent on MAP Kinase and Phosphatidylinositol 3-Kinase Signaling in Colon Cancer Cells. J Biol Chem $\underline{277}, 38205-38211$ 
Fukuda R, Kelly B, Semenza GL (2003): Vascular Endothelial Growth Factor Gene Expression in Colon Cancer Cells Exposed to Prostaglandin E2 Is Mediated by Hypoxia-inducible Factor 1. Cancer Res $\underline{63}$, 2330-2334

Fukuda R, Zhang H, Kim J, Shimoda L, Dang CV, Semenza GL (2007): HIF-1 Regulates Cytochrome Oxidase Subunits to Optimize Efficiency of Respiration in Hypoxic Cells. Cell 129, 111-122

Gabor F, Bogner E, Weissenboeck A, Wirth M (2004): The lectin-cell interaction and its implications to intestinal lectin-mediated drug delivery. Adv Drug Deliv Rev $\underline{56}$, 459-480

Gabrielsen A, Lawler PR, Yongzhong W, Steinbrüchel D, Blagoja D, Paulsson-Berne G, Kastrup J, Hansson GK (2007): Gene expression signals involved in ischemic injury, extracellular matrix composition and fibrosis defined by global mRNA profiling of the human left ventricular myocardium. J Mol Cell Cardiol $\underline{42}, 870-883$

Gaffield MA, Betz WJ (2006): Imaging synaptic vesicle exocytosis and endocytosis with FM dyes. Nat Protoc $1,2916-2921$

Galbiati F, Engelman JA, Volonte D, Zhang XL, Minetti C, Li M, Hou H, Kneitz B, Edelmann W, Lisanti MP (2001): Caveolin-3 Null Mice Show a Loss of Caveolae, Changes in the Microdomain Distribution of the Dystrophin-Glycoprotein Complex, and T-tubule Abnormalities. J Biol Chem 276, 21425-21433

Gale JE, Marcotti W, Kennedy HJ, Kros CJ, Richardson GP (2001): FM1-43 Dye Behaves as a Permeant Blocker of the Hair-Cell Mechanotransducer Channel. J Neurosci 21, 7013-7025

Galie PA, Westfall MV, Stegemann JP (2011): Reduced serum content and increased matrix stiffness promote the cardiac myofibroblast transition in 3D collagen matrices. Cardiovasc Pathol 20, 325-333

Gardner PR (1997): Superoxide-driven aconitase FE-S center cycling. Biosci Rep 17, 33-42

Garuti R, Jones C, Li W-P, Michaely P, Herz J, Gerard RD, Cohen JC, Hobbs HH (2005): The Modular Adaptor Protein Autosomal Recessive Hypercholesterolemia (ARH) Promotes Low Density Lipoprotein Receptor Clustering into Clathrin-coated Pits. J Biol Chem 280, 40996-41004

Gatto L, Christoforou A (2014): Using R and Bioconductor for proteomics data analysis. Biochim Biophys Acta BBA - Proteins Proteomics 1844, 42-51

Gaudesius G (2003): Coupling of Cardiac Electrical Activity Over Extended Distances by Fibroblasts of Cardiac Origin. Circ Res $\underline{93}, 421-428$

Gerald D, Berra E, Frapart YM, Chan DA, Giaccia AJ, Mansuy D, Pouysségur J, Yaniv M, Mechta-Grigoriou F (2004): JunD Reduces Tumor Angiogenesis by Protecting Cells from Oxidative Stress. Cell 118, 781794

Gerondopoulos A, Bastos RN, Yoshimura S, Anderson R, Carpanini S, Aligianis I, Handley MT, Barr FA (2014): Rab18 and a Rab18 GEF complex are required for normal ER structure. J Cell Biol 205, 707720

Gervásio OL, Whitehead NP, Yeung EW, Phillips WD, Allen DG (2008): TRPC1 binds to caveolin-3 and is regulated by Src kinase - role in Duchenne muscular dystrophy. J Cell Sci 121, 2246-2255

Ghiran IC (2011): Introduction to fluorescence microscopy. Methods Mol Biol Clifton NJ 689, 93-136

Giaccia AJ, Simon MC, Johnson R (2004): The biology of hypoxia: the role of oxygen sensing in development, normal function, and disease. Genes Dev $\underline{18}, 2183-2194$

Gilkes DM, Bajpai S, Chaturvedi P, Wirtz D, Semenza GL (2013): Hypoxia-inducible Factor 1 (HIF-1) Promotes Extracellular Matrix Remodeling under Hypoxic Conditions by Inducing P4HA1, P4HA2, and PLOD2 Expression in Fibroblasts. J Biol Chem 288, 10819-10829 
Gilkes DM, Semenza GL, Wirtz D (2014): Hypoxia and the extracellular matrix: drivers of tumour metastasis. Nat Rev Cancer 14, 430-439

Giordano FJ (2005): Oxygen, oxidative stress, hypoxia, and heart failure. J Clin Invest $\underline{115}$, 500-508

Girao H, Geli M-I, Idrissi F-Z (2008): Actin in the endocytic pathway: From yeast to mammals. FEBS Lett $\underline{582}, 2112-2119$

Glebov OO, Bright NA, Nichols BJ (2006): Flotillin-1 defines a clathrin-independent endocytic pathway in mammalian cells. Nat Cell Biol $\underline{8}, 46-54$

Glodowski DR, Chen CC-H, Schaefer H, Grant BD, Rongo C (2007): RAB-10 Regulates Glutamate Receptor Recycling in a Cholesterol-dependent Endocytosis Pathway. Mol Biol Cell 18, 4387-4396

Goda N, Ryan HE, Khadivi B, McNulty W, Rickert RC, Johnson RS (2003): Hypoxia-Inducible Factor $1 \propto$ Is Essential for Cell Cycle Arrest during Hypoxia. Mol Cell Biol 23, 359-369

Goetz JG, Minguet S, Navarro-Lérida I, Lazcano JJ, Samaniego R, Calvo E, Tello M, Osteso-Ibáñez T, Pellinen T, Echarri A, et al. (2011): Biomechanical remodeling of the microenvironment by stromal Caveolin-1 favors tumor invasion and metastasis. Cell $\underline{146}, 148-163$

Goffin JM, Pittet P, Csucs G, Lussi JW, Meister J-J, Hinz B (2006): Focal adhesion size controls tensiondependent recruitment of $\alpha$-smooth muscle actin to stress fibers. J Cell Biol 172, 259-268

Goldenberg NM, Grinstein S, Silverman M (2007): Golgi-bound Rab34 Is a Novel Member of the Secretory Pathway. Mol Biol Cell $\underline{18}$, 4762-4771

Goldsmith EC, Bradshaw AD, Zile MR, Spinale FG (2014): Myocardial Fibroblast-Matrix Interactions and Potential Therapeutic Targets. J Mol Cell Cardiol 70, 92-99

González-Muñoz E, López-Iglesias C, Calvo M, Palacín M, Zorzano A, Camps M (2009): Caveolin-1 Loss of Function Accelerates Glucose Transporter 4 and Insulin Receptor Degradation in 3T3-L1 Adipocytes. Endocrinology 150, 3493-3502

Gordan JD, Bertout JA, Hu C-J, Diehl JA, Simon MC (2007): HIF-2 $\alpha$ Promotes Hypoxic Cell Proliferation by Enhancing c-Myc Transcriptional Activity. Cancer Cell 11, 335-347

Gorlach A, Diebold I, Schini-Kerth VB, Berchner-Pfannschmidt U, Roth U, Brandes RP, Kietzmann T, Busse R (2001): Thrombin Activates the Hypoxia-Inducible Factor-1 Signaling Pathway in Vascular Smooth Muscle Cells : Role of the p22phox-Containing NADPH Oxidase. Circ Res $\underline{89}$, 47-54

Gosens R, Stelmack GL, Dueck G, Mutawe MM, Hinton M, McNeill KD, Paulson A, Dakshinamurti S, Gerthoffer W'T, Thliveris JA, et al. (2007): Caveolae facilitate muscarinic receptor-mediated intracellular $\mathrm{Ca}^{2+}$ mobilization and contraction in airway smooth muscle. Am J Physiol-Lung Cell Mol Physiol 293, L1406-L1418

Gothié E, Richard DE, Berra E, Pagès G, Pouysségur J (2000): Identification of Alternative Spliced Variants of Human Hypoxia-inducible Factor-1 $\alpha$. J Biol Chem 275, 6922-6927

Grant BD, Donaldson JG (2009): Pathways and mechanisms of endocytic recycling. Nat Rev Mol Cell Biol $\underline{10}, 597-608$

Gu YZ, Moran SM, Hogenesch JB, Wartman L, Bradfield CA (1998): Molecular characterization and chromosomal localization of a third alpha-class hypoxia inducible factor subunit, HIF3alpha. Gene Expr 1, 205-213 
Gunaratnam L, Morley M, Franovic A, Paulsen N de, Mekhail K, Parolin DAE, Nakamura E, Lorimer IAJ, Lee S (2003): Hypoxia Inducible Factor Activates the Transforming Growth Factor- $\alpha /$ Epidermal Growth Factor Receptor Growth Stimulatory Pathway in VHL-/- Renal Cell Carcinoma Cells. J Biol Chem 278, 44966-44974

Guo J, Wang T, Li X, Shallow H, Yang T, Li W, Xu J, Fridman MD, Yang X, Zhang S (2012): Cell Surface Expression of Human Ether-a-go-go-related Gene (hERG) Channels Is Regulated by Caveolin-3 Protein via the Ubiquitin Ligase Nedd4-2. J Biol Chem 287, 33132-33141

Guo Y, Linstedt AD (2014): Binding of the vesicle docking protein p115 to the GTPase Rab1b regulates membrane recruitment of the COPI vesicle coat. Cell Logist $\underline{3}$, e27687

Gustafsson MV, Zheng X, Pereira T, Gradin K, Jin S, Lundkvist J, Ruas JL, Poellinger L, Lendahl U, Bondesson M (2005): Hypoxia Requires Notch Signaling to Maintain the Undifferentiated Cell State. Dev Cell $\underline{9}, 617-628$

Guzy RD, Hoyos B, Robin E, Chen H, Liu L, Mansfield KD, Simon MC, Hammerling U, Schumacker PT (2005): Mitochondrial complex III is required for hypoxia-induced ROS production and cellular oxygen sensing. Cell Metab 1, 401-408

Hagen T, Taylor CT, Lam F, Moncada S (2003): Redistribution of Intracellular Oxygen in Hypoxia by Nitric Oxide: Effect on HIF1 $\alpha$. Science 302, 1975-1978

Hagiwara M, Shinomiya H, Kashihara M, Kobayashi K-I, Tadokoro T, Yamamoto Y (2011): Interaction of activated Rab5 with actin-bundling proteins, $\mathrm{L}$ - and T-plastin and its relevance to endocytic functions in mammalian cells. Biochem Biophys Res Commun 407, 615-619

Hall A (2012): Rho family GTPases. Biochem Soc Trans 뜨, 1378-1382

Handley MG, Medina RA, Nagel E, Blower PJ, Southworth R (2011): PET imaging of cardiac hypoxia: Opportunities and challenges. J Mol Cell Cardiol 51, 640-650

Hansen CG, Howard G, Nichols BJ (2011): Pacsin 2 is recruited to caveolae and functions in caveolar biogenesis. J Cell Sci 124, 2777-2785

Hansen CG, Shvets E, Howard G, Riento K, Nichols BJ (2013): Deletion of cavin genes reveals tissuespecific mechanisms for morphogenesis of endothelial caveolae. Nat Commun $\underline{4}, 1831$

Hao M, Maxfield FR (2000): Characterization of Rapid Membrane Internalization and Recycling. J Biol Chem 275, 15279-15286

Hara Y, Kawasaki N, Hirano K, Hashimoto Y, Adachi J, Watanabe S, Tomonaga T (2013): Quantitative proteomic analysis of cultured skin fibroblast cells derived from patients with triglyceride deposit cardiomyovasculopathy. Orphanet J Rare Dis $\underline{8}, 197$

Harrison L, Blackwell K (2004): Hypoxia and Anemia: Factors in Decreased Sensitivity to Radiation Therapy and Chemotherapy? The Oncologist $\underline{9}, 31-40$

Hartmann G, Tschöp M, Fischer R, Bidlingmaier C, Riepl R, Tschöp K, Hautmann H, Endres S, Toepfer M (2000): High altitude increases circulating interleukin-6, interleukin-1 receptor antagonist and C-reactive protein. Cytokine 12, 246-252

Hasenfuss G (1998): Animal models of human cardiovascular disease, heart failure and hypertrophy. Cardiovasc Res $\underline{39}$, 60-76

Hattula K, Furuhjelm J, Tikkanen J, Tanhuanpää K, Laakkonen P, Peränen J (2006): Characterization of the Rab8-specific membrane traffic route linked to protrusion formation. J Cell Sci $\underline{119}, 4866-4877$ 
Hayer A, Stoeber M, Ritz D, Engel S, Meyer HH, Helenius A (2010): Caveolin-1 is ubiquitinated and targeted to intralumenal vesicles in endolysosomes for degradation. J Cell Biol 191, 615-629

Helbig AO, Heck AJR, Slijper M (2010): Exploring the membrane proteome-Challenges and analytical strategies. J Proteomics $\underline{73}, 868-878$

Hell SW (2007): Far-Field Optical Nanoscopy. Science 316, 1153-1158

Henkel AW, Lübke J, Betz WJ (1996): FM1-43 dye ultrastructural localization in and release from frog motor

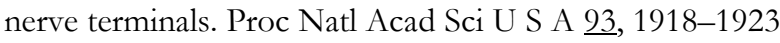

Henley JR, Krueger EWA, Oswald BJ, McNiven MA (1998): Dynamin-mediated Internalization of Caveolae. J Cell Biol 141, 85-99

Henne WM, Boucrot E, Meinecke M, Evergren E, Vallis Y, Mittal R, McMahon HT (2010): FCHo Proteins Are Nucleators of Clathrin-Mediated Endocytosis. Science $\underline{328}, 1281-1284$

Hernandez VJ, Weng J, Ly P, Pompey S, Dong H, Mishra L, Schwarz M, Anderson RG, Michaely P (2013): Cavin-3 dictates the balance between ERK and Akt signaling. eLife $\underline{2}$, e00905

Hernández-Deviez DJ, Howes MT, Laval SH, Bushby K, Hancock JF, Parton RG (2008): Caveolin Regulates Endocytosis of the Muscle Repair Protein, Dysferlin. J Biol Chem 283, 6476-6488

Hewitson KS, Liénard BMR, McDonough MA, Clifton IJ, Butler D, Soares AS, Oldham NJ, McNeill LA, Schofield CJ (2007): Structural and Mechanistic Studies on the Inhibition of the Hypoxia-inducible Transcription Factor Hydroxylases by Tricarboxylic Acid Cycle Intermediates. J Biol Chem 282, 32933301

Hezel M, de Groat WC, Galbiati F (2010): Caveolin-3 Promotes Nicotinic Acetylcholine Receptor Clustering and Regulates Neuromuscular Junction Activity. Mol Biol Cell 21, 302-310

Hill MM, Bastiani M, Luetterforst R, Kirkham M, Kirkham A, Nixon SJ, Walser P, Abankwa D, Oorschot VMJ, Martin S, et al. (2008): PTRF-cavin, a conserved cytoplasmic protein required for caveola formation and function. Cell $\underline{132}, 113-124$

Hirsilä M, Koivunen P, Günzler V, Kivirikko KI, Myllyharju J (2003): Characterization of the Human Prolyl 4-Hydroxylases That Modify the Hypoxia-inducible Factor. J Biol Chem 278, 30772-30780

Höckel M, Vaupel P (2001): Tumor hypoxia: definitions and current clinical, biologic, and molecular aspects. J Natl Cancer Inst 93, 266-276

Höckel M, Knoop C, Schlenger K, Vorndran B, Baussmann E, Mitze M, Knapstein PG, Vaupel P (1993): Intratumoral $\mathrm{pO}_{2}$ predicts survival in advanced cancer of the uterine cervix. Radiother Oncol J Eur Soc Ther Radiol Oncol 26, 45-50

Hoffman EC, Reyes H, Chu FF, Sander F, Conley LH, Brooks BA, Hankinson O (1991): Cloning of a factor required for activity of the Ah (dioxin) receptor. Science 252, 954-958

Holmquist-Mengelbier L, Fredlund E, Löfstedt T, Noguera R, Navarro S, Nilsson H, Pietras A, VallonChristersson J, Borg A, Gradin K, et al. (2006): Recruitment of HIF-1alpha and HIF-2alpha to common target genes is differentially regulated in neuroblastoma: HIF-2alpha promotes an aggressive phenotype. Cancer Cell 10, 413-423

Holstein SE (1996): Mechanism of clathrin basket dissociation: separate functions of protein domains of the DnaJ homologue auxilin. J Cell Biol 135, 925-937

Hoopmann P, Rizzoli SO, Betz WJ (2012): Imaging synaptic vesicle recycling by staining and destaining vesicles with FM dyes. Cold Spring Harb Protoc 2012, 77-83 
Hopkins AL, Groom CR (2002): The druggable genome. Nat Rev Drug Discov 1, 727-730

Horino Y, Takahashi S, Miura T, Takahashi Y (2002): Prolonged hypoxia accelerates the posttranscriptional process of collagen synthesis in cultured fibroblasts. Life Sci $\underline{71}$, 3031-3045

Hosler JP, Ferguson-Miller S, Mills DA (2006): Energy Transduction: Proton Transfer Through the Respiratory Complexes. Annu Rev Biochem 75, 165-187

Hosseinibarkooie S, Peters M, Torres-Benito L, Rastetter RH, Hupperich K, Hoffmann A, Mendoza-Ferreira N, Kaczmarek A, Janzen E, Milbradt J, et al. (2016): The Power of Human Protective Modifiers: PLS3 and CORO1C Unravel Impaired Endocytosis in Spinal Muscular Atrophy and Rescue SMA Phenotype. Am J Hum Genet 99, 647-665

Hossmann K-A (2012): The two pathophysiologies of focal brain ischemia: implications for translational stroke research. J Cereb Blood Flow Metab $\underline{32}$, 1310-1316

Hu C-J, Wang L-Y, Chodosh LA, Keith B, Simon MC (2003): Differential Roles of Hypoxia-Inducible Factor $1 \alpha(\mathrm{HIF}-1 \alpha)$ and HIF-2 $\alpha$ in Hypoxic Gene Regulation. Mol Cell Biol 23, 9361-9374

Hu C-J, Sataur A, Wang L, Chen H, Simon MC (2007): The N-Terminal Transactivation Domain Confers Target Gene Specificity of Hypoxia-inducible Factors HIF-1 $\alpha$ and HIF-2 $\alpha$. Mol Biol Cell 18, 4528-4542

Huang C-C, You J-L, Wu M-Y, Hsu K-S (2004): Rap1-induced p38 mitogen-activated protein kinase activation facilitates AMPA receptor trafficking via the GDI.Rab5 complex. Potential role in (S)-3,5dihydroxyphenylglycene-induced long-term depression. J Biol Chem 279, 12286-12292

Huang LE, Arany Z, Livingston DM, Bunn HF (1996): Activation of Hypoxia-inducible Transcription Factor Depends Primarily upon Redox-sensitive Stabilization of Its $\alpha$ Subunit. J Biol Chem 271, 32253-32259

Huang LE, Gu J, Schau M, Bunn HF (1998): Regulation of hypoxia-inducible factor $1 \alpha$ is mediated by an $\mathrm{O}_{2^{-}}$ dependent degradation domain via the ubiquitin-proteasome pathway. Proc Natl Acad Sci U S A $\underline{95}$, $7987-7992$

Hutagalung AH, Novick PJ (2011): Role of Rab GTPases in Membrane Traffic and Cell Physiology. Physiol Rev 91, 119-149

Ivan M, Kondo K, Yang H, Kim W, Valiando J, Ohh M, Salic A, Asara JM, Lane WS, Jr WGK (2001): HIF $\alpha$ Targeted for VHL-Mediated Destruction by Proline Hydroxylation: Implications for O2 Sensing. Science 292, 464-468

Iyer NV, Kotch LE, Agani F, Leung SW, Laughner E, Wenger RH, Gassmann M, Gearhart JD, Lawler AM, Yu AY, Semenza GL (1998): Cellular and developmental control of $\mathrm{O}_{2}$ homeostasis by hypoxiainducible factor $1 \alpha$. Genes Dev $\underline{12}, 149-162$

Jaakkola P, Mole DR, Tian Y-M, Wilson MI, Gielbert J, Gaskell SJ, Kriegsheim A von, Hebestreit HF, Mukherji M, Schofield CJ, et al. (2001): Targeting of HIF- $\alpha$ to the von Hippel-Lindau Ubiquitylation Complex by $\mathrm{O}_{2}$-Regulated Prolyl Hydroxylation. Science 292, 468-472

Jauniaux E, Watson AL, Hempstock J, Bao Y-P, Skepper JN, Burton GJ (2000): Onset of Maternal Arterial Blood Flow and Placental Oxidative Stress : A Possible Factor in Human Early Pregnancy Failure. Am J Pathol 157, 2111-2122

Jelínková A, Malínská K, Simon S, Kleine-Vehn J, Pařezová M, Pejchar P, Kubeš M, Martinec J, Friml J, Zažímalová E, Petrášek J (2010): Probing plant membranes with FM dyes: tracking, dragging or blocking? Plant J $\underline{61}, 883-892$ 
Jeong C-H, Lee H-J, Cha J-H, Kim JH, Kim KR, Kim J-H, Yoon D-K, Kim K-W (2007): Hypoxia-inducible Factor-1 $\alpha$ Inhibits Self-renewal of Mouse Embryonic Stem Cells in Vitro via Negative Regulation of the Leukemia Inhibitory Factor-STAT3 Pathway. J Biol Chem 282, 13672-13679

Jewell UR, Kvietikova I, Scheid A, Bauer C, Wenger RH, Gassmann M (2001): Induction of HIF-1 $\alpha$ in response to hypoxia is instantaneous. FASEB J 15 , 1312-1314

Jiang B-H, Rue E, Wang GL, Roe R, Semenza GL (1996a): Dimerization, DNA Binding, and Transactivation Properties of Hypoxia-inducible Factor 1. J Biol Chem 271, 17771-17778

Jiang BH, Semenza GL, Bauer C, Marti HH (1996b): Hypoxia-inducible factor 1 levels vary exponentially over a physiologically relevant range of O2 tension. Am J Physiol 271, C1172-1180

Jiang Z-S, Jeyaraman M, Wen G-B, Fandrich RR, Dixon IMC, Cattini PA, Kardami E (2007): High- but not low-molecular weight FGF-2 causes cardiac hypertrophy in vivo; possible involvement of cardiotrophin-1. J Mol Cell Cardiol 42, 222-233

Jin HG, Yamashita H, Nagano Y, Fukuba H, Hiji M, Ohtsuki T, Takahashi T, Kohriyama T, Kaibuchi K, Matsumoto M (2006): Hypoxia-induced upregulation of endothelial small G protein RhoA and Rhokinase/ROCK2 inhibits eNOS expression. Neurosci Lett 408, 62-67

Johannes L, Popoff V (2008): Tracing the Retrograde Route in Protein Trafficking. Cell 135, 1175-1187

Johannes L, Wunder C, Bassereau P (2014): Bending “On the Rocks”-A Cocktail of Biophysical Modules to Build Endocytic Pathways. Cold Spring Harb Perspect Biol $\underline{6}$, a016741

Kabe Y, Ando K, Hirao S, Yoshida M, Handa H (2005): Redox Regulation of NF- $x$ B Activation: Distinct Redox Regulation Between the Cytoplasm and the Nucleus. Antioxid Redox Signal 7, 395-403

Kaelin WG, Ratcliffe PJ (2008): Oxygen Sensing by Metazoans: The Central Role of the HIF Hydroxylase Pathway. Mol Cell 30, 393-402

Kahles T, Brandes RP (2013): Which NADPH Oxidase Isoform Is Relevant for Ischemic Stroke? The Case for Nox 2. Antioxid Redox Signal 18, 1400-1417

Kaiser R, Friedrich D, Chavakis E, Böhm M, Friedrich EB (2012): Effect of hypoxia on integrin-mediated adhesion of endothelial progenitor cells. J Cell Mol Med 16, 2387-2393

Kakkar R, Lee RT (2010): Intramyocardial Fibroblast Myocyte Communication. Circ Res 106, 47-57

Kaksonen M, Toret CP, Drubin DG (2005): A Modular Design for the Clathrin- and Actin-Mediated Endocytosis Machinery. Cell $\underline{123}, 305-320$

Kallio PJ, Okamoto K, O’Brien S, Carrero P, Makino Y, Tanaka H, Poellinger L (1998): Signal transduction in hypoxic cells: inducible nuclear translocation and recruitment of theCBP/p300 coactivator by the hypoxia-induciblefactor-1 $\alpha$. EMBO J $\underline{17}$, 6573-6586

Kallio PJ, Wilson WJ, O’Brien S, Makino Y, Poellinger L (1999): Regulation of the Hypoxia-inducible Transcription Factor $1 \alpha$ by the Ubiquitin-Proteasome Pathway. J Biol Chem 274, 6519-6525

Kalluri R, Zeisberg M (2006): Fibroblasts in cancer. Nat Rev Cancer $\underline{6}$, 392-401

Kamin D, Revelo NH, Rizzoli SO (2014): FM Dye Photo-Oxidation as a Tool for Monitoring Membrane Recycling in Inner Hair Cells. PLoS ONE ㅁ, e88353

Kapitsinou PP, Liu Q, Unger TL, Rha J, Davidoff O, Keith B, Epstein JA, Moores SL, Erickson-Miller CL, Haase VH (2010): Hepatic HIF-2 regulates erythropoietic responses to hypoxia in renal anemia. Blood 116, 3039-3048 
Kapus A, Janmey P (2013): Plasma membrane--cortical cytoskeleton interactions: a cell biology approach with biophysical considerations. Compr Physiol $\underline{3}, 1231-1281$

Kasuno K, Takabuchi S, Fukuda K, Kizaka-Kondoh S, Yodoi J, Adachi T, Semenza GL, Hirota K (2004): Nitric Oxide Induces Hypoxia-inducible Factor 1 Activation That Is Dependent on MAPK and Phosphatidylinositol 3-Kinase Signaling. J Biol Chem 279, 2550-2558

Katschinski D, Le L, Schindler S, Thomas T, Voss A, Wenger R (2004): Interaction of the PAS B Domain with HSP90 Accelerates Hypoxia-Inducible Factor-1 $\alpha$ Stabilization. Cell Physiol Biochem 14, 351-360

Kawaguchi M, Takahashi M, Hata T, Kashima Y, Usui F, Morimoto H, Izawa A, Takahashi Y, Masumoto J, Koyama J, et al. (2011): Inflammasome Activation of Cardiac Fibroblasts Is Essential for Myocardial Ischemia/Reperfusion Injury. Circulation 123, 594-604

Kelf TA, Sreenivasan VKA, Sun J, Kim EJ, Goldys EM, Zvyagin AV (2010): Non-specific cellular uptake of surface-functionalized quantum dots. Nanotechnology 21, 285105

Kelly EE, Giordano F, Horgan CP, Jollivet F, Raposo G, McCaffrey MW (2012): Rab30 is required for the morphological integrity of the Golgi apparatus. Biol Cell 104, 84-101

Keren K (2011): Cell motility: the integrating role of the plasma membrane. Eur Biophys J 40, 1013-1027

Kerr MC, Teasdale RD (2009): Defining Macropinocytosis. Traffic 10, 364-371

Khaidakov M, Mercanti F, Wang X, Ding Z, Dai Y, Romeo F, Sawamura T, Mehta JL (2014): Prevention of export of anoxia/reoxygenation injury from ischemic to nonischemic cardiomyocytes via inhibition of endocytosis. Am J Physiol-Heart Circ Physiol 306, H1700-H1707

Kietzmann T, Görlach A (2005): Reactive oxygen species in the control of hypoxia-inducible factor-mediated gene expression. Semin Cell Dev Biol 16, 474-486

Kim J, Tchernyshyov I, Semenza GL, Dang CV (2006): HIF-1-mediated expression of pyruvate dehydrogenase kinase: A metabolic switch required for cellular adaptation to hypoxia. Cell Metab $\underline{3}$, $177-185$

Kirchhausen T (2009): Imaging endocytic clathrin structures in living cells. Trends Cell Biol 19, 596-605

Kirchhausen T (2012): Bending membranes. Nat Cell Biol 14, 906-908

Kirchhausen T, Harrison SC (1981): Protein organization in clathrin trimers. Cell $\underline{23}, 755-761$

Kirchhausen T, Owen D, Harrison SC (2014): Molecular Structure, Function, and Dynamics of ClathrinMediated Membrane Traffic. Cold Spring Harb Perspect Biol $\underline{6}$, a016725

Kirkham M, Parton RG (2005): Clathrin-independent endocytosis: New insights into caveolae and noncaveolar lipid raft carriers. Biochim Biophys Acta BBA - Mol Cell Res 1745, 273-286

Kline DD, Peng Y-J, Manalo DJ, Semenza GL, Prabhakar NR (2002): Defective carotid body function and impaired ventilatory responses to chronic hypoxia in mice partially deficient for hypoxia-inducible factor

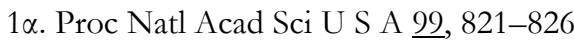

Knowles HJ, Raval RR, Harris AL, Ratcliffe PJ (2003): Effect of Ascorbate on the Activity of Hypoxiainducible Factor in Cancer Cells. Cancer Res $\underline{63}, 1764-1768$

Knowles HJ, Mole DR, Ratcliffe PJ, Harris AL (2006): Normoxic Stabilization of Hypoxia-Inducible Factor$1 \alpha$ by Modulation of the Labile Iron Pool in Differentiating U937 Macrophages: Effect of Natural Resistance-Associated Macrophage Protein 1. Cancer Res 66, 2600-2607 
Koh MY, Lemos R, Liu X, Powis G (2011): The Hypoxia-Associated Factor Switches Cells from HIF-1 $\alpha$ - to HIF-2 $\alpha$-Dependent Signaling Promoting Stem Cell Characteristics, Aggressive Tumor Growth and Invasion. Cancer Res $\underline{71}$, 4015-4027

Kohl P, Kamkin A, Kiseleva I, Noble D (1994): Mechanosensitive fibroblasts in the sino-atrial node region of rat heart: interaction with cardiomyocytes and possible role. Exp Physiol 79, 943-956

Kohl P, Hunter P, Noble D (1999): Stretch-induced changes in heart rate and rhythm: clinical observations, experiments and mathematical models. Prog Biophys Mol Biol 71, 91-138

Koivunen P, Hirsilä M, Günzler V, Kivirikko KI, Myllyharju J (2004): Catalytic Properties of the Asparaginyl Hydroxylase (FIH) in the Oxygen Sensing Pathway Are Distinct from Those of Its Prolyl 4Hydroxylases. J Biol Chem 279, 9899-9904

Koivunen P, Hirsilä M, Kivirikko KI, Myllyharju J (2006): The Length of Peptide Substrates Has a Marked Effect on Hydroxylation by the Hypoxia-inducible Factor Prolyl 4-Hydroxylases. J Biol Chem 281, 28712-28720

Koivunen P, Tiainen P, Hyvärinen J, Williams KE, Sormunen R, Klaus SJ, Kivirikko KI, Myllyharju J (2007a): An Endoplasmic Reticulum Transmembrane Prolyl 4-Hydroxylase Is Induced by Hypoxia and Acts on Hypoxia-inducible Factor $\alpha$. J Biol Chem 282, 30544-30552

Koivunen P, Hirsilä M, Remes AM, Hassinen IE, Kivirikko KI, Myllyharju J (2007b): Inhibition of hypoxiainducible factor (HIF) hydroxylases by citric acid cycle intermediates: possible links between cell metabolism and stabilization of HIF. J Biol Chem 282, 4524-4532

Kokate SB, Dixit P, Das L, Rath S, Roy AD, Poirah I, Chakraborty D, Rout N, Singh SP, Bhattacharyya A (2018): Acetylation-mediated Siah2 stabilization enhances PHD3 degradation in Helicobacter pyloriinfected gastric epithelial cancer cells. FASEB J $\underline{32}$, 5378-5389

Kong X, Lin Z, Liang D, Fath D, Sang N, Caro J (2006): Histone Deacetylase Inhibitors Induce VHL and Ubiquitin-Independent Proteasomal Degradation of Hypoxia-Inducible Factor $1 \alpha$. Mol Cell Biol 26, 2019-2028

Koshiji M, Kageyama Y, Pete EA, Horikawa I, Barrett JC, Huang LE (2004): HIF-1 $\alpha$ induces cell cycle arrest by functionally counteracting Myc. EMBO J 23, 1949-1956

Koshiji M, To KK-W, Hammer S, Kumamoto K, Harris AL, Modrich P, Huang LE (2005): HIF-1 $\alpha$ Induces Genetic Instability by Transcriptionally Downregulating MutS $\alpha$ Expression. Mol Cell 17, 793-803

Krauss M, Kinuta M, Wenk MR, Camilli PD, Takei K, Haucke V (2003): ARF6 stimulates clathrin/AP-2 recruitment to synaptic membranes by activating phosphatidylinositol phosphate kinase type I $\gamma$. J Cell Biol 162, 113-124

Krenning G, Zeisberg EM, Kalluri R (2010): The Origin of Fibroblasts and Mechanism of Cardiac Fibrosis. J Cell Physiol 225, 631-637

Krishnan J, Ahuja P, Bodenmann S, Knapik D, Perriard E, Krek W, Perriard J-C (2008): Essential Role of Developmentally Activated Hypoxia-Inducible Factor $1 \alpha$ for Cardiac Morphogenesis and Function. Circ Res 103, 1139-1146

Kuiper C, Molenaar IGM, Dachs GU, Currie MJ, Sykes PH, Vissers MCM (2010): Low Ascorbate Levels Are Associated with Increased Hypoxia-Inducible Factor-1 Activity and an Aggressive Tumor Phenotype in Endometrial Cancer. Cancer Res $\underline{70}, 5749-5758$

Kulshreshtha R, Ferracin M, Wojcik SE, Garzon R, Alder H, Agosto-Perez FJ, Davuluri R, Liu C-G, Croce CM, Negrini M, et al. (2007): A MicroRNA Signature of Hypoxia. Mol Cell Biol 27, 1859-1867 
Kumar R, Singh VP, Baker KM (2008): The intracellular renin-angiotensin system: implications in cardiovascular remodeling. Curr Opin Nephrol Hypertens 17, 168-173

Laemmli UK (1970): Cleavage of structural proteins during the assembly of the head of bacteriophage T4. Nature 227, 680-685

Lamaze C, Chuang T-H, Terlecky LJ, Bokoch GM, Schmid SL (1996): Regulation of receptor-mediated endocytosis by Rho and Rac. Nature $\underline{382}$, 177-179

Lamaze C, Dujeancourt A, Baba T, Lo CG, Benmerah A, Dautry-Varsat A (2001): Interleukin 2 Receptors and Detergent-Resistant Membrane Domains Define a Clathrin-Independent Endocytic Pathway. Mol Cell I, 661-671

Lando D, Peet DJ, Whelan DA, Gorman JJ, Whitelaw ML (2002): Asparagine Hydroxylation of the HIF Transactivation Domain: A Hypoxic Switch. Science 295, 858-861

Lang KJD, Kappel A, Goodall GJ (2002): Hypoxia-inducible Factor-1 $\alpha$ mRNA Contains an Internal Ribosome Entry Site That Allows Efficient Translation during Normoxia and Hypoxia. Mol Biol Cell $\underline{13}, 1792-1801$

Langlois S, Cowan KN, Shao Q, Cowan BJ, Laird DW (2008): Caveolin-1 and -2 Interact with Connexin43 and Regulate Gap Junctional Intercellular Communication in Keratinocytes. Mol Biol Cell 19, 912-928

Laughner E, Taghavi P, Chiles K, Mahon PC, Semenza GL (2001): HER2 (neu) Signaling Increases the Rate of Hypoxia-Inducible Factor $1 \alpha$ (HIF-1 $\alpha$ ) Synthesis: Novel Mechanism for HIF-1-Mediated Vascular Endothelial Growth Factor Expression. Mol Cell Biol 21, 3995-4004

Leach RM, Hill HM, Snetkov VA, Robertson TP, Ward JPT (2001): Divergent roles of glycolysis and the mitochondrial electron transport chain in hypoxic pulmonary vasoconstriction of the rat: identity of the hypoxic sensor. J Physiol 536, 211-224

Lee I-H, Campbell CR, Song S-H, Day ML, Kumar S, Cook DI, Dinudom A (2009): The Activity of the Epithelial Sodium Channels Is Regulated by Caveolin-1 via a Nedd4-2-dependent Mechanism. J Biol Chem 284, 12663-12669

Lee K-H, Park J-W, Chun Y-S (2004): Non-hypoxic transcriptional activation of the aryl hydrocarbon receptor nuclear translocator in concert with a novel hypoxia-inducible factor-1alpha isoform. Nucleic Acids Res $\underline{32}$, 5499-5511

Lee KJ, Lee KY, Lee YM (2010): Downregulation of a tumor suppressor RECK by hypoxia through recruitment of HDAC1 and HIF- $1 \alpha$ to reverse HRE site in the promoter. Biochim Biophys Acta BBA Mol Cell Res $\underline{1803}$, 608-616

Lee SH, Wolf PL, Escudero R, Deutsch R, Jamieson SW, Thistlethwaite PA (2000): Early Expression of Angiogenesis Factors in Acute Myocardial Ischemia and Infarction. N Engl J Med $\underline{342}$, 626-633

Lee SH, Lee YJ, Han HJ (2011): Role of hypoxia-induced fibronectin-integrin $\beta 1$ expression in embryonic stem cell proliferation and migration: Involvement of PI3K/Akt and FAK. J Cell Physiol 226, 484-493

Lee SW, Reimer CL, Oh P, Campbell DB, Schnitzer JE (1998): Tumor cell growth inhibition by caveolin reexpression in human breast cancer cells. Oncogene 16, 1391-1397

Lencer WI, Weyer P, Verkman AS, Ausiello DA, Brown D (1990): FITC-dextran as a probe for endosome function and localization in kidney. Am J Physiol-Cell Physiol 258, C309-C317

Li D, Hérault K, Oheim M, Ropert N (2009): FM dyes enter via a store-operated calcium channel and modify calcium signaling of cultured astrocytes. Proc Natl Acad Sci U S A 106, 21960-21965 
Li F, Sonveaux P, Rabbani ZN, Liu S, Yan B, Huang Q, Vujaskovic Z, Dewhirst MW, Li C-Y (2007a): Regulation of HIF-1 $\alpha$ Stability through S-Nitrosylation. Mol Cell 26, $63-74$

Li L, Wan T, Wan M, Liu B, Cheng R, Zhang R (2015): The effect of the size of fluorescent dextran on its endocytic pathway: Size-based endocytic entry for fluid cargoes. Cell Biol Int $\underline{39}, 531-539$

Li R, Jia Z, Trush MA (2016): Defining ROS in Biology and Medicine. React Oxyg Species Apex NC 1, 9-21

Li W, Li Y, Guan S, Fan J, Cheng C-F, Bright AM, Chinn C, Chen M, Woodley DT (2007b): Extracellular heat shock protein-90 $\alpha$ : linking hypoxia to skin cell motility and wound healing. EMBO J 26, 1221-1233

Li Y-L, Sun S-Y, Overholt JL, Prabhakar NR, Rozanski GJ, Zucker IH, Schultz HD (2004): Attenuated outward potassium currents in carotid body glomus cells of heart failure rabbit: involvement of nitric oxide. J Physiol 555, 219-229

Li Y-L, Zheng H, Ding Y, Schultz HD (2010): Expression of Neuronal Nitric Oxide Synthase in Rabbit Carotid Body Glomus Cells Regulates Large-Conductance Ca ${ }^{2+}$-Activated Potassium Currents. J Neurophysiol $\underline{103}, 3027-3033$

Li Z, Wang D, Messing EM, Wu G (2005): VHL protein-interacting deubiquitinating enzyme 2 deubiquitinates and stabilizes HIF-1 $\alpha$. EMBO Rep $\underline{6}, 373-378$

Lieb ME, Menzies K, Moschella MC, Ni R, Taubman MB (2002): Mammalian EGLN genes have distinct patterns of mRNA expression and regulation. Biochem Cell Biol $\underline{80}, 421-426$

Lipton P (1999): Ischemic cell death in brain neurons. Physiol Rev $\underline{79}, 1431-1568$

Liu L, Brown D, McKee M, LeBrasseur NK, Yang D, Albrecht KH, Ravid K, Pilch PF (2008): Deletion of Cavin/PTRF causes global loss of caveolae, dyslipidemia and glucose intolerance. Cell Metab $\underline{8}, 310$ 317

Liu S-L, Zhang Z-L, Sun E-Z, Peng J, Xie M, Tian Z-Q, Lin Y, Pang D-IW (2011): Visualizing the endocytic and exocytic processes of wheat germ agglutinin by quantum dot-based single-particle tracking. Biomaterials $\underline{32}, 7616-7624$

Liu YV, Baek JH, Zhang H, Diez R, Cole RN, Semenza GL (2007): RACK1 Competes with HSP90 for Binding to HIF- $1 \alpha$ and Is Required for $\mathrm{O}_{2}$-Independent and HSP90 Inhibitor-Induced Degradation of HIF-1 $\alpha$. Mol Cell 25, 207-217

Loenarz C, Schofield CJ (2008): Expanding chemical biology of 2-oxoglutarate oxygenases. Nat Chem Biol $\underline{4}$, 152-156

Loenarz C, Schofield CJ (2011): Physiological and biochemical aspects of hydroxylations and demethylations catalyzed by human 2-oxoglutarate oxygenases. Trends Biochem Sci $\underline{36}, 7-18$

Löfstedt T, Fredlund E, Holmquist-Mengelbier L, Pietras A, Ovenberger M, Poellinger L, Påhlman S (2007): Hypoxia Inducible Factor-2 $\alpha$ in Cancer. Cell Cycle $\underline{6}$, 919-926

Loftus AF, Hsieh VL, Parthasarathy R (2012): Modulation of membrane rigidity by the human vesicle trafficking proteins Sar1A and Sar1B. Biochem Biophys Res Commun 426, 585-589

Lössner C, Warnken U, Pscherer A, Schnölzer M (2011): Preventing arginine-to-proline conversion in a cellline-independent manner during cell cultivation under stable isotope labeling by amino acids in cell culture (SILAC) conditions. Anal Biochem 412, 123-125

Lowry OH, Rosebrough NJ, Farr AL, Randall RJ (1951): Protein Measurement with the Folin Phenol Reagent. J Biol Chem $\underline{193}, 265-275$ 
Luo W, Zhong J, Chang R, Hu H, Pandey A, Semenza GL (2010): Hsp70 and CHIP Selectively Mediate Ubiquitination and Degradation of Hypoxia-inducible Factor (HIF) $-1 \alpha$ but Not HIF-2 $\alpha$. J Biol Chem $\underline{285}, 3651-3663$

Macé G, Miaczynska M, Zerial M, Nebreda AR (2005): Phosphorylation of EEA1 by p38 MAP kinase regulates $\mu$ opioid receptor endocytosis. EMBO J 24, 3235-3246

Mahon PC, Hirota K, Semenza GL (2001): FIH-1: a novel protein that interacts with HIF-1 $\alpha$ and VHL to mediate repression of HIF-1 transcriptional activity. Genes Dev $\underline{15}$, 2675-2686

Makino Y, Cao R, Svensson K, Bertilsson G, Asman M, Tanaka H, Cao Y, Berkenstam A, Poellinger L (2001): Inhibitory PAS domain protein is a negative regulator of hypoxia-inducible gene expression. Nature $\underline{414}, 550-554$

Makino Y, Uenishi R, Okamoto K, Isoe T, Hosono O, Tanaka H, Kanopka A, Poellinger L, Haneda M, Morimoto C (2007): Transcriptional up-regulation of inhibitory PAS domain protein gene expression by hypoxia-inducible factor 1 (HIF-1): a negative feedback regulatory circuit in HIF-1-mediated signaling in hypoxic cells. J Biol Chem 282, 14073-14082

Manalo DJ, Rowan A, Lavoie T, Natarajan L, Kelly BD, Ye SQ, Garcia JGN, Semenza GL (2005): Transcriptional regulation of vascular endothelial cell responses to hypoxia by HIF-1. Blood 105, 659669

Manavski Y, Carmona G, Bennewitz K, Tang Z, Zhang F, Sakurai A, Zeiher AM, Gutkind JS, Li X, Kroll J, et al. (2014): Brag2 differentially regulates $\beta 1$ - and $\beta 3$-integrin-dependent adhesion in endothelial cells and is involved in developmental and pathological angiogenesis. Basic Res Cardiol 109, 404

Mann M, Hendrickson RC, Pandey A (2001): Analysis of proteins and proteomes by mass spectrometry. Annu Rev Biochem 무, 437-473

Mansfield KD, Guzy RD, Pan Y, Young RM, Cash TP, Schumacker PT, Simon MC (2005): Mitochondrial dysfunction resulting from loss of cytochrome $\mathrm{c}$ impairs cellular oxygen sensing and hypoxic HIF- $\alpha$ activation. Cell Metab 1, 393-399

Mao Y, Finnemann SC (2015): Regulation of phagocytosis by Rho GTPases. Small GTPases $\underline{6}$, 89-99

Maranchie JK, Zhan Y (2005): Nox4 Is Critical for Hypoxia-Inducible Factor 2- $\alpha$ Transcriptional Activity in von Hippel-Lindau-Deficient Renal Cell Carcinoma. Cancer Res 65, 9190-9193

Marsh M, Helenius A (2006): Virus Entry: Open Sesame. Cell 124, 729-740

Marxsen JH, Stengel P, Doege K, Heikkinen P, Jokilehto T, Wagner T, Jelkmann W, Jaakkola P, Metzen E (2004): Hypoxia-inducible factor-1 (HIF-1) promotes its degradation by induction of HIF- $\alpha$-prolyl-4hydroxylases. Biochem J $\underline{381}, 761-767$

Masedunskas A, Weigert R (2008): Intravital two-photon microscopy for studying the uptake and trafficking of fluorescently conjugated molecules in live rodents. Traffic Cph Den $\underline{9}, 1801-1810$

Massol RH, Boll W, Griffin AM, Kirchhausen T (2006): A burst of auxilin recruitment determines the onset of clathrin-coated vesicle uncoating. Proc Natl Acad Sci U S A $\underline{103}, 10265-10270$

Masson N, Willam C, Maxwell PH, Pugh CW, Ratcliffe PJ (2001): Independent function of two destruction domains in hypoxia-inducible factor- $\alpha$ chains activated by prolyl hydroxylation. EMBO J 20, 5197-5206

Masson N, Singleton RS, Sekirnik R, Trudgian DC, Ambrose LJ, Miranda MX, Tian Y-M, Kessler BM, Schofield CJ, Ratcliffe PJ (2012): The FIH hydroxylase is a cellular peroxide sensor that modulates HIF transcriptional activity. EMBO Rep 13, 251-257 
Mastrogiannaki M, Matak P, Keith B, Simon MC, Vaulont S, Peyssonnaux C (2009): HIF-2 $\alpha$, but not HIF-1 $\alpha$, promotes iron absorption in mice. J Clin Invest 119, 1159-1166

Maxfield FR, McGraw TE (2004): Endocytic recycling. Nat Rev Mol Cell Biol 모 121-132

Maxwell PH, Wiesener MS, Chang G-W, Clifford SC, Vaux EC, Cockman ME, Wykoff CC, Pugh CW, Maher ER, Ratcliffe PJ (1999): The tumour suppressor protein VHL targets hypoxia-inducible factors for oxygen-dependent proteolysis. Nature $\underline{399}, 271-275$

Maynard MA, Qi H, Chung J, Lee EHL, Kondo Y, Hara S, Conaway RC, Conaway JW, Ohh M (2003): Multiple Splice Variants of the Human HIF-3 $\alpha$ Locus Are Targets of the von Hippel-Lindau E3 Ubiquitin Ligase Complex. J Biol Chem 278, 11032-11040

Mazure NM, Chauvet C, Bois-Joyeux B, Bernard M-A, Nacer-Chérif H, Danan J-L (2002): Repression of $\alpha$ Fetoprotein Gene Expression under Hypoxic Conditions in Human Hepatoma Cells: Characterization of a Negative Hypoxia Response Element That Mediates Opposite Effects of Hypoxia Inducible Factor-1 and c-Myc. Cancer Res $\underline{62}, 1158-1165$

Mazzone SB, Mori N, Burman M, Palovich M, Belmonte KE, Canning BJ (2006): Fluorescent styryl dyes FM1-43 and FM2-10 are muscarinic receptor antagonists: intravital visualization of receptor occupancy. J Physiol $\underline{575}, 23-35$

McMahon K-A, Zajicek H, Li W-P, Peyton MJ, Minna JD, Hernandez VJ, Luby-Phelps K, Anderson RGW (2009): SRBC/cavin-3 is a caveolin adapter protein that regulates caveolae function. EMBO J $\underline{28}, 1001-$ 1015

McMahon S, Charbonneau M, Grandmont S, Richard DE, Dubois CM (2006): Transforming Growth Factor $\beta 1$ Induces Hypoxia-inducible Factor-1 Stabilization through Selective Inhibition of PHD2 Expression. J Biol Chem 281, 24171-24181

McNeill LA, Flashman E, Buck MRG, Hewitson KS, Clifton IJ, Jeschke G, Claridge TDW, Ehrismann D, Oldham NJ, Schofield CJ (2005): Hypoxia-inducible factor prolyl hydroxylase 2 has a high affinity for ferrous iron and 2-oxoglutarate. Mol Biosyst 1 , 321-324

Medugorac I, Jacob R (1983): Characterisation of left ventricular collagen in the rat. Cardiovasc Res 17, 15-21

Menard JA, Christianson HC, Kucharzewska P, Bourseau-Guilmain E, Svensson KJ, Lindqvist E, Chandran VI, Kjellén L, Welinder C, Bengzon J, et al. (2016): Metastasis Stimulation by Hypoxia and AcidosisInduced Extracellular Lipid Uptake Is Mediated by Proteoglycan-Dependent Endocytosis. Cancer Res $\underline{76}, 4828-4840$

Mercer J, Helenius A (2009): Virus entry by macropinocytosis. Nat Cell Biol 11, 510-520

Mercure MZ, Ginnan R, Singer HA (2008): CaM kinase II 22 -dependent regulation of vascular smooth muscle cell polarization and migration. Am J Physiol-Cell Physiol 294, C1465-C1475

Merrifield CJ, Perrais D, Zenisek D (2005): Coupling between Clathrin-Coated-Pit Invagination, Cortactin Recruitment, and Membrane Scission Observed in Live Cells. Cell 121, 593-606

Metzen E, Berchner-Pfannschmidt U, Stengel P, Marxsen JH, Stolze I, Klinger M, Huang WQ, Wotzlaw C, Hellwig-Bürgel T, Jelkmann W, et al. (2003a): Intracellular localisation of human HIF-1 $\alpha$ hydroxylases: implications for oxygen sensing. J Cell Sci 116, 1319-1326

Metzen E, Zhou J, Jelkmann W, Fandrey J, Brüne B (2003b): Nitric Oxide Impairs Normoxic Degradation of HIF-1 $\alpha$ by Inhibition of Prolyl Hydroxylases. Mol Biol Cell $\underline{14}$, 3470-3481 
Meyers JR, MacDonald RB, Duggan A, Lenzi D, Standaert DG, Corwin JT, Corey DP (2003): Lighting up the Senses: FM1-43 Loading of Sensory Cells through Nonselective Ion Channels. J Neurosci 23 , 4054 4065

Mi H, Muruganujan A, Casagrande JT, Thomas PD (2013): Large-scale gene function analysis with the PANTHER classification system. Nat Protoc $\underline{8}, 1551-1566$

Mi H, Huang X, Muruganujan A, Tang H, Mills C, Kang D, Thomas PD (2017): PANTHER version 11: expanded annotation data from Gene Ontology and Reactome pathways, and data analysis tool enhancements. Nucleic Acids Res 45, D183-D189

Mogford JE, Tawil N, Chen A, Gies D, Xia Y, Mustoe TA (2002): Effect of age and hypoxia on TGF $\beta 1$ receptor expression and signal transduction in human dermal fibroblasts: Impact on cell migration. J Cell Physiol 190, 259-265

Mole DR, Blancher C, Copley RR, Pollard PJ, Gleadle JM, Ragoussis J, Ratcliffe PJ (2009): Genome-wide Association of Hypoxia-inducible Factor (HIF)- $1 \alpha$ and HIF- $2 \alpha$ DNA Binding with Expression Profiling of Hypoxia-inducible Transcripts. J Biol Chem 284, 16767-16775

Moncada S, Erusalimsky JD (2002): Does nitric oxide modulate mitochondrial energy generation and apoptosis? Nat Rev Mol Cell Biol $\underline{3}, 214-220$

Morén B, Shah C, Howes MT, Schieber NL, McMahon HT, Parton RG, Daumke O, Lundmark R (2012): EHD2 regulates caveolar dynamics via ATP-driven targeting and oligomerization. Mol Biol Cell $\underline{23}$, 1316-1329

Mosesson Y, Mills GB, Yarden Y (2008): Derailed endocytosis: an emerging feature of cancer. Nat Rev Cancer $\underline{8}, 835-850$

Mrozowska PS, Fukuda M (2016): Regulation of podocalyxin trafficking by Rab small GTPases in 2D and 3D epithelial cell cultures. J Cell Biol 213, 355-369

Muller M, Padberg W, Schindler E, Sticher J, Osmer C, Friemann S, Hempelmann G (1998): Renocortical Tissue Oxygen Pressure Measurements in Patients Undergoing Living Donor Kidney Transplantation: Anesth Analg 구, 474-476

Mundy DI, Machleidt T, Ying Y, Anderson RGW, Bloom GS (2002): Dual control of caveolar membrane traffic by microtubules and the actin cytoskeleton. J Cell Sci $\underline{115}, 4327-4339$

Mungai PT, Waypa GB, Jairaman A, Prakriya M, Dokic D, Ball MK, Schumacker PT (2011): Hypoxia Triggers AMPK Activation through Reactive Oxygen Species-Mediated Activation of Calcium ReleaseActivated Calcium Channels. Mol Cell Biol 31, 3531-3545

Muriel O, Echarri A, Hellriegel C, Pavón DM, Beccari L, Pozo MAD (2011): Phosphorylated filamin A regulates actin-linked caveolae dynamics. J Cell Sci $\underline{124}$, 2763-2776

Murry CE, Jennings RB, Reimer KA (1986): Preconditioning with ischemia: a delay of lethal cell injury in ischemic myocardium. Circulation 74, 1124-1136

Myllyharju J. (2013): Prolyl 4-hydroxylases, master regulators of the hypoxia response. Acta Physiol 208, 148165

Nagaraj N, Wisniewski JR, Geiger T, Cox J, Kircher M, Kelso J, Pääbo S, Mann M (2011): Deep proteome and transcriptome mapping of a human cancer cell line. Mol Syst Biol , 548

Nakai W, Kondo Y, Saitoh A, Naito T, Nakayama K, Shin H-W (2013): ARF1 and ARF4 regulate recycling endosomal morphology and retrograde transport from endosomes to the Golgi apparatus. Mol Biol Cell $\underline{24}, 2570-2581$ 
Nakayama K, Frew IJ, Hagensen M, Skals M, Habelhah H, Bhoumik A, Kadoya T, Erdjument-Bromage H, Tempst P, Frappell PB, et al. (2004): Siah2 Regulates Stability of Prolyl-Hydroxylases, Controls HIF1 $\alpha$ Abundance, and Modulates Physiological Responses to Hypoxia. Cell 117, 941-952

Naslavsky N, Weigert R, Donaldson JG (2004): Characterization of a Nonclathrin Endocytic Pathway: Membrane Cargo and Lipid Requirements. Mol Biol Cell 15, 3542-3552

Neutra MR, Ciechanover A, Owen LS, Lodish HF (1985): Intracellular transport of transferrin- and asialoorosomucoid-colloidal gold conjugates to lysosomes after receptor-mediated endocytosis. J Histochem Cytochem $\underline{33}, 1134-1144$

Nisimoto Y, Diebold BA, Cosentino-Gomes D, Constentino-Gomes D, Lambeth JD (2014): Nox4: a hydrogen peroxide-generating oxygen sensor. Biochemistry $\underline{53}, 5111-5120$

Nizet V, Johnson RS (2009): Interdependence of hypoxic and innate immune responses. Nat Rev Immunol $\underline{9}$, 609-617

Nurse CA (2010): Neurotransmitter and neuromodulatory mechanisms at peripheral arterial chemoreceptors. Exp Physiol 모, 657-667

Oh P, McIntosh DP, Schnitzer JE (1998): Dynamin at the Neck of Caveolae Mediates Their Budding to Form Transport Vesicles by GTP-driven Fission from the Plasma Membrane of Endothelium. J Cell Biol 141, 101-114

Oh P, Borgström P, Witkiewicz H, Li Y, Borgström BJ, Chrastina A, Iwata K, Zinn KR, Baldwin R, Testa JE, Schnitzer JE (2007): Live dynamic imaging of caveolae pumping targeted antibody rapidly and specifically across endothelium in the lung. Nat Biotechnol 25, 327-337

Ohno H, Stewart J, Fournier MC, Bosshart H, Rhee I, Miyatake S, Saito T, Gallusser A, Kirchhausen T, Bonifacino JS (1995): Interaction of tyrosine-based sorting signals with clathrin-associated proteins. Science 269, 1872-1875

Okamoto T, Schlegel A, Scherer PE, Lisanti MP (1998): Caveolins, a Family of Scaffolding Proteins for Organizing "Preassembled Signaling Complexes" at the Plasma Membrane. J Biol Chem 273, 5419_ 5422

Olson KR (2013): Hydrogen sulfide as an oxygen sensor. Clin Chem Lab Med 1ㅡ, 623-632

Ong S-E, Blagoev B, Kratchmarova I, Kristensen DB, Steen H, Pandey A, Mann M (2002): Stable Isotope Labeling by Amino Acids in Cell Culture, SILAC, as a Simple and Accurate Approach to Expression Proteomics. Mol Cell Proteomics 1, 376-386

Opazo F, Rizzoli SO (2010): Studying Synaptic Vesicle Pools using Photoconversion of Styryl Dyes. J Vis $\operatorname{Exp} \underline{36}, 1790$

Pagé EL, Chan DA, Giaccia AJ, Levine M, Richard DE (2008): Hypoxia-inducible Factor-1 $\alpha$ Stabilization in Nonhypoxic Conditions: Role of Oxidation and Intracellular Ascorbate Depletion. Mol Biol Cell $\underline{19}$, 86-94

Palmer LA, Gaston B, Johns RA (2000): Normoxic Stabilization of Hypoxia-Inducible Factor-1 Expression and Activity: Redox-Dependent Effect of Nitrogen Oxides. Mol Pharmacol 58, 1197-1203

Pan Y, Mansfield KD, Bertozzi CC, Rudenko V, Chan DA, Giaccia AJ, Simon MC (2007): Multiple Factors Affecting Cellular Redox Status and Energy Metabolism Modulate Hypoxia-Inducible Factor Prolyl Hydroxylase Activity In Vivo and In Vitro. Mol Cell Biol 27, 912-925

Pankov R, Yamada KM (2002): Fibronectin at a glance. J Cell Sci 115, 3861-3863 
Papandreou I, Cairns RA, Fontana L, Lim AL, Denko NC (2006): HIF-1 mediates adaptation to hypoxia by actively downregulating mitochondrial oxygen consumption. Cell Metab $\underline{3}, 187-197$

Parat M-O, Anand-Apte B, Fox PL (2003): Differential Caveolin-1 Polarization in Endothelial Cells during Migration in Two and Three Dimensions. Mol Biol Cell 14, 3156-3168

Park EC, Ghose P, Shao Z, Ye Q, Kang L, Xu XZS, Powell-Coffman JA, Rongo C (2012): Hypoxia regulates glutamate receptor trafficking through an HIF-independent mechanism. EMBO J $\underline{31}$, 1379-1393

Park S, Dadak AM, Haase VH, Fontana L, Giaccia AJ, Johnson RS (2003): Hypoxia-Induced Gene Expression Occurs Solely through the Action of Hypoxia-Inducible Factor $1 \alpha$ (HIF-1 $\alpha$ ): Role of Cytoplasmic Trapping of HIF-2 $\alpha$. Mol Cell Biol 23 2 , 4959-4971

Parton RG, Simons K (2007): The multiple faces of caveolae. Nat Rev Mol Cell Biol $\underline{8}, 185-194$

Parton RG, Pozo MA del (2013): Caveolae as plasma membrane sensors, protectors and organizers. Nat Rev Mol Cell Biol $\underline{14}, 98-112$

Pavlos NJ, Cheng TS, Qin A, Ng PY, Feng H-T, Ang ESM, Carrello A, Sung C-H, Jahn R, Zheng M-H, Xu J (2011): Tctex-1, a Novel Interaction Partner of Rab3D, Is Required for Osteoclastic Bone Resorption. Mol Cell Biol 31, 1551-1564

Payen VL, Brisson L, Dewhirst MW, Sonveaux P (2015): Common responses of tumors and wounds to hypoxia. Cancer J Sudbury Mass $\underline{21}, 75-87$

Peláez-García A, Barderas R, Batlle R, Viñas-Castells R, Bartolomé RA, Torres S, Mendes M, Lopez-Lucendo M, Mazzolini R, Bonilla F, et al. (2015): A Proteomic Analysis Reveals That Snail Regulates the Expression of the Nuclear Orphan Receptor Nuclear Receptor Subfamily 2 Group F Member 6 (Nr2f6) and Interleukin 17 (IL-17) to Inhibit Adipocyte Differentiation. Mol Cell Proteomics MCP 14, 303-315

Pelkmans L, Zerial M (2005): Kinase-regulated quantal assemblies and kiss-and-run recycling of caveolae. Nature $\underline{436}, 128-133$

Pelkmans L, Bürli T, Zerial M, Helenius A (2004): Caveolin-Stabilized Membrane Domains as Multifunctional Transport and Sorting Devices in Endocytic Membrane Traffic. Cell $\underline{118}, 767-780$

Peng J, Zhang L, Drysdale L, Fong G-H (2000): The transcription factor EPAS-1/hypoxia-inducible factor $2 \alpha$ plays an important role in vascular remodeling. Proc Natl Acad Sci U S A $\underline{97}, 8386-8391$

Peng Y-J, Nanduri J, Raghuraman G, Souvannakitti D, Gadalla MM, Kumar GK, Snyder SH, Prabhakar NR (2010): $\mathrm{H}_{2} \mathrm{~S}$ mediates $\mathrm{O}_{2}$ sensing in the carotid body. Proc Natl Acad Sci U S A $\underline{107}, 10719-10724$

Peng Y-J, Nanduri J, Khan SA, Yuan G, Wang N, Kinsman B, Vaddi DR, Kumar GK, Garcia JA, Semenza GL, Prabhakar NR (2011): Hypoxia-inducible factor $2 \alpha$ (HIF-2 $\alpha$ ) heterozygous-null mice exhibit exaggerated carotid body sensitivity to hypoxia, breathing instability, and hypertension. Proc Natl Acad Sci U S A $\underline{108}, 3065-3070$

Penzes P, Cahill ME, Jones KA, Srivastava DP (2008): Convergent CaMK and RacGEF signals control dendritic structure and function. Trends Cell Biol $\underline{18}, 405-413$

Peter BJ, Kent HM, Mills IG, Vallis Y, Butler PJG, Evans PR, McMahon HT (2004): BAR Domains as Sensors of Membrane Curvature: The Amphiphysin BAR Structure. Science 303, 495-499

Pinto AR, Ilinykh A, Ivey MJ, Kuwabara JT, D’Antoni ML, Debuque R, Chandran A, Wang L, Arora K, Rosenthal N, Tallquist MD (2016): Revisiting Cardiac Cellular Composition. Circ Res 118, 400-409

Pittet MJ, Weissleder R (2011): Intravital Imaging. Cell 147, 983-991 
Poderoso JJ, Carreras MC, Lisdero C, Riobó N, Schöpfer F, Boveris A (1996): Nitric Oxide Inhibits Electron Transfer and Increases Superoxide Radical Production in Rat Heart Mitochondria and Submitochondrial Particles. Arch Biochem Biophys $\underline{328}$, 85-92

Ponte J, Purves MJ (1974): Frequency response of carotid body chemoreceptors in the cat to changes of $\mathrm{PaCO}_{2}, \mathrm{PaO}_{2}$, and pHa. J Appl Physiol 37, 635-647

Porter KE, Turner NA (2009): Cardiac fibroblasts: At the heart of myocardial remodeling. Pharmacol Ther 123, 255-278

Powelka AM, Sun J, Li J, Gao M, Shaw LM, Sonnenberg A, Hsu VW (2004): Stimulation-Dependent Recycling of Integrin $\beta 1$ Regulated by ARF6 and Rab11. Traffic $\underline{5}, 20-36$

Prabhakar NR (2013): Sensing hypoxia: physiology, genetics and epigenetics. J Physiol 모1, 2245-2257

Prabhakar NR, Semenza GL (2012): Adaptive and maladaptive cardiorespiratory responses to continuous and intermittent hypoxia mediated by hypoxia-inducible factors 1 and 2. Physiol Rev $\underline{92}$, 967-1003

Prabhakar NR, Semenza GL (2015): Oxygen Sensing and Homeostasis. Physiology 30, 340-348

Prabhakar NR, Kumar GK, Chang CH, Agani FH, Haxhiu MA (1993): Nitric oxide in the sensory function of the carotid body. Brain Res $\underline{625}, 16-22$

Pringle KG, Kind KL, Sferruzzi-Perri AN, Thompson JG, Roberts CT (2010): Beyond oxygen: complex regulation and activity of hypoxia inducible factors in pregnancy. Hum Reprod Update $\underline{16}, 415-431$

Rabilloud T (2003): Membrane proteins ride shotgun. Nat Biotechnol 21, 508-510

Ramírez-Bergeron DL, Runge A, Dahl KDC, Fehling HJ, Keller G, Simon MC (2004): Hypoxia affects mesoderm and enhances hemangioblast specification during early development. Development $\underline{131}$, 4623-4634

Rana MK, Srivastava J, Yang M, Chen CS, Barber DL (2015): Hypoxia increases the abundance but not the assembly of extracellular fibronectin during epithelial cell transdifferentiation. J Cell Sci $\underline{128}$, 1083-1089

Rane S, He M, Sayed D, Vashistha H, Malhotra A, Sadoshima J, Vatner DE, Vatner SF, Abdellatif M (2009): Downregulation of MiR-199a Derepresses Hypoxia-Inducible Factor-1 $\alpha$ and Sirtuin 1 and Recapitulates Hypoxia Preconditioning in Cardiac Myocytes. Circ Res 104, 879-886

Ranftler C, Auinger P, Meisslitzer-Ruppitsch C, Ellinger A, Neumüller J, Pavelka M: Electron Microscopy of Endocytic Pathways. In: Taatjes D, Roth J (Hrsg.): Cell Imaging Techniques. Methods in Molecular Biology (Methods and Protocols). Band 931. Humana Press, Totowa 2012, 437-447

Rankin EB, Biju MP, Liu Q, Unger TL, Rha J, Johnson RS, Simon MC, Keith B, Haase VH (2007): Hypoxiainducible factor-2 (HIF-2) regulates hepatic erythropoietin in vivo. J Clin Invest 117, 1068-1077

Raposo G, Stoorvogel W (2013): Extracellular vesicles: Exosomes, microvesicles, and friends. J Cell Biol 200, 373-383

Ratcliffe PJ (2013): Oxygen sensing and hypoxia signalling pathways in animals: the implications of physiology for cancer. J Physiol 591, 2027-2042

Rathore R, Zheng Y-M, Niu C-F, Liu Q-H, Korde A, Ho Y-S, Wang Y-X (2008): Hypoxia activates NADPH oxidase to increase [ROS]i and [Ca2+]i through mitochondrial ROS-PKC $\varepsilon$ signaling axis in pulmonary artery smooth muscle cells. Free Radic Biol Med $\underline{45}$, 1223-1231

Raval RR, Lau KW, Tran MGB, Sowter HM, Mandriota SJ, Li J-L, Pugh CW, Maxwell PH, Harris AL, Ratcliffe PJ (2005): Contrasting Properties of Hypoxia-Inducible Factor 1 (HIF-1) and HIF-2 in von Hippel-Lindau-Associated Renal Cell Carcinoma. Mol Cell Biol 25, 5675-5686 
Ren Y, Hao P, Dutta B, Cheow ESH, Sim KH, Gan CS, Lim SK, Sze SK (2013): Hypoxia Modulates A431 Cellular Pathways Association to Tumor Radioresistance and Enhanced Migration Revealed by Comprehensive Proteomic and Functional Studies. Mol Cell Proteomics 12, 485-498

Revelo NH, Kamin D, Truckenbrodt S, Wong AB, Reuter-Jessen K, Reisinger E, Moser T, Rizzoli SO (2014): A new probe for super-resolution imaging of membranes elucidates trafficking pathways. J Cell Biol 205, 591-606

Rhee SG (2006): Cell signaling. $\mathrm{H}_{2} \mathrm{O}_{2}$, a necessary evil for cell signaling. Science $\underline{312}$, 1882-1883

Richards DA, Guatimosim C, Betz WJ (2000): Two Endocytic Recycling Routes Selectively Fill Two Vesicle Pools in Frog Motor Nerve Terminals. Neuron 27, 551-559

Richardson RS, Noyszewski EA, Kendrick KF, Leigh JS, Wagner PD (1995): Myoglobin O2 desaturation during exercise. Evidence of limited O2 transport. J Clin Invest 96, 1916-1926

Richter T, Floetenmeyer M, Ferguson C, Galea J, Goh J, Lindsay MR, Morgan GP, Marsh BJ, Parton RG (2008): High-resolution 3D quantitative analysis of caveolar ultrastructure and caveola-cytoskeleton interactions. Traffic Cph Den $\underline{9}, 893-909$

Ridley AJ (2006): Rho GTPases and actin dynamics in membrane protrusions and vesicle trafficking. Trends Cell Biol 16, 522-529

Ridley AJ, Schwartz MA, Burridge K, Firtel RA, Ginsberg MH, Borisy G, Parsons JT, Horwitz AR (2003): Cell Migration: Integrating Signals from Front to Back. Science 302, 1704-1709

Ritz D, Vuk M, Kirchner P, Bug M, Schütz S, Hayer A, Bremer S, Lusk C, Baloh RH, Lee H, et al. (2011): Endolysosomal sorting of ubiquitinated caveolin-1 is regulated by VCP/p97 and UBXD1 and impaired by VCP disease mutations. Nat Cell Biol 13, 1116-1123

Rius J, Guma M, Schachtrup C, Akassoglou K, Zinkernagel AS, Nizet V, Johnson RS, Haddad GG, Karin M (2008): NF-xB links innate immunity to the hypoxic response through transcriptional regulation of HIF$1 \alpha$. Nature $\underline{453}, 807-811$

Rizzo V, Morton C, DePaola N, Schnitzer JE, Davies PF (2003): Recruitment of endothelial caveolae into mechanotransduction pathways by flow conditioning in vitro. Am J Physiol-Heart Circ Physiol 285, H1720-H1729

Rohr S (2011): Cardiac Fibroblasts in Cell Culture Systems: Myofibroblasts All Along? J Cardiovasc Pharmacol 57, 389-399

Römer W, Berland L, Chambon V, Gaus K, Windschiegl B, Tenza D, Aly MRE, Fraisier V, Florent J-C, Perrais D, et al. (2007): Shiga toxin induces tubular membrane invaginations for its uptake into cells. Nature $\underline{450}, 670-675$

Rook MB, Jongsma HJ, de Jonge B (1989): Single channel currents of homo- and heterologous gap junctions between cardiac fibroblasts and myocytes. Pflüg Arch 414, 95-98

Roth TF, Porter KR (1964): Yolk Protein Uptake in the Oocyte of the Mosquito Aedes Aegypti. L. J Cell Biol 20, 313-332

Rothberg KG, Heuser JE, Donzell WC, Ying Y-S, Glenney JR, Anderson RGW (1992): Caveolin, a protein component of caveolae membrane coats. Cell $\underline{68}, 673-682$

Roux J-C, Brismar H, Aperia A, Lagercrantz H (2005): Developmental Changes in HIF Transcription Factor in Carotid Body: Relevance for $\mathrm{O}_{2}$ Sensing by Chemoreceptors. Pediatr Res $\underline{58}, 53-57$ 
Roy S, Khanna S, Bickerstaff AA, Subramanian SV, Atalay M, Bierl M, Pendyala S, Levy D, Sharma N, Venojarvi M, et al. (2003): Oxygen Sensing by Primary Cardiac Fibroblasts: A Key Role of p21Waf1/Cip1/Sdi1. Circ Res 2ㅡ, 264-271

Rozen-Zvi B, Hayashida T, Hubchak SC, Hanna C, Platanias LC, William Schnaper H (2013): TGF- $\beta /$ Smad3 activates mammalian target of rapamycin complex-1 to promote collagen production by increasing HIF$1 \alpha$ expression. Am J Physiol-Ren Physiol $\underline{305}$, F485-F494

Ryan HE, Lo J, Johnson RS (1998): HIF-1 $\alpha$ is required for solid tumor formation and embryonic vascularization. EMBO J 17, 3005-3015

Ryman-Rasmussen JP, Riviere JE, Monteiro-Riviere NA (2007): Surface Coatings Determine Cytotoxicity and Irritation Potential of Quantum Dot Nanoparticles in Epidermal Keratinocytes. J Invest Dermatol 127, 143-153

Sabharanjak S, Sharma P, Parton RG, Mayor S (2002): GPI-Anchored Proteins Are Delivered to Recycling Endosomes via a Distinct cdc42-Regulated, Clathrin-Independent Pinocytic Pathway. Dev Cell 2, 411423

Sabharwal SS, Schumacker PT (2014): Mitochondrial ROS in cancer: initiators, amplifiers or an Achilles' heel? Nat Rev Cancer 14, 709-721

Sadakata T, Shinoda Y, Sekine Y, Saruta C, Itakura M, Takahashi M, Furuichi T (2010): Interaction of Calcium-dependent Activator Protein for Secretion 1 (CAPS1) with the Class II ADP-ribosylation Factor Small GTPases Is Required for Dense-core Vesicle Trafficking in the trans-Golgi Network. J Biol Chem 285, 38710-38719

Saeed MF, Kolokoltsov AA, Albrecht T, Davey RA (2010): Cellular Entry of Ebola Virus Involves Uptake by a Macropinocytosis-Like Mechanism and Subsequent Trafficking through Early and Late Endosomes. PLoS Pathog $\underline{6}$, e1001110

Salceda S, Caro J (1997): Hypoxia-inducible factor 1alpha (HIF-1alpha) protein is rapidly degraded by the ubiquitin-proteasome system under normoxic conditions. Its stabilization by hypoxia depends on redoxinduced changes. J Biol Chem 272, 22642-22647

Salnikow K, Donald SP, Bruick RK, Zhitkovich A, Phang JM, Kasprzak KS (2004): Depletion of Intracellular Ascorbate by the Carcinogenic Metals Nickel and Cobalt Results in the Induction of Hypoxic Stress. J Biol Chem 279, 40337-40344

Samudram A, Mangalassery BM, Kowshik M, Patincharath N, Varier GK (2016): Passive permeability and effective pore size of HeLa cell nuclear membranes: Permeability of nuclear membranes. Cell Biol Int 40, 991-998

Sanchez M, Galy B, Muckenthaler MU, Hentze MW (2007): Iron-regulatory proteins limit hypoxia-inducible factor- $2 \alpha$ expression in iron deficiency. Nat Struct Mol Biol 14, 420-426

Sandau KB, Fandrey J, Brüne B (2001): Accumulation of HIF-1 $\alpha$ under the influence of nitric oxide. Blood 97, 1009-1015

Sandri C, Caccavari F, Valdembri D, Camillo C, Veltel S, Santambrogio M, Lanzetti L, Bussolino F, Ivaska J, Serini G (2012): The R-Ras/RIN2/Rab5 complex controls endothelial cell adhesion and morphogenesis via active integrin endocytosis and Rac signaling. Cell Res 22, 1479-1501

Sanghi S, Kumar R, Smith M, Baker KM, Dostal DE (2005): Activation of protein kinase A by atrial natriuretic peptide in neonatal rat cardiac fibroblasts: Role in regulation of the local renin-angiotensin system. Regul Pept 132, 1-8 
Sarasij RC, Mayor S, Rao M (2007): Chirality-Induced Budding: A Raft-Mediated Mechanism for Endocytosis and Morphology of Caveolae? Biophys J 92, 3140-3158

Sato M, Severinghaus JW, Powell FL, Xu FD, Spellman MJ (1992): Augmented hypoxic ventilatory response in men at altitude. J Appl Physiol 73, 101-107

Scheiffele P, Verkade P, Fra AM, Virta H, Simons K, Ikonen E (1998): Caveolin-1 and -2 in the Exocytic Pathway of MDCK Cells. J Cell Biol 140, 795-806

Scherer PE, Okamoto T, Chun M, Nishimoto I, Lodish HF, Lisanti MP (1996): Identification, sequence, and expression of caveolin-2 defines a caveolin gene family. Proc Natl Acad Sci U S A $\underline{\text { 93, }}$ 131-135

Schlörmann W, Steiniger F, Richter W, Kaufmann R, Hause G, Lemke C, Westermann M (2010): The shape of caveolae is omega-like after glutaraldehyde fixation and cup-like after cryofixation. Histochem Cell Biol 133, 223-228

Schmid EM, McMahon HT (2007): Integrating molecular and network biology to decode endocytosis. Nature $\underline{448}, 883-888$

Schmidt C, Urlaub H: iTRAQ-Labeling of In-Gel Digested Proteins for Relative Quantification. In: Reinders J., Sickmann A (Hrsg.): Proteomics. Methods in Molecular Biology ${ }^{\mathrm{TM}}$ (Methods and Protocols). Band 564. Humana Press, New York 2009, 207-226

Schnelle MT: Untersuchungen zur Regulation der Zelladhäsion durch PHD2 in Tumorzellen. Med. Diss. Göttingen 2012

Schödel J, Oikonomopoulos S, Ragoussis J, Pugh CW, Ratcliffe PJ, Mole DR (2011): High-resolution genome-wide mapping of HIF-binding sites by ChIP-seq. Blood 117, e207-e217

Schroedl C, McClintock DS, Budinger GRS, Chandel NS (2002): Hypoxic but not anoxic stabilization of HIF-1 $\alpha$ requires mitochondrial reactive oxygen species. Am J Physiol-Lung Cell Mol Physiol 283, L922L931

Scortegagna M, Ding K, Oktay Y, Gaur A, Thurmond F, Yan L-J, Marck BT, Matsumoto AM, Shelton JM, Richardson JA, et al. (2003): Multiple organ pathology, metabolic abnormalities and impaired homeostasis of reactive oxygen species in Epas $1^{-1-}$ mice. Nat Genet $\underline{35}$, 331-340

Seagroves TN, Ryan HE, Lu H, Wouters BG, Knapp M, Thibault P, Laderoute K, Johnson RS (2001): Transcription Factor HIF-1 Is a Necessary Mediator of the Pasteur Effect in Mammalian Cells. Mol Cell Biol 21, 3436-3444

Sedding DG, Hermsen J, Seay U, Eickelberg O, Kummer W, Schwencke C, Strasser RH, Tillmanns H, Braun-Dullaeus RC (2005): Caveolin-1 facilitates mechanosensitive protein kinase B (Akt) signaling in vitro and in vivo. Circ Res $\underline{96}, 635-642$

Semenza GL (2009): Oxygen homeostasis. Wiley Interdiscip Rev Syst Biol Med 2, 336-361

Semenza GL (2012): Hypoxia-Inducible Factors in Physiology and Medicine. Cell 148, 399-408

Semenza GL (2014): Hypoxia-Inducible Factor 1 and Cardiovascular Disease. Annu Rev Physiol 76, 39-56

Semenza GL, Wang GL (1992): A nuclear factor induced by hypoxia via de novo protein synthesis binds to the human erythropoietin gene enhancer at a site required for transcriptional activation. Mol Cell Biol $\underline{12}, 5447-5454$

Semenza GL, Roth PH, Fang HM, Wang GL (1994): Transcriptional regulation of genes encoding glycolytic enzymes by hypoxia-inducible factor 1. J Biol Chem 269, 23757-23763 
Semenza GL, Jiang B-H, Leung SW, Passantino R, Concordet J-P, Maire P, Giallongo A (1996): Hypoxia Response Elements in the Aldolase A, Enolase 1, and Lactate Dehydrogenase A Gene Promoters Contain Essential Binding Sites for Hypoxia-inducible Factor 1. J Biol Chem 271, 32529-32537

Sengupta P, Philip F, Scarlata S (2008): Caveolin-1 alters Ca2+ signal duration through specific interaction with the G $\alpha$ q family of $\mathrm{G}$ proteins. J Cell Sci 121, 1363-1372

Sham JSK (2002): Hypoxic Pulmonary Vasoconstriction: Ups and Downs of Reactive Oxygen Species. Circ Res $\underline{91}, 649-651$

Shevchenko A, Simons K (2010): Lipidomics: coming to grips with lipid diversity. Nat Rev Mol Cell Biol 11 , $593-598$

Shnyrova AV, Frolov VA, Zimmerberg J (2009): Domain-Driven Morphogenesis of Cellular Membranes. Curr Biol 19, R772-R780

Shnyrova AV, Bashkirov PV, Akimov SA, Pucadyil TJ, Zimmerberg J, Schmid SL, Frolov VA (2013): Geometric Catalysis of Membrane Fission Driven by Flexible Dynamin Rings. Science 339, 1433-1436

Short M, Nemenoff RA, Zawada WM, Stenmark KR, Das M (2004): Hypoxia induces differentiation of pulmonary artery adventitial fibroblasts into myofibroblasts. Am J Physiol-Cell Physiol 286, C416-C425

Sieber JJ, Willig KI, Kutzner C, Gerding-Reimers C, Harke B, Donnert G, Rammner B, Eggeling C, Hell SW, Grubmüller H, Lang T (2007): Anatomy and Dynamics of a Supramolecular Membrane Protein Cluster. Science $\underline{317}, 1072-1076$

Sigismund S, Confalonieri S, Ciliberto A, Polo S, Scita G, Di Fiore PP (2012): Endocytosis and Signaling: Cell Logistics Shape the Eukaryotic Cell Plan. Physiol Rev 92, 273-366

Simionescu M, Simionescu N, Palade GE (1974): Morphometric data on the endothelium of blood capillaries. J Cell Biol $\underline{60}, 128-152$

Simon MC, Keith B (2008): The role of oxygen availability in embryonic development and stem cell function. Nat Rev Mol Cell Biol $\underline{9}$, 285-296

Simpson P, Savion S (1982): Differentiation of rat myocytes in single cell cultures with and without proliferating nonmyocardial cells. Cross-striations, ultrastructure, and chronotropic response to isoproterenol. Circ Res 무, 101-116

Sinha B, Köster D, Ruez R, Gonnord P, Bastiani M, Abankwa D, Stan RV, Butler-Browne G, Vedie B, Johannes L, et al. (2011): Cells Respond to Mechanical Stress by Rapid Disassembly of Caveolae. Cell $\underline{144}, 402-413$

Sitkovsky MV (2009): T regulatory cells: hypoxia-adenosinergic suppression and re-direction of the immune response. Trends Immunol $\underline{30}$, 102-108

Slavin I, García IA, Monetta P, Martinez H, Romero N, Alvarez C (2011): Role of Rab1b in COPII dynamics and function. Eur J Cell Biol 90, 301-311

Soilleux E J, Turley H, Tian Y M, Pugh C W, Gatter K C, Harris A L (2005): Use of novel monoclonal antibodies to determine the expression and distribution of the hypoxia regulatory factors PHD-1, PHD2, PHD-3 and FIH in normal and neoplastic human tissues. Histopathology 47, 602-610

Soldati T, Schliwa M (2006): Powering membrane traffic in endocytosis and recycling. Nat Rev Mol Cell Biol 7, 897-908

Sommer N, Strielkov I, Pak O, Weissmann N (2016): Oxygen sensing and signal transduction in hypoxic pulmonary vasoconstriction. Eur Respir J 47, 288-303 
Souders CA, Bowers SLK, Baudino TA (2009): Cardiac Fibroblast: The Renaissance Cell. Circ Res $\underline{105}$, 1164-1176

Spach MS, Boineau JP (1997): Microfibrosis Produces Electrical Load Variations Due to Loss of Side-to-Side Cell Connections; A Major Mechanism of Structural Heart Disease Arrhythmias. Pacing Clin Electrophysiol 20, 397-413

Spencer JA, Ferraro F, Roussakis E, Klein A, Wu J, Runnels JM, Zaher W, Mortensen LJ, Alt C, Turcotte R, et al. (2014): Direct measurement of local oxygen concentration in the bone marrow of live animals. Nature $\underline{508}, 269-273$

Stachowiak JC, Schmid EM, Ryan CJ, Ann HS, Sasaki DY, Sherman MB, Geissler PL, Fletcher DA, Hayden CC (2012): Membrane bending by protein-protein crowding. Nat Cell Biol 14, 944-949

Stahlhut M, van Deurs B (2000): Identification of Filamin as a Novel Ligand for Caveolin-1: Evidence for the Organization of Caveolin-1-associated Membrane Domains by the Actin Cytoskeleton. Mol Biol Cell $\underline{11}, 325-337$

Stan RV (2005): Structure of caveolae. Biochim Biophys Acta BBA - Mol Cell Res 1746, 334-348

Stenmark H (2009): Rab GTPases as coordinators of vesicle traffic. Nat Rev Mol Cell Biol 10, 513-525

Stenmark H, Vitale G, Ullrich O, Zerial M (1995): Rabaptin-5 is a direct effector of the small GTPase Rab5 in endocytic membrane fusion. Cell $\underline{83}, 423-432$

Stiehl DP, Wirthner R, Köditz J, Spielmann P, Camenisch G, Wenger RH (2006): Increased prolyl 4 hydroxylase domain proteins compensate for decreased oxygen levels. Evidence for an autoregulatory oxygen-sensing system. J Biol Chem 281, 23482-23491

Stockbridge LL, French AS (1988): Stretch-activated cation channels in human fibroblasts. Biophys J $\underline{54}$, 187-190

Stroka DM, Burkhardt T, Desbaillets I, Wenger RH, Neil D a. H, Bauer C, Gassmann M, Candinas D (2001): HIF-1 is expressed in normoxic tissue and displays an organ-specific regulation under systemic hypoxia. FASEB J 15, 2445-2453

Suda T, Takubo K, Semenza GL (2011): Metabolic Regulation of Hematopoietic Stem Cells in the Hypoxic Niche. Cell Stem Cell 2, 298-310

Sun G, Peng H (2015): HIF-1 $\alpha$-induced microRNA-210 reduces hypoxia-induced osteoblast MG-63 cell apoptosis. Biosci Biotechnol Biochem 79, 1232-1239

Sun P, Yamamoto H, Suetsugu S, Miki H, Takenawa T, Endo T (2003): Small GTPase Rah/Rab34 Is Associated with Membrane Ruffles and Macropinosomes and Promotes Macropinosome Formation. J Biol Chem 278, 4063-4071

Sunaga N, Miyajima K, Suzuki M, Sato M, White MA, Ramirez RD, Shay JW, Gazdar AF, Minna JD (2004): Different Roles for Caveolin-1 in the Development of Non-Small Cell Lung Cancer versus Small Cell Lung Cancer. Cancer Res 64, 4277-4285

Swanson J: Chapter 9 Fluorescent Labeling of Endocytic Compartments. In: Wang YL, Lansing Taylor D, Jeon KW (Hrsg.): Fluorescence Microscopy of Living Cells in Culture Part A. Fluorescent Analogs, Labeling Cells, and Basic Microscopy (Methods in Cell Biology). Band 29. Academic Press, San Diego 1988, 137-151

Swanson JA (2008): Shaping cups into phagosomes and macropinosomes. Nat Rev Mol Cell Biol 2 , 639-649

Swenson ER (2013): Hypoxic pulmonary vasoconstriction. High Alt Med Biol 14, 101-110 
Swiatecka-Urban A (2013): Membrane trafficking in podocyte health and disease. Pediatr Nephrol Berl Ger $\underline{28}, 1723-1737$

Taabazuing CY, Hangasky JA, Knapp MJ (2014): Oxygen Sensing Strategies in Mammals and Bacteria. J Inorg Biochem 133, 63-72

Takeda K, Ho VC, Takeda H, Duan L-J, Nagy A, Fong G-H (2006): Placental but Not Heart Defects Are Associated with Elevated Hypoxia-Inducible Factor $\alpha$ Levels in Mice Lacking Prolyl Hydroxylase Domain Protein 2. Mol Cell Biol 26, 8336-8346

Takeda K, Aguila HL, Parikh NS, Li X, Lamothe K, Duan L-J, Takeda H, Lee FS, Fong G-H (2008): Regulation of adult erythropoiesis by prolyl hydroxylase domain proteins. Blood 111, 3229-3235

Takeda N, O’Dea EL, Doedens A, Kim J, Weidemann A, Stockmann C, Asagiri M, Simon MC, Hoffmann A, Johnson RS (2010): Differential activation and antagonistic function of HIF- $\alpha$ isoforms in macrophages are essential for NO homeostasis. Genes Dev 24, 491-501

Tang Z, Scherer PE, Okamoto T, Song K, Chu C, Kohtz DS, Nishimoto I, Lodish HF, Lisanti MP (1996): Molecular Cloning of Caveolin-3, a Novel Member of the Caveolin Gene Family Expressed Predominantly in Muscle. J Biol Chem 271, 2255-2261

Tanimoto K, Makino Y, Pereira T, Poellinger L (2000): Mechanism of regulation of the hypoxia-inducible factor- $1 \alpha$ by the von Hippel-Lindau tumor suppressor protein. EMBO J $\underline{19}$, 4298-4309

Telezhkin V, Brazier SP, Cayzac SH, Wilkinson WJ, Riccardi D, Kemp PJ (2010): Mechanism of inhibition by hydrogen sulfide of native and recombinant BKCa channels. Respir Physiol Neurobiol 172, 169-178

The Gene Ontology Consortium (2017): Expansion of the Gene Ontology knowledgebase and resources. Nucleic Acids Res 4푸, D331-D338

Thomas JD, Johannes GJ (2007): Identification of mRNAs that continue to associate with polysomes during hypoxia. RNA $\underline{13}, 1116-1131$

Thomas PD, Campbell MJ, Kejariwal A, Mi H, Karlak B, Daverman R, Diemer K, Muruganujan A, Narechania A (2003): PANTHER: A Library of Protein Families and Subfamilies Indexed by Function. Genome Res $\underline{13}, 2129-2141$

Thompson TC, Timme TL, Li L, Goltsov A (1999): Caveolin-1, a metastasis-related gene that promotes cell survival in prostate cancer. Apoptosis $\underline{4}, 233-237$

Thorn H, Stenkula KG, Karlsson M, Örtegren U, Nystrom FH, Gustavsson J, Strålfors P (2003): Cell Surface Orifices of Caveolae and Localization of Caveolin to the Necks of Caveolae in Adipocytes. Mol Biol Cell 14, 3967-3976

Thorne RG, Nicholson C (2006): In vivo diffusion analysis with quantum dots and dextrans predicts the width of brain extracellular space. Proc Natl Acad Sci U S A $\underline{103}, 5567-5572$

Tian H, McKnight SL, Russell DW (1997): Endothelial PAS domain protein 1 (EPAS1), a transcription factor selectively expressed in endothelial cells. Genes Dev $\underline{11}, 72-82$

Tian H, Hammer RE, Matsumoto AM, Russell DW, McKnight SL (1998): The hypoxia-responsive transcription factor EPAS1 is essential for catecholamine homeostasis and protection against heart failure during embryonic development. Genes Dev 12, 3320-3324

Tinton SA, Buc-Calderon PM (1999): Hypoxia increases the association of 4E-binding protein 1 with the initiation factor 4E in isolated rat hepatocytes. FEBS Lett $\underline{446}, 55-59$ 
To KKW, Huang LE (2005): Suppression of hypoxia-inducible factor 1alpha (HIF-1alpha) transcriptional activity by the HIF prolyl hydroxylase EGLN1. J Biol Chem 280, 38102-38107

Towbin H, Staehelin T, Gordon J (1979): Electrophoretic transfer of proteins from polyacrylamide gels to nitrocellulose sheets: procedure and some applications. Proc Natl Acad Sci U S A $\underline{76}$, 4350-4354

Traub LM, Bonifacino JS (2013): Cargo Recognition in Clathrin-Mediated Endocytosis. Cold Spring Harb Perspect Biol $\underline{5}$, a016790

Travers JG, Kamal FA, Robbins J, Yutzey KE, Blaxall BC (2016): Cardiac Fibrosis: The Fibroblast Awakens. Circ Res 118, 1021-1040

Treins C, Giorgetti-Peraldi S, Murdaca J, Semenza GL, Obberghen EV (2002): Insulin Stimulates Hypoxiainducible Factor 1 through a Phosphatidylinositol 3-Kinase/Target of Rapamycin-dependent Signaling Pathway. J Biol Chem 277, 27975-27981

Turcotte S, Desrosiers RR, Béliveau R (2003): HIF-1 $\alpha$ mRNA and protein upregulation involves Rho GTPase expression during hypoxia in renal cell carcinoma. J Cell Sci 116, 2247-2260

Turcotte S, Desrosiers RR, Béliveau R (2004): Hypoxia upregulates von Hippel-Lindau tumor-suppressor protein through RhoA-dependent activity in renal cell carcinoma. Am J Physiol-Ren Physiol 286, F338F348

Ungewickell E, Branton D (1981): Assembly units of clathrin coats. Nature $\underline{289}$, 420-422

Vanden Hoek TL, Becker LB, Shao Z, Li C, Schumacker PT (1998): Reactive oxygen species released from mitochondria during brief hypoxia induce preconditioning in cardiomyocytes. J Biol Chem 273 , 18092 18098

van Uden P, Kenneth NS, Rocha S (2008): Regulation of hypoxia-inducible factor- $1 \alpha$ by NF- $x$ B. Biochem J 412, 477-484

Varas R, Wyatt CN, Buckler KJ (2007): Modulation of TASK-like background potassium channels in rat arterial chemoreceptor cells by intracellular ATP and other nucleotides. J Physiol $\underline{583}, 521-536$

Vaupel P, Höckel M, Mayer A (2007): Detection and characterization of tumor hypoxia using pO2 histography. Antioxid Redox Signal ㅁ, 1221-1235

Vaux EC, Metzen E, Yeates KM, Ratcliffe PJ (2001): Regulation of hypoxia-inducible factor is preserved in the absence of a functioning mitochondrial respiratory chain. Blood $\underline{98}$, 296-302

Veiga E, Cossart P (2005): Listeria hijacks the clathrin-dependent endocytic machinery to invade mammalian cells. Nat Cell Biol I, 894-900

Veit F, Pak O, Brandes RP, Weissmann N (2015): Hypoxia-Dependent Reactive Oxygen Species Signaling in the Pulmonary Circulation: Focus on Ion Channels. Antioxid Redox Signal 22, 537-552

Vetterlein M, Ellinger A, Neumüller J, Pavelka M (2002): Golgi apparatus and TGN during endocytosis. Histochem Cell Biol 117, 143-150

Vit O, Petrak J (2017): Integral membrane proteins in proteomics. How to break open the black box? J Proteomics $153,8-20$

Vogler M, Vogel S, Krull S, Farhat K, Leisering P, Lutz S, Wuertz CM, Katschinski DM, Zieseniss A (2013): Hypoxia Modulates Fibroblastic Architecture, Adhesion and Migration: A Role for HIF-1 $\alpha$ in Cofilin Regulation and Cytoplasmic Actin Distribution. PLOS ONE $\underline{8}$, e69128

Volpicelli-Daley LA, Li Y, Zhang C-J, Kahn RA (2005): Isoform-selective Effects of the Depletion of ADPRibosylation Factors 1-5 on Membrane Traffic. Mol Biol Cell $\underline{16}$, 4495-4508 
Wakefield AJ, Sawyerr AM, Dhillon AP, Pittilo RM, Rowles PM, Lewis AA, Pounder RE (1989): Pathogenesis of Crohn's disease: multifocal gastrointestinal infarction. Lancet Lond Engl 2, 1057-1062

Wallin E, von Heijne G (1998): Genome-wide analysis of integral membrane proteins from eubacterial, archaean, and eukaryotic organisms. Protein Sci Publ Protein Soc 7, 1029-1038

Walmsley SR, Cowburn AS, Clatworthy MR, Morrell NW, Roper EC, Singleton V, Maxwell P, Whyte MKB, Chilvers ER (2006): Neutrophils from patients with heterozygous germline mutations in the von Hippel Lindau protein (pVHL) display delayed apoptosis and enhanced bacterial phagocytosis. Blood $\underline{108}$, 3176-3178

Walseng E, Bakke O, Roche PA (2008): Major Histocompatibility Complex Class II-Peptide Complexes Internalize Using a Clathrin- and Dynamin-independent Endocytosis Pathway. J Biol Chem 283, 1471714727

Walser PJ, Ariotti N, Howes M, Ferguson C, Webb R, Schwudke D, Leneva N, Cho K-J, Cooper L, Rae J, et al. (2012): Constitutive Formation of Caveolae in a Bacterium. Cell $\underline{150}, 752-763$

Wang GL, Jiang BH, Rue EA, Semenza GL (1995): Hypoxia-inducible factor 1 is a basic-helix-loop-helixPAS heterodimer regulated by cellular O2 tension. Proc Natl Acad Sci U S A $\underline{92}, 5510-5514$

Wang J, Seth A, McCulloch C a. G (2000): Force regulates smooth muscle actin in cardiac fibroblasts. Am J Physiol-Heart Circ Physiol 279, H2776-H2785

Wang J, Fresquez T, Kandachar V, Deretic D (2017): The Arf GEF GBF1 and Arf4 synergize with the sensory receptor cargo, rhodopsin, to regulate ciliary membrane trafficking. J Cell Sci 130, 3975-3987

Wang T, Hong W (2002): Interorganellar Regulation of Lysosome Positioning by the Golgi Apparatus through Rab34 Interaction with Rab-interacting Lysosomal Protein. Mol Biol Cell $\underline{13}$, 4317-4332

Wang Y, Ohh M (2010): Oxygen-mediated endocytosis in cancer. J Cell Mol Med 14, 496-503

Wang Y, Roche O, Yan MS, Finak G, Evans AJ, Metcalf JL, Hast BE, Hanna SC, Wondergem B, Furge KA, et al. (2009): Regulation of endocytosis via the oxygen-sensing pathway. Nat Med $\underline{15}, 319-324$

Wang Y, Roche O, Xu C, Moriyama EH, Heir P, Chung J, Roos FC, Chen Y, Finak G, Milosevic M, et al. (2012): Hypoxia promotes ligand-independent EGF receptor signaling via hypoxia-inducible factormediated upregulation of caveolin-1. Proc Natl Acad Sci U S A 109, 4892-4897

Ward JPT (2008): Oxygen sensors in context. Biochim Biophys Acta BBA - Bioenerg 1777, 1-14

Warnecke C, Zaborowska Z, Kurreck J, Erdmann VA, Frei U, Wiesener M, Eckardt K-U (2004): Differentiating the functional role of hypoxia-inducible factor (HIF)- $1 \alpha$ and HIF- $2 \alpha$ (EPAS-1) by the use of RNA interference: erythropoietin is a HIF-2 $\alpha$ target gene in Hep3B and Kelly cells. FASEB J $\underline{18}$, $1462-1464$

Watson CJ, Collier P, Tea I, Neary R, Watson JA, Robinson C, Phelan D, Ledwidge MT, McDonald KM, McCann A, et al. (2014): Hypoxia-induced epigenetic modifications are associated with cardiac tissue fibrosis and the development of a myofibroblast-like phenotype. Hum Mol Genet $\underline{23}$, 2176-2188

Waypa GB, Marks JD, Guzy R, Mungai PT, Schriewer J, Dokic D, Schumacker PT (2010): Hypoxia triggers subcellular compartmental redox signaling in vascular smooth muscle cells. Circ Res $\underline{106}, 526-535$

Waypa GB, Marks JD, Guzy RD, Mungai PT, Schriewer JM, Dokic D, Ball MK, Schumacker PT (2013): Superoxide Generated at Mitochondrial Complex III Triggers Acute Responses to Hypoxia in the Pulmonary Circulation. Am J Respir Crit Care Med 187, 424-432

Waypa GB, Smith KA, Schumacker PT (2016): O2 sensing, mitochondria and ROS signaling: the fog is lifting. Mol Aspects Med 47-48, 76-89 
Weerd WFC de, Leeb-Lundberg LMF (1997): Bradykinin Sequesters B2 Bradykinin Receptors and the Receptor-coupled G $\alpha$ Subunits G $\alpha$ q and G $\alpha$ iin Caveolae in DDT1 MF-2 Smooth Muscle Cells. J Biol Chem $\underline{272}, 17858-17866$

Weigert R (2014): Imaging the Dynamics of Endocytosis in Live Mammalian Tissues. Cold Spring Harb Perspect Biol $\underline{6}$, a017012

Weir EK, Archer SL (2010): The Role of Redox Changes in Oxygen Sensing. Respir Physiol Neurobiol 174 , 182-191

Weir EK, López-Barneo J, Buckler KJ, Archer SL (2005): Acute Oxygen-Sensing Mechanisms. N Engl J Med 353, 2042-2055

Wenger RH, Rolfs A, Marti HH, Guénet J-L, Gassmann M (1996): Nucleotide Sequence, Chromosomal Assignment and mRNA Expression of Mouse Hypoxia-Inducible Factor- $1 \alpha$. Biochem Biophys Res Commun 223, 54-59

White CW, Jackson JH, McMurtry IF, Repine JE (1988): Hypoxia increases glutathione redox cycle and protects rat lungs against oxidants. J Appl Physiol $\underline{65}$, 2607-2616

Wickström SA, Lange A, Hess MW, Polleux J, Spatz JP, Krüger M, Pfaller K, Lambacher A, Bloch W, Mann M, et al. (2010): Integrin-Linked Kinase Controls Microtubule Dynamics Required for Plasma Membrane Targeting of Caveolae. Dev Cell 19, 574-588

Wiener CM, Booth G, Semenza GL (1996): In VivoExpression of mRNAs Encoding Hypoxia-Inducible Factor 1. Biochem Biophys Res Commun 225, 485-488

Wiesener MS, Turley H, Allen WE, Willam C, Eckardt K-U, Talks KL, Wood SM, Gatter KC, Harris AL, Pugh CW, et al. (1998): Induction of Endothelial PAS Domain Protein-1 by Hypoxia: Characterization and Comparison With Hypoxia-Inducible Factor-1 $\alpha$. Blood 22, 2260-2268

Wiesener MS, Jürgensen JS, Rosenberger C, Scholze CK, Hörstrup JH, Warnecke C, Mandriota S, Bechmann I, Frei UA, Pugh CW, et al. (2002): Widespread hypoxia-inducible expression of HIF-2 $\alpha$ in distinct cell populations of different organs. FASEB J $\underline{17}, 271-273$

Wilcke M, Johannes L, Galli T, Mayau V, Goud B, Salamero J (2000): Rab11 Regulates the Compartmentalization of Early Endosomes Required for Efficient Transport from Early Endosomes to the Trans-Golgi Network. J Cell Biol 151, 1207-1220

Willam C, Maxwell PH, Nichols L, Lygate C, Tian YM, Bernhardt W, Wiesener M, Ratcliffe PJ, Eckardt K-U, Pugh CW (2006): HIF prolyl hydroxylases in the rat; organ distribution and changes in expression following hypoxia and coronary artery ligation. J Mol Cell Cardiol 41, 68-77

Wong DL, Tai TC, Wong-Faull DC, Claycomb R, Siddall BJ, Bell RA, Kvetnansky R (2010): Stress and Adrenergic Function: HIF1 $\alpha$, a Potential Regulatory Switch. Cell Mol Neurobiol 30, 1451-1457

Wottawa M, Naas S, Böttger J, Belle GJ van, Möbius W, Revelo NH, Heidenreich D, Ahlen M von, Zieseniss A, Kröhnert K, et al. (2017): Hypoxia-stimulated membrane trafficking requires T-plastin. Acta Physiol $\underline{221}, 59-73$

Wyatt CN, Mustard KJW, Pearson SA, Dallas ML, Atkinson L, Kumar P, Peers C, Hardie DG, Evans AM (2007): AMP-activated protein kinase mediates carotid body exitation by hypoxia. J Biol Chem $\underline{282}$, 8092-8098

Xia X, Lemieux ME, Li W, Carroll JS, Brown M, Liu XS, Kung AL (2009): Integrative analysis of HIF binding and transactivation reveals its role in maintaining histone methylation homeostasis. Proc Natl Acad Sci U S A 106, 4260-4265 
Xiao Y, Forry SP, Gao X, Holbrook RD, Telford WG, Tona A (2010): Dynamics and mechanisms of quantum dot nanoparticle cellular uptake. J Nanobiotechnology $\underline{8}, 13$

Xing Y, Böcking T, Wolf M, Grigorieff N, Kirchhausen T, Harrison SC (2010): Structure of clathrin coat with bound Hsc70 and auxilin: mechanism of Hsc70-facilitated disassembly. EMBO J 29, 655-665

Xu BJ, Yan W, Jovanovic B, An AQ, Cheng N, Aakre ME, Yi Y, Eng J, Link AJ, Moses HL (2010): Quantitative analysis of the secretome of TGF- $\beta$ signaling-deficient mammary fibroblasts. Proteomics $\underline{10}, 2458-2470$

Xue Y, Bi F, Zhang X, Zhang S, Pan Y, Liu N, Shi Y, Yao X, Zheng Y, Fan D (2006): Role of Rac1 and $\mathrm{Cdc} 42$ in hypoxia induced $\mathrm{p} 53$ and von Hippel-Lindau suppression and HIF1 $\alpha$ activation. Int J Cancer $\underline{118}, 2965-2972$

Yamada E (1955): The Fine Structure of the Gall Bladder Epithelium of the Mouse. J Cell Biol 1, 445-458

Yan Q, Bartz S, Mao M, Li L, Kaelin WG (2007): The Hypoxia-Inducible Factor $2 \alpha$ N-Terminal and CTerminal Transactivation Domains Cooperate To Promote Renal Tumorigenesis In Vivo. Mol Cell Biol 27, 2092-2102

Yang M, Chowdhury R, Ge W, Hamed RB, McDonough MA, Claridge TDW, Kessler BM, Cockman ME, Ratcliffe PJ, Schofield CJ (2011): Factor-inhibiting hypoxia-inducible factor (FIH) catalyses the posttranslational hydroxylation of histidinyl residues within ankyrin repeat domains. FEBS J 278, 1086-1097

Yeh C-K, Mertz PM, Oliver C, Baum BJ, Kousvelari EE (1991): Cellular Characteristics of Long-Term Cultured Rat Parotid Acinar Cells. In Vitro Cell Dev Biol 27A, 707-712

Yellon DM, Hausenloy DJ (2007): Myocardial Reperfusion Injury. N Engl J Med $\underline{357}, 1121-1135$

Yi X, Liang Y, Huerta-Sanchez E, Jin X, Cuo ZXP, Pool JE, Xu X, Jiang H, Vinckenbosch N, Korneliussen TS, et al. (2010): Sequencing of 50 Human Exomes Reveals Adaptation to High Altitude. Science $\underline{329}$, $75-78$

Yoon D, Pastore YD, Divoky V, Liu E, Mlodnicka AE, Rainey K, Ponka P, Semenza GL, Schumacher A, Prchal JT (2006): Hypoxia-inducible Factor-1 Deficiency Results in Dysregulated Erythropoiesis Signaling and Iron Homeostasis in Mouse Development. J Biol Chem 281, 25703-25711

Yoon S-O, Shin S, Mercurio AM (2005): Hypoxia Stimulates Carcinoma Invasion by Stabilizing Microtubules and Promoting the Rab11 Trafficking of the $\alpha 6 \beta 4$ Integrin. Cancer Res $\underline{65}, 2761-2769$

Yoshida Y, Kinuta M, Abe T, Liang S, Araki K, Cremona O, Paolo GD, Moriyama Y, Yasuda T, Camilli PD, Takei K (2004): The stimulatory action of amphiphysin on dynamin function is dependent on lipid bilayer curvature. EMBO J 23, 3483-3491

Young RM, Wang S-J, Gordan JD, Ji X, Liebhaber SA, Simon MC (2008): Hypoxia-mediated Selective mRNA Translation by an Internal Ribosome Entry Site-independent Mechanism. J Biol Chem $\underline{283}$, 16309-16319

Yu AY, Frid MG, Shimoda LA, Wiener CM, Stenmark K, Semenza GL (1998): Temporal, spatial, and oxygen-regulated expression of hypoxia-inducible factor-1 in the lung. Am J Physiol-Lung Cell Mol Physiol 275, L818-L826

Yu F, White SB, Zhao Q, Lee FS (2001): HIF-1 $\alpha$ binding to VHL is regulated by stimulus-sensitive proline hydroxylation. Proc Natl Acad Sci U S A $\underline{98}$, 9630-9635

Yu J, Bergaya S, Murata T, Alp IF, Bauer MP, Lin MI, Drab M, Kurzchalia TV, Stan RV, Sessa WC (2006): Direct evidence for the role of caveolin-1 and caveolae in mechanotransduction and remodeling of blood vessels. J Clin Invest 116, 1284-1291 
Yuan G, Vasavda C, Peng Y-J, Makarenko VV, Raghuraman G, Nanduri J, Gadalla MM, Semenza GL, Kumar GK, Snyder SH, Prabhakar NR (2015): Protein kinase G-regulated production of H2S governs oxygen sensing. Sci Signal $\underline{8}$, ra37

Zeisberg EM, Kalluri R (2010): Origins of Cardiac Fibroblasts. Circ Res 107, 1304-1312

Zhang H, Bosch-Marce M, Shimoda LA, Tan YS, Baek JH, Wesley JB, Gonzalez FJ, Semenza GL (2008): Mitochondrial Autophagy Is an HIF-1-dependent Adaptive Metabolic Response to Hypoxia. J Biol Chem 283, 10892-10903

Zhang J, Zhang X, Liu G, Chang D, Liang X, Zhu X, Tao W, Mei L (2016a): Intracellular Trafficking Network of Protein Nanocapsules: Endocytosis, Exocytosis and Autophagy. Theranostics $\underline{6}, 2099-2113$

Zhang J, Wang X, Vikash V, Ye Q, Wu D, Liu Y, Dong W (2016b): ROS and ROS-Mediated Cellular Signaling. Oxid Med Cell Longev 2016, 4350965

Zhang LW, Monteiro-Riviere NA (2009): Mechanisms of Quantum Dot Nanoparticle Cellular Uptake. Toxicol Sci $\underline{110}, 138-155$

Zhang Z, Ren J, Stammers DK, Baldwin JE, Harlos K, Schofield CJ (2000): Structural origins of the selectivity of the trifunctional oxygenase clavaminic acid synthase. Nat Struct Mol Biol $\underline{\underline{y}}, 127-133$

Zhao J-P, Zhou Z-G, Hu H-L, Guo Z, Wang T, Zhen G-H, Zhang Z-X (2007): The relationships among reactive oxygen species, hypoxia-inducible factor 1alpha and cell proliferation in rat pulmonary arterial smooth muscle cells under hypoxia. Sheng Li Xue Bao $\underline{59}$, 319-324

Zheng L-Q, Chi S-M, Li C-X (2017): Rab23's genetic structure, function and related diseases: a review. Biosci Rep $\underline{37}$, BSR20160410

Zheng X, Linke S, Dias JM, Zheng X, Gradin K, Wallis TP, Hamilton BR, Gustafsson M, Ruas JL, Wilkins S, et al. (2008): Interaction with factor inhibiting HIF-1 defines an additional mode of cross-coupling between the Notch and hypoxia signaling pathways. Proc Natl Acad Sci U S A $\underline{105}$, 3368-3373

Zhong H, Chiles K, Feldser D, Laughner E, Hanrahan C, Georgescu M-M, Simons JW, Semenza GL (2000): Modulation of Hypoxia-inducible Factor $1 \alpha$ Expression by the Epidermal Growth Factor/Phosphatidylinositol 3-Kinase/PTEN/AKT/FRAP Pathway in Human Prostate Cancer Cells: Implications for Tumor Angiogenesis and Therapeutics. Cancer Res 60, 1541-1545

Zhou G, Dada LA, Chandel NS, Iwai K, Lecuona E, Ciechanover A, Sznajder JI (2008): Hypoxia-mediated $\mathrm{Na}-\mathrm{K}$-ATPase degradation requires von Hippel Lindau protein. FASEB J 22, 1335-1342

Zhou J, Gunsior M, Bachmann BO, Townsend CA, Solomon EI (1998): Substrate Binding to the $\alpha$ Ketoglutarate-Dependent Non-Heme Iron Enzyme Clavaminate Synthase 2: Coupling Mechanism of Oxidative Decarboxylation and Hydroxylation. J Am Chem Soc 120, 13539-13540

Zhu B, Swärd K, Ekman M, Uvelius B, Rippe C (2017): Cavin-3 (PRKCDBP) deficiency reduces the density of caveolae in smooth muscle. Cell Tissue Res $\underline{368}, 591-602$

Zhuang Z, Marshansky V, Breton S, Brown D (2011): Is caveolin involved in normal proximal tubule function? Presence in model PT systems but absence in situ. Am J Physiol - Ren Physiol 300, F199_ F206

Zieseniss A (2014): Hypoxia and the modulation of the actin cytoskeleton - emerging interrelations. Hypoxia 2, 11-21

Zimmerberg J, Kozlov MM (2006): How proteins produce cellular membrane curvature. Nat Rev Mol Cell Biol 7, 9-19 


\section{Danksagung}

Mein besonderer Dank gilt meiner Doktormutter, Frau Prof. Dr. D. M. Katschinski für die Vergabe des Themas dieser Arbeit und die Möglichkeit, in ihrer Arbeitsgruppe einen Einblick in wissenschaftliches Arbeiten $\mathrm{zu}$ erhalten. Durch viele Anregungen, Ideen und Lösungsvorschläge hat sie dieses Projekt inhaltlich ermöglicht. Ausdrücklich bedanken möchte ich mich für ihre außerordentlich geduldige Unterstützung während der Fertigstellung dieser Arbeit.

Ebenfalls danke ich meiner Betreuerin, Frau Dr. Marieke Wottawa, von der ich die Laborarbeit gelernt habe und die mich mit Geduld und großer Hilfsbereitschaft unterstützt hat. Durch ihre mannigfaltigen Ratschläge und praktische Hilfen hat sie entscheidend zu dieser Arbeit beigetragen. Mein Dank gilt zudem den Mitarbeiterinnen und Doktorandinnen des Institutes für Herz- und Kreislaufphysiologie für unzählige Hilfestellungen und eine positive und unterstützende Arbeitsumgebung.

Mein herzlicher Dank gilt zudem Herrn Prof. Dr. Silvio O. Rizzoli für seine Hilfe bei der Planung, Durchführung und Auswertung der Membranfärbungen, für die er sein Labor zur Verfügung gestellt hat. Danken möchte ich auch den Mitgliedern seiner Arbeitsgruppe und ganz besonders Frau Katharina Kröhnert, ohne deren Einsatz viele Experimente dieses Projektes nicht hätten durchgeführt werden können.

Darüber hinaus gilt mein Dank Frau Prof. Dr. Susanne Lutz und ihrer Arbeitsgruppe, insbesondere Frau Dr. Svenja Hartmann und Herrn Dr. Naim Kittana für viele Anregungen sowie für die Bereitstellung von Zellen für meine Experimente.

Ich danke Herrn Prof. Dr. Manuel Mayr für die Möglichkeit, in seinem Labor neue wissenschaftliche Methoden kennenzulernen. Ich wurde als Gast außerordentlich freundlich aufgenommen.

Nicht zuletzt danke ich allen Beteiligten des internationalen Graduiertenkollegs 1816 für eine anregende, positive und unterstützende Forschungs- und Lernumgebung. 